\title{
Perceived cognitive problems in young-old adults contextual factors, assessment and intervention
}

Citation for published version (APA):

Hoogenhout, E. M. (2010). Perceived cognitive problems in young-old adults contextual factors, assessment and intervention. [Doctoral Thesis, Maastricht University]. NeuroPsych Publishers. https://doi.org/10.26481/dis.20101216eh

Document status and date:

Published: 01/01/2010

DOI:

10.26481/dis.20101216eh

Document Version:

Publisher's PDF, also known as Version of record

\section{Please check the document version of this publication:}

- A submitted manuscript is the version of the article upon submission and before peer-review. There can be important differences between the submitted version and the official published version of record. People interested in the research are advised to contact the author for the final version of the publication, or visit the DOI to the publisher's website.

- The final author version and the galley proof are versions of the publication after peer review.

- The final published version features the final layout of the paper including the volume, issue and page numbers.

Link to publication

\footnotetext{
General rights rights.

- You may freely distribute the URL identifying the publication in the public portal. please follow below link for the End User Agreement:

www.umlib.nl/taverne-license

Take down policy

If you believe that this document breaches copyright please contact us at:

repository@maastrichtuniversity.nl

providing details and we will investigate your claim.
}

Copyright and moral rights for the publications made accessible in the public portal are retained by the authors and/or other copyright owners and it is a condition of accessing publications that users recognise and abide by the legal requirements associated with these

- Users may download and print one copy of any publication from the public portal for the purpose of private study or research.

- You may not further distribute the material or use it for any profit-making activity or commercial gain

If the publication is distributed under the terms of Article $25 \mathrm{fa}$ of the Dutch Copyright Act, indicated by the "Taverne" license above, 
Perceived cognitive problems in young-old adults contextual factors, assessment and intervention 
(C) Copyright E.M. Hoogenhout, Maastricht 2010

$\begin{array}{ll}\text { Lay-out en cover } & \text { Esther Hoogenhout } \\ \text { Druk } & \text { Datawyse / Universitaire Pers Maastricht } \\ \text { Publisher } & \text { NeuroPsych Publishers } \\ \text { ISBN } & 978-90755-79-499\end{array}$

NeuroPsych Publishers is a non-profit organization, which aims at promoting the science of 'Brain and Behaviour' and improving the application of the products of this science in health care and education. NeuroPsych Publishers accomplishes these aims by publishing books, dissertations and other products of scientific activity, by disseminating educational material and publication of tests, assessment scales and other psychometric instruments in the field of Neuropsychology, Neuropsychiatry and other areas within the domain of Brain and Behavior.

NeuroPsych Publishers

Department of Psychiatry and Neuropsychology

Maastricht University

P.O. Box 616

NL-6200 MD Maastricht

www.np.unimaas.nl 


\title{
Perceived cognitive problems in young-old adults contextual factors, assessment and intervention
}

\author{
Proefschrift
}
Ter verkrijging van de graad van doctor aan de Universiteit Maastricht, op gezag van de Rector Magnificus, Prof. mr. G.P.M.F. Mols, volgens het besluit van het College van Decanen, in het openbaar te verdedigen op donderdag 16 december 2010 om 12.00 uur door

\section{Esther Maria Hoogenhout}

Geboren op 22 september 1980 te Dordrecht 


\section{Promotor}

Prof. dr. J. Jolles (Vrije Universiteit Amsterdam)

\section{Copromotores}

Dr. R.H.M. de Groot (Open Universiteit)

Dr. W. van der Elst

\section{Beoordelingscommissie}

Prof. dr. F.R.J. Verhey (voorzitter)

Dr. P.W.M. van Gerven

Prof. dr. G.I.J.M. Kempen

Prof. dr. R.P.C. Kessels (Radboud Universiteit)

Prof. dr. B.A. Schmand (Universiteit van Amsterdam)

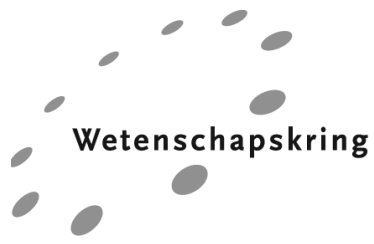

de Wetenschapskring bevordert wetenschappelijk onderzoek op het gebied van de GGZ in Zuid-Limburg

The research described in this thesis was performed in the School for Mental Health \& Neuroscience (MHeNS), and the Department of Psychiatry and Neuropsychology, Maastricht University, The Netherlands.

Financial support for the publication of this thesis was kindly provided by the Vitalis WoonZorg- en Behandelgroep Eindhoven, the Stichting Alzheimer Nederland Bunnik and the Internationale Stichting Alzheimer Onderzoek (ISAO). 
Voor mijn oma en mijn dochter, die mij voorging en die mij volgt in het leven 



\section{Contents}

Chapter 1 General Introduction 9

Chapter 2 Metacognition in aging: the Maastricht Metacognition 23

Inventory, and effects of age, gender, and educational level

Chapter 3 The Neurovegetative Complaints Questionnaire in the 45

Maastricht Aging Study: psychometric properties and normative data

Chapter 4 The Dutch Memory Compensation Questionnaire: 63 psychometric properties and regression based norms

Chapter 5 Everyday memory compensation in older adults with 85 cognitive complaints is moderated by depressive symptoms

Chapter 6 Everyday memory compensation, cognitive reserve, 103 and changes in subjective and objective memory: a 12-year longitudinal investigation based on the Maastricht Aging Study

Chapter 7 A new comprehensive educational group intervention for older adults with cognitive complaints: background, content, and process evaluation

Chapter 8 Effects of a comprehensive educational group intervention in older women with cognitive complaints: a randomized controlled trial

$\begin{array}{lll}\text { Chapter } 9 & \text { Concluding remarks } & 161\end{array}$

$\begin{array}{ll}\text { Summary } & 177\end{array}$

$\begin{array}{ll}\text { Samenvatting } & 181\end{array}$

Dankwoord 185

Publications 189

$\begin{array}{ll}\text { Curriculum Vitae } & 191\end{array}$ 

CHAPTER 1

Introduction 
Western societies are aging rapidly. In the Netherlands, for example, the proportion of individuals aged 65 years and older in the total population has changed from 11.5 percent in 1980 to 14.8 percent in 2008 (CBS, 2010b). It is expected that almost 26 percent of the total population will be aged 65 years and older in 2040 (De Jong \& Van Duin, 2010). Aging is often accompanied by decrements in physical, psychosocial, and cognitive functioning (Baltes \& Baltes, 1990; Birren \& Schaie, 2001; Jolles, Houx, Van Boxtel, \& Ponds, 1995) and by an increased health care consumption (CBS, 2010a). As a consequence of their aging populations, Western societies will face increasing social and economical costs in the upcoming decades (CBS, 2009; World Health Organization, 2006).

A common complaint of relatively healthy aging individuals refers to changes in cognitive functions. A previous large scale community-based study revealed that 41 percent of adults aged 54 to 66 years, and 52 percent of adults aged 69 to 86 years considered themselves as being forgetful (Ponds, Commissaris, \& Jolles, 1997). Several other studies reported comparable rates. Exact prevalences varied greatly dependent on the study sample and the way in which 'cognitive complaints' were defined and measured (Blazer, Hays, Fillenbaum, \& Gold, 1997; Gino et al., 2010; Jonker, Launer, Hooijer, \& Lindeboom, 1996; Mendes et al., 2008; Minett, Da Silva, Ortiz, \& Bertolucci, 2008). For many individuals their perceived cognitive problems are a source of worry and frustration (Commissaris et al., 1993; Commissaris, Ponds, \& Jolles, 1998), and are associated with a lowered quality of life (Mol et al., 2007; Mol, Van Boxtel, Willems, Verhey, \& Jolles, 2009). Some of these people are even afraid about becoming demented (Commissaris et al., 1993; Commissaris et al., 1998). Nevertheless, only a small proportion of them will actually develop a pathological cognitive disease (e.g., Alzheimer's dementia) (Jonker, Geerlings, \& Schmand, 2000; Jorm, Christensen, Korten, Jacomb, \& Henderson, 2001). There is a substantial need for intervention (most preferably education and memory training) among these people (Commissaris et al., 1998). At this moment, individuals with subjective cognitive complaints appeal on highly specialized and costly healthcare facilities (e.g., Memory Clinics) that are not primarily intended for them (Comijs, Dik, Aartsen, Deeg, \& Jonker, 2005; Verhey et al., 2007).

Perceived cognitive problems in the absence of actual cognitive impairments can thus be considered a highly relevant health issue in older adults. In face of our rapidly aging society, the number of individuals with such problems will increase irrevocably in the upcoming decades. This group of older adults requires specific attention and more appropriate intervention programs. The present thesis will therefore focus on the development and evaluation of an intervention program for healthy older adults with perceived cognitive problems. In addition, the present thesis will consider several factors (i.e., metacognitive functioning, depressive affect, and everyday memory compensation) that are important in this context. More specifically, attention will be paid to the assessment of these factors. In the remain- 
ing sections of this chapter, background information will be provided about the nature of perceived cognitive problems in relatively healthy older individuals. Furthermore, two important factors (i.e., metacognitive functioning and depressive affect) will be elaborated upon. These factors are relevant in the context of cognitive aging and perceived cognitive problems in older adults. Furthermore, the concept of everyday memory compensation and trends in cognitive intervention research among healthy older adults will be discussed. Finally, a brief overview of the aims and outline of the present thesis will be given.

\section{The nature of perceived cognitive problems in aging}

The exact nature of perceived cognitive problems in relatively healthy older adults remains unclear. Aging is often characterized by actual changes in cognitive functioning. The most widely researched topic in this field concerned the effects of aging on memory functions (Hess, 2005; Zacks, Hasher, \& Li, 2000). But age-related changes in other domains, like mental speed (Salthouse, 1996), inhibitory functions and executive functions (Craik \& Bialystok, 2006; Craik \& Grady, 2002; Van Hooren, Valentijn, Bosma, Ponds, Van Boxtel, \& Jolles, 2007), have also been generally established. Furthermore, previous research revealed that many aging individuals complain about diminishing cognitive capacities (Gino et al., 2010; Mendes et al., 2008; Minett et al., 2008; Ponds et al., 1997). Such perceived cognitive problems may have some predictive value for actual age-related changes in cognitive functions (Jorm et al., 2001), Mild Cognitive Impairment (Petersen et al., 1999; Winblad et al., 2004), or dementia (Geerlings, Jonker, Bouter, Ader, \& Schmand, 1999; Jonker et al., 2000). This association is however weak (Kliegel, Zimprich, \& Eschen, 2005; Mol, Van Boxtel, Willems, \& Jolles, 2006; Zimprich, Martin, \& Kliegel, 2003). The association between cognitive complaints and contextual factors, including metacognitive functioning (Mol, Ruiter, Verhey, Dijkstra, \& Jolles, 2008; Ponds \& Jolles, 1996a) and depressive affect (Cargin, Collie, Masters, \& Maruff, 2008; Comijs, Deeg, Dik, Twisk, \& Jonker, 2002; Dux et al., 2008; Kliegel \& Zimprich, 2005; Zimprich et al., 2003), is much more pronounced. Thus, although cognitive functions often decline when people grow older, previous research revealed that the majority of older adults exhibit perceived cognitive problems that are largely independent of actual cognitive changes. It has been suggested previously that it is necessary to incorporate such contextual factors in models of cognitive aging (Hess, 2005), and consider them when developing interventions for older adults with cognitive complaints (Floyd \& Scogin, 1997; Hess, 2005; Hohaus, 2007; Lachman, 1991; Stuss et al., 2007). 


\section{Metacognitive functioning}

Metacognition (i.e., cognitions about cognition) is an umbrella term that covers three major categories: knowledge about cognition and cognitive functions, monitoring of the current state of the cognitive system, and beliefs about cognition. Especially the third category (i.e., beliefs about cognition) has received much attention in the context of cognitive aging (Hertzog, 2002; Hertzog \& Hultsch, 2000). Aspects of metacognition (e.g., memory self-efficacy or memory related anxiety) have been linked to objective (McDougall, 2009; Valentijn et al., 2006) and subjective cognitive functioning (McDougall, 2009; Mol et al., 2008; Ponds \& Jolles, 1996a) as well as to general wellbeing (Verhaeghen, Geraerts, \& Marcoen, 2000).

Metacognition in aging is usually assessed with self-report questionnaires, for example the Metamemory in Adulthood Questionnaire (MIA; Dixon, Hultsch, \& Hertzog, 1988; Ponds \& Jolles, 1996b) and the Memory Functioning Questionnaire (Gilewski, Zelinski, \& Schaie, 1990; Lane \& Zelinski, 2003). There are several drawbacks associated with the use of these instruments, including their ignorance of other potentially relevant cognitive domains besides memory (Hertzog, 2002; Hertzog \& Hultsch, 2000; Troyer \& Rich, 2002). It might thus be advantageous to have an instrument available that assesses a broader spectrum of cognitive domains, which might increase ecological validity of measurement.

\section{Depressive affect}

Previous research revealed that older adults with depressive symptoms experience, for example, more functional impairments in daily life (Gallo, Rebok, Tennsted, Wadley, \& Horgas, 2003; Oxman, Barrett, Sengupta, \& Williams, 2000), and more subjective cognitive problems (Dux et al., 2008; Kliegel \& Zimprich, 2005; Mol et al., 2008; Sachs-Ericsson, Joiner, \& Blazer, 2008). Depressive symptoms in older adults have also been associated with worse performance on objective cognitive tasks (Bierman, Comijs, Jonker, \& Beekman, 2005; Dux et al., 2008), and a more pronounced decline in cognitive functions over time (Comijs, Dik, Deeg, \& Jonker, 2004; Köhler et al., 2010; Paterniti, Verdier-Taillefer, Dufouil, \& Alperovitch, 2002; Zimprich et al., 2003). Older adults with depressive problems are thus considered a highly vulnerable group in the context of aging.

Depressive affect in older adults often remains unnoticed. This might be caused by the fact that older adults often present themselves with alternative clinical clues to depression (Gallo \& Rabins, 1999). They tend to report many somatic and neurovegetative symptoms (i.e., symptoms associated with suboptimal functioning of the autonomic nervous system, like sleeping problems, fatigue, and a lack of energy), rather than affective symptoms (Christensen et al., 1999; Gallo \& Rabins, 
1999; Gallo, Rabins, \& Anthony, 1999; Oxman et al., 2000). This condition has previously been described as 'masked depression' (Collins \& Abeles, 1996; Neskes \& Jarvik, 1987; Weiss, Nagel, \& Aronson, 1986) or 'depression without sadness' (Alexopoulos et al., 2002; Gallo \& Rabins, 1999). The use of DSM-IV-criteria based instruments like the Beck Depression Inventory (Beck, Steer, \& Garbin, 1988) or the Centre of Epidemiologic Studies Depression Scale (Bouma, Ranchor, Sanderman, \& Van Sonderen, 1995) might lead to an underestimation of mental health problems and depressive symptoms in older adults, because these instruments primarily focus on affective symptoms. It seems thus important to pay specific attention to neurovegetative and somatic complaints in older adults (Alexopoulos et al., 2002; Collins \& Abeles, 1996; Gallo \& Rabins, 1999; Klapow et al., 2002; Neskes \& Jarvik, 1987).

\section{Everyday memory compensation}

The concept of psychological compensation is applicable to various domains of functioning (e.g., sensory handicaps, interpersonal losses, and cognitive losses) (Bäckman \& Dixon, 1992). In the context of cognitive losses, it has attracted attention in both aging research (De Frias, Dixon, \& Bäckman, 2003; Dixon, 1995; Dixon \& Bäckman, 1992; Dixon, de Frias, \& Bäckman, 2001; Garrett, Grady, \& Hasher, 2010) and neurorehabilitation (Dixon \& Backman, 2005; Evans, Wilson, Needham, \& Brentnall, 2003; Wilson, 2000; Wilson \& Watson, 1996). Everyday memory compensation is commonly measured by means of self-report questionnaires. In the past, the assessment of everyday memory compensation has been restricted to the use of external aids and internal mnemonic strategies (Dixon et al., 1988; Ponds \& Jolles, 1996b). Several other forms of compensatory behavior (e.g., the investment of more time and effort, the recruitment of other people as memory aids) are however relevant too. For that reason, the Memory Compensation Questionnaire (MCQ; De Frias \& Dixon, 2005; Dixon et al., 2001) has been developed. It measures a broader spectrum of everyday memory compensatory behaviors.

It is relevant to know which factors influence compensatory behavior in aging as this may gain further insight in mechanisms of successful aging (Baltes \& Baltes, 1990; Dixon, 1995) and individual adaptability to age-related cognitive changes (De Frias et al., 2003; Garrett et al., 2010). Previous studies indicated that the use of everyday memory compensation strategies is influenced by age and gender (De Frias et al., 2003; Ponds \& Jolles, 1996b), and educational level (De Frias et al., 2003; Garrett et al., 2010). Other known predictors are subjective cognitive complaints (Garrett et al., 2010), metacognition (De Frias et al., 2003; McDougall, 1996), and health and personality factors (De Frias et al., 2003). Although it is commonly known that older adults with depressive symptoms are a highly vulnerable group in the 
context of aging (Dux et al., 2008; Gallo et al., 2003; Köhler et al., 2010), the relation between depressive symptoms and everyday memory compensation has never been investigated.

Compensation has also been related to the concept of cognitive reserve (Stern, 2002, 2003). It is assumed that individuals with high levels of cognitive reserve exhibit less age-related cognitive decline - in part as a consequence of compensation (Garrett et al., 2010; Stern, 2002). Studies on functional compensation provide evidence for this assumption (Cabeza, 2002; Reuter-Lorenz \& Cappell, 2008). The relation between psychological compensation and cognitive reserve is much less evident and needs further investigation. It is assumed that by implementing everyday memory compensation strategies, individuals are able to overcome or mitigate perceived or actual age-related cognitive losses (Bäckman \& Dixon, 1992). People are thus thought to age more successfully if they compensate (Baltes \& Baltes, 1990; Dixon, 1995; Dixon \& de Frias, 2004). This assumption is fundamental to the development of many cognitive interventions that often incorporate some form of strategy training. Indeed, such cognitive interventions often exhibit positive effects on objective cognitive functioning and sometimes also on subjective cognitive functioning in older adults (Floyd \& Scogin, 1997; Glisky \& Glisky, 2005; Rebok, Carlson, \& Langbaum, 2007; Troyer, 2001; Valentijn et al., 2005; Verhaeghen, Marcoen, \& Goossens, 1992). Until now, it has however never been investigated whether spontaneous compensatory behavior (uninitiated by a formal memory training program) is related to different trajectories of change in subjective and objective memory over time.

\section{Interventions for older adults with cognitive complaints}

There is a major challenge in developing suitable and effective interventions for older adults with cognitive complaints, especially in the face of our rapidly aging Western Society. Many intervention studies focused on cognitive training and aimed to improve cognitive function per se. Such interventions generally have task and domain specific effects that hardly generalize to subjective cognitive functioning, wellbeing or everyday outcome (Ball et al., 2002; Floyd \& Scogin, 1997; Glisky \& Glisky, 2005; Jobe et al., 2001; Rebok et al., 2007; Verhaeghen et al., 1992; Willis et al., 2006). Consequently, it has been stated that future intervention studies should find a way to increase awareness and knowledge, decrease negative beliefs, and decrease negative memory-related affect. In the past decade there has been a shift from cognitive training interventions to multidimensional approaches that additionally incorporate several non-cognitive factors (Hess, 2005; McDougall, 2009; Rebok et al., 2007; Stuss et al., 2007). Such multidimensional interventions combine strategy training with, for example, cognitive restructuring (Lachman, Weaver, Bandura, 
Elliott, \& Lewkowicz, 1992), psychosocial training (Stuss et al., 2007; Winocur, Palmer et al., 2007), and education about metacognitive processes (McDougall, 2009; Valentijn et al., 2005; West, Bagwell, \& Dark-Freudeman, 2008) and other contextual factors (Hohaus, 2007; Mohs et al., 1998; Troyer, 2001; Van Hooren, Valentijn, Bosma, Ponds, Van Boxtel, Levine et al., 2007). Contrary to the cognitive training interventions previously mentioned, these multidimensional interventions exhibit positive effects on, for example, subjective cognitive functioning (Hohaus, 2007; Lachman et al., 1992; Mohs et al., 1998; Troyer, 2001; Valentijn et al., 2005; Van Hooren, Valentijn, Bosma, Ponds, Van Boxtel, Levine et al., 2007; West et al., 2008; Winocur, Craik et al., 2007), and psychosocial wellbeing (Winocur, Palmer et al., 2007). Thus, older adults with cognitive complaints may benefit more from such multidimensional intervention approaches than from interventions that focus on the enhancement of cognitive functions per se.

\section{Aims of this thesis}

The present thesis will pay more attention to the growing group of older adults that exhibit perceived cognitive problems in the absence of actual cognitive impairment. The main aim of the present thesis is to develop and evaluate a comprehensive educational group intervention for healthy older adults with cognitive complaints. Furthermore, this thesis aims to provide a broader range of psychometrically sound instruments to assess relevant contextual factors (i.e., metacognitive functioning, neurovegetative and somatic complaints, and everyday memory compensation). Finally, this thesis aims to gain further insight in mechanisms and consequences of everyday memory compensation.

\section{Outline of this thesis}

Chapter 2 presents a new self-report instrument to measure several aspects of metacognitive functioning in older adults. Its psychometric properties are investigated in a community-based sample of 552 older adults aged between 50 and 95 years. Furthermore, the impact of several demographic variables on metacognitive functioning is evaluated.

Chapter 3 presents a questionnaire that assesses neurovegetative and somatic complaints as well as reactive emotional complaints. These symptoms are often indicative for 'masked depression 'or' depression without sadness, especially in older adults. Data from the Maastricht Aging Study (MAAS) are used to investigate the psychometric properties of this questionnaire. 
Chapter 4 presents the Dutch version of the Memory Compensation Questionnaire. Psychometric properties are investigated by means of a postal survey that was conducted in large community-based sample of adults aged 50 to 95 years.

Chapter 5 investigates the predictive value of several background variables on everyday memory compensation in healthy older adults. Special attention was paid to the moderating effect of depressive symptoms on the relationship between perceived cognitive problems and everyday memory compensation. Several known predictors like demographic variables and aspects of metamemory were also included.

Chapter 6 presents a longitudinal investigation of the consequences of everyday memory compensation on trajectories of subjective and objective memory over time. Specific attention is paid to the relation with cognitive reserve (estimated by educational level). For this purpose, longitudinal analyses are carried out using twelve years follow-up data from 231 healthy adults aged 50 years and older who participated in the MAAS.

Chapter 7 presents the background, content, and process evaluation of a comprehensive group intervention that was developed for healthy older adults with cognitive complaints. This intervention program offers psycho-education about changes in several cognitive domains that result from normal aging, differences between normal and pathological aging, and the influence of contextual factors on cognition. Furthermore, it incorporates strategy training and group discussion about attitudes and beliefs concerning cognitive aging.

Chapter 8 presents the results of a randomized controlled trial that investigates the effects of this intervention program in healthy community dwelling women aged 60 to 75 years with normal age-related cognitive complaints.

Chapter 9 discusses the results of this thesis in the form of a general discussion. Implications and recommendations for further research are addressed. 


\section{References}

Alexopoulos, G. S., Borson, S., Cuthbert, B. N., Devanand, D. P., Mulsant, B. H., Olin, J. T., \& Oslin, D. W. (2002). Assessment of late life depression. Biological Psychiatry, 52, 164-174.

Bäckman, L., \& Dixon, R. A. (1992). Psychological compensation: a theoretical framework. Psychological Bulletin, 112, 259-283.

Ball, K., Berch, D. B., Helmers, K. F., Jobe, J. B., Leveck, M. D., Marsiske, M., Morris, J. N., Rebok, G. W., Smith, D. M., Tennstedt, S. L., Unverzagt, F. W., \& Willis, S. L. (2002). Effects of cognitive training interventions with older adults: a randomized controlled trial. Journal of the American Medical Association, 288, 2271-2281.

Baltes, P. B., \& Baltes, M. M. (1990). Psychological perspectives on successful aging: the model of selective optimization with compensation. In P. B. Baltes (Ed.), Successful aging: Perspectives from the behavioral sciences (pp. 1-34). Cambridge: Cambridge University Press.

Beck, A. T., Steer, R. A., \& Garbin, M. G. (1988). Psychometric properties of the Beck Depression Inventory: twenty-five years of evaluation. Clinical Psychology Review, 8, 77-100.

Bierman, E. J., Comijs, H. C., Jonker, C., \& Beekman, A. T. (2005). Effects of anxiety versus depression on cognition in later life. American Journal of Geriatric Psychiatry, 13, 686-693.

Birren, J. E., \& Schaie, K. W. (2001). Handbook of the psychology of aging. San Diego, California: Elsevier.

Blazer, D. G., Hays, J. C., Fillenbaum, G. G., \& Gold, D. T. (1997). Memory complaint as a predictor of cognitive decline: a comparison of African American and White elders. Journal of Aging and Health, 9, 171-184.

Bouma, J., Ranchor, A. V., Sanderman, R., \& Van Sonderen, E. (1995). Measuring symptoms of depression using the CES-D: a manual [Het meten van symptomen van depressie met de CES-D: een handleiding]. Groningen: Noordelijk Centrum voor Gezondheidsvraagstukken, Rijksuniversiteit Groningen.

Cabeza, R. (2002). Hemispheric asymmetry reduction in older adults: the HAROLD model. Psychology and Aging, 17, 85-100.

Cargin, J. W., Collie, A., Masters, C., \& Maruff, P. (2008). The nature of cognitive complaints in healthy older adults with and without objective memory decline. Journal of Clinical and Experimental Neuropsychology, 30, 245-257.

CBS (2009). Health and care in figures 2009 [Gezondheid en zorg in cijfers 2009]. Den Haag/Heerlen: Centraal Bureau voor de Statistiek.

CBS (2010a). Statline database: healthcare. Retrieved 20 May 2010: http://statline.cbs.nl

CBS (2010b). Statline database: population. Retrieved 20 May 2010: http://statline.cbs.nl

Christensen, H., Jorm, A. F., Mackinnon, A. J., Korten, A. E., Jacomb, P. A., Henderson, A. S., \& Rodgers, B. (1999). Age differences in depression and anxiety symptoms: a structural equation modelling analysis of data from a general population sample. Psychological Medicine, 29, 325-339.

Collins, M. W., \& Abeles, N. (1996). Subjective memory complaints and depression in the able elderly. Clinical Gerontologist, 16, 29-54.

Comijs, H. C., Deeg, D. J., Dik, M. G., Twisk, J. W., \& Jonker, C. (2002). Memory complaints; the association with psycho-affective and health problems and the role of personality characteristics. A 6-year follow-up study. Journal of Affective Disorders, 72, 157-165.

Comijs, H. C., Dik, M. G., Aartsen, M. J., Deeg, D. J., \& Jonker, C. (2005). The impact of change in cognitive functioning and cognitive decline on disability, well-being, and the use of healthcare services in older persons. Results of Longitudinal Aging Study Amsterdam. Dementia and Geriatric Cognitive Disorders, 19, 316-323.

Comijs, H. C., Dik, M. G., Deeg, D. J., \& Jonker, C. (2004). The course of cognitive decline in older persons: results from the Longitudinal Aging Study Amsterdam. Dementia and Geriatric Cognitive Disorders, 17, 136-142.

Commissaris, C. J., Jolles, J., Verhey, F. R., Ponds, R. W. H. M., Damoiseaux, V., \& Kok, G. J. (1993). Forgetful or demented? Who worries and why?. [Vergeetachtig of dement? Wie maakt zich zorgen en waarom?] Tijdschrift voor Gerontologie en Geriatrie, 24, 144-149. 
Commissaris, C. J., Ponds, R. W. H. M., \& Jolles, J. (1998). Subjective forgetfulness in a normal Dutch population: possibilities for health education and other interventions. Patient Education and Counseling, 34, 25-32.

Craik, F. I., \& Bialystok, E. (2006). Cognition through the lifespan: mechanisms of change. Trends in Cognitive Sciences, 10, 131-138.

Craik, F. I., \& Grady, J. G. (2002). Aging, memory, and frontal lobe functioning. In D. T. Stuss \& R. T. Knight (Eds.), Principles of frontal lobe function (pp. 528-540). New York: Oxford University Press.

De Frias, C. M., \& Dixon, R. A. (2005). Confirmatory factor structure and measurement invariance of the Memory Compensation Questionnaire. Psychological Assessment, 17, 168-178.

De Frias, C. M., Dixon, R. A., \& Bäckman, L. (2003). Use of memory compensation strategies is related to psychosocial and health indicators. Journals of Gerontology Series B: Psychological Sciences and Social Sciences, 58, P12-22.

De Jong, A., \& Van Duin, C. (2010). Regional prognosis 2009-2040: greying and change from growth to shrinkage [Regionale prognose 2009-2040: vergrijzing en omslag van groei naar krimp]. Bilthoven: Planbureau voor de Leefomgeving.

Dixon, R. A. (1995). Promoting competence through compensation. In L. A. Bond (Ed.), Promoting successful and productive aging (Vol. 1, pp. 220-238). Thousand Oaks, Calif: Sage Publications.

Dixon, R. A., \& Backman, L. (2005). Principles of compensation in cognitive neurorehabilitation. In D. T. Stuss \& G. Winocur (Eds.), Cognitive neurorehabilitation (Vol. 2, pp. 59-72). Cambridge: Cambridge University Press.

Dixon, R. A., \& Bäckman, L. (1992). The concept of compensation in cognitive aging: the case of prose processing in adulthood. International Journal of Aging and Human Development, 36, 199-217.

Dixon, R. A., \& de Frias, C. M. (2004). The Victoria Longitudinal Aging Study: From characterizing cognitive aging to illustrating patterns and predictors of changes in memory compensation. Aging, Neuropsychology, and Cognition, 11, 346-376.

Dixon, R. A., de Frias, C. M., \& Bäckman, L. (2001). Characteristics of self-reported memory compensation in older adults. Journal of Clinical and Experimental Neuropsychology, 23, 650-661.

Dixon, R. A., Hultsch, D. F., \& Hertzog, C. (1988). The Metamemory in Adulthood (MIA) questionnaire. Psychopharmacological Bulletin, 24, 671-688.

Dux, M. C., Woodard, J. L., Calamari, J. E., Messina, M., Arora, S., Chik, H., \& Pontarelli, N. (2008). The moderating role of negative affect on objective verbal memory performance and subjective memory complaints in healthy older adults. Journal of the International Neuropsychological Society, 14, 327336.

Evans, J. J., Wilson, B. A., Needham, P., \& Brentnall, S. (2003). Who makes good use of memory aids? Results of a survey of people with acquired brain injury. Journal of the International Neuropsychological Society, 9, 925-935.

Floyd, M., \& Scogin, F. (1997). Effects of memory training on the subjective memory functioning and mental health of older adults: a meta-analysis. Psychology and Aging, 12, 150-161.

Gallo, J. J., \& Rabins, P. V. (1999). Depression without sadness: alternative presentations of depression in late life. American Family Physician, 60, 820-826.

Gallo, J. J., Rabins, P. V., \& Anthony, J. C. (1999). Sadness in older persons: 13-year follow-up of a community sample in Baltimore, Maryland. Psychological Medicine, 29, 341-350.

Gallo, J. J., Rebok, G. W., Tennsted, S., Wadley, V. G., \& Horgas, A. (2003). Linking depressive symptoms and functional disability in late life. Aging and Mental Health, 7, 469-480.

Garrett, D. D., Grady, C. L., \& Hasher, L. (2010). Everyday memory compensation: the impact of cognitive reserve, subjective memory, and stress. Psychology and Aging, 25, 74-83.

Geerlings, M. I., Jonker, C., Bouter, L. M., Ader, H. J., \& Schmand, B. (1999). Association between memory complaints and incident Alzheimer's disease in elderly people with normal baseline cognition. The American Journal of Psychiatry, 156, 531-537.

Gilewski, M. J., Zelinski, E. M., \& Schaie, K. W. (1990). The Memory Functioning Questionnaire for assessment of memory complaints in adulthood and old age. Psychology and Aging, 5, 482-490. 
Gino, S., Mendes, T., Maroco, J., Ribeiro, F., Schmand, B. A., de Mendonca, A., \& Guerreiro, M. (2010). Memory complaints are frequent but qualitatively different in young and elderly healthy people. Gerontology, 56, 272-277.

Glisky, E. L., \& Glisky, M. L. (2005). Memory rehabilition in the elderly. In D. T. Stuss, G. Winocur \& I. H. Robertson (Eds.), Cognitive neurorehabilitation (pp. 347-361). Cambridge: Cambridge University Press.

Hertzog, C. (2002). Metacognition in older adults: implications for application. In T. J. Perfect \& B. L. Schwartz (Eds.), Applied metacognition (pp. 169-196). London: Cambridge University Press.

Hertzog, C., \& Hultsch, D. F. (2000). Metacognition in adulthood and old age. In F. I. Craik \& T. A. Salthouse (Eds.), Handbook of aging and cognition (pp. 417-466). Mahwah, NJ: Lawrence Erlbaum Associates.

Hess, T. M. (2005). Memory and aging in context. Psychological Bulletin, 131, 383-406.

Hohaus, L. (2007). Remembering to age successfully: evaluation of a successful aging approach to memory enhancement. International Psychogeriatrics, 19, 137-150.

Jobe, J. B., Smith, D. M., Ball, K., Tennstedt, S. L., Marsiske, M., Willis, S. L., Rebok, G. W., Morris, J. N., Helmers, K. F., Leveck, M. D., \& Kleinman, K. (2001). ACTIVE: a cognitive intervention trial to promote independence in older adults. Controlled Clinical Trials, 22, 453-479.

Jolles, J., Houx, P. J., Van Boxtel, M. P. J., \& Ponds, R. W. H. M. (1995). Maastricht Aging Study: determinants of cognitive aging. Maastricht: Neuropsych Publishers.

Jonker, C., Geerlings, M. I., \& Schmand, B. (2000). Are memory complaints predictive for dementia? A review of clinical and population-based studies. International Journal of Geriatric Psychiatry, 15, 983991.

Jonker, C., Launer, L. J., Hooijer, C., \& Lindeboom, J. (1996). Memory complaints and memory impairment in older individuals. Journal of the American Geriatrics Society, 44, 44-49.

Jorm, A. F., Christensen, H., Korten, A. E., Jacomb, P. A., \& Henderson, A. S. (2001). Memory complaints as a precursor of memory impairment in older people: a longitudinal analysis over 7-8 years. Psychological Medicine, 31, 441-449.

Klapow, J., Kroenke, K., Horton, T., Schmidt, S., Spitzer, R., \& Williams, J. B. (2002). Psychological disorders and distress in older primary care patients: a comparison of older and younger samples. Psychosomatic Medicine, 64, 635-643.

Kliegel, M., \& Zimprich, D. (2005). Predictors of cognitive complaints in older adults: a mixture regression approach. European Journal of Ageing, 2, 13-23.

Kliegel, M., Zimprich, D., \& Eschen, A. (2005). What do subjective cognitive complaints in persons with aging-associated cognitive decline reflect? International Psychogeriatrics, 17, 499-512.

Köhler, S., Van Boxtel, M. P., van Os, J., Thomas, A. J., O’Brien, J. T., Jolles, J., Verhey, F. R., \& Allardyce, J. (2010). Depressive Symptoms and Cognitive Decline in Community-Dwelling Older Adults. Journal of the American Geriatrics Society, 58, 873-879.

Lachman, M. E. (1991). Perceived control over memory aging: developmental and intervention perspectives. Journal of Social Issues, 47, 159-175.

Lachman, M. E., Weaver, S. L., Bandura, M., Elliott, E., \& Lewkowicz, C. J. (1992). Improving memory and control beliefs through cognitive restructuring and self-generated strategies. Journal of Gerontology, 47, P293-299.

Lane, C. J., \& Zelinski, E. M. (2003). Longitudinal hierarchical linear models of the memory functioning questionnaire. Psychology and Aging, 18, 38-53.

McDougall, G. J. (1996). Predictors of the use of memory improvement strategies by older adults. Rehabilitation Nursing, 21, 202-209.

McDougall, G. J. (2009). A framework for cognitive interventions targeting everyday memory performance and memory self-efficacy. Family and Community Health, 32, S15-26.

Mendes, T., Gino, S., Ribeiro, F., Guerreiro, M., de Sousa, G., Ritchie, K., \& de Mendonca, A. (2008). Memory complaints in healthy young and elderly adults: Reliability of memory reporting. Aging and Mental Health, 12, 177-182. 
Minett, T. S., Da Silva, R. V., Ortiz, K. Z., \& Bertolucci, P. H. (2008). Subjective memory complaints in an elderly sample: a cross-sectional study. International Journal of Geriatric Psychiatry, 23, 49-54.

Mohs, R. C., Ashman, T. A., Jantzen, K., Albert, M., Brandt, J., Gordon, B., Rasmusson, X., Grossman, M., Jacobs, D., \& Stern, Y. (1998). A study of the efficacy of a comprehensive memory enhancement program in healthy elderly persons. Psychiatry Research, 77, 183-195.

Mol, M. E., Carpay, M., Ramakers, I., Rozendaal, N., Verhey, F., \& Jolles, J. (2007). The effect of perceived forgetfulness on quality of life in older adults; a qualitative review. International Journal of Geriatric Psychiatry, 22, 393-400.

Mol, M. E., Ruiter, R. A., Verhey, F. R., Dijkstra, J., \& Jolles, J. (2008). A study into the psychosocial determinants of perceived forgetfulness: implications for future interventions. Aging and Mental Health, 12, 167-176.

Mol, M. E., Van Boxtel, M. P., Willems, D., \& Jolles, J. (2006). Do subjective memory complaints predict cognitive dysfunction over time? A six-year follow-up of the Maastricht Aging Study. International Journal of Geriatric Psychiatry, 21, 432-441.

Mol, M. E., Van Boxtel, M. P., Willems, D., Verhey, F. R., \& Jolles, J. (2009). Subjective forgetfulness is associated with lower quality of life in middle-aged and young-old individuals: a 9-year follow-up in older participants from the Maastricht Aging Study. Aging and Mental Health, 13, 699-705.

Neskes, R. E., \& Jarvik, L. F. (1987). Affective disorders in the elderly. Annual Review of Medicine, 38, 445-456.

Oxman, T. E., Barrett, J. E., Sengupta, A., \& Williams, J. W., Jr. (2000). The relationship of aging and dysthymia in primary care. American Journal of Geriatric Psychiatry, 8, 318-326.

Paterniti, S., Verdier-Taillefer, M. H., Dufouil, C., \& Alperovitch, A. (2002). Depressive symptoms and cognitive decline in elderly people. Longitudinal study. British Journal of Psychiatry, 181, 406-410.

Petersen, R. C., Smith, G. E., Waring, S. C., Ivnik, R. J., Tangalos, E. G., \& Kokmen, E. (1999). Mild cognitive impairment: clinical characterization and outcome. Archives of Neurology, 56, 303-308.

Ponds, R. W., Commissaris, C. J., \& Jolles, J. (1997). Prevalence and covariates of subjective forgetfulness in a normal population in The Netherlands. International Journal of Aging and Human Development, 45, 207-221.

Ponds, R. W., \& Jolles, J. (1996a). Memory complaints in elderly people: the role of memory abilities, metamemory, depression, and personality. Educational Gerontology, 22, 341-357.

Ponds, R. W., \& Jolles, J. (1996b). The Abridged Dutch Metamemory in Adulthood (MIA) Questionnaire: structure and effects of age, sex, and education. Psychology and Aging, 11, 324-332.

Rebok, G. W., Carlson, M. C., \& Langbaum, J. B. (2007). Training and maintaining memory abilities in healthy older adults: traditional and novel approaches. Journals of Gerontology Series B: Psychological Sciences and Social Sciences, 62 Spec No 1, 53-61.

Reuter-Lorenz, P., \& Cappell, K. A. (2008). Neurocognitive aging and the compensation hypothesis. Current Directions in Psychological Sciences, 17, 177-182.

Sachs-Ericsson, N., Joiner, T., \& Blazer, D. G. (2008). The influence of lifetime depression on self-reported memory and cognitive problems: Results from the National Comorbidity Survey-Replication. Aging and Mental Health, 12, 183-192.

Salthouse, T. A. (1996). The processing-speed theory of adult age differences in cognition. Psychological Review, 103, 403-428.

Stern, Y. (2002). What is cognitive reserve? Theory and research application of the reserve concept. Journal of the International Neuropsychological Society, 8, 448-460.

Stern, Y. (2003). The concept of cognitive reserve: a catalyst for research. Journal of Clinical and Experimental Neuropsychology, 25, 589-593.

Stuss, D. T., Robertson, I. H., Craik, F. I., Levine, B., Alexander, M. P., Black, S., Dawson, D., Binns, M. A., Palmer, H., Downey-Lamb, M., \& Winocur, G. (2007). Cognitive rehabilitation in the elderly: a randomized trial to evaluate a new protocol. Journal of the International Neuropsychological Society, 13, 120-131.

Troyer, A. K. (2001). Improving memory knowledge, satisfaction, and Functioning, via an education and intervention program for older adults. Aging, Neuropsychology, and Cognition, 8, 256-268. 
Troyer, A. K., \& Rich, J. B. (2002). Psychometric properties of a new metamemory questionnaire for older adults. Journals of Gerontology Series B: Psychological Sciences and Social Sciences, 57, P19-27.

Valentijn, S. A., Hill, R. D., Van Hooren, S. A., Bosma, H., Van Boxtel, M. P., Jolles, J., \& Ponds, R. W. (2006). Memory self-efficacy predicts memory performance: results from a 6-year follow-up study. Psychology and Aging, 21, 165-172.

Valentijn, S. A., Van Hooren, S. A., Bosma, H., Touw, D. M., Jolles, J., Van Boxtel, M. P., \& Ponds, R. W. H. M. (2005). The effect of two types of memory training on subjective and objective memory performance in healthy individuals aged 55 years and older: a randomized controlled trial. Patient Education and Counseling, 57, 106-114.

Van Hooren, S. A., Valentijn, A. M., Bosma, H., Ponds, R. W., Van Boxtel, M. P., \& Jolles, J. (2007). Cognitive functioning in healthy older adults aged 64-81: a cohort study into the effects of age, sex, and education. Aging, Neuropsychology, and Cognition, 14, 40-54.

Van Hooren, S. A., Valentijn, S. A., Bosma, H., Ponds, R. W., Van Boxtel, M. P., Levine, B., Robertson, I., \& Jolles, J. (2007). Effect of a structured course involving goal management training in older adults: A randomised controlled trial. Patient Education and Counseling, 65, 205-213.

Verhaeghen, P., Geraerts, N., \& Marcoen, A. (2000). Memory complaints, coping, and well-being in old age: a systemic approach. Gerontologist, 40, 540-548.

Verhaeghen, P., Marcoen, A., \& Goossens, L. (1992). Improving memory performance in the aged through mnemonic training: a meta-analytic study. Psychology and Aging, 7, 242-251.

Verhey, F. R., Ramakers, I., Jolles, J., Scheltens, P., Vernooij-Dassen, M. J., \& Olde Rikkert, M. (2007). Memory clinics in the Netherlands: development since 1998 [Geheugenpoli's in Nederland: ontwikkelingen sinds 1998]. Tijdschrift voor Gerontologie en Geriatrie, 38, 237-245.

Weiss, I. K., Nagel, C. L., \& Aronson, M. K. (1986). Applicability of depression scales to the old old person. Journal of the American Geriatrics Society, 34, 215-218.

West, R. L., Bagwell, D. K., \& Dark-Freudeman, A. (2008). Self-Efficacy and Memory Aging: The Impact of a Memory Intervention Based on Self-Efficacy. Aging, Neuropsychology, and Cognition, 15, 302-329.

Willis, S. L., Tennstedt, S. L., Marsiske, M., Ball, K., Elias, J., Koepke, K. M., Morris, J. N., Rebok, G. W., Unverzagt, F. W., Stoddard, A. M., \& Wright, E. (2006). Long-term effects of cognitive training on everyday functional outcomes in older adults. Journal of the American Medical Association, 296, 2805-2814.

Wilson, B. A. (2000). Compensating for cognitive deficits following brain injury. Neuropsychology Review, 10, 233-243.

Wilson, B. A., \& Watson, P. C. (1996). A practical framework for understanding compensatory behaviour in people with organic memory impairment. Memory, 4, 465-486.

Winblad, B., Palmer, K., Kivipelto, M., Jelic, V., Fratiglioni, L., Wahlund, L. O., Nordberg, A., Backman, L., Albert, M., Almkvist, O., Arai, H., Basun, H., Blennow, K., de Leon, M., DeCarli, C., Erkinjuntti, T., Giacobini, E., Graff, C., Hardy, J., Jack, C., Jorm, A., Ritchie, K., van Duijn, C., Visser, P., \& Petersen, R. C. (2004). Mild cognitive impairment--beyond controversies, towards a consensus: report of the International Working Group on Mild Cognitive Impairment. Journal of Internal Medicine, 256, 240-246.

Winocur, G., Craik, F. I., Levine, B., Robertson, I. H., Binns, M. A., Alexander, M., Black, S., Dawson, D., Palmer, H., McHugh, T., \& Stuss, D. T. (2007). Cognitive rehabilitation in the elderly: overview and future directions. Journal of the International Neuropsychological Society, 13, 166-171.

Winocur, G., Palmer, H., Dawson, D., Binns, M. A., Bridges, K., \& Stuss, D. T. (2007). Cognitive rehabilitation in the elderly: an evaluation of psychosocial factors. Journal of the International Neuropsychological Society, 13, 153-165.

World Health Organization, W. (2006). The world health report 2006: working together for health.

Zacks, R. T., Hasher, L., \& Li, K. Z. H. (2000). Human memory. In F. I. M. Craik \& T. A. Salthouse (Eds.), The handbook of aging and cognition (Vol. 2, pp. 293-357). Mahwah, NJ: Erbaum.

Zimprich, D., Martin, M., \& Kliegel, M. (2003). Subjective cognitive complaints, memory performance, and depressive affect in old age: a change-oriented approach. International Journal of Aging and Human Development, 57, 339-366. 

CHAPTER 2

Metacognition in aging: the Maastricht Metacognition Inventory and effects of age, gender, and educational level 


\begin{abstract}
Metacognition is a key construct in aging research. It is usually measured with the help of self-report questionnaires that solely focus on metamemory. In contrast, the Maastricht Metacognition Inventory (MMI) measures four aspects of metacognition (i.e., everyday cognitive failures, emotional reactions to cognitive failures, sense of control, and the use of compensation strategies). The current study investigates the psychometric properties of the $\mathrm{MMI}$ and evaluates the impact of several demographic variables on metacognitive functioning. A postal survey was administered to 552 cognitively healthy people, aged between 50 and 95 years. Confirmatory factor analyses were carried out to investigate the factor structure. In order to investigate convergent validity, $\mathrm{MMI}$ subscales were correlated to subscales of the Cognitive Failure Questionnaire and the Metamemory in Adulthood questionnaire. Factorial validity, reliability, and convergent validity of the $\mathrm{MMI}$ were confirmed. Older individuals reported: (i) more everyday cognitive failures, (ii) more complaints about a low sense of control, and (iii) more frequent use of compensation strategies. Lowereducated individuals reported: (i) more everyday cognitive failures, (ii) more emotional reactions towards cognitive failures, and (iii) more complaints about a low sense of control. Gender did not affect any of the metacognition components. Regression-based normative data were provided. The $\mathrm{MMI}$ is a psychometrically sound self-report instrument that assesses four aspects of metacognition. It has several advantages over existing questionnaires. Metacognitive functioning is associated with demographic variables. These findings may have several implications, for example in the context of the development of interventions for older individuals with cognitive complaints.
\end{abstract}




\section{Introduction}

Complaints about cognitive functioning are highly prevalent, especially in older adults (Jonker, Geerlings, \& Schmand, 2000; Ponds, Commissaris, \& Jolles, 1997). They appear to affect the quality of life adversely (Mol, Van Boxtel, Willems, Verhey, \& Jolles, 2009). Until the present, findings about the nature of these cognitive complaints have however been inconsistent. While some studies suggested that cognitive complaints were indicative for objective cognitive decline or clinical dementia (Jonker et al., 2000; Jorm, Christensen, Korten, Jacomb, \& Henderson, 2001), the majority of studies could not establish such a relation (Blazer, Hays, Fillenbaum, \& Gold, 1997; Mol, Van Boxtel, Willems, \& Jolles, 2006). In fact, the association between cognitive complaints and, for example, self-efficacy, affective state, personality, health, and lifestyle factors seems much stronger (Comijs, Deeg, Dik, Twisk, \& Jonker, 2002; Kliegel \& Zimprich, 2005; Mol, Ruiter, Verhey, Dijkstra, \& Jolles, 2008; Ponds et al., 1997; Ponds \& Jolles, 1996a). Apparently, aging is characterized by cognitive complaints and subjective feelings that are not necessarily accompanied by declines in objective cognitive abilities. A key construct that has received considerable attention in this context is metacognition (i.e., cognitions about cognition) (Dixon \& Hultsch, 1983; Hertzog, 2002; Hertzog \& Hultsch, 2000; Troyer \& Rich, 2002).

Metacognition is an umbrella term that covers three major categories, namely knowledge about cognition and cognitive functions, monitoring of the current state of the cognitive system, and beliefs about cognition (Hertzog, 2002; Hertzog \& Hultsch, 2000). Especially the third construct, which can further be divided into several relevant dimensions such as efficacy, personal control, perceived change, and emotional reactions, has received considerable attention in research on aging (Hertzog, 2002; Hertzog \& Hultsch, 2000). Self-report questionnaires provide a wellestablished method to gain further insight in metacognitive functioning. Some of them are multidimensional, for example the Metamemory in Adulthood Questionnaire (MIA; Dixon, Hultsch, \& Hertzog, 1988; Ponds \& Jolles, 1996b), the Memory Functioning Questionnaire (MFQ; Gilewski, Zelinski, \& Schaie, 1990; Lane \& Zelinski, 2003), and the Multifactorial Memory Questionnaire (MMQ; Fort, Adoul, Holl, Kaddour, \& Gana, 2004; Troyer \& Rich, 2002). Other instruments focus on a single aspect of metacognition, for example the Cognitive Failure Questionnaire (CFQ; Broadbent, Cooper, FitzGerald, \& Parkes, 1982), the Memory Controllability Inventory (MCl; Lachman, Bandura, Weaver, \& Elliott, 1995), and the Memory Compensation Questionnaire (MCQ; De Frias \& Dixon, 2005). Although these instruments are well established, there are several drawbacks associated with their use, such as the large number of items they contain as well as their lack of items concerning emotional reactions other than memory-related anxiety (e.g., frustration, irritation, and unhappiness) (M. Floyd \& Scogin, 1997; Hertzog \& Hultsch, 2000; Troyer \& Rich, 
2002; Verhaeghen, van Ranst, \& Marcoen, 1993). Furthermore, these instruments focus on memory, whilst other potentially relevant cognitive domains are largely neglected (Hertzog, 2002; Hertzog \& Hultsch, 2000). Previous research has however indicated that objective age-related cognitive changes are not limited to memory functioning per se, but extend to other cognitive domains (Craik \& Bialystok, 2006; Salthouse, 1996; Van Hooren et al., 2007). Likewise, subjective cognitive complaints seem to extend beyond the domain of memory (Ponds, Van Boxtel, \& Jolles, 2000). Hence, it might be advantageous to develop a metacognition instrument that assesses a broader spectrum of cognitive domains (e.g., to increase the ecological validity of measurement).

For these reasons, we developed a new self-report questionnaire that covers a broader spectrum of cognitive domains and metacognitive functions, i.e., the Maastricht Metacognition Inventory ( $\mathrm{MMI}$ ). The $\mathrm{MMI}$ is a short and easily administered multidimensional instrument that aims to assess four major aspects of metacognitive functioning (i.e., the occurrence of everyday cognitive failures, emotional reactions to everyday cognitive failures, complaints about a low sense of control over cognitive functioning, and the use of compensation strategies). The MMI was especially devised to extend our knowledge about the impact of demographic variables on metacognition.

Previous studies that made use of metamemory instruments indicated that older adults (relative to younger adults) tended to: (i) report lower levels of memory self-efficacy or capacity (Fort et al., 2004; Gilewski et al., 1990; Ponds \& Jolles, 1996b); (ii) have more memory-related anxiety (Ponds \& Jolles, 1996b); (iii) believe their memory has declined more over time (Gilewski et al., 1990; Ponds \& Jolles, 1996b); (iv) report less control over their memory functioning (Lachman et al., 1995); and (v) use more strategies to compensate for their perceived deficits (Fort et al., 2004; Ponds \& Jolles, 1996b). Moreover, longitudinal studies showed that as people age they experience decreased memory capacity, a more strongly perceived memory decline, higher memory-related anxiety, and more strategy use (Hertzog \& Hultsch, 2000; McDonald-Miszczak, Hertzog, \& Hultsch, 1995).

Age-extrinsic factors, like educational level and gender, were also found to affect metamemory. For example, lower educational levels were associated with (i) a lower level of perceived memory capacity), and (ii) a stronger perceived cognitive decline (Ponds \& Jolles, 1996b). Being female has been associated with (i) lower levels of perceived memory capacity, (ii) higher memory related anxiety, and (iii) the use of more compensatory strategies (Ponds \& Jolles, 1996b).

Previous research suggested that educational level and gender moderate the relation between age and objective cognitive functioning (Anstey \& Christensen, 2000; Stern, 2002), although findings are inconsistent (Van Dijk, Van Gerven, Van Boxtel, Van der Elst, \& Jolles, 2008). It is thus conceivable that educational level and gender exert a similar influence on the relation between age and metacognition, 
although no interaction effects of educational level, gender, and age were established in a previous study on metamemory by Ponds and Jolles (1996b).

The aim of present study was twofold. First, psychometric properties (i.e., factor structure, reliability, and validity) of the MMI were investigated. Second, the impact of demographic variables on various aspects of metacognition was examined and regression-based normative data were provided.

\section{Methods}

\section{Participants and procedure}

Participants were recruited within a Dutch community organization for healthy elderly who are at least 50 years old. We aimed to recruit 500 participants in order to obtain an optimal sample size for factor analysis (MacCallum, Widaman, Zhang, \& Hong, 1999). In line with a previous study in a similar study population (Mol et al., 2008), we anticipated non-response and incomplete questionnaires. The sampling frame thus comprised approximately 3,000 members of this organization. These people were sent a questionnaire enclosed in the organization's monthly magazine. The questionnaires were sent between $1^{\text {st }}$ April and $1^{\text {st }}$ June 2008 , with a prepaid response envelope and a cover letter, which detailed the aims of the study. In total, $N=813$ participants returned the questionnaire (i.e., a response rate of $27.1 \%$ ).

Respondents who were younger than $50(n=27)$ and people whose age could not be determined due to missing or erroneous self-reported date information ( $n=$ 6 ) were excluded. Participants who reported to suffer from (previous) illnesses that could interfere with cognitive functioning were excluded (i.e., dementia $(n=20)$, stroke $(n=63)$, brain tumours $(n=4)$, central nervous diseases $(n=8)$, and epilepsy $(n=10))$. The cognitive status of the participants was evaluated by means of a clockdrawing test included in the questionnaire. In this test, participants were asked to draw in the numbers as in a clock face in a pre-drawn circle of $8.3 \mathrm{~cm}$ in diameter (Paganini-Hill, Clark, Henderson, \& Birge, 2001). This questionnaire version of the clock-drawing task provides reliable and valid information regarding the general cognitive status of an individual (Paganini-Hill \& Clark, 2007; Paganini-Hill et al., 2001). Age group and gender-corrected cut-off scores for cognitive disability (Paganini-Hill et al., 2001) identified $n=20$ participants as cognitively impaired. These participants were thus excluded from the subsequent analyses. Moreover, the data of $n=82$ and $n=21$ participants were excluded because they did not complete the clock-drawing test or because they had more than five missing values on the MMI, respectively. Thus the data of a total sample of $N=552$ participants were analyzed. Demographics of the sample are given in Table 1. 
Table 1 Distribution of gender and educational level per age group $(N=552)$

\begin{tabular}{lccccc}
\hline & $\begin{array}{c}\mathbf{5 0 - 6 0} \\
\text { years }\end{array}$ & $\begin{array}{c}\mathbf{6 0 - 7 0} \\
\text { years }\end{array}$ & $\begin{array}{c}\mathbf{7 0 - 8 0} \\
\text { years }\end{array}$ & $\begin{array}{c}\mathbf{8 0 - 9 5} \\
\text { years }\end{array}$ & Total \\
\hline $\mathrm{N} \quad$ & 174 & 227 & 131 & 552 \\
$\begin{array}{l}\text { Gender } \\
\quad \text { \% women }\end{array}$ & 20 & & & & \\
$\quad \begin{array}{l}\text { \% men } \\
\text { Education }\end{array}$ & 60.0 & 64.5 & 60.8 & 59.5 & 61.6 \\
$\quad$ \% low & 40.0 & 35.5 & 39.2 & 40.5 & 38.4 \\
$\quad$ \% medium & & & & & \\
$\quad$ \% high & 10.0 & 26.6 & 27.8 & 29.5 & 27.1 \\
\hline
\end{tabular}

Mean age of the sample was 73.7 years (range $50-95$ years; $S D=8.0$ ). There were significantly more women in the sample $(61.6 \%)$ than men $(38.4 \%, p<.01)$. Level of education was measured by classifying the formal schooling of the participants in one of three groups, i.e., those with at most primary education (LE low; $27.1 \%$ of the sample), those with at most junior vocational training or high school (LE average; $44.7 \%$ of the sample), and those with at most senior vocational or academic training (LE high; $28.2 \%$ of the sample). This LE system is often used in the Netherlands (De Bie, 1987) and is comparable with the International Standard Classification of Education (UNESCO, 1976).

\section{Measures}

\section{Maastricht Metacognition Inventory}

The original version of the $\mathrm{MMI}$ contained 56 items that were designed to assess four dimensions of metacognition. The first dimension (Ability) referred to the occurrence of everyday cognitive failures and included sixteen items concerning perceived memory failures (e.g., 'I have difficulty to retrieve common belongings'), failures related to attention capacity or speed of information processing (e.g., 'I am easily distracted when taking part in a conversation') and executive failures (e.g., 'I have difficulties to carry out complex activities, like planning a holiday or organizing a party'). The second dimension (Affect) included twelve items that cover a wide range of common emotional reactions to everyday cognitive failures, including worries (e.g., 'I am worried about my cognitive capacities') and unhappiness (e.g., 'I feel unhappy when thinking about my memory capacities'). The third dimension (Control) aimed to measure complaints about the sense of control with ten items (e.g., 'There is little I can do to prevent my memory to decline'). Compensatory behavior (i.e., using strategies to cope with cognitive problems) (Bäckman \& Dixon, 1992) was measured with eighteen items (Strategy) (e.g., the use of notes, visualising information, and slowing down reading speed). All items were rated on a 5-point Likert scale (i.e., strongly disagree, disagree, nor disagree/nor agree, agree, strongly agree). For each item, 1 (strongly disagree) to 5 (strongly agree) points was given 
depending on the level of agreement. Higher Ability, Affect, Control, and Strategy scale scores indicate a larger number of perceived everyday cognitive failures, a larger number of emotional reactions to everyday cognitive failures, more complaints about a low sense of control, and the use of more compensatory strategies, respectively.

\section{Other measures}

The Cognitive Failure Questionnaire (CFQ; Broadbent et al., 1982; Merckelbach, Muris, Nijman, \& De Jong, 1996) and the Capacity, Anxiety, Locus and Strategy subscales of the abridged Dutch Metamemory in Adulthood Questionnaire (MIA; Ponds \& Jolles, 1996b) were included in the postal questionnaire to evaluate the convergent validity of the MMI. The CFQ consisted of 25 items that assess the frequency of everyday cognitive failures (such as failing to hear people speak or forgetting what you came to the shop to buy). All items were rated on a 5-point Likert scale with a score range between 0 (never) and 4 (all the time). Higher scores indicated more everyday cognitive failures.

The Capacity subscale of the abridged MIA (Ponds \& Jolles, 1996b) consisted of 12 items, which assess the participants' beliefs regarding their own memory capacities. The Anxiety subscale consisted of 12 items that measure perceived anxiety regarding memory performance. The Locus subscale consisted of seven items regarding a participant's perceived sense of control over memory skills. These three subscales were scored on a 5-point Likert scale ranging from 1 (strongly disagree) to 5 (strongly agree). Higher scale scores indicated decreased reported memory capacity, more perceived stress and anxiety regarding memory functioning, and less perceived control, respectively. The 16 items of the Strategy subscale assessed the frequency of the use of memory strategies. All items were scored on a 5-point Likert scale ranging from 1 (never) to 5 (all the time). Higher Strategy scale scores indicated a more frequent use of memory strategies of various types (Ponds \& Jolles, 1996b).

\section{Statistical Analyses}

Confirmatory Factor Analysis (CFA) was used to evaluate the factor structure of the MMI. A model was specified in which the four dimensions of metacognition (i.e., the Ability, Affect, Control and Strategy dimensions) underlie the 56 item responses. Moreover, each item was expected to load on only one factor. Pilot testing of the items to be factor analyzed was conducted to ensure that the items that were designed to measure a common construct (i.e., the items designed to measure the Ability, Affect, Control and Strategy dimensions) correlated at least moderately with each other (i.e., inter-item correlations of at least .20) (F. J. Floyd \& Widaman, 1995). Maximum likelihood CFA was used to evaluate the factor structure of the 
MMI using LISREL 8.8 for Windows. Factor scale identification was established by fixing the factor loading of one item from each factor to a value of 1.0. Covariance matrices were analyzed. Items with modification indices higher than 100 were removed from the model. Additionally, regression weights were inspected and items with cross-loadings were removed one by one. Model fit was evaluated with the root-mean-square error of approximation (RMSEA). RMSEA values below .05 are indicative for a good model fit (Bentler, 1990; Browne \& Cudeck, 1992).

Internal consistency (which is a lower bound for reliability) of the items of the scale scores as identified with the CFA was assessed by calculating Cronbach's alpha coefficients. In addition, the average inter-item correlations per scale were calculated because the usefulness of Cronbach's alpha as an indicator of internal consistency has been questioned (i.e., Cronbach's alpha values are not only a function of the height of the intercorrelations between the items of a scale but also of the number of items of that scale) (Clark \& Watson, 1995). Pearson's correlations between the obtained scale scores of the MMI, the CFQ, and the relevant subscales of the MIA were calculated to evaluate convergent validity.

The relation between the established scale scores of the MMI and demographic variables was evaluated by regressing the scale scores on age, age ${ }^{2}$, gender (coded as male $=1$ and female $=0$ ), educational level (dummy coded into three levels with LE average as the reference category), and the age $x$ gender and age $x$ educational level interaction terms. To avoid multicollinearity, age was centered (age = calendar age -75$)$ before quadratic terms and interactions were calculated. Non-significant predictors $(p>.01)$ were excluded from the full models (i.e., the models that included all predictors), but no predictor was removed as long as it was also included in a higher order term in the model (Aiken \& West, 1991). The assumptions of regression analysis were tested for each model. Homoscedasticity was evaluated using visual inspection of scatter plots of the residuals against the predicted values and by grouping participants into quartiles of the predicted scores and applying the Levene test. Normal distributions of the residuals were investigated using visual inspection of the histograms of the residuals, and by conducting KolmogorovSmirnov tests on the residuals. The occurrence of multicollinearity was checked by calculating the Variance Inflation Factors (VIFs), which should not exceed 10 (Belsley, Kuh, \& Welsch, 1980).

Standardized residuals were calculated to obtain normative data for the scale scores of the MMI. The standardized residuals were converted into percentiles by means of a standard normal distribution table with cumulative probabilities (if the model assumption of normality of the residuals was met), or by means of a table with the observed distribution of the standardized residuals with cumulative probabilities (if the residuals were not normally distributed in the normative sample). For details on the normative method, see Van der Elst and colleagues (2007). Analyses were conducted using PASW 18.0 for Macintosh. 


\section{Results}

\section{Factor structure}

The inter-item correlations between five items that were designed to measure the Control construct were below .20. These items were thus excluded from further analyses. Cross-loadings were observed for one, five, and eight items that were intended to measure the Ability, Affect, and Strategy dimensions, respectively. These items were removed from the model one by one. The final model consisted of 43 items. Sixteen, eleven, five, and eleven items loaded on the Ability, Affect, Control, and Strategy dimensions, respectively (see Table 2).

Table 2 Standardized factor loadings, error variances, means, standard deviations, and Cronbach's alpha coefficients for the final four-factor model of the MMI

\begin{tabular}{|c|c|c|c|c|}
\hline \multicolumn{2}{|c|}{ MMI item } & Ability & Affect & Control Strategy \\
\hline \multicolumn{5}{|c|}{ Ability } \\
\hline 1 & Easily distracted when taking part in conversation & $.63(.59)$ & & \\
\hline 2 & Difficulty remembering people's names & $.53(.90)$ & & \\
\hline 3 & Difficulty performing activities automatically & $.65(.60)$ & & \\
\hline 4 & Forgetting to buy something that one intended to buy & $.67(.58)$ & & \\
\hline 5 & Failing to hear people speak when doing something else & $.48(.86)$ & & \\
\hline 6 & Difficulty remembering future activities & $.67(.55)$ & & \\
\hline 7 & Difficulty retrieving everyday belongings & $.51(.81)$ & & \\
\hline 8 & Difficulty learning new skills & $.55(.83)$ & & \\
\hline 9 & Difficulty taking quick decisions & $.57(.66)$ & & \\
\hline 10 & Difficulty sustaining attention & $.73(.53)$ & & \\
\hline 11 & Easily distracted & $.74(.49)$ & & \\
\hline 12 & Difficulty carrying out two simultaneous tasks & $.58(.86)$ & & \\
\hline 13 & Difficulty organizing complex activities & $.64(.90)$ & & \\
\hline 14 & Need to put in a lot of time in tasks & $.58(.61)$ & & \\
\hline 15 & Difficulty remembering information that was read & $.67(.69)$ & & \\
\hline 16 & Difficulty concentrating & $.76(.49)$ & & \\
\hline \multicolumn{5}{|c|}{ Affect } \\
\hline 1 & Get put out when forgetting something & & $.73(.49)$ & \\
\hline 2 & Be ashamed for one's memory capacities & & $.65(.38)$ & \\
\hline 3 & Feel unhappy when thinking of one's memory capacity & & $.60(.85)$ & \\
\hline 4 & Feel uneasy when attempting a problem that requires memory capacity & & $.71(.53)$ & \\
\hline 5 & Feel tense when asked to remember something & & $.78(.36)$ & \\
\hline 6 & Worried about memory capacities & & $.79(.42)$ & \\
\hline 7 & Concern that others will notice memory problems & & 69 (.49) & \\
\hline 8 & Be afraid about becoming demented & & $.53(.72)$ & \\
\hline 9 & Be afraid to forget something important & & $.72(.53)$ & \\
\hline 10 & Get irritated and annoyed when forgetting something & & $.59(.85)$ & \\
\hline 11 & Be afraid to forget something somebody has told you & & $.68(.61)$ & \\
\hline \multicolumn{5}{|c|}{ Control } \\
\hline 1 & Little control of memory functioning & & & $.63(.53)$ \\
\hline 2 & Unable to protect oneself from age-related memory decline & & & $.62(.68)$ \\
\hline 3 & Unable to prevent age related memory problems & & & $.53(.90)$ \\
\hline 4 & Unable to solve any problems in memory functioning & & & $.67(.46)$ \\
\hline 5 & Little control over things that happen to memory & & & $.60(.60)$ \\
\hline
\end{tabular}




\begin{tabular}{|c|c|c|c|c|c|}
\hline \multicolumn{2}{|c|}{ MMI item } & \multirow[t]{2}{*}{ Ability } & \multirow[t]{2}{*}{ Affect } & \multicolumn{2}{|c|}{ Control Strategy } \\
\hline \multicolumn{4}{|c|}{ Strategy } & & \\
\hline 1 & Write things down, for example in a calendar or notebook & & & & $.50(.48)$ \\
\hline 2 & Put things in certain places & & & & $.58(.61)$ \\
\hline 3 & Repeat information in my thoughts to remember it better & & & & $.69(.61)$ \\
\hline 4 & Relate information to something that is known well & & & & $.52(.59)$ \\
\hline 5 & Try to visualise & & & & $.54(.71)$ \\
\hline 6 & Repeat information aloud & & & & $.46(1.25)$ \\
\hline 7 & Make use of routines & & & & $.62(.76)$ \\
\hline 8 & Ask friend or family member for support & & & & $.58(.68)$ \\
\hline 9 & Slow down reading in order to remember & & & & $.53(.88)$ \\
\hline & Take more time & & & & $.54(.73)$ \\
\hline & Put in a lot of effort & & & & $.64(.75)$ \\
\hline \multicolumn{2}{|c|}{ Mean } & 40.13 & 25.71 & 12.11 & 37.93 \\
\hline \multicolumn{2}{|r|}{ Standard deviation } & 10.89 & 7.98 & 3.50 & 7.01 \\
\hline \multicolumn{2}{|r|}{ Mean inter-item correlations } & .39 & .46 & .37 & .32 \\
\hline \multicolumn{2}{|c|}{ Cronbach's alpha coefficient } & .91 & .90 & .74 & .83 \\
\hline
\end{tabular}

This 4-factor model fitted the data well (RMSEA $=.052,90 \% \mathrm{Cl}=.050-.055, p=$ .071). All factor loadings and factor variances were significantly different from zero ( $p s<.01$ ) (see Table 2). Inter-factor correlations ranged from .42 to .78 and could be interpreted as large (Cohen, 1988) (see Table 3).

Table 3 Inter-factor correlations between the MMI factors

\begin{tabular}{lcccc}
\hline Factor & Ability & Affect & Control & Strategy \\
\hline Ability & 1.00 & & & \\
Affect & .78 & 1.00 & & \\
Control & .65 & .68 & 1.00 & \\
Strategy & .61 & .60 & .42 & 1.00 \\
\hline
\end{tabular}

\section{Reliability and validity}

All items of the four MMI scales were internally consistent, with Cronbach's alpha coefficients ranging from .74 for Control and .83 for Strategy, to .90 for Affect and .91 for Ability (see Table 2). These values are lower bounds for reliability, which means that at least 74-91 percent of the total within-test score variance of the scales was due to true score variance rather than due to item content heterogeneity or poor item quality. The average inter-item correlations for the Ability, Affect, Control, and Strategy scales were $.39, .46, .37$, and .32 , respectively. Unidimensionality of the scales could, as a result, be confirmed (Clark \& Watson, 1995).

Convergent validity was evaluated by calculating Pearson correlations between the four MMI scores on the one hand, and the CFQ and several MIA subscales on the other hand. The Ability scale scores of the $\mathrm{MMI}$ were significantly correlated with the CFQ score and the MIA Capacity scale scores $(r(501)=-.720, p<.001$ and $r(517)=-.500, p<.001$, respectively). As expected, the Affect scale scores of the $\mathrm{MMI}$ were significantly correlated with the MIA Anxiety scale scores $(r(518)=.829$, $p<.001)$. Moreover, significant correlations were found between the Control scale 
scores of the MMI and the MIA Locus scale scores $(r(533)=-.290, p<.001)$. Finally, the Strategy scale scores of the MMI were significantly correlated with the MIA Strategy scale scores $(r(531)=.616, p<.01)$. Correlation coefficients of $.10, .30$ and .50 can be interpreted as small, medium, and large, respectively (Cohen, 1988). Consequently, all correlations mentioned could be interpreted as having a medium to high effect size.

\section{Relation to age, gender, and educational level}

All assumptions of linear regression analysis were met. The final regression models are shown in Table 4.

Table 4 Final multiple linear regression models for the Ability, Affect, Control, and Strategy scale scores of the Maastricht Metacognition Inventory following a step-down hierarchical procedure.

\begin{tabular}{|c|c|c|c|c|c|c|c|c|}
\hline Score & Variable & B & Std.Error B & $\mathbf{T}$ & & Standardized B & SD (Error) & $\mathbf{R}^{2}$ \\
\hline \multirow[t]{4}{*}{ Ability } & (constant) & 40.588 & .689 & 58.900 & $*$ & & & \\
\hline & Age & .229 & .057 & 4.005 & $*$ & .167 & & \\
\hline & LE low & 2.717 & 1.101 & 2.469 & & .111 & & \\
\hline & LE high & -3.095 & 1.093 & -2.832 & $*$ & -.128 & 10.562 & .064 \\
\hline \multirow[t]{3}{*}{ Affect } & (constant) & 26.090 & .503 & 51.859 & $*$ & & & \\
\hline & LE low & 1.313 & .818 & 1.605 & & .073 & & \\
\hline & LE high & -2.509 & .808 & -3.105 & $*$ & -.141 & 7.875 & .030 \\
\hline \multirow[t]{4}{*}{ Control } & (constant) & 12.305 & .223 & 55.274 & $*$ & & & \\
\hline & Age & .071 & .018 & 3.870 & $*$ & .162 & & \\
\hline & LE low & .714 & .356 & 2.007 & & .091 & & \\
\hline & LE high & -.990 & .353 & -2.805 & $*$ & -.127 & 3.412 & .056 \\
\hline \multirow[t]{2}{*}{ Strategy } & (constant) & 38.093 & .299 & 127.246 & $*$ & & & \\
\hline & Age & .126 & .037 & 3.399 & $*$ & .143 & 6.940 & .021 \\
\hline
\end{tabular}

Note: The full models included age, age ${ }^{2}$, gender, LE low, LE high, age $\times$ gender, age $\times$ LE low, and age $\times$ LE high.

$* p<.01$

The Ability scale score (indicative for everyday cognitive failures) increased linearly as a function of age and was higher for lower-educated people. The Affect scale score (indicative for emotional reactions to cognitive failures) was significantly affected by educational level, with higher predicted Affect scale scores (i.e., more emotional reactions) for lower-educated individuals. The Control scale score (indicative for complaints about a low sense of control) increased linearly as a function of age, and was higher (i.e., more complaints about a low sense of control) for lowereducated people. Finally, the Strategy scale score (indicative for degree of compensatory behavior) increased linearly as a function of age (i.e., older participants report the use of more compensation strategies). 


\section{MMI normative data}

Normative tables are provided for the Ability, Affect, Control, and Strategy scale scores of the MMI (see Appendix 1-4). If an individual's age is not exactly as indicated in the tables (i.e., 50, 55, ..., 95 years old), then that person's age should be rounded up to the closest age given in the normative tables. Interpretation of the raw scale scores has been facilitated with the aid of the normative tables. For example, in the case of a 74-year-old woman with a high educational level who had a raw score of 51 on the Ability scale, 35 on the Affect scale, 17 on the Control scale, and 22 on the Strategy scale: the normative tables indicate that these raw scores correspond with percentiles of 10 (i.e., an above average amount of everyday cognitive failures), 5 to 10 (i.e., an above average amount of emotional reactions to cognitive failures), 1 to 5 (i.e., a lot of complaints about a low sense of control), and 1 to 5 (i.e., the use of few compensation strategies), respectively.

\section{Discussion}

Metacognition, and more specifically self-referent beliefs about cognition, can be seen as a key construct in cognitive aging. Until now, most research has focussed on metamemory. Several well-established and psychometrically sound self-report questionnaires are available, but there are several drawbacks associated with their use (see Introduction). The current study examined the newly developed Maastricht Metacognition Inventory (MMI) that was devised as a short and multidimensional self-report instrument, which covers several cognitive domains and includes items that reflect four aspects of metacognition (i.e., everyday cognitive failures, emotional reactions to cognitive failures, sense of control, and the use of compensation strategies).

Results of the present study showed that this four-factor model had a good fit with the data. Pilot testing and confirmatory factor analysis of the MMI reduced the initial number of 56 items to 43 items. Overall, the psychometric properties of all scales were good to excellent (e.g., high levels of internal consistency, confirmation of unidimensionality of the scales, and satisfactory convergent validity). Linear regression analyses showed that mean-level scores on the different scales were affected by age and/or educational level, but not by gender. Regression-based normative tables for the MMI scale scores were provided, appropriately corrected for the effects of the relevant demographical variables (see Appendix 1-4).

Older individuals in our sample reported: (i) more everyday cognitive failures, (ii) more complaints about a low sense of control, and (iii) the use of more compensation strategies. As an example, Figure 1 shows the predicted scale scores at ages $50,55, \ldots 95$ relative to predicted scale scores at age 50 for average educated indi- 
viduals. As shown, the scores on the Ability and Control scales increased linearly as a function of age (i.e., older adults report more everyday cognitive failures and more complaints about a low sense of control). The scores of the Strategy scale increased as a function of age too. However, the relative increase in compensatory behavior lags behind the increase in everyday cognitive complaints and the level of complaints about a low sense of control. These findings are comparable to those of previous studies on metamemory that established significant associations between age and reported memory capacity (lower) (Fort et al., 2004; Gilewski et al., 1990; Ponds \& Jolles, 1996b), sense of control over memory functioning (lower) (Lachman et al., 1995), and the use of compensation strategies (higher) (Fort et al., 2004; Ponds \& Jolles, 1996b).

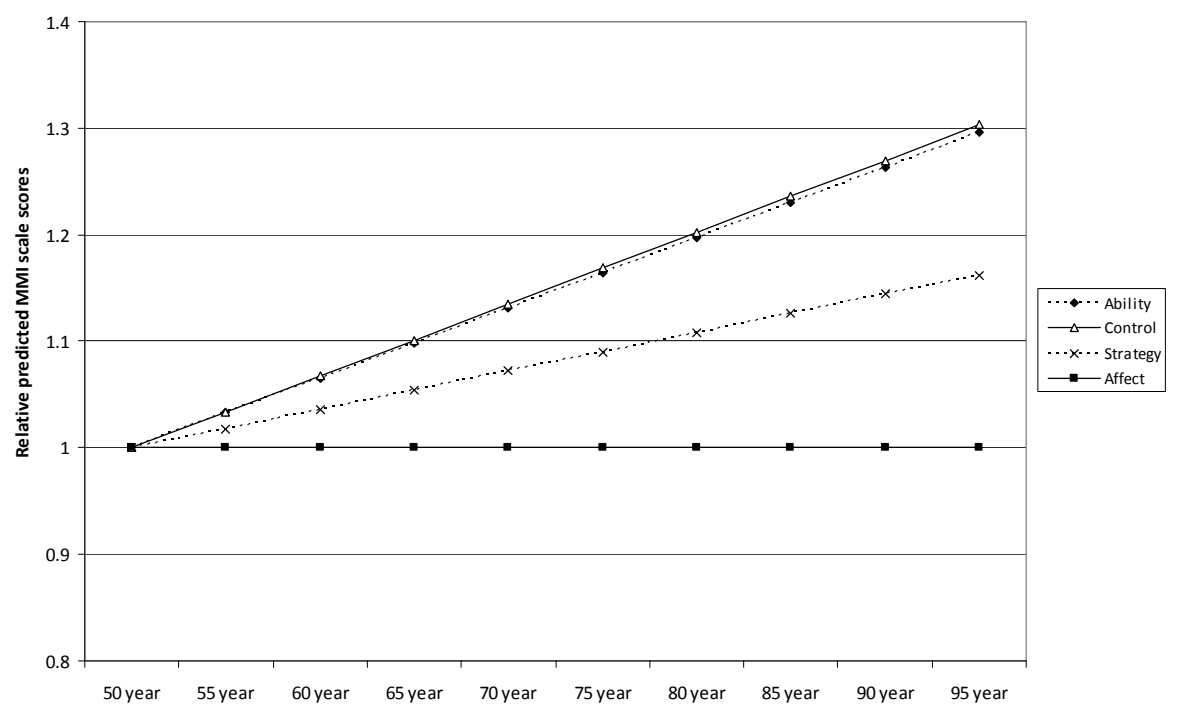

Figure 1 Predicted MMI scale scores at ages 50, 55, ...and 95 years relative to the predicted MMI scale scores at age 50 , for average educated individuals

The current study also established significant associations between educational level and metacognition. More specifically, in our study, lower-educated individuals reported: (i) more everyday cognitive failures, (ii) more emotional reactions towards cognitive failures, and (iii) more complaints about a low sense of control. Contrary to previous studies (Saczynski, Rebok, Whitfield, \& Plude, 2007), we did not establish a relation between educational level and the use of compensation strategies. The effect of educational level on predicted Ability and Affect scores was remarkably high in our study. For example, the predicted Ability scores of lower-educated participants were about 5.8 points higher than the predicted Ability scores of higher-educated participants. Similarly, the predicted Affect scores of lower- 
educated participants were about 3.8 points higher than that of higher-educated participants. By way of illustration, the effect of education (high versus low) on predicted Ability scores was equivalent to the effect of about 25 years of aging (i.e., a highly educated 75-year-old individual reported as many perceived everyday cognitive failures as a lower-educated 50-year-old individual) (see Table 4). Previous studies only revealed that educational level affected perceived memory capacity and perceived cognitive decline. Effects of educational level on feelings of control or emotional reactions towards cognitive failures have not yet been established (Fort et al., 2004; Gilewski et al., 1990; Lachman et al., 1995; Ponds \& Jolles, 1996b). In accordance with Ponds and Jolles (1996b), we did not find any age by gender or age by educational level interaction effects on the metacognitive measure. It could thus be concluded that both gender and educational level did not exert a moderating influence on the relation between age and different aspects of metacognition as measured with the $\mathrm{MMI}$, although trajectories of objective cognitive change in aging differ for men and women, as well as for higher-educated versus lower-educated individuals (Anstey \& Christensen, 2000; Stern, 2002).

There are some limitations of this study that warrant discussion. First, results support a good factorial and convergent validity of the $\mathrm{MMI}$, but other types of validity (e.g., discriminant validity, predictive validity) as well as test-retest reliability were not evaluated in the current study. This remains to be determined.

Second, we aimed to include a cognitively healthy sample. We therefore used the questionnaire format clock-drawing test as a cognitive screening tool. Previous large-scale longitudinal studies of community dwelling older adults have shown that these questionnaire format clock-drawing scores were associated with risk factors for cognitive decline and with the risk to develop dementia within 7 years (PaganiniHill \& Clark, 2007; Paganini-Hill et al., 2001). It is, however, evident that this test cannot match the diagnostic accuracy of an in-depth cognitive evaluation. Furthermore, this test is administered in absence of an examiner. It is thus possible that participants may have asked someone else to complete their clock-drawing test. Previous research has revealed that there is good agreement between questionnaire-based clock drawings and clocks that were drawn in the presence of an examiner (Paganini-Hill et al., 2001). It is thus unlikely that this has substantially affected the results. Approximately 10 percent of all participants who returned the questionnaire did not complete the clock-drawing test. This may have been caused by a lack of face validity rather than real cognitive impairment (i.e., a significant number of cognitively intact participants may not have completed the test as it seemed trivial). The cognitive status of these individuals could not be ascertained. Consequently, their data were excluded. Nevertheless, we further evaluated the extent to which the use of the questionnaire format clock-drawing test as a cognitive screening tool may have affected the results. Re-analyses of the data in which $n=82$ people with missing clock-drawing test values were included, and in which the $n=102$ 
people with missing clock-drawing test values or scores below the cut-off for cognitive impairment were included, showed an identical factor structure in terms of item loadings compared to the data in Table 2.

Third, the normative sample was not representative of the general population of older adults. There are two main reasons for this. First, individuals who were at risk of cognitive impairment (e.g., as a consequence of their medical condition or because of a low questionnaire-based clock-drawing score) were excluded from the final sample. This is common practice in normative procedures, as norms by definition require a sample of individuals within the normal range. Second, the response rate was 27.1 percent, which is comparable to that of other postal surveys (Groves et al., 2009; Mol et al., 2008). This may however have caused a non-response bias, which is a common problem in survey research. Response rates are for example affected by socioeconomic status and interest in the topic of the survey (Groves et al., 2009).

Nevertheless, our findings may have several implications, for example for the development of interventions for older adults with cognitive complaints. Our findings indicate that older adults (in a sample aged 50-95 years) report more perceived everyday cognitive failures and more complaints about a low sense of control. At the same time, although an increase is reported, their use of compensation strategies lags behind. These results suggest that effective interventions for older adults with cognitive complaints need to focus both on enhancing feelings of control and on the use of compensatory strategies. These findings are in line with previous claims and suggestions in the context of intervention research. For example, effective interventions should incorporate elements that improve attitudes towards the effects of aging on memory functioning (M. Floyd \& Scogin, 1997), should enhance self-efficacy (McDougall, 2009; Valentijn et al., 2005; West, Bagwell, \& DarkFreudeman, 2008), and should combine cognitive restructuring with strategy training (Lachman, Weaver, Bandura, Elliott, \& Lewkowicz, 1992).

Our findings also indicate that lower-educated individuals - independent of their age - are particularly prone to experience metacognitive problems. They report more perceived everyday cognitive failures, more emotional reactions towards cognitive failures, and more complaints about a low sense of control over cognitive functioning. It might thus be worthwhile to develop interventions that are specifically aimed at lower-educated individuals. This may be a particular challenge as previous studies revealed that lower-educated individuals are less likely to comply to cognitive intervention (Bagwell \& West, 2008), are less likely to self-generate mnemonic strategies (Saczynski et al., 2007), and benefit less from memory training (Langbaum, Rebok, Bandeen-Roche, \& Carlson, 2009) than their higher-educated counterparts. The development of tailor-made interventions that are, for example, more extensive and emphasize the enhancement of metacognition may prove helpful to lower-educated individuals. 


\section{References}

Aiken, L. S., \& West, S. G. (1991). Multiple regression: Testing and interpreting interactions. Newbury Park, California: Sage.

Anstey, K., \& Christensen, H. (2000). Education, activity, health, blood pressure and apolipoprotein E as predictors of cognitive change in old age: a review. Gerontology, 46, 163-177.

Bäckman, L., \& Dixon, R. A. (1992). Psychological compensation: a theoretical framework. Psychological Bulletin, 112, 259-283.

Bagwell, D. K., \& West, R. L. (2008). Assessing compliance: active versus inactive trainees in a memory intervention. Clinical Interventions in Aging, 3, 371-382.

Belsley, D. A., Kuh, E., \& Welsch, R. E. (1980). Regression diagnostics: Identifying influential data and sources of collinearity. New York: Wiley.

Bentler, P. M. (1990). Fit indices, LaGrange multipliers, constraint changes, and incomplete data in structural models. Multivariate Behavioral Research, 25, 163-172.

Blazer, D. G., Hays, J. C., Fillenbaum, G. G., \& Gold, D. T. (1997). Memory complaint as a predictor of cognitive decline: a comparison of African American and White elders. Journal of Aging and Health, 9, 171-184.

Broadbent, D. E., Cooper, P. F., FitzGerald, P., \& Parkes, K. R. (1982). The Cognitive Failures Questionnaire (CFQ) and its correlates. British Journal of Clinical Psychology, 21 (Pt 1), 1-16.

Browne, M. W., \& Cudeck, R. (1992). Alternative ways of assessing model fit. Sociological Methods and Research, 21, 230-258.

Clark, L. A., \& Watson, D. (1995). Constructing validity: basic issues in objective scale development. Psychological Assessment, 7, 309-319.

Cohen, A. L. (1988). Statistical power analysis for the behavioral sciences. Hillsdale, NJ: Erlbaum.

Comijs, H. C., Deeg, D. J., Dik, M. G., Twisk, J. W., \& Jonker, C. (2002). Memory complaints; the association with psycho-affective and health problems and the role of personality characteristics. A 6-year follow-up study. Journal of Affective Disorders, 72, 157-165.

Craik, F. I., \& Bialystok, E. (2006). Cognition through the lifespan: mechanisms of change. Trends in Cognitive Sciences, 10, 131-138.

De Bie, S. E. (1987). Toward a standardization of questions concerning demographic variables in population studies [Standaardvragen 1987 - Voorstellen voor uniformering van vraagstellingen naar achtergrondkenmkernen en interviews]. Leiden, The Netherlands: Leiden University Press.

De Frias, C. M., \& Dixon, R. A. (2005). Confirmatory factor structure and measurement invariance of the Memory Compensation Questionnaire. Psychological Assessment, 17, 168-178.

Dixon, R. A., \& Hultsch, D. F. (1983). Structure and development of metamemory in adulthood. Journal of Gerontology, 38, 682-688.

Dixon, R. A., Hultsch, D. F., \& Hertzog, C. (1988). The Metamemory in Adulthood (MIA) questionnaire. Psychopharmacological Bulletin, 24, 671-688.

Floyd, F. J., \& Widaman, K. F. (1995). Factor analysis in the development and refinement of clinical assessment instruments. Psychological Assessment, 7, 286-299.

Floyd, M., \& Scogin, F. (1997). Effects of memory training on the subjective memory functioning and mental health of older adults: a meta-analysis. Psychology and Aging, 12, 150-161.

Fort, I., Adoul, L., Holl, D., Kaddour, J., \& Gana, K. (2004). Psychometric properties of the French version of the Multifactorial Memory Questionnaire for adults and the elderly. Canadian Journal of Aging, 23, 347-357.

Gilewski, M. J., Zelinski, E. M., \& Schaie, K. W. (1990). The Memory Functioning Questionnaire for assessment of memory complaints in adulthood and old age. Psychology and Aging, 5, 482-490.

Groves, R. M., Fowler, F. J., Couper, M. P., Lepkowski, J. M., Singer, E., \& Tourangeau, R. (2009). Survey methodology (2nd ed.). Hoboken, NJ: Wiley.

Hertzog, C. (2002). Metacognition in older adults: implications for application. In T. J. Perfect \& B. L. Schwartz (Eds.), Applied metacognition (pp. 169-196). London: Cambridge University Press. 
Hertzog, C., \& Hultsch, D. F. (2000). Metacognition in adulthood and old age. In T. Salthouse \& F. I. M. Craik (Eds.), Handbook of aging and cognition (pp. 417-466). Mahwah, NJ: Lawrence Erlbaum Associates.

Jonker, C., Geerlings, M. I., \& Schmand, B. (2000). Are memory complaints predictive for dementia? A review of clinical and population-based studies. International Journal of Geriatric Psychiatry, 15, 983991.

Jorm, A. F., Christensen, H., Korten, A. E., Jacomb, P. A., \& Henderson, A. S. (2001). Memory complaints as a precursor of memory impairment in older people: a longitudinal analysis over 7-8 years. Psychological Medicine, 31, 441-449.

Kliegel, M., \& Zimprich, D. (2005). Predictors of cognitive complaints in older adults: a mixture regression approach. European Journal of Ageing, 2, 13-23.

Lachman, M. E., Bandura, M., Weaver, S. L., \& Elliott, E. (1995). Assessing memory control beliefs: the Memory Controllability Inventory. Aging and Cognition, 2, 67-84.

Lachman, M. E., Weaver, S. L., Bandura, M., Elliott, E., \& Lewkowicz, C. J. (1992). Improving memory and control beliefs through cognitive restructuring and self-generated strategies. Journal of Gerontology, 47, P293-299.

Lane, C. J., \& Zelinski, E. M. (2003). Longitudinal hierarchical linear models of the memory functioning questionnaire. Psychology and Aging, 18, 38-53.

Langbaum, J. B., Rebok, G. W., Bandeen-Roche, K., \& Carlson, M. C. (2009). Predicting memory training response patterns: results from ACTIVE. Journals of Gerontology B Series: Psychological Sciences and Social Sciences, 64, 14-23.

MacCallum, R. C., Widaman, K. F., Zhang, S., \& Hong, S. (1999). Sample size in factor analysis. Psychological Methods, 4, 84-99.

McDonald-Miszczak, L., Hertzog, C., \& Hultsch, D. F. (1995). Stability and accuracy of metamemory in adulthood and aging: a longitudinal analysis. Psychology and Aging, 10, 553-564.

McDougall, G. J., Jr. (2009). A framework for cognitive interventions targeting everyday memory performance and memory self-efficacy. Family and Community Health, 32, S15-26.

Merckelbach, H., Muris, P., Nijman, H., \& De Jong, P. (1996). Self-reported cognitive failures and neurotic symptomatology. Personality and Individual Differences, 20, 715-724.

Mol, M. E., Ruiter, R. A., Verhey, F. R., Dijkstra, J., \& Jolles, J. (2008). A study into the psychosocial determinants of perceived forgetfulness: implications for future interventions. Aging and Mental Health, 12, 167-176.

Mol, M. E., Van Boxtel, M. P., Willems, D., \& Jolles, J. (2006). Do subjective memory complaints predict cognitive dysfunction over time? A six-year follow-up of the Maastricht Aging Study. International Journal of Geriatric Psychiatry, 21, 432-441.

Mol, M. E., Van Boxtel, M. P., Willems, D., Verhey, F. R., \& Jolles, J. (2009). Subjective forgetfulness is associated with lower quality of life in middle-aged and young-old individuals: a 9-year follow-up in older participants from the Maastricht aging study. Aging and Mental Health, 13, 699-705.

Paganini-Hill, A., \& Clark, L. J. (2007). Preliminary assessment of cognitive function in older adults by clock drawing, box copying and narrative writing. Dementia and Geriatric Cognitive Disorders, 23, 74-81.

Paganini-Hill, A., Clark, L. J., Henderson, V. W., \& Birge, S. J. (2001). Clock drawing: analysis in a retirement community. Journal of the American Geriatrics Society, 49, 941-947.

Ponds, R. W., Commissaris, C. J., \& Jolles, J. (1997). Prevalence and covariates of subjective forgetfulness in a normal population in The Netherlands. International Journal of Aging and Human Development, 45, 207-221.

Ponds, R. W., \& Jolles, J. (1996a). Memory complaints in elderly people: the role of memory abilities, metamemory, depression, and personality. Educational Gerontology, 22, 341-357.

Ponds, R. W., \& Jolles, J. (1996b). The Abridged Dutch Metamemory in Adulthood (MIA) Questionnaire: structure and effects of age, sex, and education. Psychology and Aging, 11, 324-332.

Ponds, R. W., Van Boxtel, M. P., \& Jolles, J. (2000). Age-related changes in subjective cognitive functioning. Educational Gerontology, 26, 67-81. 
Saczynski, J. S., Rebok, G. W., Whitfield, K. E., \& Plude, D. L. (2007). Spontaneous production and use of mnemonic strategies in older adults. Experimental Aging Research, 33, 273-294.

Salthouse, T. A. (1996). The processing-speed theory of adult age differences in cognition. Psychological Review, 103, 403-428.

Stern, Y. (2002). What is cognitive reserve? Theory and research application of the reserve concept. Journal of the International Neuropsychological Society, 8, 448-460.

Troyer, A. K., \& Rich, J. B. (2002). Psychometric properties of a new metamemory questionnaire for older adults. Journals of Gerontology Series B: Psychological Sciences and Social Sciences, 57, P19-27.

UNESCO (1976). International Standard Classification of Education (ISCED). Paris: United Nations Educational, Scientific and Cultural Organisation.

Valentijn, S. A., Van Hooren, S. A., Bosma, H., Touw, D. M., Jolles, J., Van Boxtel, M. P., \& Ponds, R. W. H. M. (2005). The effect of two types of memory training on subjective and objective memory performance in healthy individuals aged 55 years and older: a randomized controlled trial. Patient Education and Counseling, 57, 106-114.

Van der Elst, W., Van Boxtel, M. P., Van Breukelen, G. J., \& Jolles, J. (2007). Assessment of information processing in working memory in applied settings: the paper and pencil memory scanning test. Psychological Medicine, 37, 1335-1344.

Van Dijk, K. R., Van Gerven, P. W., Van Boxtel, M. P., Van der Elst, W., \& Jolles, J. (2008). No protective effects of education during normal cognitive aging: results from the 6-year follow-up of the Maastricht Aging Study. Psychology and Aging, 23, 119-130.

Van Hooren, S. A., Valentijn, S. A., Bosma, H., Ponds, R. W., Van Boxtel, M. P., \& Jolles, J. (2007). Cognitive functioning in healthy older adults aged 64-81: a cohort study into the effects of age, sex, and education. Aging, Neuropsychology, and Cognition, 14, 40-54.

Verhaeghen, P., van Ranst, N., \& Marcoen, A. (1993). Memory training in the community: evaluations by participants and effects on metamemory. Journal of Gerontology, 19, 525-534.

West, R. L., Bagwell, D. K., \& Dark-Freudeman, A. (2008). Self-Efficacy and Memory Aging: The Impact of a Memory Intervention Based on Self-Efficacy. Aging, Neuropsychology, and Cognition, 15, 302-329. 


\section{Appendix 1}

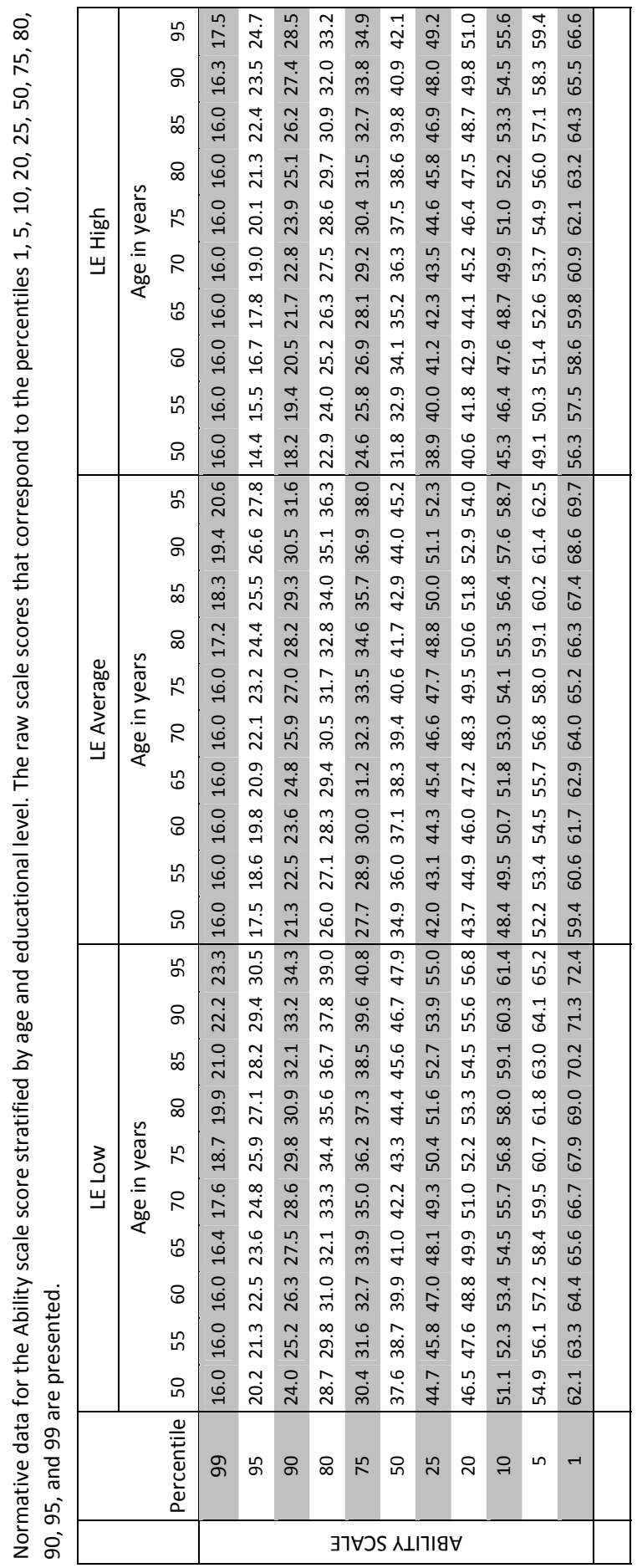




\section{Appendix 2}

Normative data for the Affect scale score stratified by educational level. The raw scale scores that correspond to the percentiles $1,5,10,20,25,50,75,80,90,95$, and 99 are presented.

\begin{tabular}{|c|c|c|c|c|}
\hline & & LE Low & LE Average & LE high \\
\hline & Percentile & All ages & All ages & All ages \\
\hline \multirow{11}{*}{ 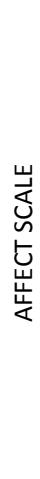 } & 99 & 11.0 & 11.0 & 11.0 \\
\hline & 95 & 14.4 & 13.1 & 11.0 \\
\hline & 90 & 17.3 & 16.0 & 13.5 \\
\hline & 80 & 20.8 & 19.5 & 17.0 \\
\hline & 75 & 22.1 & 20.8 & 18.3 \\
\hline & 50 & 27.4 & 26.1 & 23.6 \\
\hline & 25 & 32.7 & 31.4 & 28.9 \\
\hline & 20 & 34.0 & 32.7 & 30.2 \\
\hline & 10 & 37.5 & 36.2 & 33.7 \\
\hline & 5 & 40.4 & 39.0 & 36.5 \\
\hline & 1 & 45.7 & 44.4 & 41.9 \\
\hline
\end{tabular}




\section{Appendix 3}

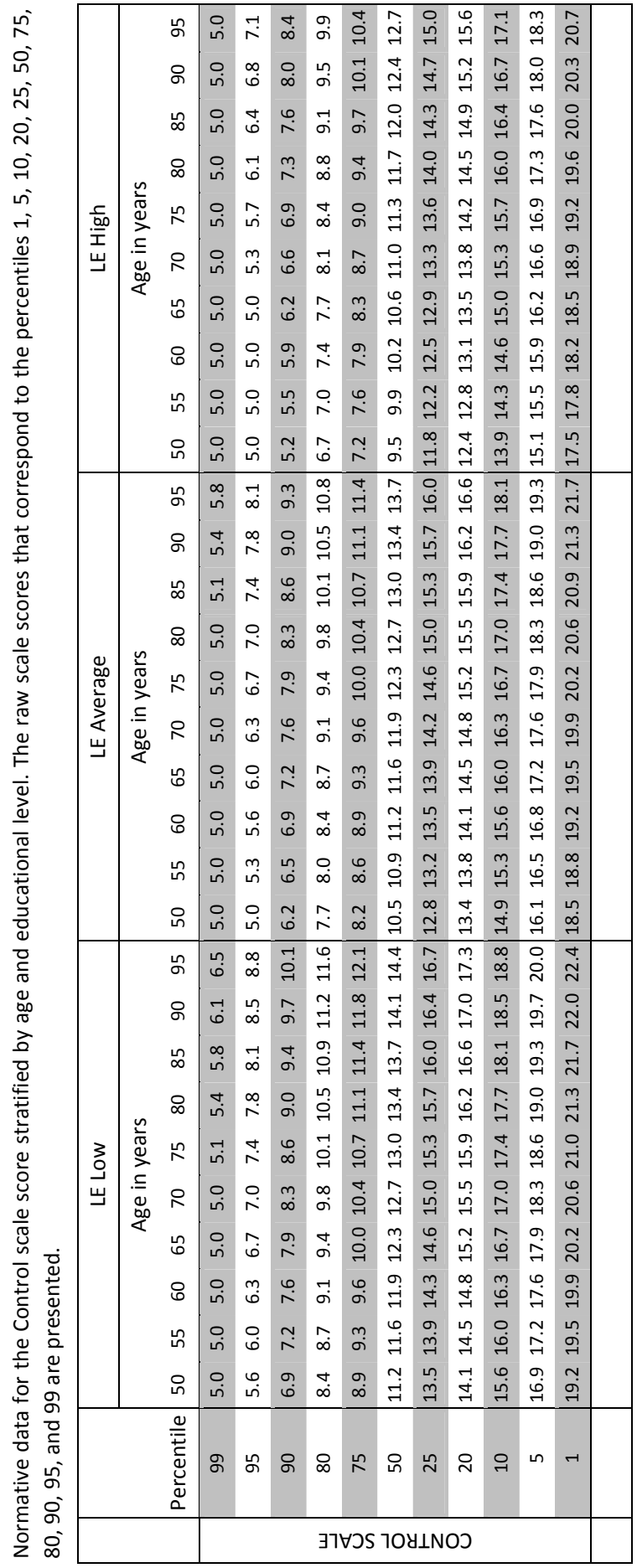




\section{Appendix 4}

Normative data for the Strategy scale score stratified by age. The raw scale scores that correspond to the percentiles 1, 5, 10, 20, 25, 50, 75, 80, 90, 95, and 99 are presented.

\begin{tabular}{|c|c|c|c|c|c|c|c|c|c|c|c|}
\hline & \multirow[b]{3}{*}{ Percentile } & \multicolumn{10}{|c|}{ All levels of education } \\
\hline & & \multicolumn{10}{|c|}{ Age in years } \\
\hline & & 50 & 55 & 60 & 65 & 70 & 75 & 80 & 85 & 90 & 95 \\
\hline \multirow{11}{*}{ 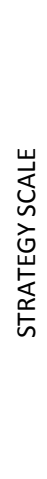 } & 99 & 51.1 & 51.7 & 52.3 & 53.0 & 53.6 & 54.2 & 54.9 & 55.0 & 55.0 & 55.0 \\
\hline & 95 & 46.4 & 47.0 & 47.6 & 48.2 & 48.9 & 49.5 & 50.1 & 50.8 & 51.4 & 52.0 \\
\hline & 90 & 43.8 & 44.5 & 45.1 & 45.7 & 46.4 & 47.0 & 47.6 & 48.2 & 48.9 & 49.5 \\
\hline & 80 & 40.8 & 41.4 & 42.0 & 42.7 & 43.3 & 43.9 & 44.6 & 45.2 & 45.8 & 46.5 \\
\hline & 75 & 39.6 & 40.3 & 40.9 & 41.5 & 42.1 & 42.8 & 43.4 & 44.0 & 44.7 & 45.3 \\
\hline & 50 & 34.9 & 35.6 & 36.2 & 36.8 & 37.5 & 38.1 & 38.7 & 39.4 & 40.0 & 40.6 \\
\hline & 25 & 30.3 & 30.9 & 31.5 & 32.1 & 32.8 & 33.4 & 34.0 & 34.7 & 35.3 & 35.9 \\
\hline & 20 & 29.1 & 29.7 & 30.4 & 31.0 & 31.6 & 32.2 & 32.9 & 33.5 & 34.1 & 34.8 \\
\hline & 10 & 26.0 & 26.7 & 27.3 & 27.9 & 28.6 & 29.2 & 29.8 & 30.5 & 31.1 & 31.7 \\
\hline & 5 & 23.5 & 24.2 & 24.8 & 25.4 & 26.0 & 26.7 & 27.3 & 27.9 & 28.6 & 29.2 \\
\hline & 1 & 18.8 & 19.4 & 20.1 & 20.7 & 21.3 & 21.9 & 22.6 & 23.2 & 23.8 & 24.5 \\
\hline
\end{tabular}


The Neurovegetative Complaints Questionnaire in the Maastricht Aging Study: psychometric properties and normative data 


\section{Abstract}

Neurovegetative and somatic symptoms (such as headaches, heart palpitations, and dizziness) have a high prevalence. These symptoms are often indicative for 'masked depression' or 'depression without sadness,' especially in older adults. At present, no instrument exists that enables the assessment of these symptoms. The current study presents a questionnaire that assesses neurovegetative and somatic complaints, as well as reactive emotional complaints: the 'Neurovegetative Complaints Questionnaire' (NCQ). The factor structure, internal consistency, and validity of the NCQ were evaluated in a large sample of 1,105 healthy subjects aged 24-81 years from the Maastricht Aging Study. The effects of age, gender and educational level on the NCQ measures were established to provide demographically corrected normative data. Two constructs underlay the responses to the NCQ items, i.e., the Neurovegetative/Somatic and Reactive/Emotional complaints factors (eigenvalues were 4.63 and 1.65 respectively, $33.0 \%$ of the variance was explained, Pearson's $r$ between both factors equalled .448). Internal consistency of both scales was acceptable (i.e. Cronbach's $\alpha=.74$ and .71 , respectively) and convergent validity was sufficient (Pearson's $r=|.387-.499|$ ). Females and older participants were characterized by more Neurovegetative/Somatic and Reactive/Emotional complaints compared to males and younger people. Demographically corrected regression-based norms were provided for use in research and clinical settings. The NCQ is a psychometrically sound questionnaire that is specifically aimed at assessing neurovegetative/somatic and reactive/emotional complaints, symptoms that often are indicative for a 'masked depression.' 


\section{Introduction}

Depressive problems (i.e., major depression, minor depression, dysthymia, subsyndromal depression, or depressive symptoms) are common in both younger (Ohayon, 2007; Zung, Broadhead, \& Roth, 1993) and older adults (Beekman, Deeg, van Tilburg et al., 1995; Hybels \& Blazer, 2003; Ohayon, 2007; Zung et al., 1993). However, due to the atypical phenomenology of depression in the latter age group, depressive problems in older adults often remain unnoticed, and its prevalence may consequently be underestimated. This may be caused by the discrepancy between diagnostic criteria for depressive problems as described by the DSM-IV (APA, 1994) and the way in which older adults with depressive problems present themselves in primary care (Alexopoulos et al., 2002; Christensen et al., 1999; Gallo \& Rabins, 1999; Hybels \& Blazer, 2003; Lyness, King, Cox, Yoediono, \& Caine, 1999).

According to Gallo and Rabins (1999), older adults with depressive problems often present themselves with somatic complaints for which a medical etiology cannot be found. Others report somatic complaints that are atypical or disproportionate to their medical illness. In fact, these people tend to report more somatic and neurovegetative symptoms (symptoms associated with suboptimal functioning of the autonomic nervous system, like sleeping problems, fatigue, and lack of energy (Venes, Thomas, \& Wilbur Taber, 2001)), rather than affective symptoms (Christensen et al., 1999; Gallo, Rabins, \& Anthony, 1999; Oxman, Barrett, Sengupta, \& Williams, 2000). This condition has previously been described as 'masked depression' (Collins \& Abeles, 1996; Neskes \& Jarvik, 1987; Weiss, Nagel, \& Aronson, 1986) or 'depression without sadness' (Alexopoulos et al., 2002; Gallo \& Rabins, 1999), a 'diagnosis' for which a golden standard or DSM-classification currently is lacking. Thus, although somatic and neurovegetative complaints frequently result from physical illness, they may also mask underlying depressive problems in older adults. This issue is of great importance for clinicians and researchers who work with older adults, because depressive problems are often related to impaired functional status (Cui, Lyness, Tang, Tu, \& Conwell, 2008; Gallo, Rebok, Tennsted, Wadley, \& Horgas, 2003; Oxman et al., 2000), increased subjective cognitive complaints (Collins \& Abeles, 1996; Dux et al., 2008; Mol, Ruiter, Verhey, Dijkstra, \& Jolles, 2008) and lowered cognitive performance (Bierman, Comijs, Jonker, \& Beekman, 2005; Den Hartog, Derix, Van Bemmel, Kremer, \& Jolles, 2003; Dux et al., 2008; Gallo et al., 2003), amongst others.

It is thus important to objectify these neurovegetative and somatic complaints in older persons (Alexopoulos et al., 2002; Collins \& Abeles, 1996; Gallo \& Rabins, 1999; Oxman et al., 2000). The Neurovegetative Complaints Questionnaire (NCQ) has been especially developed to measure neurovegetative and somatic as well as reactive emotional complaints. It has been shown a useful instrument in several specific populations, like brain injured adults (Bohnen, Jolles, Twijnstra, Mellink, \& 
Wijnen, 1995; Bohnen, Twijnstra, \& Jolles, 1992) and postmenopausal women (Hogervorst, Boshuisen, Riedel, Willeken, \& Jolles, 1999). Bohnen and colleagues (1995) showed that the NCQ was a valid instrument to distinguish several patterns of complaints in subgroups of patients with traumatic brain injury. In the study of Hogervorst and colleagues (1999), the NCQ was used to detect differences in subjective feelings of wellbeing between postmenopausal women who were offered hormone replacement therapy, and a non-treated group. However, until now, the psychometric properties of the NCQ have not been established in a general population sample.

The aims of the present study were therefore to investigate the factor structure, reliability (i.e., internal consistency) and validity of the NCQ in a general population sample. For that purpose, data of the Maastricht Aging Study, a large and unique community based study involving healthy adults aged 24 to 81 years, were used. Furthermore, the association between the NCQ scale scores and age, gender, and educational level was investigated, and normative data for its use in clinical and research settings were provided.

\section{Methods}

\section{Participants}

Data from the Maastricht Aging Study (MAAS) (Jolles, Houx, Van Boxtel, \& Ponds, 1995), a prospective study into the determinants of cognitive aging, were used. Baseline measurements were conducted between 1993 and 1996. Participants were recruited from a regional registration network of general practitioners (Metsemakers, Hoppener, Knottnerus, Kocken, \& Limonard, 1992). Participants with a medical condition that could interfere with normal cognitive functioning were excluded (i.e., overt cerebrovascular disease, chronic neurological pathology, mental retardation, psychopathology, or chronic psychotropic drug use). Data were collected in 1,823 individuals. Participants were stratified for three demographic variables that are known to affect cognitive functioning, namely age (ranging from $25 \pm 1$ up to $80 \pm 1$ years), gender, and general ability (two levels, based on the professional achievement level). All participants filled in several questionnaires and were neuropsychologically tested. The Mini-Mental State Examination (MMSE) (Folstein, Folstein, \& McHugh, 1975) was administered to participants aged 50 years and older. The medical ethics committee of the Maastricht University Medical Centre approved the study. More details on the design and rationale of the Maastricht Aging Study were described elsewhere (Jolles et al., 1995).

In total, $N=1,325$ participants filled in the NCQ. The Mini-Mental State Examination (MMSE) scores of $n=19$ participants were below 24. The data of these peo- 
ple were not used in the present study because they were considered to be at risk of dementia (Folstein et al., 1975). In the remaining group, $n=191$ participants had one or more missing values in the NCQ. A total number of $N=1,105$ participants answered all questions and were included in the current study. Participants who did not respond to all questions were older, lower educated, and more often female $(p<.001)$. The SF-36, which was used to assess mental and physical wellbeing (Ware, Kosinski, \& Keller, 1994; Ware \& Sherbourne, 1992), was administered to 742 participants of the remaining group. Table 1 shows the distribution of gender and educational level of the total sample and per age group in detail.

Table 1 Distribution of gender and educational level per age group

\begin{tabular}{|c|c|c|c|c|c|c|c|c|c|c|c|c|c|}
\hline Age group & $\begin{array}{r}25 \\
\pm 1 \\
\end{array}$ & $\begin{array}{r}30 \\
\pm 1 \\
\end{array}$ & $\begin{array}{r}35 \\
\pm 1 \\
\end{array}$ & $\begin{array}{r}40 \\
\pm 1 \\
\end{array}$ & $\begin{array}{r}45 \\
\pm 1 \\
\end{array}$ & $\begin{array}{r}50 \\
\pm 1 \\
\end{array}$ & $\begin{array}{r}55 \\
\pm 1 \\
\end{array}$ & $\begin{array}{r}60 \\
\pm 1 \\
\end{array}$ & $\begin{array}{r}65 \\
\pm 1 \\
\end{array}$ & $\begin{array}{r}70 \\
\pm 1 \\
\end{array}$ & $\begin{array}{r}75 \\
\pm 1 \\
\end{array}$ & $>79$ & Total \\
\hline $\mathrm{N}$ & 106 & 106 & 111 & 106 & 107 & 104 & 98 & 93 & 82 & 99 & 75 & 18 & 1,105 \\
\hline \multicolumn{14}{|l|}{ Gender } \\
\hline$\%$ women & 47.2 & 45.3 & 50.5 & 48.1 & 51.4 & 48.1 & 46.9 & 41.9 & 40.2 & 46.5 & 42.7 & 50.0 & 46.5 \\
\hline$\%$ men & 52.8 & 54.7 & 50.5 & 51.9 & 48.6 & 51.9 & 53.1 & 58.1 & 59.8 & 53.5 & 57.3 & 50.0 & 53.5 \\
\hline \multicolumn{14}{|l|}{ Education } \\
\hline \% low & 11.3 & 15.1 & 18.0 & 20.8 & 33.6 & 29.8 & 51.0 & 43.0 & 52.4 & 56.6 & 42.7 & 50.0 & 33.2 \\
\hline$\%$ medium & 46.2 & 54.7 & 51.4 & 45.2 & 40.2 & 45.2 & 30.6 & 44.1 & 34.1 & 29.3 & 38.7 & 16.7 & 41.8 \\
\hline$\%$ high & 42.5 & 30.2 & 30.6 & 34.0 & 26.2 & 25.0 & 18.4 & 12.9 & 13.3 & 14.1 & 18.6 & 33.3 & 25.0 \\
\hline
\end{tabular}

The ethnic background of all participants was Caucasian, and all were native Dutch speakers. Mean IQ score, as estimated with a shortened version of the Groningen Intelligence Test (Luteijn \& van der Ploeg, 1983), was 114.5 (SD = 12.6). Level of education (LE) was measured by classifying the formal schooling of participants in one of three groups, those with at most primary education (LE low), those with at most junior vocational training or high school (LE average) and those with at most senior vocational or academic training (LE high). This LE system is often used in The Netherlands (De Bie, 1987) and is comparable with the International Standard Classification of Education (UNESCO, 1976). LE low, LE average and LE high correspond with an average of $8.72,11.54$ and 15.34 years of full-time education in the sample $(S D=1.82,2.57$, and 3.29), respectively.

\section{Measures}

\section{Neurovegetative Complaints Questionnaire}

The Neurovegetative Complaints Questionnaire (NCQ) was originally developed to measure neurovegetative and somatic as well as emotional complaints in postconcussive patients (Bohnen et al., 1992). The original questionnaire consisted of 28 items concerning headaches, problems with falling asleep, restlessness, chest pain, indigestion, slowness of working, sensitivity to light, effort, flushing, concentration, dyspnoea, preference to be left alone, tiredness, fainting, heart palpitations, noise, 
difficulty with doing two tasks simultaneously, preference to work at ones own pace, dizziness, depression, wet hands, crying spells, libido, irritability, lack of initiative, awakening at night, defeatism, and not being appreciated by others. Participants had to indicate the frequency of occurrence of these symptoms on a 4-point Likert scale (1 = "no, never"; 2 = "yes, sometimes"; 3 = "yes, regularly," and 4 = "yes, often"). Higher scores indicated more complaints.

\section{Other measures}

The Depression and Anxiety subscales of the Symptom Checklist-90 (SCL-90; Arrindell \& Ettema 1986), a self-report measure of psychopathology, were administered to evaluate the convergent validity of the NCQ. The SCL-90 Depression subscale consisted of 16 items that assess both affective complaints (such as lack of interest) and somatic/neurovegetative symptoms of depression (such as lack of libido). The Anxiety subscale consisted of 10 items that assess affective and somatic symptoms that are related to high levels of anxiety (such as heart palpitations and restlessness). All SCL-90 items were rated on a 5-point Likert scale with a score range between 1 and 5. Higher scores indicated more symptoms (Arrindell \& Ettema, 1986; Derogatis, 1977).

The Medical Outcomes Study 36-item Short-Form Health Survey (SF-36) (Ware \& Sherbourne, 1992) is a self-report generic health measure that contained 36 items. Nine subscales can be derived from this questionnaire, respectively 1) physical functioning, 2) social functioning, 3) role limitations (physical problem), 4) role limitations (emotional problem), 5) mental health, 6) vitality, 7) pain, 8) general health, and 9) health change. From these subscales, two main factors can be composed, namely the Mental and the Physical wellbeing composite scores (Ware et al., 1995; Ware et al., 1994).

\section{Statistical Analyses}

Exploratory Principal Component Analyses (PCAs) with an oblique rotation (Promax), which allows the factors to correlate, were conducted on the individual item scores of the NCQ to assess its dimensionality and to identify meaningful underlying constructs. The screeplot was used to determine the number of components to be retained (Cattell, 1966). Items with factor loadings of at least 0.40 were considered relevant. Items that loaded on two or more factors, or on no factor at all, were removed one at a time. Scale scores were established by adding up the raw item scores of the items that loaded at least $\geq .40$ on the components at hand.

Internal consistency (which is a lower bound of reliability) of the scales was assessed by calculating Cronbach's alpha coefficients. Pearson's correlations were calculated between the obtained scale scores of the NCQ and scores on the subscales Depression and Anxiety of the SCL-90, and the Mental and Physical composite 
scores of the SF-36 in order to test convergent validity. Both the SCL-90 subscale scores as well as the Mental and Physical composite scores of the SF-36 were expected to correlate high with the Neurovegetative Complaints scale scores.

Normative analyses were performed by regressing the established scale scores of the NCQ on age, age ${ }^{2}$, gender, educational level (dummy coded into three levels with LE average as the reference category) and all two-way interactions between these predictors (the 'full models'). In order to avoid multicollinearity, age was centered (age $=$ calendar age -50 ) before quadratic terms and interactions were calculated. Non-significant predictors $(p>.01)$ were excluded from the model, but no predictor was removed as long as it was also included in a higher order term in the model (Aiken \& West, 1991). The assumptions of regression analysis were tested for each model. Homoscedasticity was evaluated by means of scatter plots of the residuals against the predicted values, and by grouping participants into quartiles of the predicted scores and applying the Levene test. Normal distribution of the residuals was investigated by visual inspection of the histograms of the residuals, and by conducting Kolmogorov-Smirnov tests on the residuals. The occurrence of multicollinearity was checked by calculating the Variance Inflation Factors (VIFs), which should not exceed 10 (Belsley, Kuh, \& Welsch, 1980). Potential influential cases were identified by calculating Cook's distances. All analyses were conducted using SPSS 15.0 for Windows.

Normative data for the scale scores of the NCQ can be obtained by calculating standardized residuals. These standardized residuals are converted into percentiles by means of a standard normal distribution table with cumulative probabilities (if the model assumption of normality of the residuals was met), or by means of a table with the observed distribution of the standardized residuals with cumulative probabilities (if the residuals were not normally distributed in the normative sample) (for details on the normative method, see Van der Elst, Van Boxtel, Van Breukelen, \& Jolles, 2007).

\section{Results}

\section{Factor structure}

The results of the Principal Component Analyses are shown in Table 2. Of the initial 28 items, 9 items were excluded because they loaded high on both factors. The remaining 19 items of the NCQ loaded high (> .40) on a single factor. The first factor was labelled as 'Neurovegetative/Somatic complaints'. Items that assess headaches, problems falling asleep, restlessness, chest pain, slowness of working, sensitivity to light, effort, concentration, dyspnoea, heart palpitations and dizziness loaded high on this factor. The second factor was labelled as 'Reactive/Emotional complaints' 
and items concerning preference to be left alone, difficulty to endure noise, difficulty doing two simultaneous tasks, preference to work at own pace, irritability, lack of initiative, defeatism and appreciation by others loaded high on this factor. The raw item scores of items that loaded at least $\geq .40$ on these two factors were summated for use in the subsequent analyses. These scale scores are referred to as the Neurovegetative/Somatic complaints scale score (mean $\pm S D=17.60 \pm 4.374$; range 11-34 in the normative sample) and the Reactive/Emotional complaints scale score (16.08 \pm 3.633 ; range 8-31 in the normative sample). Higher scale scores indicate more complaints (i.e., worse functioning). Eigenvalues of the factors were 4.63 and 1.65 , respectively. The two factors accounted for 33.0 percent of the variance in the data. Pearson's correlations indicated a medium relation $(r(1105)=.448, p<.01)$ between the Neurovegetative/Somatic complaints and Reactive/Emotional complaints scale scores.

Table 2 Factor loadings obtained by Principal Component Analyses with Promax rotation in which two factors were extracted

\begin{tabular}{lcc}
\hline Item & Neurovegetative/Somatic & Reactive/Emotional \\
\hline Headaches & .411 & .026 \\
Problems with falling asleep & .431 & .062 \\
Restlessness & .690 & -.148 \\
Chest pain & .522 & -.019 \\
Slowness of working & .490 & .272 \\
Sensitivity to light & .615 & -.343 \\
Effort & .529 & .180 \\
Concentration & .624 & -.148 \\
Dyspnoea & .506 & .135 \\
Preference to be left alone & .004 & .597 \\
Heart palpitations & .534 & .056 \\
Noise & .129 & .472 \\
Difficulty doing two simultaneous tasks & .093 & .555 \\
Preference to work at own pace & -.325 & .663 \\
Dizziness & .424 & .110 \\
Irritability & .127 & .619 \\
Lack of initiative & .218 & .493 \\
Defeatism & .254 & .465 \\
Not being appreciated by others & -.248 & .565 \\
Initial eigenvalue for each component & & 1.65 \\
Percentage of variance accounted for & 4.63 & 8.7 \\
Cronbach's alpha & 24.4 & .71 \\
\hline
\end{tabular}

\section{Reliability and validity}

Internal consistency was examined by calculating Cronbach's alpha. The items of the Neurovegetative/Somatic complaints and Reactive/Emotional complaints scales had an acceptable internal consistency ( $\alpha=.74$ and .71 , respectively). These values are lower bounds on reliability, which means that at least 71-74 percent of the total 
within-test score variance for the Reactive/Emotional complaints and the Neurovegetative/Somatic complaints scale scores was due to true score variance rather than to item content heterogeneity or poor item quality.

Convergent validity was evaluated by calculating Pearson correlations between the Neurovegetative/Somatic complaints and the Reactive/Emotional complaints scale scores of the NCQ on the one hand, and the Depression and Anxiety subscale scores of the SCL-90, and the Physical and Mental composite scores of the SF-36 on the other hand. For the Neurovegetative/Somatic scale score, correlations showed medium effect sizes (Cohen, 1988) with the SCL-90-Depression score $(r(1080)=$ $.434, p<.01)$, the SCL-Anxiety score $(r(1081)=-.485, p<.01)$, and the SF-36-Mental composite score $(r(742)=-.436, p<.01)$, and a large effect size with the SF-36Physical composite score $(r(742)=-.499, p<.01)$. For the Reactive/Emotional complaints scale score, correlations showed medium effect sizes with the SCL-90Depression score $(r(1080)=.398, p<.01)$, the SCL-90-Anxiety score $(r(1081)=.387$, $p<.01)$ and the SF-36-Mental component score $(r(742)=-.442, p<.01)$. The relation between the Reactive/Emotional complaints scale score and the SF-36-Physical component score was weaker but still significant $(r(742)=-.172, p<.01)$.

\section{Normative data}

The final regression models for the Neurovegetative/Somatic complaints and the Reactive/Emotional complaints scale scores are presented in Table 3. No influential cases were identified (maximum Cook's distance equalled .043) for either model, and no multicollinearity occurred (maximum VIF $=2.535$ ). Scatter plots of the residuals against the predicted scores suggested a trend to heteroscedasticity for the Neurovegetative/Somatic complaints score model, which was confirmed by the Levene test $(p<.01)$. This was taken into account by calculating the standard deviations of the residuals per quartile of the predicted scores. These $S D$ (residual)s equalled 3.36 for predicted Neurovegetative/Somatic scale scores below 16.05, 4.12 for predicted scores between 16.06 and 17.45, 3.88 for predicted scores between 17.46 and 19.15 , and 4.50 for predicted scores higher than 19.16. Scatter plots and the Levene test suggested that the homoscedasticity assumption was met for the final model of the Reactive/Emotional scale score. The $S D$ (residual) to be used in the standardization of the Reactive/Emotional complaints scale scores equals 3.58. The histograms of the residuals of both the Neurovegetative/Somatic complaints and the Reactive/Emotional complaints scale scores suggested that the residuals were not normally distributed (which was confirmed by the Kolmogorov-Smirnov test, $Z=$ $2.539, p<.001$ and $Z=1.828, p=.003$, respectively). This was taken into account by converting the standardized residuals into percentiles by means of the observed distribution of the standardized residuals (rather than by means of the standard normal distribution). 
The final models showed that female participants reported more neurovegetative and somatic complaints (i.e., worse functioning) than their male counterparts. There was a significant age $x$ educational level interaction, which suggested that the effect of educational level on Neurovegetative/Somatic complaints varied as a function of age. Reactive/Emotional complaints scale scores were affected by age and gender, i.e., older and female participants reported more reactive emotional complaints than younger and male participants (see Table 3 ).

Table 3 Final multiple linear regression models for the Neurovegetative/Somatic and the Reactive/Emotional complaints scale scores following a step-down hierarchical procedure.

\begin{tabular}{llrrrrr}
\hline Scale score & Variable & B & Std.Error B & T & Standardized B & $\mathbf{R}^{2}$ \\
\hline Neurovegetative/Somatic & (constant) & 17.857 & .231 & $77.408^{*}$ & & \\
& Age & .077 & .012 & $6.389^{*}$ & .208 & \\
& Gender & -1.149 & .246 & $-4.670^{*}$ & -.131 & \\
& LE Low & 2.199 & .297 & $7.413^{*}$ & .237 & \\
& LE High & -.967 & .319 & $-3.030^{*}$ & -.096 & \\
& Age $\times$ LE Low & -.060 & .019 & $-3.140^{*}$ & -.119 & \\
& Age $\times$ LE High & -.027 & .020 & -1.363 & -.050 & .170 \\
& & & & & & \\
Reactive/Emotional & (constant) & 16.533 & .158 & $104.542^{*}$ & & \\
& Age & .031 & .007 & $4.601^{*}$ & .137 & \\
& Gender & -.809 & .216 & $-3.743^{*}$ & -.111 & .030 \\
\hline
\end{tabular}

Note. The full model included age, age ${ }^{2}$, LE low, LE high, gender, and all 2-way interactions between these predictors. $L E=$ Level of education. Coding of the predictors: Age = calendar age - 50; Gender: male = 1, female = 0; LE Low: Low education = 1, Average or High Education = 0; LE High: High Education = 1, Low or Average Education $=0$.

$* p<.01$

Normative tables are provided for the Neurovegetative/Somatic complaints scale score (see Appendix 1) and for the Reactive/Emotional complaints scale score (see Appendix 2). If an individual is not exactly $25,30, \ldots, 80$ years old, then that person's age should be rounded up to the closest age given in the normative tables. Interpretation of the raw scale scores is straightforward by means of the normative tables. For example, a 64 year old man with an average educational level had a score of 24 on the Neurovegetative/Somatic complaints scale score and a score of 10 on the Reactive/Emotional complaints scale score. His age is rounded up to the closest age given in the tables, i.e. 65 years. The normative tables indicate that a raw Neurovegetative/Somatic complaints scale score of 24 corresponds with a percentile between 1 and 5 (i.e., a lot of complaints) and a raw Reactive/Emotional complaints scale score of 10 corresponds with a percentile score between 90 and 95 (i.e., few complaints). 


\section{Discussion}

The NCQ was developed to measure neurovegetative and somatic as well as emotional complaints in adults. It has been proven a useful assessment tool in several clinical populations (Bohnen et al., 1995; Bohnen et al., 1992; Hogervorst et al., 1999), but until now its psychometric properties have not been evaluated in a general population sample. Neurovegetative and somatic symptoms may be a sign of 'masked depression' (Collins \& Abeles, 1996; Neskes \& Jarvik, 1987; Weiss et al., 1986) or 'depression without sadness' (Alexopoulos et al., 2002; Gallo \& Rabins, 1999). In other words, older adults may present with alternative clinical clues to depression (Gallo \& Rabins, 1999). Furthermore, neurovegetative and somatic complaints are common in other target groups too, like chronic pain patients (Geisser, Roth, \& Robinson, 1997; Wesley, Gatchel, Polatin, Kinney, \& Mayer, 1991) and brain injured individuals (Bohnen et al., 1995; Bohnen et al., 1992). It is, therefore, important to develop new instruments that measure these neurovegetative and somatic symptoms. In the current study, the factor structure, reliability and validity of the NCQ were investigated in a large population sample $(N=1,105$ healthy adults aged 24-81 years), and normative data were provided.

PCAs using an oblique rotation reduced the number of items from 28 to 19 items that loaded on two factors. The primary factor assesses neurovegetative and somatic symptoms (like heart palpitations and headaches), whereas the secondary factor reflects reactive emotional symptoms (like irritability and lack of initiative). Both the Neurovegetative/Somatic complaints scale and the Reactive/Emotional complaints scale had acceptable levels of internal consistency (> .70), indicating that their items measure the same underlying constructs. Convergent validity was examined by correlating both scale scores to established measures that assess comparable constructs, i.e., the SCL-90 Depression and Anxiety subscales (Arrindell \& Ettema, 1986; Derogatis, 1977), and the Mental and Physical component scores of the SF-36 (Ware et al., 1994). Significant correlations were found between both scale scores of the NCQ and these other measures. All correlations showed medium to large effect sizes, except for the correlation between Reactive/Emotional symptoms and the Physical component of the SF-36, which showed a small effect size. This pattern of correlations was expected, because items of the SF-36 Physical component primarily reflect physical wellbeing (Ware et al., 1994), whereas items of the Reactive/Emotional complaints scale of the NCQ resemble more affective and mental aspects of wellbeing. In sum, these results point to a satisfactory convergent validity of the Neurovegetative/Somatic complaints and the Reactive/Emotional complaints scales of the NCQ.

Normative data for both scale scores were obtained with multiple regression analyses following a step-down hierarchical procedure. Normative tables that take the relevant demographical variables for each scale score into account were estab- 
lished (see Appendix 1 and 2). The final models showed that older and female participants reported more neurovegetative/somatic and reactive/emotional complaints than their younger and male counterparts. This is in accordance with other studies. For example, more severe self-reported (somatic and affective) depressive symptoms were associated to higher age and being female (Beekman, Kriegsman, Deeg, \& van Tilburg, 1995; Zung et al., 1993). Looking at individual items of selfreported measures of depression, Christensen et al. (1999) established a direct effect of age on both somatic as well as psychological symptoms of depression. However, being female was only significantly associated to reporting somatic symptoms, but not to reporting psychological symptoms (Christensen et al., 1999). In our study, neurovegetative and somatic complaints were affected by a significant age $x$ educational level interaction, which suggested that the differences in reported somatic symptoms of high, moderate and low educated people decreased as a function of age. Reactive emotional complaints were not affected by educational level. Previous findings on this topic are inconsistent. Some studies found no association between educational level and (somatic and affective) symptoms of depression (Beekman, Deeg, Smit, \& van Tilburg, 1995; Beekman, Kriegsman et al., 1995), whereas others found a significant negative association (Christensen et al., 1999; Zung et al., 1993). However, to our knowledge, no previous study has investigated the association between educational level and neurovegetative/somatic complaints or emotional complaints separately.

Existing self-report measures, like the BDI (Beck, Steer, \& Garbin, 1988) and the CES-D (Radloff, 1977), contain several somatic and affective items that fit the DSMIV-criteria for depression (APA, 1994). Other well established tools are the PHQ, an established measure for making DSM-IV-criteria based diagnosis of mental disorders in primary care (Spitzer, Kroenke, \& Williams, 1999), and the shortened PHQ-15 (for somatic symptom severity) (Kroenke, Spitzer, \& Williams, 2002) and the PHQ-9 (for depressive symptom severity) (Kroenke, Spitzer, \& Williams, 2001). However, the way in which older adults with depressive problems present themselves in primary care may differ from these DSM-IV-based criteria. They often report mainly neurovegetative and somatic complaints, like headaches, heart palpitations, or dizziness, instead of affective and emotional complaints. Although these neurovegetative and somatic complaints frequently result from physical illness, they are in some cases atypical or disproportionate to medical illness, and may rather mask underlying depressive problems. The use of DSM-IV-criteria based instruments may lead to an underestimation of mental health problems and depressive symptoms (Alexopoulos et al., 2002; Collins \& Abeles, 1996; Gallo \& Rabins, 1999; Klapow et al., 2002; Neskes \& Jarvik, 1987). Thus when considering wellbeing in older adults, it is of high importance to pay special attention to these neurovegetative and somatic complaints. 
From the current study it can be concluded that the NCQ is a psychometrically sound questionnaire for which normative data are available. It may provide a useful tool in clinical as well as in research settings to assess neurovegetative and somatic complaints, and reactive emotional complaints. However, normative data are based on a Dutch sample and need further validation in an English speaking population. Furthermore, additional research is needed to further investigate aspects of construct and criterion validity (Drenth \& Sijtsma, 1990) of the NCQ. Moreover, it is necessary to investigate if it is a better tool to screen for masked depression or depression without sadness than DSM-IV-criteria based instruments like the BDI, $\mathrm{PHQ}$, or CES-D. Unfortunately, a gold standard and official diagnostic criteria for this condition are lacking until now. The NCQ should thus be used in addition to existing instruments. Finally, the NCQ could be investigated in other populations in which neurovegetative and somatic complaints may be relevant, like chronic pain patients (Geisser et al., 1997; Wesley et al., 1991) or adults with depressive symptoms (Levitan, Lesage, Parikh, Goering, \& Kennedy, 1997; Nierenberg, Pava, Clancy, Rosenbaum, \& Fava, 1996; Rapaport et al., 2002), in order to study its clinical usefulness. 


\section{References}

Aiken, L. S., \& West, S. G. (1991). Multiple regression: Testing and interpreting interactions. Newbury Park, California: Sage.

Alexopoulos, G. S., Borson, S., Cuthbert, B. N., Devanand, D. P., Mulsant, B. H., Olin, J. T., \& Oslin, D. W. (2002). Assessment of late life depression. Biological Psychiatry, 52, 164-174.

APA (1994). Diagnostic and Statistical Manual of Mental Disorders: DSM-IV. Washington: American Psychiatric Association.

Arrindell, W. A., \& Ettema, J. H. M. (1986). SCL-90: Manual for a multi-dimensional indicator of psychopathology [Handleiding bij een multidimensionele psychopathologie-indicator]. Lisse, the Netherlands: Swets \& Zeitlinger BV.

Beck, A. T., Steer, R. A., \& Garbin, M. G. (1988). Psychometric properties of the Beck Depression Inventory: twenty-five years of evaluation. Clinical Psychology Review, 8, 77-100.

Beekman, A. T., Deeg, D. J., Smit, J. H., \& van Tilburg, W. (1995). Predicting the course of depression in the older population: results from a community-based study in The Netherlands. Journal of Affective Disorders, 34, 41-49.

Beekman, A. T., Deeg, D. J., van Tilburg, T., Smit, J. H., Hooijer, C., \& van Tilburg, W. (1995). Major and minor depression in later life: a study of prevalence and risk factors. Journal of Affective Disorders, 36, 65-75.

Beekman, A. T., Kriegsman, D. M., Deeg, D. J., \& van Tilburg, W. (1995). The association of physical health and depressive symptoms in the older population: age and sex differences. Social Psychiatry and Psychiatric Epidemiology, 30, 32-38.

Belsley, D. A., Kuh, E., \& Welsch, R. E. (1980). Regression diagnostics: Identifying influential data and sources of collinearity. New York: Wiley.

Bierman, E. J., Comijs, H. C., Jonker, C., \& Beekman, A. T. (2005). Effects of anxiety versus depression on cognition in later life. American Journal of Geriatric Psychiatry, 13, 686-693.

Bohnen, N. I., Jolles, J., Twijnstra, A., Mellink, R., \& Wijnen, G. (1995). Late neurobehavioural symptoms after mild head injury. Brain Injury, 9, 27-33.

Bohnen, N. I., Twijnstra, A., \& Jolles, J. (1992). Post-traumatic and emotional symptoms in different subgroups of patients with mild head injury. Brain Injury, 6, 481-487.

Cattell, R. B. (1966). The scree test for the number of factors. Multivariate Behavioral Research, 1, 629637.

Christensen, H., Jorm, A. F., Mackinnon, A. J., Korten, A. E., Jacomb, P. A., Henderson, A. S., \& Rodgers, B. (1999). Age differences in depression and anxiety symptoms: a structural equation modelling analysis of data from a general population sample. Psychological Medicine, 29, 325-339.

Cohen, A. L. (1988). Statistical power analysis for the behavioral sciences. Hillsdale, NJ: Erlbaum

Collins, M. W., \& Abeles, N. (1996). Subjective memory complaints and depression in the able elderly. Clinical Gerontologist, 16, 29-54.

Cui, X., Lyness, J. M., Tang, W., Tu, X., \& Conwell, Y. (2008). Outcomes and predictors of late-life depression trajectories in older primary care patients. American Journal of Geriatric Psychiatry, 416, 406415.

De Bie, S. E. (1987). Toward a standardization of questions concerning demographic variables in population studies [Standaardvragen 1987 - Voorstellen voor uniformering van vraagstellingen naar achtergrondkenmkernen en interviews]. Leiden, The Netherlands: Leiden University Press.

Den Hartog, H. M., Derix, M. M., Van Bemmel, A. L., Kremer, B., \& Jolles, J. (2003). Cognitive functioning in young and middle-aged unmedicated out-patients with major depression: testing the effort and cognitive speed hypotheses. Psychological Medicine, 33, 1443-1451.

Derogatis, L. R. (1977). SCL-90: Administration, scoring and procedures manual-i for the R(evised) version. Baltimore MD: John Hopkins School of Medicine, Clinical Psychometrics Research Unit. 
Drenth, P. J., \& Sijtsma, K. (1990). Theory of testing: Introduction to the theory of psychological testing and its application [Testtheorie: Inleiding in de theorie van de psychologische test en zijn toepassingen]. Houten/Diegem: Bohn Stafleu Van Loghum.

Dux, M. C., Woodard, J. L., Calamari, J. E., Messina, M., Arora, S., Chik, H., \& Pontarelli, N. (2008). The moderating role of negative affect on objective verbal memory performance and subjective memory complaints in healthy older adults. Journal of the International Neuropsychological Society, 14, 327336.

Folstein, M. F., Folstein, S. E., \& McHugh, P. R. (1975). “Mini-mental state." A practical method for grading the cognitive state of patients for the clinician. Journal of Psychiatric Research, 12, 189-198.

Gallo, J. J., \& Rabins, P. V. (1999). Depression without sadness: alternative presentations of depression in late life. American Family Physician, 60, 820-826.

Gallo, J. J., Rabins, P. V., \& Anthony, J. C. (1999). Sadness in older persons: 13-year follow-up of a community sample in Baltimore, Maryland. Psychological Medicine, 29, 341-350.

Gallo, J. J., Rebok, G. W., Tennsted, S., Wadley, V. G., \& Horgas, A. (2003). Linking depressive symptoms and functional disability in late life. Aging and Mental Health, 7, 469-480.

Geisser, M. E., Roth, R. S., \& Robinson, M. E. (1997). Assessing depression among persons with chronic pain using the Center for Epidemiological Studies-Depression Scale and the Beck Depression Inventory: a comparative analysis. The Clinical Journal of Pain, 13, 163-170.

Hogervorst, E., Boshuisen, M., Riedel, W., Willeken, C., \& Jolles, J. (1999). 1998 Curt P. Richter Award. The effect of hormone replacement therapy on cognitive function in elderly women. Psychoneuroendocrinology, 24, 43-68.

Hybels, C. F., \& Blazer, D. G. (2003). Epidemiology of late-life mental disorders. Clinics in Geriatric Medicine, 19, 663-696.

Jolles, J., Houx, P. J., Van Boxtel, M. P., \& Ponds, R. W. (1995). Maastricht Aging Study: determinants of cognitive aging. Maastricht: Neuropsych Publishers.

Klapow, J., Kroenke, K., Horton, T., Schmidt, S., Spitzer, R., \& Williams, J. B. (2002). Psychological disorders and distress in older primary care patients: a comparison of older and younger samples. Psychosomatic Medicine, 64, 635-643.

Kroenke, K., Spitzer, R. L., \& Williams, J. B. (2001). The PHQ-9: validity of a brief depression severity measure. Journal of General Internal Medicine, 16, 606-613.

Kroenke, K., Spitzer, R. L., \& Williams, J. B. (2002). The PHQ-15: validity of a new measure for evaluating the severity of somatic symptoms. Psychosomatic Medicine, 64, 258-266.

Levitan, R. D., Lesage, A., Parikh, S. V., Goering, P., \& Kennedy, S. H. (1997). Reversed neurovegetative symptoms of depression: a community study of Ontario. American Journal of Psychiatry, 154, 934940.

Luteijn, F., \& van der Ploeg, F. A. E. (1983). Manual Groningen Intelligence Test [Handleiding Groninger Intelligentietest (GIT)]. Lisse: Swets \& Zeitlinger.

Lyness, J. M., King, D. A., Cox, C., Yoediono, Z., \& Caine, E. D. (1999). The importance of subsyndromal depression in older primary care patients: prevalence and associated functional disability. Journal of the American Geriatrics Society, 47, 647-652.

Metsemakers, J. F., Hoppener, P., Knottnerus, J. A., Kocken, R. J., \& Limonard, C. B. (1992). Computerized health information in The Netherlands: a registration network of family practices. British Journal of General Practice, 42, 102-106.

Mol, M. E., Ruiter, R. A., Verhey, F. R., Dijkstra, J., \& Jolles, J. (2008). A study into the psychosocial determinants of perceived forgetfulness: implications for future interventions. Aging and Mental Health, $12,167-176$.

Neskes, R. E., \& Jarvik, L. F. (1987). Affective disorders in the elderly. Annual Review of Medicine, 38, 445456.

Nierenberg, A. A., Pava, J. A., Clancy, K., Rosenbaum, J. F., \& Fava, M. (1996). Are neurovegetative symptoms stable in relapsing or recurrent atypical depressive episodes? Biological Psychiatry, 40, 691696. 
Ohayon, M. M. (2007). Epidemiology of depression and its treatment in the general population. Journal of Psychiatric Research, 41, 207-213.

Oxman, T. E., Barrett, J. E., Sengupta, A., \& Williams, J. W., Jr. (2000). The relationship of aging and dysthymia in primary care. American Journal of Geriatric Psychiatry, 8, 318-326.

Radloff, L. (1977). The CES-D scale: a self-report depression scale for research in the general population. Journal of Applied Psychological Measurement, 1, 385-401.

Rapaport, M. H., Judd, L. L., Schettler, P. J., Yonkers, K. A., Thase, M. E., Kupfer, D. J., Frank, E., Plewes, J. M., Tollefson, G. D., \& Rush, A. J. (2002). A descriptive analysis of minor depression. American Journal of Psychiatry, 159, 637-643.

Spitzer, R. L., Kroenke, K., \& Williams, J. B. (1999). Validation and utility of a self-report version of PRIMEMD: the PHQ primary care study. Primary Care Evaluation of Mental Disorders. Patient Health Questionnaire. Journal of the American Medical Association, 282, 1737-1744.

UNESCO (1976). International Standard Classification of Education (ISCED). Paris: United Nations Educational, Scientific and Cultural Organisation.

Van der Elst, W., Van Boxtel, M. P., Van Breukelen, G. J., \& Jolles, J. (2007). Assessment of information processing in working memory in applied settings: the paper and pencil memory scanning test. Psychological Medicine, 37, 1335-1344.

Venes, D., Thomas, C. L., \& Wilbur Taber, C. (2001). Taber's cyclopedic medical dictionary. Philadelphia: F.A. Davis Company.

Ware, J. E., Kosinski, M., Bayliss, M. S., McHorney, C. A., Rogers, W. H., \& Raczek, A. (1995). Comparison of methods for the scoring and statistical analysis of SF-36 health profile and summary measures: summary of results from the Medical Outcomes Study. Medical Care, 33, AS264-279.

Ware, J. E., Kosinski, M., \& Keller, S. D. (1994). SF-36 Physical and Mental summary scales: a user's manual. Boston, MA: The Health Institute.

Ware, J. E., \& Sherbourne, C. D. (1992). The MOS 36-item short-form healt survey (SF-36): I. conceptual framework and item selection. Medical Care, 30, 473-483.

Weiss, I. K., Nagel, C. L., \& Aronson, M. K. (1986). Applicability of depression scales to the old old person. Journal of the American Geriatrics Society, 34, 215-218.

Wesley, A. L., Gatchel, R. J., Polatin, P. B., Kinney, R. K., \& Mayer, T. G. (1991). Differentiation between somatic and cognitive/affective components in commonly used measurements of depression in patients with chronic low-back pain. Let's not mix apples and oranges. Spine, 16, S213-S215.

Zung, W. W., Broadhead, W. E., \& Roth, M. E. (1993). Prevalence of depressive symptoms in primary care. The Journal of Family Practice, 37, 337-344. 


\section{Appendix 1}

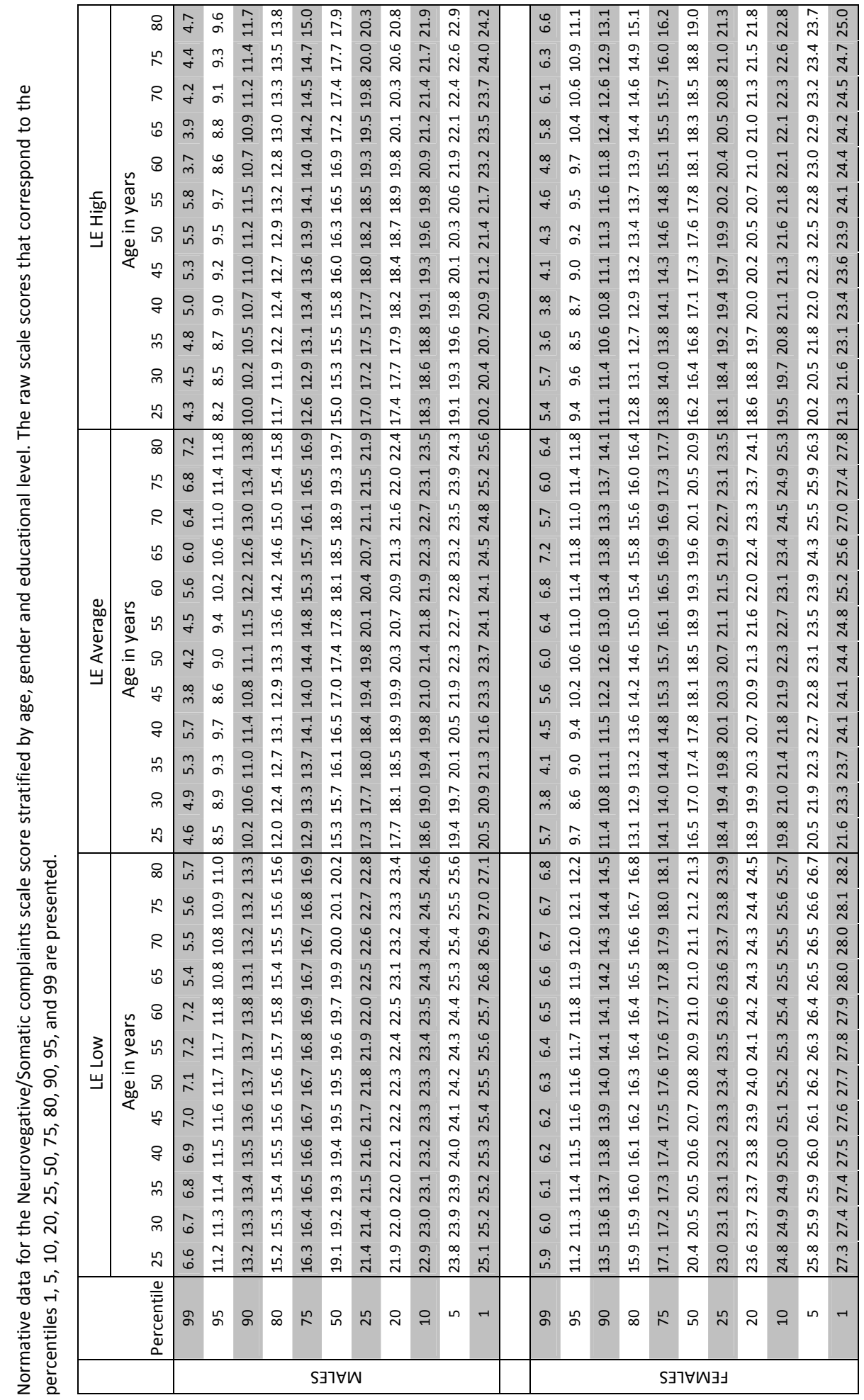




\section{Appendix 2}

Normative data for the Reactive/Emotional complaints scale score, stratified by age and gender. The raw scale scores that correspond to the percentiles 1, 5, 10, 20, 25, 50, 75, 80, 90, 95, and 99 are presented.

\begin{tabular}{|c|c|c|c|c|c|c|c|c|c|c|c|c|c|}
\hline & \multirow[b]{3}{*}{ Percentile } & \multicolumn{12}{|c|}{ LE Low, average or high } \\
\hline & & \multicolumn{12}{|c|}{ Age in years } \\
\hline & & 25 & 30 & 35 & 40 & 45 & 50 & 55 & 60 & 65 & 70 & 75 & 80 \\
\hline \multirow{11}{*}{$\frac{\tilde{\Psi}}{\frac{\Psi}{\Sigma}}$} & 99 & 4.9 & 5.1 & 5.2 & 5.4 & 5.5 & 5.7 & 5.8 & 6.0 & 6.2 & 6.3 & 6.5 & 6.6 \\
\hline & 95 & 8.2 & 8.4 & 8.5 & 8.7 & 8.9 & 9.0 & 9.2 & 9.3 & 9.5 & 9.6 & 9.8 & 9.9 \\
\hline & 90 & 10.3 & 10.5 & 10.6 & 10.8 & 10.9 & 11.1 & 11.2 & 11.4 & 11.5 & 11.7 & 11.9 & 12.0 \\
\hline & 80 & 12.2 & 12.4 & 12.5 & 12.7 & 12.8 & 13.0 & 13.1 & 13.3 & 13.5 & 13.6 & 13.8 & 13.9 \\
\hline & 75 & 13.0 & 13.2 & 13.3 & 13.5 & 13.6 & 13.8 & 13.9 & 14.1 & 14.2 & 14.4 & 14.5 & 14.7 \\
\hline & 50 & 15.2 & 15.3 & 15.5 & 15.6 & 15.8 & 15.9 & 16.1 & 16.2 & 16.4 & 16.5 & 16.7 & 16.9 \\
\hline & 25 & 17.3 & 17.5 & 17.7 & 17.8 & 18.0 & 18.1 & 18.3 & 18.4 & 18.6 & 18.7 & 18.9 & 19.0 \\
\hline & 20 & 17.9 & 18.1 & 18.2 & 18.4 & 18.5 & 18.7 & 18.8 & 19.0 & 19.1 & 19.3 & 19.4 & 19.6 \\
\hline & 10 & 19.3 & 19.4 & 19.6 & 19.7 & 19.9 & 20.0 & 20.2 & 20.4 & 20.5 & 20.7 & 20.8 & 21.0 \\
\hline & 5 & 20.5 & 20.6 & 20.8 & 21.0 & 21.1 & 21.3 & 21.4 & 21.6 & 21.7 & 21.9 & 22.0 & 22.2 \\
\hline & 1 & 22.1 & 22.2 & 22.4 & 22.5 & 22.7 & 22.8 & 23.0 & 23.2 & 23.3 & 23.5 & 23.6 & 23.8 \\
\hline \multirow{11}{*}{ 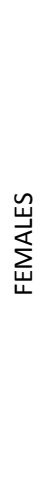 } & 99 & 5.7 & 5.9 & 6.0 & 6.2 & 6.3 & 6.5 & 6.7 & 6.8 & 7.0 & 7.1 & 7.3 & 7.4 \\
\hline & 95 & 9.0 & 9.2 & 9.4 & 9.5 & 9.7 & 9.8 & 10.0 & 10.1 & 10.3 & 10.4 & 10.6 & 10.7 \\
\hline & 90 & 11.1 & 11.3 & 11.4 & 11.6 & 11.7 & 11.9 & 12.0 & 12.2 & 12.4 & 12.5 & 12.7 & 12.8 \\
\hline & 80 & 13.0 & 13.2 & 13.3 & 13.5 & 13.6 & 13.8 & 14.0 & 14.1 & 14.3 & 14.4 & 14.6 & 14.7 \\
\hline & 75 & 13.8 & 14.0 & 14.1 & 14.3 & 14.4 & 14.6 & 14.7 & 14.9 & 15.0 & 15.2 & 15.4 & 15.5 \\
\hline & 50 & 16.0 & 16.1 & 16.3 & 16.4 & 16.6 & 16.7 & 16.9 & 17.0 & 17.2 & 17.4 & 17.5 & 17.7 \\
\hline & 25 & 18.2 & 18.3 & 18.5 & 18.6 & 18.8 & 18.9 & 19.1 & 19.2 & 19.4 & 19.5 & 19.7 & 19.9 \\
\hline & 20 & 18.7 & 18.9 & 19.0 & 19.2 & 19.3 & 19.5 & 19.6 & 19.8 & 19.9 & 20.1 & 20.3 & 20.4 \\
\hline & 10 & 20.1 & 20.2 & 20.4 & 20.5 & 20.7 & 20.8 & 21.0 & 21.2 & 21.3 & 21.5 & 21.6 & 21.8 \\
\hline & 5 & 21.3 & 21.5 & 21.6 & 21.8 & 21.9 & 22.1 & 22.2 & 22.4 & 22.5 & 22.7 & 22.9 & 23.0 \\
\hline & 1 & 22.9 & 23.0 & 23.2 & 23.3 & 23.5 & 23.7 & 23.8 & 24.0 & 24.1 & 24.3 & 24.4 & 24.6 \\
\hline
\end{tabular}


The Dutch Memory Compensation Questionnaire: psychometric properties and regression-based norms 


\section{Abstract}

The Memory Compensation Questionnaire (MCQ) is a psychometrically sound instrument, which assesses the variety and extent to which an individual compensates for actual or perceived memory losses. Until now, only an English version of the MCQ has been psychometrically evaluated. The aim of the present study was to establish a Dutch version of the MCQ and evaluate its psychometric properties. The MCQ data of 556 cognitively healthy adults (61.8\% females) aged between 50.1 and 95.3 years $(M=73.9$ years, $S D=8.0)$ were analyzed. The results showed that the factor structure of the Dutch version of the MCQ corresponded well with that of the English version of the MCQ. The reliabilities of the scales of the Dutch version of the MCQ were all high (all Cronbach's $\alpha$-values $\geq .77$ ). Demographic variables (especially age and gender) affected most of the MCQ scale scores. Regression-based normative data, which take these demographic influences into account, were established. 


\section{Introduction}

Aging is associated with a decrease in episodic memory abilities (Craik \& Salthouse, 2000; La Rue, 1992; Van der Elst, Van Boxtel, Van Breukelen, \& Jolles, 2005, 2008) and an increase in memory complaints (Ponds, Commissaris, \& Jolles, 1997). To cope with these actual or perceived memory problems, compensation strategies are often initiated (Unverzagt et al., 2007). Memory compensation refers to the use of strategies to overcome or mitigate declines in memory functioning (De Frias, Dixon, \& Bäckman, 2003). Several memory compensation strategies have been distinguished, including substitution (for example, the use of a new technique to overcome memory losses), remediation (for example, the investment of more time or effort to overcome memory losses), and accommodation (for example, the matching of memory demands and memory skills by adjusting one's goals) (Bäckman \& Dixon, 1992; Dixon \& Bäckman, 1995).

The Memory Compensation Questionnaire (MCQ; De Frias \& Dixon, 2005) is a self-report instrument, which was especially devised to assess everyday memory compensation strategies (De Frias \& Dixon, 2005; De Frias et al., 2003). The MCQ contains seven scales. The first three scales assess memory substitution mechanisms. The External scale contains eight items regarding the use of external memory aids to enhance everyday memory performance (e.g., "Do you use shopping lists when you go shopping?"). The Internal scale contains ten items regarding the use of mnemonic strategies to improve memory performance (e.g., "When you want to remember something from a T.V. program, do you use 'memory tricks' like grouping or repeating yourself?"). The Time scale contains four items regarding the extent to which respondents invest more time in performing valued everyday memory tasks (e.g., "Do you ask people to speak slowly when you want to remember what they are saying?"). The next two MCQ scales assess memory remediation mechanisms. The Reliance scale contains five items regarding the extent to which the respondents recruit other people as memory aids (e.g., "When you want to remember an important appointment, do you ask somebody else (for example, spouse or friend) to remind you?"). The Effort scale contains six items regarding the investment of more effort in performing memory tasks (e.g., "Do you put in a lot of effort when you want to remember an important conversation with a person?"). The final two MCQ scales assess more general aspects of memory compensation strategies. The Success scale contains five items regarding the use of accommodation strategies (e.g., relaxing the criteria of success) to cope with memory losses (e.g., "When you want to remember a newspaper article, is it important to you to remember it perfectly?"). The Change scale contains five items regarding the extent to which the respondent believes that changes in the External, Internal, Time, Reliance, and Success dimensions of memory compensation behavior have occurred over the last 5 to 10 years (e.g., "Do you spend more or less time learning important things today 
compared to 5-10 years (for example, reading things more slowly or reading them more than once?").

The psychometric properties of the MCQ (including its construct validity, testretest reliability, internal consistency, and discriminant validity) were shown to be good to excellent (De Frias \& Dixon, 2005; Dixon, de Frias, \& Bäckman, 2001). These sound psychometric characteristics have been confirmed only for the English version of the MCQ. It is unknown to what extent a non-English version of the MCQ would produce equivalent measurement and structural characteristics, and be generally applicable to non-English speaking populations. The main aims of the present study were to establish a Dutch version of the $\mathrm{MCQ}$, evaluate its psychometric properties (i.e., construct validity and reliability), and establish normative data. Previous research with the English version of the MCQ has shown that demographic (and other) variables affected several of the MCQ scale scores (De Frias \& Dixon, 2005; De Frias et al., 2003; Dixon \& de Frias, 2007; Dixon et al., 2001). Thus we also evaluated the effects of age, gender, and level of education on the scale scores of the Dutch version of the MCQ, so that the normative data could be appropriately corrected for the relevant demographic influences. These normative data provide an empirical frame of reference to understand what constitutes a 'normal' test score for an individual. The norms facilitate interpretation of the test scores, and allow for a direct comparison of the different MCQ scale scores of an individual (as all measures are expressed in percentile units).

\section{Methods}

\section{Participants}

About $N=3,000$ members of a large Dutch community organization for healthy elderly were mailed a questionnaire which was accompanied by the organization's monthly magazine. Based on previous research in a similar population (Mol, Ruiter, Verhey, Dijkstra, \& Jolles, 2008), a 20 percent response rate was anticipated (i.e., 500 respondents). We aimed at 500 respondents in view of the sample size recommendations for factor analytic studies in the literature, which range between 300 and 500 participants (MacCallum, Widaman, Zhang, \& Hong, 1999; Tabachnick \& Fidell, 2001). All questionnaires were sent between April $1^{\text {st }}$ and June $1^{\text {st }} 2008$, together with a prepaid response envelope and a cover letter, which detailed the aims of the study. In total, $N=813$ people returned the questionnaire (i.e., 27 percent response rate).

We excluded respondents on the basis of age in the following two circumstances: 1$)$ if they were below 50 years old $(n=27)$ and 2$)$ if their age was unknown or could not be established due to erroneous self-reported birth date information 
(e.g., reporting a birth year of 2008) ( $n=6)$. Moreover, people who reported to suffer from (previous) medical conditions known to interfere with cognitive functioning (i.e., dementia $(n=20)$, stroke $(n=63)$, brain tumors $(n=4)$, central nervous diseases $(n=8)$ and epilepsy $(n=10)$ ) were excluded. To further screen for cognitive impairment, the 'questionnaire format' clock-drawing test was administered. The 'questionnaire format' clock-drawing test requires the participants to draw in the numbers as in a clock face on a predrawn circle of $8.3 \mathrm{~cm}$ in diameter (Paganini-Hill \& Clark, 2007; Paganini-Hill, Clark, Henderson, \& Birge, 2001). The clock-drawing tests were scored following a procedure described in Paganini-Hill et al. (2001). People with a clock-drawing test score below an age- and gender-corrected threshold level for cognitive impairment (Paganini-Hill et al., 2001) were excluded $(n=20)$. In addition, the data of $n=82$ and $n=17$ participants were excluded from the analyses because they did not complete the clock-drawing test or because they had more than four missing values on the $M C Q$, respectively. Thus the data of a total sample of $N=556$ participants were analyzed in the present study.

The mean age of the participants was 73.8 years (range 50.1 - 95.3 years; $S D=$ 8.0). Level of education (LE) was measured by classifying the formal schooling of the participants in one of three groups, i.e., those with at most primary education (LE low; $26.8 \%$ of the sample), those with at most junior vocational training or high school (LE average; $45.0 \%$ of the sample), and those with at most senior vocational or academic training (LE high; $28.2 \%$ of the sample). This LE system is often used in The Netherlands (De Bie, 1987) and is comparable with the International Standard Classification of Education (UNESCO, 1976). These three levels of education correspond with about 9, 11, and 15 years of full-time education (Van der Elst et al., 2005). There were more female than male participants ( $61.8 \%$ females).

\section{Procedure and instruments}

Initial development of the English version of the MCQ reduced a large pool of items to 44 items (Dixon \& Bäckman, 1992; Dixon et al., 2001; Hopp, 1993). De Frias and Dixon (2005) further evaluated the psychometric properties of this initial MCQ version and dropped one additional item from the Time scale (due to item crossloadings). The final English version of the MCQ thus contained 43 items (De Frias \& Dixon, 2005). This version was translated into Dutch and back translated by a bilingual English/Dutch speaker. The translation closely resembled the original English items.

The English version of the MCQ (De Frias \& Dixon, 2005) represents seven dimensions of memory compensation behavior (as was described in the Introduction). The responses for the items of the External, Internal, Time, Reliance, Effort and Success MCQ scales were presented on a 5-point Likert scale with the choice options $0=$ never, $1=$ seldom, $2=$ sometimes, $3=$ often and $4=$ always. Higher scale 
scores are thus indicative for more frequent use of the specified compensation strategy. The item "Do you spend more or less time learning important things today compared to 5-10 years (for example, reading things more slowly or reading them more than once?)" of the Change scale had the choice options $0=$ much less time, 1 $=$ less time, $2=$ no difference, $3=$ more time, and $4=$ much more time. The other items of the Change scale had the choice options $0=$ much less often, $1=$ less often, $2=$ no difference, $3=$ more often, and $4=$ much more often. Higher Change scale scores indicate that the respondent believes that more changes in memory compensation strategies have occurred in the last 5-10 years.

\section{Statistical analyses}

Confirmatory Factor Analysis (CFA) was used to evaluate the factor structure of the Dutch version of the MCQ. An a priori model was specified in which (a) seven factors underlied the item responses and (b) each item loaded on only one factor (i.e., the model that was obtained by De Frias \& Dixon, 2005). Due to the categorical nature of the item responses and the non-normal score distributions of a number of items, the Diagonally Weighted Least Squares method for polychoric correlation matrices was used instead of the standard Maximum Likelihood estimation method. Thus, polychoric coefficients and an asymptotic covariance matrix were generated in PRELIS for subsequent analysis in LISREL. The fit of the seven-factor MCQ model was evaluated with the Root Mean Square Error of Approximation (RMSEA; $<.08$ acceptable, <.05 excellent) (Browne \& Cudeck, 1992), the Comparative Fit Index (CFI; $>.90$ acceptable, > .95 excellent) (Bentler, 1990; Bentler \& Bonett, 1980), and the Normed Fit Index (NFI; > .90 acceptable) (Bentler \& Bonett, 1980). Corrected itemscale correlations (i.e., correlations between items and scale scores that did not include the items being evaluated) and item descriptives (means, SDs, and item response distributions) were provided. The internal consistencies of the items of the established MCQ scales were estimated with Cronbach's alpha coefficients. Intercorrelations and standard errors of measurement of the MCQ scale scores were also calculated.

The effects of demographic variables on the MCQ scale scores were evaluated by regressing the scale scores on age, age ${ }^{2}$, gender and educational level. Age was centered (age = calendar age -75 ) before quadratic terms and interactions were calculated to avoid multicollinearity. Gender was coded as male $=1$ and female $=0$. Educational level was dummy coded into three levels (with LE average as the reference category). Non-significant predictors $(p>.01)$ were excluded from the full models (i.e., the models that included all predictors), but no predictor was removed as long as it was also included in a higher order term in the model (Aiken \& West, 1991). The assumptions of regression analysis were tested for each model. Homoscedasticity was evaluated by grouping the participants into quartiles of the pre- 
dicted scores and applying the Levene test. Normality of the residuals was investigated by conducting Kolmogorov-Smirnov tests on the standardized residuals. The occurrence of multicollinearity was checked by calculating Variance Inflation Factors (VIFs), which should not exceed ten (Belsley, Kuh, \& Welsch, 1980). Potential influential cases were identified by calculating Cook's distances.

The MCQ scale scores are normed by means of a four-step procedure (Van der Elst, Van Boxtel, Van Breukelen, \& Jolles, 2007). First, the user of the normative data calculates the testee's predicted MCQ scale scores by means of the final regression models (predicted MCQ scale score $=B_{0}+B_{1} X_{1}+\ldots+B_{n} X_{n}$, with $B_{0}=$ the intercept, $B_{n}=$ the regression weight(s), and $X_{n}=$ the predictor value(s)). Second, the residuals are calculated $\left(e_{i}=\right.$ observed MCQ scale score - predicted MCQ scale score). Third, the residuals are standardized $\left(Z_{\mathrm{i}}=e_{\mathrm{i}} / S D\right.$ (residual), with $S D$ (residual) $=$ the standard deviation of the residuals in the normative sample). Fourth, the standardized residuals are converted into percentiles via the standard normal cumulative distribution function (if the model assumption of normality of the residuals was met in the normative sample), or via the empirical cumulative distribution function of the standardized residuals (if the standardized residuals were not normally distributed in the normative sample). All analyses were conducted with R 2.8.1, PRELIS and LISREL 8.8 for Windows. An alpha level of .01 was used in all analyses.

\section{Results}

\section{Factor structure and psychometric properties}

The seven-factor CFA model is shown in Table 1 (left). The model adequately fitted the data (i.e., RMSEA = .049; CFI = .98; NFI = .96), and all items loaded significantly on the a priori expected factors. The average standardized factor loadings of the items were high (i.e., External $(M=.65)$, Internal $(M=.65)$, Reliance $(M=.83)$, Time $(M=.74)$, Effort $(M=.64)$, Success $(M=.73)$, and Change $(M=.69))$. The corrected item-scale correlations were all significantly positive and ranged between .37 and .78 (all ps <.01; see Table 1, right). 


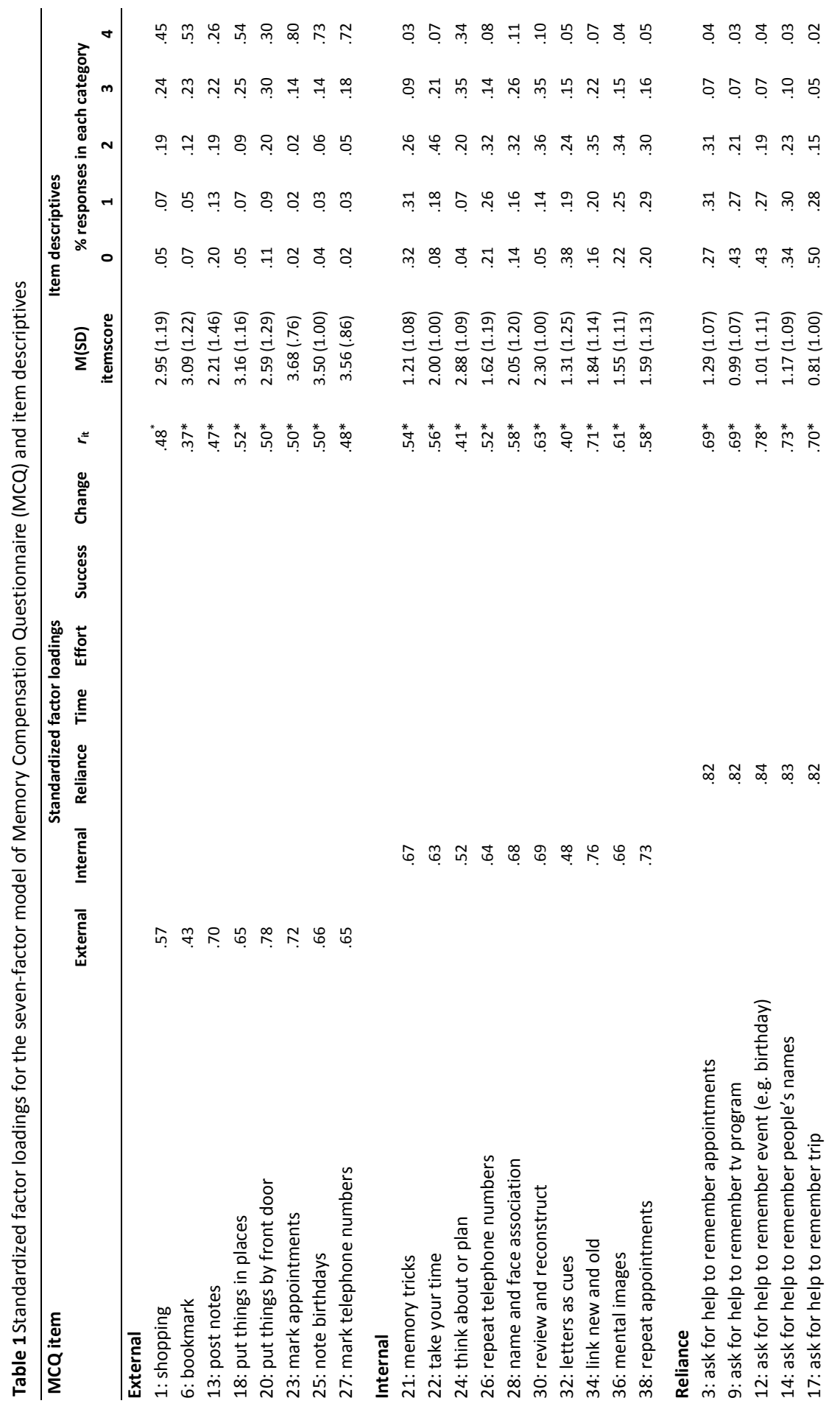




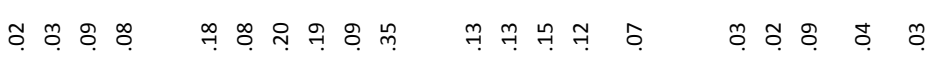

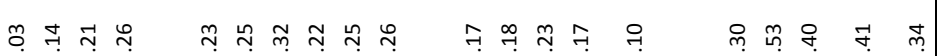

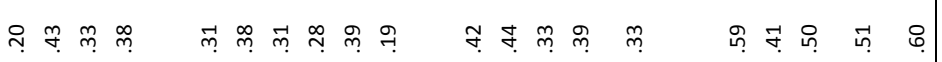

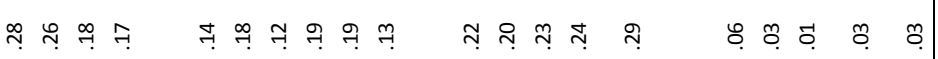

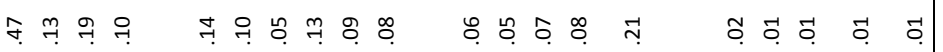

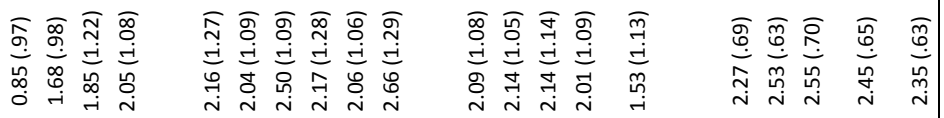
芦

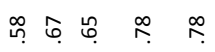
난ㄷㄴ 무

유 ๓

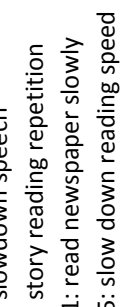

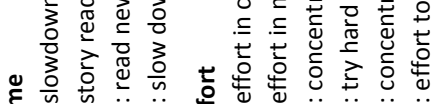
卢
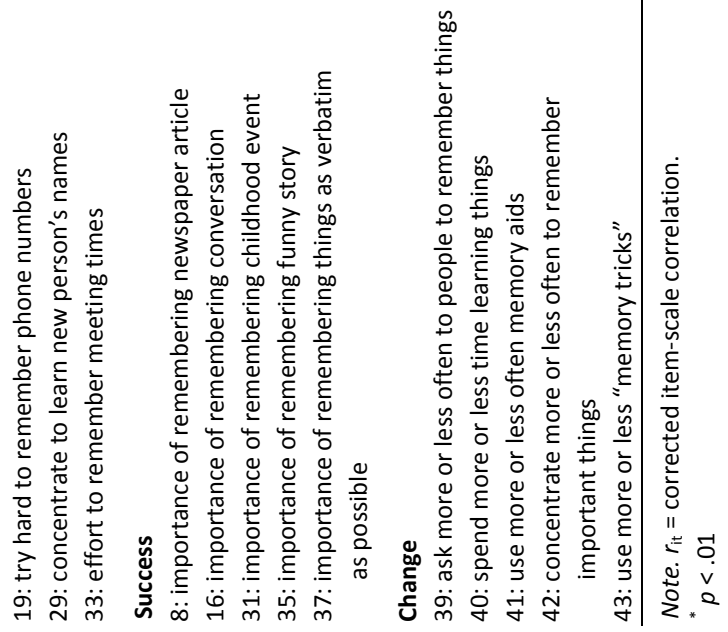
Internal consistency was high for the items of all MCQ scales (all Cronbach's alpha values $\geq .77$; see Table 2, left). The correlations between the MCQ scale scores were all significantly positive and ranged between .20 and .73 (all $p$ s $<.01$; see Table 2, right).

Table 2 MCQ scale descriptives and scale score inter-correlations

\begin{tabular}{|c|c|c|c|c|c|c|c|c|c|c|c|}
\hline \multirow[t]{2}{*}{ Scales } & \multicolumn{4}{|c|}{ Descriptives } & \multicolumn{7}{|c|}{ Inter-correlations } \\
\hline & $\mathrm{M}$ & SD & SEM & $\alpha$ & External & Internal & Reliance & Time & Effort & Success & Change \\
\hline External & 24.75 & 5.62 & 2.70 & .77 & 1 & & & & & & \\
\hline Internal & 18.33 & 7.30 & 2.83 & .85 & $.49 *$ & 1 & & & & & \\
\hline Reliance & 5.27 & 4.40 & 1.53 & .88 & $.29 *$ & $.48^{*}$ & 1 & & & & \\
\hline Time & 6.42 & 3.30 & 1.55 & .78 & $.45^{*}$ & $.56^{*}$ & $.54^{*}$ & 1 & & & \\
\hline Effort & 13.58 & 4.89 & 2.29 & .78 & $.53^{*}$ & $.73^{*}$ & $.46^{*}$ & $.63^{*}$ & 1 & & \\
\hline Success & 9.91 & 4.18 & 1.77 & .82 & $.20 *$ & $.50 *$ & $.28^{*}$ & $.31^{*}$ & $.48^{*}$ & 1 & \\
\hline Change & 12.13 & 2.36 & 1.14 & .77 & $.34 *$ & $.41 *$ & $.44^{*}$ & $.41^{*}$ & $.42 *$ & $.22 *$ & 1 \\
\hline
\end{tabular}

Note. SEM = Standard Error of Measurement.

$* p<.01$

\section{Effects of age, gender, and educational level}

The final regression models for the MCQ scale scores are presented in Table 3. There was no serious influence of outliers (the maximum Cook's distance equaled .073) or multicollinearity (maximum VIF $<1.001$ ) observed for any of these models. The Levene test suggested that there was no heteroscedasticity for any of the models (all $p s>.01$ ). The standardized residuals were normally distributed for all MCQ scale score models with the exception of the residuals for the External and Reliance scale score models ( $p$ s of the Kolmogorov-Smirnov $Z s<.01$ ).

The final regression models showed that age affected the External, Time, Effort and Success scale scores positively. Females obtained higher External and higher Effort scale scores as compared to males, and males obtained higher Reliance scale scores than females. Lower educated people obtained higher Reliance scale scores as compared to their higher educated counterparts. The Internal and Change scale scores were not significantly affected by any of the demographic variables. 
Table 3 Final multiple linear regression models of the MCQ scale scores following a step-down hierarchical procedure; the full model included Age, Age $^{2}$, LE low, LE high, and Gender

\begin{tabular}{llccccc}
\hline MCQ scale score & Variable & $\mathbf{B}$ & Std. Error B & $\mathbf{T}$ & $\mathbf{R}^{2}$ & SD(residual) \\
\hline External & (constant) & 25.62 & 0.29 & $87.10^{*}$ & & \\
& Age & 0.11 & 0.03 & $3.68^{*}$ & & \\
& Gender & -1.87 & 0.47 & $-3.95^{*}$ & .046 & 5.40 \\
Internal & (constant) & 18.36 & 0.31 & $59.30^{*}$ & - & 7.28 \\
Reliance & (constant) & 4.59 & 0.29 & $15.44^{*}$ & & \\
& Gender & 1.24 & 0.39 & $3.22^{*}$ & & \\
& LE low & 1.25 & 0.45 & $2.79^{*}$ & & \\
& LE high & -0.42 & 0.45 & -0.95 & .031 & \\
Time & (constant) & 6.49 & 0.14 & $46.19^{*}$ & & \\
& Age & 0.05 & 0.01 & $2.82^{*}$ & .012 & 3.27 \\
Effort & (constant) & 14.33 & 0.26 & $55.42^{*}$ & & \\
& Age & 0.08 & 0.03 & $3.07^{*}$ & & \\
& Gender & -1.74 & 0.42 & $-4.17^{*}$ & .042 & 4.75 \\
Success & (constant) & 10.01 & 0.18 & $56.52^{*}$ & & \\
& Age & 0.07 & 0.02 & $3.40^{*}$ & .019 & 4.12 \\
Change & (constant) & 12.13 & 0.10 & $120.90^{*}$ & - & 2.36 \\
\hline
\end{tabular}

Note. The $S D$ (residual) values correspond with Standard Errors of the estimates of the regression models. The $\mathrm{R}^{2}$ values for the Internal and Change models could not be computed because there was no variability in the predicted scores (i.e., none of the predictors affected the Internal and Change scale scores). LE $=$ Level of education. Coding of the predictors: Age = calendar age -75 ; Gender: Male =1, Female $=0$; LE Low: Low Education = 1, Average or High Education = 0; LE High: High Education = 1, Low or Average Education $=0$.

$* p<.01$

\section{Regression-based normative data}

Norms for the MCQ scale scores are established by means of the four-step procedure described above. For example, suppose that a 60-year-old male obtained an External scale raw score of 25 . The user of the regression-based norms first calculates the expected External scale score for this person, i.e., $22.10 \quad(=25.62+((60$ $-75) \times 0.11)+(1 \times-1.87))$. Secondly, the residual is calculated, i.e., $2.90(=25-$ 22.10). Thirdly, the residual is standardized, i.e., 0.54 (= $2.90 / 5.40)$. Fourthly, the standardized residual is converted into a percentile value by means of the empirical cumulative distribution function of the standardized residuals. A standardized residual of the External scale score that equals 0.54 corresponds with a percentile value of 65 . Thus, about 65 percent of the 'normal' population of 60 -year-old males obtains an External scale score that is lower than the score of 25 that was obtained by this testee.

The four-step normative procedure provides accurate norms but lacks userfriendliness because the users of the norms have to actively make the required 
computations. Therefore, we also provided simplified normative tables that were derived from the four-step normative procedure (see Appendix 1-7). If a testee is not exactly $50,55, \ldots, 85$ years old, then the person's age should be rounded up to the closest age given in these Tables. Use of these Tables is straightforward. For example, Appendix 1 immediately shows that the External scale score of 25 that was obtained by the 60 -year-old male from the example corresponds to a percentile value between 50 and 80 .

\section{Discussion}

The results of the present study showed that seven factors underlay the item responses of the Dutch version of the MCQ (i.e., the External, Internal, Time, Reliance, Effort, Success and Change factors). The seven-factor model had an excellent fit with the data and corresponded well with the factor structure of the English version of the MCQ (De Frias \& Dixon, 2005). The established scales for the Dutch and English versions of the MCQ were identical in terms of items loading on the seven factors. Moreover, the reliabilities of corresponding scales and the overall ranges of the Cronbach's $\alpha$-values for the scales of the Dutch ( $\alpha$ range $=.77-.88$ ) and English ( $\alpha$ range $=.65-.82$ ) MCQ versions (De Frias \& Dixon, 2005) were very similar. These findings suggest that the Dutch version of the MCQ is an adequate adaptation of the English version of the MCQ with similar psychometric properties.

Mean-level scores on five of the seven scales of the Dutch version of the MCQ were affected by demographic variables (the exceptions were the Internal and Change scales). Although age and gender mean-level differences were found (see Table 3), the directions of the effects were not uniform. A theoretical account for the differential effects of the demographic variables on the different components of memory compensation behavior is beyond the scope of the present paper (for a discussion on this topic, see for example Dixon et al., 2001), but from a psychometric viewpoint this finding implies that the normative data for the MCQ scale scores should be differentially corrected for these demographic influences. We used a regression-based procedure to conduct these corrections and to establish the MCQ norms - rather than a traditional normative procedure. Traditional normative data are established by computing means and SDs per relevant subgroup, but two problems are intrinsically related to this method. First, the subgroup sizes are often small after breaking down the sample by the relevant demographic variables, even when the overall size of the normative sample is large) (Crawford \& Howell, 1998). Secondly, there is a problem with the boundary values of traditional normative tables. For example, if the continuous variable age is categorized into age groups of 50-59 years, 60-69 years, ..., and 90-99 years, the scores of people aged 69 and 70 (differing only one year) would be evaluated against different normative data whereas the 
scores of people aged 60 and 69 (differing nine years) would be evaluated against the same normative data, which is not acceptable (Capitani, 1997). Regressionbased norms are not hampered by these problems, because they are derived from equations that are based on the data of the entire sample, and because continuous predictors can be used. Regression-based normative procedures thus allow for more accurate estimates of the population statistics, which results in more accurate norms (Van der Elst, 2006). It should be noted that the traditional and the regression-based approaches yield identical norms under certain conditions, for example when the scores to be normed are not affected by any of the independent variables (which is the case for the Internal and Change scale scores of the MCQ). Indeed, when none of the independent variables affect the outcome, the final regression model only includes the intercept $B_{0}$. In other words, the predicted scores of all individuals will be equal to the mean outcome score in the normative sample. Likewise, the $S D$ (residual) will be equal to the observed $S D$ of the outcome in the normative sample. As both methods yield identical estimates of the means and $S D$ s, the traditional and regression-based norms will be identical as well.

The demographically corrected MCQ norms provide a useful tool for clinicians. For example, suppose that a participant in a memory intervention program produced raw scores on the MCQ scales External, Internal, Time, Reliance, and Effort scales that corresponded with percentile values of $80,80,20,80$ and 80 , respectively. The clinician may use such results to focus on the Reliance strategy in the memory intervention program rather than on the other strategies (because these other strategies are already intensively used by the participant).

All scale scores of the Dutch version of the MCQ were positively correlated with each other (all $r>.20$, all $p<.01$; see Table 2). This pattern is consistent with the correlations obtained with the English version of the MCQ (see Table 1 in De Frias \& Dixon, 2005). The highest correlations were observed between the MCQ scales of Internal and Effort $(r=.73)$ and between Time and Effort $(r=.63)$, but all other pairwise MCQ scale correlations were also significantly positive (see Table 2 ). This finding indicates that people often use more than one memory compensation strategy. It should also be noted that the high correlations between the five memory compensation factors of the MCQ indicate that a single higher-order factor may account for the observed relations between the first-order factors. Specifically, De Frias and Dixon (2005) showed that the five first-order memory compensation factors of the MCQ loaded on a single higher-order factor. It is unknown whether a similar second-order factor would be obtained with the Dutch version of the MCQ, but this is likely to be the case in view of the high similarity of the psychometric properties of both MCQ versions (see above).

There are some limitations of this study that warrant discussion. First, previous large-scale longitudinal studies in community dwelling elderly have shown that the questionnaire format clock-drawing test scores were associated with risk factors for 
cognitive decline and with the risk to develop dementia within seven years (Paganini-Hill \& Clark, 2007; Paganini-Hill et al., 2001). These findings support the use of the questionnaire format clock-drawing test as a cognitive screening tool, but it is evident that this test cannot match the diagnostic accuracy of an in-depth cognitive evaluation. For example, the questionnaire format clock-drawing test is administered without an examiner being present, which causes some specific problems. About 10 percent of the participants who returned the questionnaire did not complete the clock-drawing test. The cognitive status of these people could thus not be ascertained, and consequently their data were excluded from the analyses. It seems, however, unlikely that all participants who did not complete the clockdrawing test were cognitively impaired. It is conceivable that the limited face validity of the clock-drawing test is responsible for at least some of these missing values rather than the person's cognitive status (i.e., some cognitively intact people may not have completed the test as it seemed trivial). Another problem with the questionnaire format clock-drawing test is that it cannot be excluded that some of the participants may have asked someone else to complete their clock-drawing. The latter problem is, however, unlikely to have substantially affected our results because previous research has suggested that there is a good agreement between clocks that were drawn at home and clocks that were drawn in the presence of an examiner (Paganini-Hill et al., 2001). We nevertheless further evaluated the extent to which the use of the questionnaire format clock-drawing test as a cognitive screening tool may have affected the results. Re-analyses of the data (a) in which the $n=82$ people with missing clock-drawing test values were included, and (b) in which the $n=102$ people with missing clock-drawing test values or with scores below the cut-off for cognitive impairment were included, showed that the obtained factor structures of the MCQ remained identical in terms of items loading on the seven factors, and that the obtained factor loadings were very similar to the factor loadings that were reported in Table A1 (data not shown).

Second, the results of the CFA provided support for the construct validity of the Dutch version of the $M C Q$, which means that the obtained factor structure was highly consistent with the a priori expected model (Floyd \& Widaman, 1995), but other types of validity were not evaluated in the present study. Psychometric analyses of the English version of the MCQ supported its discriminant validity, predictive validity and measurement invariance across age and gender groups (De Frias \& Dixon, 2005; Dixon et al., 2001), but it remains to be determined whether these psychometric properties can also be demonstrated for the Dutch MCQ version.

Third, the normative sample was not representative of the general population of older adults for two reasons. First, adults who were at risk for cognitive impairment (as determined by their medical risk status or by low scores on the clockdrawing test) were excluded from the present analyses. It is common practice to exclude individuals with conditions that affect the trait(s) to be measured from 
normative samples, because norms, by definition, require a sample of individuals within the normal range of the distribution (Lezak, Howieson, \& Loring, 2004; Mitrushina, Boone, \& D'Elia, 1999; Van der Elst, 2006). Thus the fact that 'non-normal' individuals were excluded from the normative sample does not reduce the external validity of the norms. Rather the opposite is true. Normative data may be biased when not all 'non-normal' individuals are properly excluded from the normative sample. As noted above, the clock-drawing test cannot match the diagnostic accuracy of an in-depth cognitive evaluation, so it is still possible that early pre-clinical or mildly cognitively impaired older adults were not excluded from our normative sample. However, the number of such cases and the magnitude of the impairment are both likely to be small. Future studies should thus rely on stringent subject exclusion procedures, which allow for the detection of mildly cognitively impaired people. Second, the MCQ was sent to $N=3,000$ people, but only $n=813$ people returned it (i.e., there was a 27 percent response rate). Previous studies have shown that survey response rates are affected by various factors, including socio-economic status and interest in the topic of the survey (Groves et al., 2009). These factors may also be associated with memory compensation behavior, which could have affected the results of the present study (e.g., mean MCQ scale scores). Non-response bias is however an inevitable problem in survey research.

In conclusion, the present study established a Dutch version of the MCQ and evaluated its psychometric qualities. A large sample of community dwelling healthy adults aged between 50 and 95 years completed the Dutch version of the MCQ. The results suggested that the Dutch version of the MCQ was an adequate adaptation of the English version of the MCQ. The psychometric properties of the Dutch version of the MCQ (i.e., its construct validity and reliability) were excellent. These findings support the use of the MCQ as a new tool to assess memory compensation strategies in Dutch-speaking populations. To facilitate the interpretation of the MCQ scale scores, normative data were also established. 


\section{References}

Aiken, L. S., \& West, S. G. (1991). Multiple regression: Testing and interpreting interactions. Newbury Park, California: Sage.

Bäckman, L., \& Dixon, R. A. (1992). Psychological compensation: a theoretical framework. Psychological Bulletin, 112, 259-283.

Belsley, D. A., Kuh, E., \& Welsch, R. E. (1980). Regression diagnostics: Identifying influential data and sources of collinearity. New York: Wiley.

Bentler, P. M. (1990). Fit indices, LaGrange multipliers, constraint changes, and incomplete data in structural models. Multivariate Behavioral Research, 25, 163-172.

Bentler, P. M., \& Bonett, D. G. (1980). Significance tests and goodness of fit in the analysis of covariance structures. Psychological Bulletin, 88, 238-246.

Browne, M. W., \& Cudeck, R. (1992). Alternative ways of assessing model fit. Sociological Methods and Research, 21, 230-258.

Capitani, E. (1997). Normative data and neuropsychological assessment. Common problems in clinical practice and research. Neuropsychological Rehabilitation, 7, 295-309.

Craik, F. I. M., \& Salthouse, T. A. (2000). The handbook of aging. Mahwah, NJ: Lawrence Erlbaum.

Crawford, J. R., \& Howell, D. C. (1998). Comparing an individual's test score against norms derived from small samples. The Clinical Neuropsychologist, 12, 482-486.

De Bie, S. E. (1987). Toward a standardization of questions concerning demographic variables in population studies [Standaardvragen 1987 - Voorstellen voor uniformering van vraagstellingen naar achtergrondkenmkernen en interviews]. Leiden, The Netherlands: Leiden University Press.

De Frias, C. M., \& Dixon, R. A. (2005). Confirmatory factor structure and measurement invariance of the Memory Compensation Questionnaire. Psychological Assessment, 17, 168-178.

De Frias, C. M., Dixon, R. A., \& Bäckman, L. (2003). Use of memory compensation strategies is related to psychosocial and health indicators. Journals of Gerontology Series B: Psychological Sciences and Social Sciences, 58, P12-22.

Dixon, R. A., \& Bäckman, L. (1992). The concept of compensation in cognitive aging: the case of prose processing in adulthood. International Journal of Aging and Human Development, 36, 199-217.

Dixon, R. A., \& Bäckman, L. (1995). Compensating for psychological deficits and declines: Managing lossess and promoting gains. Mahwah, NJ: Lawrence Erlbaum.

Dixon, R. A., \& de Frias, C. M. (2007). Mild memory deficits differentially affect 6-year changes in compensatory strategy use. Psychology and Aging, 22, 632-638.

Dixon, R. A., de Frias, C. M., \& Bäckman, L. (2001). Characteristics of self-reported memory compensation in older adults. Journal of Clinical and Experimental Neuropsychology, 23, 650-661.

Floyd, F. J., \& Widaman, K. F. (1995). Factor analysis in the development and refinement of clinical assessment instruments. Psychological Assessment, 7, 286-299.

Groves, R. M., Fowler, F. J., Couper, M. P., Lepkowski, J. M., Singer, E., \& Tourangeau, R. (2009). Survey methodology (2 ed.). Hoboken, NJ: Wiley.

Hopp, G. A. (1993). A longitudinal study of the cognitive performance of healthy and demented very old adults. Unpublished master's thesis. University of Victoria.

La Rue, A. (1992). Aging and neuropsychological assessment. New York, NY: Plenum Press.

Lezak, M. D., Howieson, D. B., \& Loring, D. W. (2004). Neuropsychological Assessment. Oxford: Oxford University Press.

MacCallum, R. C., Widaman, K. F., Zhang, S., \& Hong, S. (1999). Sample size in factor analysis. Psychological Methods, 4, 84-99.

Mitrushina, M. N., Boone, K. B., \& D’Elia, L. F. (1999). Handbook of normative data for neuropsychological assessment. New York, NY: Oxford University Press.

Mol, M. E., Ruiter, R. A., Verhey, F. R., Dijkstra, J., \& Jolles, J. (2008). A study into the psychosocial determinants of perceived forgetfulness: implications for future interventions. Aging and Mental Health, $12,167-176$. 
Paganini-Hill, A., \& Clark, L. J. (2007). Preliminary assessment of cognitive function in older adults by clock drawing, box copying and narrative writing. Dementia and Geriatric Cognitive Disorders, 23, 74-81.

Paganini-Hill, A., Clark, L. J., Henderson, V. W., \& Birge, S. J. (2001). Clock drawing: analysis in a retirement community. Journal of the American Geriatrics Society, 49, 941-947.

Ponds, R. W. H. M., Commissaris, C. J., \& Jolles, J. (1997). Prevalence and covariates of subjective forgetfulness in a normal population in The Netherlands. International Journal of Aging and Human Development, 45, 207-221.

Tabachnick, B. G., \& Fidell, L. S. (2001). Using multivariate statistics. Boston: Allyn \& Bacon.

UNESCO (1976). International Standard Classification of Education (ISCED). Paris: United Nations Educational, Scientific and Cultural Organisation.

Unverzagt, F. W., Kasten, L., Johnson, K. E., Rebok, G. W., Marsiske, M., Koepke, K. M., Elias, J. W., Morris, J. N., Willis, S. L., Ball, K., Rexroth, D. F., Smith, D. M., Wolinsky, F. D., \& Tennstedt, S. L. (2007). Effect of memory impairment on training outcomes in ACTIVE. Journal of the International Neuropsychological Society, 13, 953-960.

Van der Elst, W. (2006). The neuropsychometrics of aging: Normative studies in the Maastricht Aging Study. Maastricht, The Netherlands: Neuropsy.

Van der Elst, W., Van Boxtel, M. P., Van Breukelen, G. J., \& Jolles, J. (2005). Rey's verbal learning test: normative data for 1855 healthy participants aged 24-81 years and the influence of age, sex, education, and mode of presentation. Journal of the International Neuropsychological Society, 11, 290302.

Van der Elst, W., Van Boxtel, M. P., Van Breukelen, G. J., \& Jolles, J. (2007). Assessment of information processing in working memory in applied settings: the paper and pencil memory scanning test. Psychological Medicine, 37, 1335-1344.

Van der Elst, W., Van Boxtel, M. P., Van Breukelen, G. J., \& Jolles, J. (2008). Detecting the significance of changes in performance on the Stroop Color-Word Test, Rey's Verbal Learning Test, and the Letter Digit Substitution Test: The regression-based change approach. Journal of the International Neuropsychological Society, 14, 71-80. 


\section{Appendix 1}

Normative data for the External scale score stratified by Age and Gender. The raw scale scores that correspond to the percentiles $1,5,10,20,50,80,90,95$, and 99 are presented

\begin{tabular}{|c|c|c|c|c|c|c|c|c|c|c|c|c|c|c|c|c|c|c|}
\hline & \multicolumn{8}{|c|}{ Males } & \multicolumn{8}{|c|}{ Females } \\
\hline & & & \multicolumn{8}{|c|}{ Age in years } & \multicolumn{8}{|c|}{ Age in years } \\
\hline & & & 50 & 55 & 60 & 65 & 70 & 75 & 80 & 85 & 50 & 55 & 60 & 65 & 70 & 75 & 80 & 85 \\
\hline \multirow{9}{*}{ 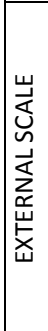 } & \multirow{9}{*}{ 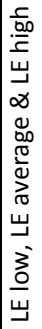 } & 99 & 29.1 & 29.6 & 30.2 & 30.7 & 31.3 & 31.8 & 32.0 & 32.0 & 30.9 & 31.5 & 32.0 & 32.0 & 32.0 & 32.0 & 32.0 & 32.0 \\
\hline & & 95 & 27.8 & 28.3 & 28.9 & 29.4 & 30.0 & 30.5 & 31.1 & 31.6 & 29.7 & 30.2 & 30.8 & 31.3 & 31.9 & 32.0 & 32.0 & 32.0 \\
\hline & & 90 & 27.0 & 27.5 & 28.1 & 28.6 & 29.2 & 29.7 & 30.3 & 30.8 & 28.8 & 29.4 & 29.9 & 30.5 & 31.0 & 31.6 & 32.0 & 32.0 \\
\hline & & 80 & 25.6 & 26.1 & 26.7 & 27.2 & 27.8 & 28.3 & 28.9 & 29.4 & 27.5 & 28.0 & 28.6 & 29.1 & 207 & 30.2 & 30.8 & 31.3 \\
\hline & & 50 & 21.9 & 22.5 & 23.0 & 23.6 & 24.1 & 24.7 & 25.2 & 25.8 & 23.8 & 24.4 & 24.9 & 25.5 & 26.0 & 26.6 & 27.1 & 27.7 \\
\hline & & 20 & 16.9 & 17.4 & 18.0 & 18.5 & 19.1 & 19.6 & 20.2 & 20.7 & 18.8 & 19.3 & 19.9 & 20.4 & 21.0 & 21.5 & 22.1 & 22.6 \\
\hline & & 10 & 14.1 & 14.6 & 15.2 & 15.7 & 16.3 & 16.8 & 17.4 & 17.9 & 15.9 & 16.5 & 17.0 & 17.6 & 18.1 & 18.7 & 19.2 & 19.8 \\
\hline & & 5 & 11.2 & 11.8 & 12.3 & 12.9 & 13.4 & 14.0 & 14.5 & 15.1 & 13.1 & 13.6 & 14.2 & 14.7 & 15.3 & 15.8 & 16.4 & 16.9 \\
\hline & & 1 & 4.8 & 5.3 & 5.9 & 6.4 & 7.0 & 7.5 & 8.1 & 8.6 & 6.6 & 7.2 & 7.7 & 8.3 & 8.8 & 9.4 & 9.9 & 10.5 \\
\hline
\end{tabular}

\section{Appendix 2}

Normative data for the Internal scale score. The raw scale scores that correspond to the percentiles 1,5 , $10,20,50,80,90,95$, and 99 are presented

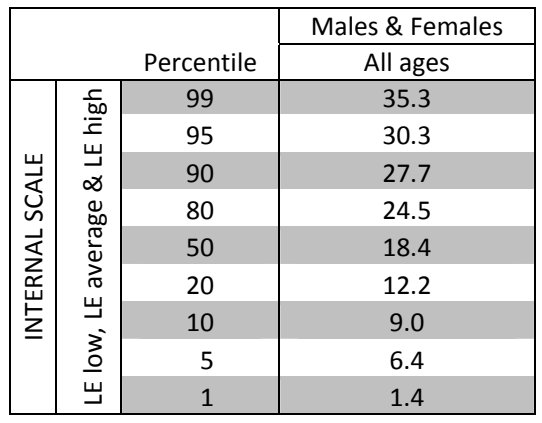




\section{Appendix 3}

Normative data for the Reliance scale score stratified by Gender and Level of Education. The raw scale scores that correspond to the percentiles $1,5,10,20,50,80,90,95$, and 99 are presented

\begin{tabular}{|c|c|c|c|c|}
\hline \multirow{2}{*}{\multicolumn{3}{|c|}{ Percentile }} & Males & Females \\
\hline & & & All ages & All ages \\
\hline \multirow{29}{*}{ 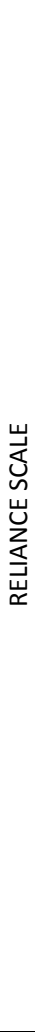 } & \multirow{9}{*}{ 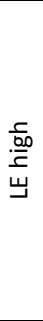 } & 99 & 16.6 & 15.4 \\
\hline & & 95 & 13.9 & 12.6 \\
\hline & & 90 & 11.2 & 10.0 \\
\hline & & 80 & 8.9 & 7.7 \\
\hline & & 50 & 4.8 & 3.6 \\
\hline & & 20 & 1.6 & 0.3 \\
\hline & & 10 & 0.8 & 0.0 \\
\hline & & 5 & 0.0 & 0.0 \\
\hline & & 1 & 0.0 & 0.0 \\
\hline & \multirow{10}{*}{ 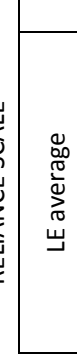 } & Percentile & & \\
\hline & & 99 & 17.0 & 15.8 \\
\hline & & 95 & 14.3 & 13.0 \\
\hline & & 90 & 11.6 & 10.4 \\
\hline & & 80 & 9.4 & 8.1 \\
\hline & & 50 & 5.2 & 4.0 \\
\hline & & 20 & 2.0 & 0.7 \\
\hline & & 10 & 1.2 & 0.0 \\
\hline & & 5 & 0.4 & 0.0 \\
\hline & & 1 & 0.0 & 0.0 \\
\hline & \multicolumn{4}{|c|}{ Percentile } \\
\hline & \multirow{9}{*}{$\frac{z}{\underline{u}}$} & 99 & 18.3 & 17.0 \\
\hline & & 95 & 15.5 & 14.3 \\
\hline & & 90 & 12.9 & 11.7 \\
\hline & & 80 & 10.6 & 9.4 \\
\hline & & 50 & 6.5 & 5.3 \\
\hline & & 20 & 3.2 & 2.0 \\
\hline & & 10 & 2.5 & 1.2 \\
\hline & & 5 & 1.7 & 0.4 \\
\hline & & 1 & 1.0 & 0.0 \\
\hline
\end{tabular}




\section{Appendix 4}

Normative data for the Time scale score stratified by Age. The raw scale scores that correspond to the percentiles $1,5,10,20,50,80,90,95$, and 99 are presented

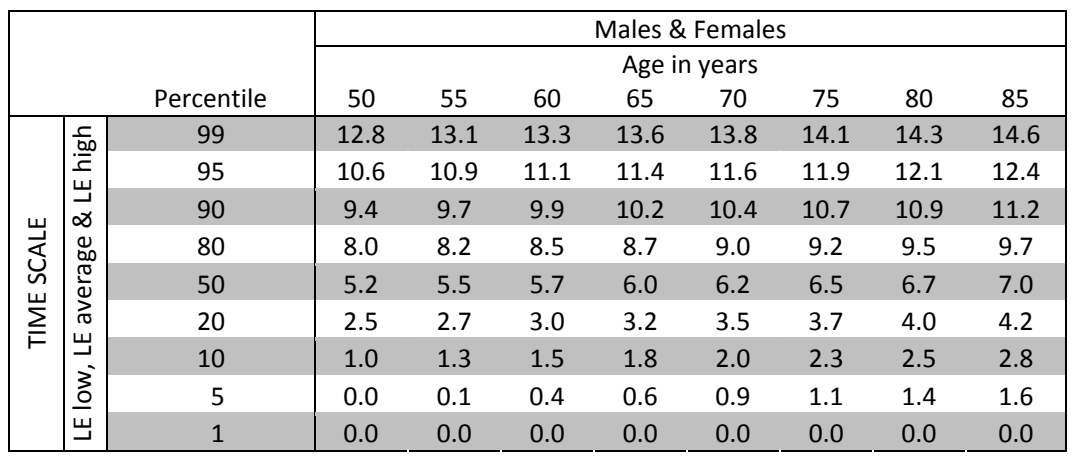

\section{Appendix 5}

Normative data for the Effort scale score stratified by Age and Gender. The raw scale scores that correspond to the percentiles $1,5,10,20,50,80,90,95$, and 99 are presented

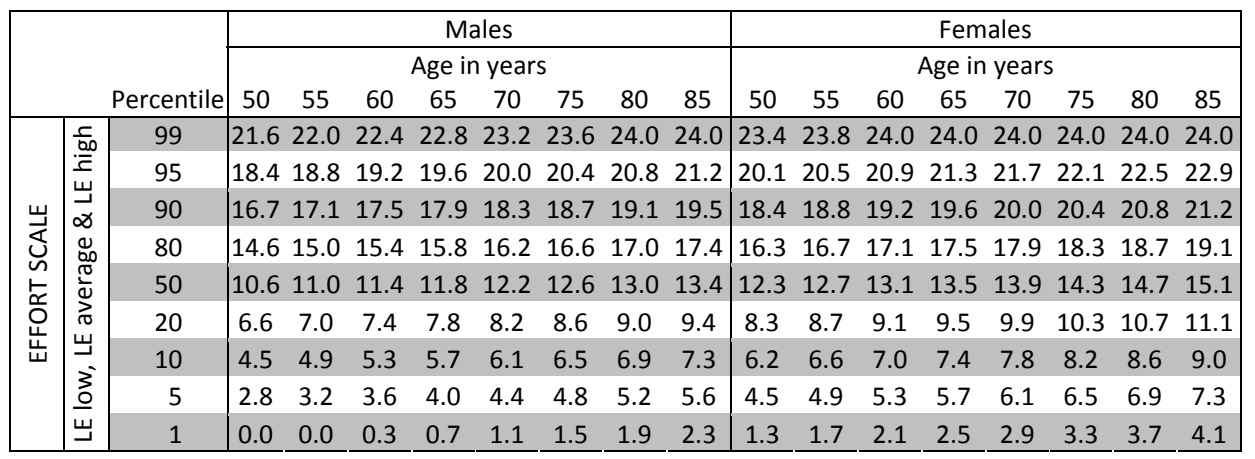




\section{Appendix 6}

Normative data for the Success scale score stratified by Age. The raw scale scores that correspond to the percentiles $1,5,10,20,50,80,90,95$, and 99 are presented

\begin{tabular}{|c|c|c|c|c|c|c|c|c|c|c|}
\hline \multirow{3}{*}{\multicolumn{3}{|c|}{ Percentile }} & \multicolumn{8}{|c|}{ Males \& Females } \\
\hline & & & \multicolumn{8}{|c|}{ Age in years } \\
\hline & & & 50 & 55 & 60 & 65 & 70 & 75 & 80 & 85 \\
\hline \multirow{9}{*}{ 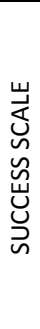 } & \multirow{9}{*}{ 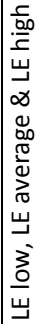 } & 99 & 17.8 & 18.2 & 18.5 & 18.9 & 19.2 & 19.6 & 19.9 & 20.3 \\
\hline & & 95 & 15.0 & 15.4 & 15.7 & 16.1 & 16.4 & 16.8 & 17.1 & 17.5 \\
\hline & & 90 & 13.5 & 13.9 & 14.2 & 14.6 & 14.9 & 15.3 & 15.6 & 16.0 \\
\hline & & 80 & 11.7 & 12.1 & 12.4 & 12.8 & 13.1 & 13.5 & 13.8 & 14.2 \\
\hline & & 50 & 8.3 & 8.6 & 9.0 & 9.3 & 9.7 & 10.0 & 10.4 & 10.7 \\
\hline & & 20 & 4.8 & 5.1 & 5.5 & 5.8 & 6.2 & 6.5 & 6.9 & 7.2 \\
\hline & & 10 & 3.0 & 3.3 & 3.7 & 4.0 & 4.4 & 4.7 & 5.1 & 5.4 \\
\hline & & 5 & 1.5 & 1.8 & 2.2 & 2.5 & 2.9 & 3.2 & 3.6 & 3.9 \\
\hline & & 1 & 0.0 & 0.0 & 0.0 & 0.0 & 0.1 & 0.4 & 0.8 & 1.1 \\
\hline
\end{tabular}

\section{Appendix 7}

Normative data for the Change scale score. The raw scale scores that correspond to the percentiles 1,5 , $10,20,50,80,90,95$, and 99 are presented

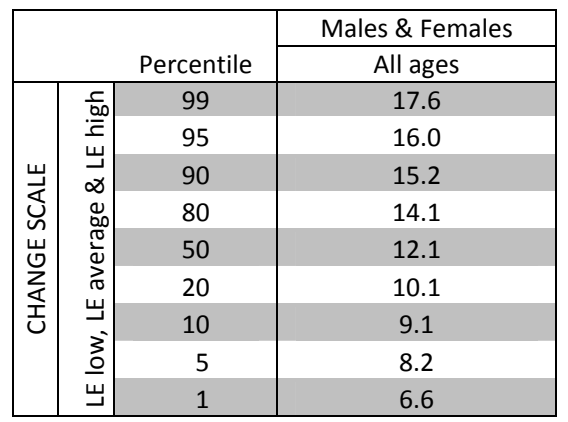





\section{Everyday memory compensation in older adults}

with cognitive complaints is moderated by depressive symptoms 


\begin{abstract}
Compensation offers an opportunity to mitigate or overcome actual or perceived age-related cognitive losses. It is highly relevant to investigate which individual factors influence compensatory behavior to gain further insight in the mechanisms of successful cognitive aging. The main aim of the present study was to evaluate the moderating effect of depressive symptoms on the relationship between subjective cognitive complaints and compensatory behavior in older adults. Demographic variables and aspects of metamemory, which are known predictors of compensatory behavior, were included as covariates. A cross-sectional study among 556 community dwelling adults aged 50 years and older was carried out. Compensatory behavior increased as a function of self-reported cognitive complaints. Interestingly, this increase was less pronounced for older adults who also reported many depressive symptoms. Furthermore, the predictive value of demographic variables (i.e., age, gender, and educational level) as well as aspects of metamemory was confirmed. It can be concluded that older adults with depressive symptoms are even more vulnerable in the context of cognitive aging than was thought until now. These people are not only at a higher risk of developing objective or subjective cognitive problems, but they also do not optimally compensate for their problems spontaneously. It seems thus necessary to screen older adults with cognitive problems for depressive symptomatology and spontaneous compensatory behavior, and offer them more tailor-made interventions to treat their problems.
\end{abstract}




\section{Introduction}

About two decades ago, Bäckman and Dixon (1992) provided a theoretical framework of psychological compensation that is applicable to various domains of functioning (e.g., sensory handicaps, interpersonal losses, cognitive losses, and brain injury). The concept of compensation has ever since attracted growing attention in aging research (Dixon, 1995; Dixon \& Bäckman, 1992; Dixon \& de Frias, 2004; Dixon, de Frias, \& Bäckman, 2001) and neurorehabilitation (Dixon \& Backman, 2005; Evans, Wilson, Needham, \& Brentnall, 2003; Wilson, 2000; Wilson \& Watson, 1996). Compensation refers to processes of overcoming or mitigating perceived or actual losses through one or more identifiable mechanisms. These mechanisms include: (i) remediation (e.g., investing more time or effort in overcoming a loss), (ii) substitution (e.g., developing new, or using latent, skills instead of declining or ineffective ones), (iii) accommodation (e.g., adjusting goals and criteria to be more concordant with current demands and skills), and (iv) assimilation (e.g., modifying the environmental demands or expectations of others). A prerequisite of compensatory behavior is a mismatch between environmental demands and personal skills that originates from either an objective or perceived decline in a given skill, or an increase in environmental demands (Bäckman \& Dixon, 1992).

Aging is often accompanied by actual (Craik \& Bialystok, 2006; Hertzog, Dixon, Hultsch, \& MacDonald, 2003; Salthouse, 1996) or perceived cognitive declines (Minett, Da Silva, Ortiz, \& Bertolucci, 2008; Ponds \& Jolles, 1996a). This is a source of worries and stress in many older adults (Commissaris et al., 1993; Mol, Van Boxtel, Willems, Verhey, \& Jolles, 2009). Consequently, many researchers have focussed their attention on the concept of successful aging that encompasses optimal physical development and health, a high level of psychosocial functioning, and the maintenance of high cognitive function in old age (Albert et al., 1995; Blazer, 2006; Crowther, Parker, Achenbaum, Larimore, \& Koenig, 2002; Depp \& Jeste, 2006; Riley, 1998; Rowe \& Kahn, 1987, 1997; Schulz \& Heckhausen, 1996). A recent review has estimated that as much as 36 percent of the older adults age successfully (Depp \& Jeste, 2006). Compensation is an essential component of successful aging (Baltes \& Baltes, 1990), because it offers an opportunity to mitigate or overcome age-related cognitive losses. Compensatory behavior may thus be targeted in intervention studies to promote successful aging (Glisky \& Glisky, 2005; Hohaus, 2007).

Dixon and colleagues (2001) identified several different compensatory strategies for everyday memory failures. Memory compensation through the mechanism of remediation occurs by the investment of more time of more effort in memory demanding tasks. The use of external devices or aids, the use of internal mnemonic strategies, and the use of other people as memory aids are examples of substitution mechanisms. They further stated that the motivation to do well in everyday memory performance as well as the awareness of changes in the need for memory com- 
pensation over time are linked to compensatory behavior (Dixon et al., 2001). Only few studies have evaluated the prevalence of different memory compensatory strategies in community-dwelling older adults. These studies have revealed that external strategies are more often used spontaneously than internal strategies (e.g., McDonald-Miszczak, Hertzog, \& Hultsch, 1995; McDougall, 1995). Another common strategy is the investment of more effort. The investment of more time and the reliance on others as memory aids are the least preferred forms of compensation (Dixon et al., 2001).

Until now, it is largely unknown which individual factors influence compensatory behavior. This question is yet highly relevant as it gains further insight in mechanisms of successful cognitive aging and individual adaptability to age-related cognitive changes. It has been demonstrated that everyday memory compensation is related to demographic variables. Older adults, for example, use more compensatory strategies than their younger counterparts (De Frias, Dixon, \& Bäckman, 2003; Dixon et al., 2001; McDougall, 1996; Ponds \& Jolles, 1996b; Van der Elst, Hoogenhout, Dixon, De Groot, \& Jolles, in press). Furthermore, men prefer different types of strategies than women (De Frias et al., 2003; Ponds \& Jolles, 1996b; Van der Elst et al., in press). Educational level, which is a proxy of cognitive reserve (Stern, 2002, 2003), has also been related to everyday memory compensation. One may a priori expect that individuals with a higher cognitive reserve (i.e., people with a higher level of education or a higher IQ) implement more compensatory strategies to meet increased cognitive demands in aging, which would result in a less pronounced agerelated cognitive decline (Garrett, Grady, \& Hasher, 2010). Recent studies on compensatory behavior in everyday memory tasks point however to the opposite. Loweducated individuals were more likely to compensate than high-educated individuals (De Frias et al., 2003; Garrett et al., 2010). Apart from these demographical factors, previous studies have linked compensatory behavior to other factors, including metamemory (De Frias et al., 2003; McDougall, 1996), health problems, personality dimensions, and affect (De Frias et al., 2003). Although it is implicitly assumed that awareness of deficits or losses is a prerequisite for compensatory behavior (Bäckman \& Dixon, 1992; Wilson \& Watson, 1996), there is only one study that actually investigated and confirmed the importance of self-reported subjective memory problems in the context of compensation (Garrett et al., 2010). It turned out that, although the existence of objective memory deficits may help determine certain compensatory efforts over time (Dixon \& de Frias, 2004, 2007), memory compensation occurs especially in people with perceived memory decline - even in absence of objective impairment (Garrett et al., 2010). Furthermore, individuals who reported a greater number of stressful life events (e.g., death of a close relative, divorce) reported more compensatory behavior. More specifically, individuals with high levels of stress compensated irrespectively of their memory errors, but older adults 
with lower levels of stress compensated only if they perceived many memory errors (Garrett et al., 2010).

There is a large amount of literature that suggests that older adults with depressive symptoms are highly vulnerable for various age-related problems. They experience, for example, more functional impairments in daily life functioning (Gallo, Rebok, Tennsted, Wadley, \& Horgas, 2003; Oxman, Barrett, Sengupta, \& Williams, 2000), more subjective cognitive problems (Collins \& Abeles, 1996; Dux et al., 2008; Kliegel \& Zimprich, 2005; Mol, Ruiter, Verhey, Dijkstra, \& Jolles, 2008; Sachs-Ericsson, Joiner, \& Blazer, 2008), and worse performance on objective cognitive tasks (Bierman, Comijs, Jonker, \& Beekman, 2005; Dux et al., 2008). Depressive symptomatology has also been associated with a more pronounced decline in cognitive functions (Comijs et al., 2004; Köhler et al., 2010; Paterniti, Verdier-Taillefer, Dufouil, \& Alperovitch, 2002; Zimprich, Martin, \& Kliegel, 2003) and a higher risk to develop dementia (Jorm, 2000). It has previously been suggested that the occurrence of depressive symptoms in people with actual or perceived cognitive losses may hamper their use of compensatory strategies. In other words, people with depressive symptoms may not optimally adopt adaptive behavior in response to perceived or actual cognitive decline (Dixon et al., 2001). This relationship has however not yet been investigated.

The main aim of the present study was to evaluate the moderating effect of depressive symptoms on the relationship between subjective memory deficits and compensatory behavior in older adults as measured with the Dutch version of the Memory Compensation Questionnaire (MCQ; De Frias \& Dixon, 2005; Dixon et al., 2001; Van der Elst et al., in press). A cross-sectional study was carried out in 556 healthy community dwelling adults aged 50 years and older. Various demographic variables (i.e., age, gender, and educational level) and aspects of metamemory (i.e., memory related anxiety and memory related sense of control) were also included in the study as covariates because previous studies have shown that they are associated with compensatory behavior.

\section{Methods}

\section{Participants and procedure}

Participants were recruited within a Dutch community organization for healthy elderly. This organization has more than 315.000 community-dwelling members (within 877 local divisions) who are at least 50 years old. The sampling frame comprised approximately 3,000 members of several divisions of this organization. They were sent a questionnaire included with the organization's monthly magazine. The questionnaires were sent between $1^{\text {st }}$ April and $1^{\text {st }}$ June 2008 , with a prepaid re- 
sponse envelope and a cover letter, which detailed the aims of the study. In total, $N=813$ participants returned the questionnaire.

Respondents who were aged below 50 years $(n=27)$ and people whose age could not be determined due to missing or erroneous self-reported date information ( $n=6)$ were excluded. Participants who reported to suffer from (previous) illnesses that could interfere with cognitive functioning were excluded (i.e., dementia $(n=20)$, stroke $(n=63)$, brain tumours $(n=4)$, central nervous diseases $(n=8)$ and epilepsy $(n=10)$ ). The cognitive status of the participants was evaluated by means of a clock-drawing test included in the questionnaire. In this test, participants were asked to draw in the numbers as in a clock face in a pre-drawn circle of $8.3 \mathrm{~cm}$ in diameter (see for more details Paganini-Hill, Clark, Henderson, \& Birge, 2001). This questionnaire-version of the clock-drawing task provides reliable and valid information regarding the general cognitive status of an individual (Paganini-Hill \& Clark, 2007; Paganini-Hill et al., 2001). Age group and gender-corrected cut-off scores for cognitive disability (Paganini-Hill et al., 2001) identified $n=20$ participants as cognitively impaired. These participants were thus excluded from the subsequent analyses. Moreover, the data of $n=82$ and $n=21$ participants were excluded, because they did not complete the clock-drawing test or because they had more than four missing values on the MCQ, respectively. Thus the data of a total sample of $N=556$ participants were analyzed.

Demographics of the sample are summated in Table 1. Mean age of the sample was 73.8 years (range $50-95$ years; $S D=8.0$ ). There were more females in the sample $(62.3 \%)$ than males (37.7\%). Level of education was measured by classifying the formal schooling of the participants in one of three groups, i.e. those with at most primary education (LE low; $26.9 \%$ of the sample), those with at most junior vocational training or high school (LE average; $44.9 \%$ of the sample), and those with at most senior vocational or academic training (LE high; $28.2 \%$ of the sample). This LE system is often used in the Netherlands (De Bie, 1987) and is comparable with the International Standard Classification of Education (UNESCO, 1976).

Table 1 Distribution of gender and educational level per age group $(N=556)$

\begin{tabular}{lccccc}
\hline & $\begin{array}{c}\mathbf{5 0 - 6 0} \\
\text { years }\end{array}$ & $\begin{array}{c}\mathbf{6 0 - 7 0} \\
\text { years }\end{array}$ & $\begin{array}{c}\mathbf{7 0 - 8 0} \\
\text { years }\end{array}$ & $\begin{array}{c}\mathbf{8 0 - 9 5} \\
\text { years }\end{array}$ & Total \\
\hline $\mathrm{N} \quad 174$ & 228 & 134 & 556 \\
$\begin{array}{l}\text { Gender } \\
\quad \text { \% women }\end{array}$ & 20 & & & & \\
$\quad \begin{array}{l}\text { \% men } \\
\text { Education }\end{array}$ & 60.0 & 64.5 & 61.4 & 38.8 & 62.3 \\
$\quad$ \% low & 40.0 & 35.5 & 38.6 & 61.2 & 37.7 \\
$\quad$ \% medium & & & & \\
$\quad$ \% high & 10.0 & 27.2 & 27.6 & 28.0 & 26.9 \\
\hline
\end{tabular}




\section{Measures}

\section{Compensatory behavior}

The Memory Compensation Questionnaire (MCQ; De Frias \& Dixon, 2005; Dixon et al., 2001) was administered to assess compensatory behavior for age-related memory problems in everyday life. The Dutch version of the MCQ was used in the present study. Previous research has shown that this test was an adequate and reliable adaptation of the English version of the MCQ with similar psychometric properties (Van der Elst et al., in press). The MCQ consists of 43 items and seven subscales. Five subscales represent several forms of compensatory behavior relevant to everyday memory functioning. The External scale contains 8 items concerning the use of external memory aids (e.g., using shopping lists). The Internal scale contains 10 items concerning the use of internal compensation strategies (e.g., repeat telephone numbers). The Time scale consists of 5 items regarding the investment of more time in everyday memory tasks (e.g., read a newspaper slowly). The Effort scale includes 6 items that focus on the investment of more effort in everyday memory tasks (e.g., put in more effort in a conversation). The Reliance scale contains 5 items that assess the reliance on others as memory aids (e.g., ask for help to remember people's names). A sixth scale (i.e., the Success scale) measured the level of commitment to success in everyday memory performance (e.g., importance of remembering a funny story). The extent to which changes have occurred in the past five to ten years in each of the forms of compensation was measured by the Change scale (e.g., ask more or less often to people to remember things). Respondents were asked to indicate the frequency with which they use different strategies on a 5point Likert scale ranging from 0 (= never) to 4 (= always), except for the Change scale that ranges from 0 (= much less time) to 4 (= much more time). Higher scores indicated more frequent use of the different compensatory strategies (De Frias \& Dixon, 2005; Van der Elst et al., in press).

\section{Memory related anxiety}

The Anxiety subscale of the abridged Metamemory in Adulthood Questionnaire (MIA; Ponds \& Jolles, 1996b) was used to measure perceived stress and anxiety regarding memory performance. It consisted of 12 items that were scored on a 5point Likert scale ranging from 1 (strongly disagree) to 5 (strongly agree). Higher scale scores indicated more perceived stress and anxiety regarding memory functioning.

\section{Memory related sense of control}

The Locus subscale of the abridged MIA (Ponds \& Jolles, 1996b) was used to measure the perceived sense of control over memory skills. It consists of 7 items that were scored on a 5-point Likert scale ranging from 1 (strongly disagree) to 5 
(strongly agree). Higher scores indicated less perceived control regarding memory functioning.

\section{Cognitive failures}

The Cognitive Failure Questionnaire (CFQ; Broadbent, Cooper, FitzGerald, \& Parkes, 1982; Merckelbach, Muris, Nijman, \& De Jong, 1996) was used to assess the frequency of everyday cognitive failures (e.g., failing to hear people speak, forgetting what you came to the shop for to buy). All 25 items were rated on a 5-point Likert scale with a score range between 0 (never) and 4 (all the time). Higher scores indicated more everyday cognitive failures.

\section{Depressive symptoms}

The Centre of Epidemiologic Studies Depression Scale (CES-D; Bouma, Ranchor, Sanderman, \& Van Sonderen, 1995) was used to measure symptoms of depression. The CES-D consisted of 20 short statement concerning symptoms of depression (e.g., feeling lonely) in the week prior to test administration. Frequency of symptoms could be indicated on a 4-point scale, ranging from 0 (fewer than 1 day in the last week) tot 3 ( 5 to 7 days in the last week). Higher scores indicated more symptoms of depression.

\section{Statistical Analyses}

The MCQ scale scores were regressed on age, age ${ }^{2}$, gender (coded as male $=1$ and female $=0$ ), educational level (dummy coded into three levels with LE average as the reference category), CFQ, CES-D, MIA Anxiety, and MIA Locus. Furthermore, the full models contained the CFQ $\times$ CES-D interaction term (see Introduction). All (semi) continuous predictors were centered before quadratic terms and the interaction were calculated to avoid multicollinearity (age = calendar age $-75, C F Q=C F Q$ total -32, CES-D = CESD total -9, MIA Anxiety = Anxiety -31, and MIA Locus = Locus -22 ). Non-significant predictors ( $p>$.05) were excluded from the full models (i.e., the models that included all predictors), but no predictor was removed as long as it was also included in a higher order term in the model (Aiken \& West, 1991).

The assumptions of regression analysis were tested for each model. Homoscedasticity was evaluated by visual inspection of scatter plots of the residuals against the predicted values and by grouping participants into quartiles of the predicted scores and applying the Levene test. Normal distributions of the residuals were investigated by visual inspection of the histograms of the residuals, and by conducting Kolmogorov-Smirnov tests on the residuals. The occurrence of multicollinearity was checked by calculating the Variance Inflation Factors (VIFs), which should not exceed 10 (Belsley, Kuh, \& Welsch, 1980). Potential influential cases were identified 
by calculating Cook's distances. Analyses were conducted using PASW 18.0 for Macintosh.

\section{Results}

\section{Relative frequency of use}

The relative frequency of use for each compensatory strategy from most to least used was as follows: External $(M=3.10, S E M=.030)$, Effort $(M=2.26, S E M=.035)$, Internal $(M=1.83, \operatorname{SEM}=.031)$, Time $(M=1.60, \operatorname{SEM}=.035)$, and Reliance $(M=$ $1.05, S E M=.037)$. Figure 1 presents the results graphically. As indicated by the 99 percent Confidence Intervals, all pair-wise differences in the mean relative frequencies of use of the different compensatory strategies were significant.

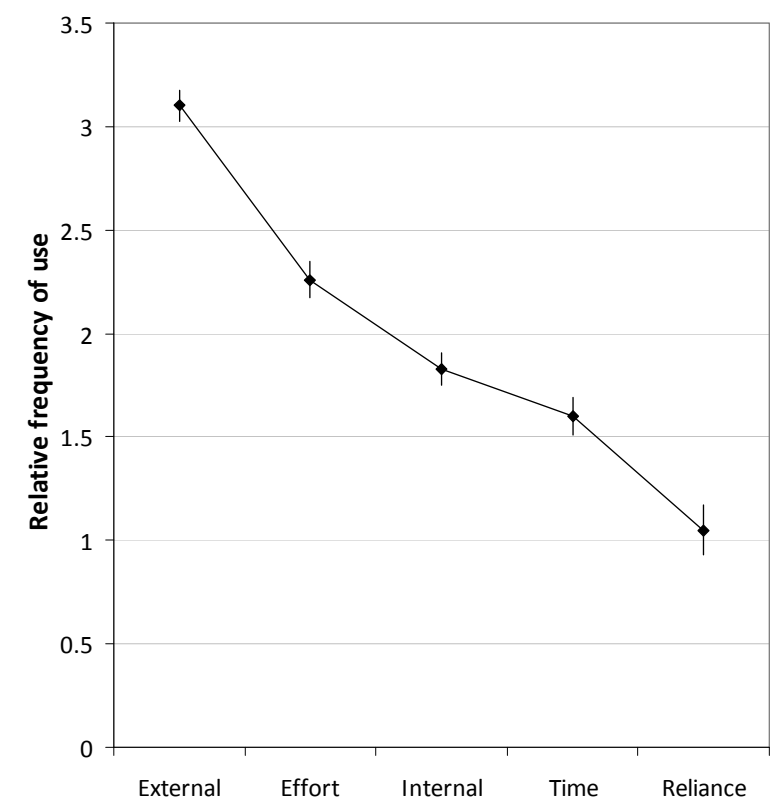

Figure 1 Relative frequency of use of different compensation strategies with 99 percent confidence intervals

\section{Predictors of compensatory behavior}

Several variables had predictive value for different forms of everyday memory compensatory behavior as well as for the commitment to memory success and change in the use of compensation strategies. Increased age was positively associated with 
the more frequent use of external strategies and the investment of more time in daily memory tasks, as well as with a higher commitment to memory success. Women reported a more frequent use of external strategies and were more likely to put in greater effort in remembering, whereas men relied more on others as memory aids. Lower educated individuals reported a more frequent use of external strategies and relied more on others as memory aids. Memory related anxiety was related to all seven MCQ scales. People who reported a higher memory related anxiety reported the use of more external and internal strategies, the investment of more time and effort in daily memory tasks, and relied more on others as memory aids. Furthermore, higher memory related anxiety was associated with a higher commitment to memory success and more change in the use of compensatory strategies. Low sense of control regarding memory functioning (i.e., higher MIA Locus scores) was associated with the reported use of more internal strategies, the investment of more effort, and more commitment to memory success. The final regression models for the MCQ scales are presented in Table 2.

Table 2 Multiple linear regression models of the MCQ scale scores following a step-down hierarchical procedure; the full models included Age, $\mathrm{Age}^{2}$, Gender, LE low, LE high, CFQ, CES-D, MIA Locus, MIA Anxiety, Age $\times$ LE low, Age $\times$ LE high, Age $\times$ Gender, Age $\times$ CFQ, Age $\times$ CES-D, Gender $\times$ CFQ, Gender $\times$ CES-D, CFQ $\times$ CES-D

\begin{tabular}{|c|c|c|c|c|c|c|}
\hline MCQ scale score & Variable & B & Std. Error B & $\mathbf{T}$ & Sig & Adj. $R^{2}$ \\
\hline \multirow[t]{9}{*}{ External } & (constant) & 26.070 & .442 & 59.044 & $<.001^{* *}$ & \\
\hline & Age & .072 & .034 & 2.127 & $.034 *$ & \\
\hline & Gender & -2.047 & .530 & -3.865 & $<.001 * *$ & \\
\hline & LE low & 1.423 & .653 & -2.179 & $.030^{*}$ & \\
\hline & LE high & .335 & .631 & .531 & .596 & \\
\hline & CFQ & .146 & .030 & 4.871 & $<.001 * *$ & \\
\hline & CES-D & -.047 & .044 & -1.077 & .282 & \\
\hline & MIA Anxiety & .115 & .042 & 2.744 & $.006 * *$ & \\
\hline & $\mathrm{CFQ} \times \mathrm{CES}-\mathrm{D}$ & -.008 & .003 & -3.118 & $.002 * *$ & .181 \\
\hline \multirow[t]{6}{*}{ Internal } & (constant) & 18.310 & .340 & 53.847 & $<.001 * *$ & \\
\hline & CFQ & .223 & .037 & 6.008 & $<.001^{* *}$ & \\
\hline & CES-D & -.086 & .055 & -1.568 & .118 & \\
\hline & MIA Locus & .184 & .089 & 2.079 & $.038^{*}$ & \\
\hline & MIA Anxiety & .204 & .051 & 4.030 & $<.001 * *$ & \\
\hline & CFQ $\times$ CES-D & -.010 & .003 & -2.891 & $.004^{* *}$ & .194 \\
\hline \multirow[t]{6}{*}{ Time } & (constant) & 6.461 & .129 & 50.034 & $<.001 * *$ & \\
\hline & Age & .031 & .015 & 1.990 & $.047^{*}$ & \\
\hline & CFQ & .133 & .014 & 9.667 & $<.001 * *$ & \\
\hline & CES-D & -.024 & .020 & -1.162 & .246 & \\
\hline & MIA Anxiety & .134 & .019 & 7.097 & $<.001 * *$ & \\
\hline & CFQ $\times$ CES-D & -.004 & .001 & -3.070 & $.002 * *$ & .447 \\
\hline
\end{tabular}




\begin{tabular}{|c|c|c|c|c|c|c|}
\hline MCQ scale score & Variable & B & Std. Error B & $\mathbf{T}$ & Sig & Adj. $R^{2}$ \\
\hline \multirow[t]{8}{*}{ Reliance } & (constant) & 4.293 & .273 & 15.739 & $<.001^{* *}$ & \\
\hline & Gender & 1.285 & .338 & 3.799 & $<.001^{* *}$ & \\
\hline & LE low & 1.015 & .417 & 2.437 & $.015^{*}$ & \\
\hline & LE high & .170 & .398 & .428 & .669 & \\
\hline & CFQ & .197 & .019 & 10.281 & $<.001 * *$ & \\
\hline & CES-D & -.050 & .028 & -1.783 & .075 & \\
\hline & MIA Anxiety & .069 & .026 & 2.629 & $.009 * *$ & \\
\hline & $C F Q \times C E S-D$ & -.003 & .002 & -2.040 & $.042 *$ & .345 \\
\hline \multirow[t]{7}{*}{ Effort } & (constant) & 14.178 & .284 & 49.884 & $<.001 * *$ & \\
\hline & Gender & -1.452 & .421 & -3.450 & $.001 * *$ & \\
\hline & CFQ & .160 & .024 & 6.627 & $<.001 * *$ & \\
\hline & CES-D & -.016 & .036 & -.436 & .663 & \\
\hline & MIA Locus & .116 & .058 & 2.020 & $.044^{*}$ & \\
\hline & MIA Anxiety & .159 & .033 & 4.844 & $<.001^{* *}$ & \\
\hline & $\mathrm{CFQ} \times \mathrm{CES}-\mathrm{D}$ & -.007 & .002 & -3.381 & $.001 * *$ & .280 \\
\hline \multirow[t]{4}{*}{ Success } & (constant) & 9.861 & .181 & 54.444 & $<.001^{* *}$ & \\
\hline & Age & .048 & .023 & 2.129 & $.034^{*}$ & \\
\hline & MIA Locus & .143 & .048 & 2.985 & $.003 * *$ & \\
\hline & MIA Anxiety & .132 & .022 & 6.020 & $<.001 * *$ & .087 \\
\hline \multirow[t]{5}{*}{ Change } & (constant) & 12.193 & .103 & 118.507 & $<.001^{* *}$ & \\
\hline & CFQ & .089 & .011 & 7.905 & $<.001 * *$ & \\
\hline & CES-D & -.017 & .017 & -1.032 & .303 & \\
\hline & MIA Anxiety & .040 & .015 & 2.612 & $.009 * *$ & \\
\hline & $C F Q \times C E S-D$ & -.003 & .001 & -3.097 & $.002 * *$ & .233 \\
\hline
\end{tabular}

Note. $\mathrm{LE}=$ Level of education. Coding of the predictors: Age $=$ calendar age $-75 ;$ Gender: Male $=1$, Female = 0; LE Low: Low Education = 1, Average or High Education = 0; LE High: High Education = 1, Low or Average Education=0. CFQ = Cognitive Failure Questionnaire; CES-D = Centre of Epidemiologic Studies - Depression Scale; MIA = Metamemory in Adulthood Questionnaire (all centered values)

$* p<.05, * * p<.01$

There was a significant interaction between perceived cognitive deficits and depressive symptoms for all five forms of compensatory behavior as well as for change in compensatory behavior. As is shown in Figure 2, the use of compensatory strategies increased as a function of self-reported cognitive complaints. This increase was however much less pronounced for individuals who also reported many depressive symptoms as compared to the increase in compensatory behavior of their less depressed counterparts. 


\section{a. External scale}

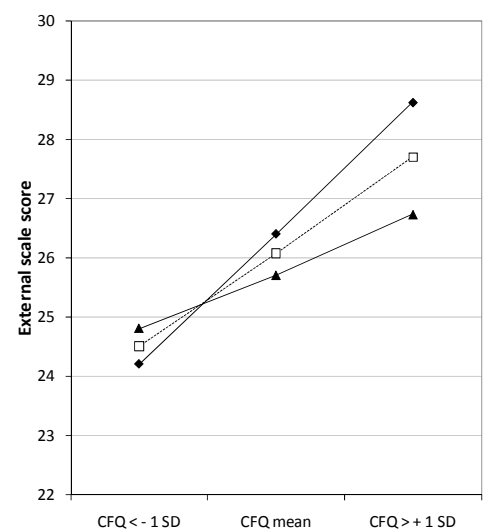

c. Internal scale

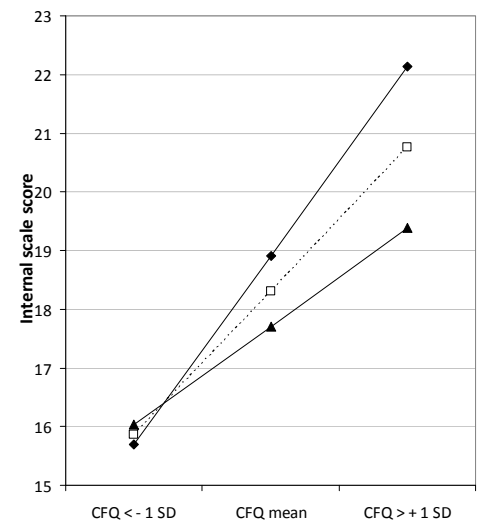

e. Reliance scale

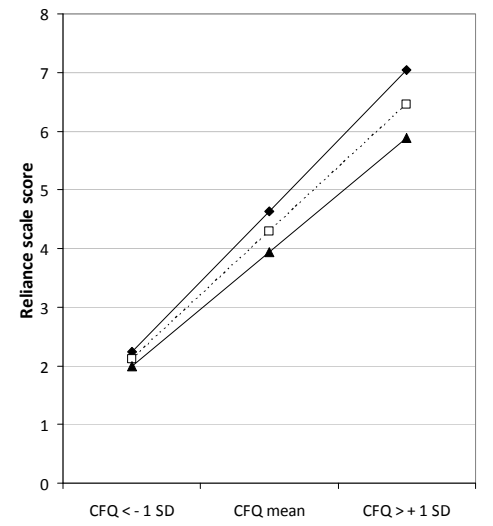

b. Effort scale

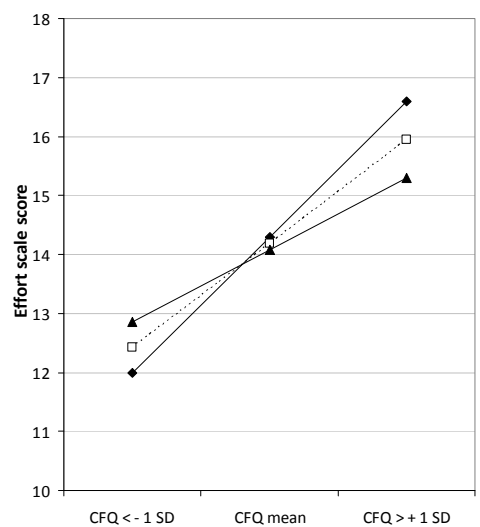

d. Time scale

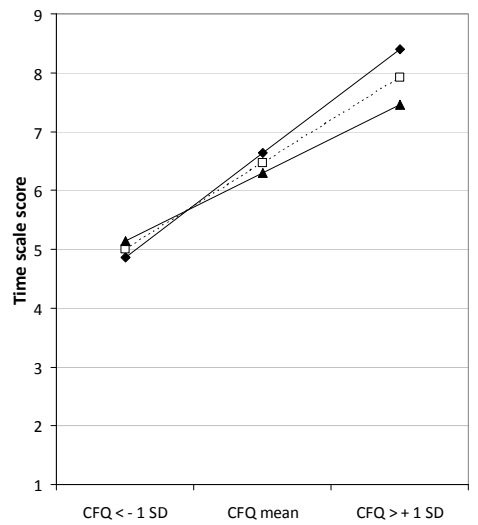

f. Change scale

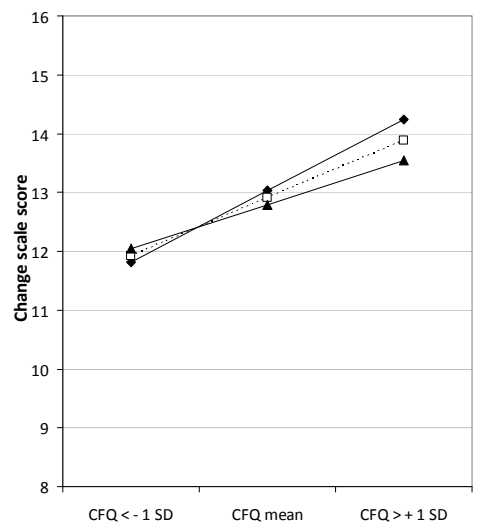

$\multimap$ CES-D <- 1 SD $\cdots \square \cdot \cdot$ CES-D mean $\longrightarrow$ CES-D > + 1 SD

Figure $\mathbf{2}$ Two-way interactions for CES-D and CFQ scores for all relevant MCQ subscales 


\section{Discussion}

Compensation is important for overall successful aging (Bäckman \& Dixon, 1992; Baltes \& Baltes, 1990), for example in the context of managing cognitive losses (Dixon, 1995; Dixon \& de Frias, 2004; Dixon et al., 2001). In order to gain further insight in individual adaptability to the consequences of cognitive aging, we investigated which factors contribute to everyday memory compensation in community dwelling older adults. We were specifically interested in the moderating influence of depressive symptoms in older adults on the relation between perceived cognitive deficits and compensatory behavior. We therefore carried out a cross-sectional study among 556 community dwelling older adults aged 50 years and older.

In line with previous research (Dixon et al., 2001), our results indicated that external aids (e.g., using shopping lists) were the most frequently used compensation strategies, followed by the investment of more effort (e.g., put in more effort in a conversation), the use of internal strategies (e.g., repeat telephone numbers), and investment of more time in everyday memory tasks (e.g., read a newspaper slowly). Although available in daily life of many older adults, the use of other people as memory aids (e.g., ask for help to remember people's names) was the least frequently used memory compensation strategy (see Figure 1).

In accordance with the theory of psychological compensation (Bäckman \& Dixon, 1992) and findings of a previous study (Garrett et al., 2010), our results indicated that the use of everyday memory compensatory strategies increased as a function of self-reported cognitive complaints. A salient finding was that this increase was much less pronounced for individuals who also reported many depressive symptoms. In other words, the presence of depressive symptoms in individuals with high levels of everyday cognitive complaints suppressed their compensatory behavior. Thus, although these people perceived many cognitive deficits, they do not optimally compensate for them. It has previously been suggested that people with depressive symptoms may not optimally adopt adaptive behavior in response to perceived or actual cognitive decline (Dixon et al., 2001). To our knowledge, our study is the first that indeed established such an association. It is well known that the presence of depressive symptoms in older adults is related to more subjective cognitive complaints (Dux et al., 2008; Kliegel \& Zimprich, 2005; Mol et al., 2008; Sachs-Ericsson et al., 2008; Zimprich et al., 2003), worse cognitive performance (Bierman et al., 2005; Dux et al., 2008; Zimprich et al., 2003), and worse functional outcome. Moreover, depressive symptoms are related to more pronounced cognitive decline over time (Comijs et al., 2004; Köhler et al., 2010; Paterniti et al., 2002; Zimprich et al., 2003), and a higher risk of developing dementia (Jorm, 2000). Our findings indicate that older adults with depressive symptoms are even more vulnerable in the context of cognitive aging than was thought until now. After all, they are 
not only at a higher risk of developing objective or subjective cognitive problems, but also do not optimally compensate for their problems spontaneously.

Like previous studies (De Frias et al., 2003; Dixon et al., 2001; McDougall, 1996; Ponds \& Jolles, 1996b), we also established significant effects of demographic variables on compensatory behavior. Older adults used more external aids, invested more time in daily memory tasks, and had a higher commitment to memory success. It seems thus that higher age is not only associated with more cognitive challenges (Craik \& Bialystok, 2006; Hertzog et al., 2003), but also with more attempts to compensate and a higher motivation to be successful in memory demanding situations. Women reported more frequent use of external aids and men more often relied on other people as memory aids. Low-educated individuals used more compensatory strategies than their high-educated counterparts. It has previously been suggested that high cognitive reserve (estimated by level of education) might be related to a more frequent use of compensatory strategies, which may result in a less pronounced age-related cognitive decline (Garrett et al., 2010; Stern, 2002, 2003). Yet, findings of our study as well as that of others (De Frias et al., 2003; Garrett et al., 2010) point to an opposite relation between educational level and compensatory behavior (i.e., lower educated individuals use more compensation strategies than higher educated individuals), which goes against the cognitive reserve theory (Stern, 2002, 2003). There are several explanations to account for these findings. Garrett and colleagues (2010) suggest that educational level may in fact be a weak estimate of cognitive reserve, which is supported by their findings that low educated individuals with high verbal IQ estimates use more compensation strategies than individuals with concordant levels of education and IQ. In our opinion another explanation may be more valid. Our results indicated that low educated individuals engage more often in compensatory behavior, but the compensation strategies that are used by them (i.e., use of external aids, and reliance on others as memory aids) are the least cognitively demanding ones. In other words, perhaps these specific forms of strategies are used to cope with a lack of cognitive reserve. If this hypothesis is correct, then higher educated individuals who have higher levels of cognitive reserves face fewer cognitive challenges that need to be compensated for and therefore report the use of fewer compensation strategies. In a crosssectional study design as used in most available studies on compensatory behavior, the causality of these associations remains however unclear. Longitudinal studies in which compensatory behavior is linked to the concept of cognitive reserve may clarify whether people who use many strategies indeed exhibit less cognitive impairment over time.

Aspects of metamemory (i.e., memory related anxiety and memory related sense of control) were also related to compensatory behavior. Individuals who perceived more stress and anxiety regarding their memory performance reported a more frequent use of all forms of compensation strategies, more change in com- 
pensatory behavior over the last years, and a higher commitment to memory success. They thus feel a higher necessity to conduct compensatory behavior in memory demanding situations as compared to individuals with little stress and anxiety regarding memory performance. Our findings are in line with those of previous studies (De Frias et al., 2003; McDougall, 1996), which revealed that metamemory and more specifically low memory self-efficacy (i.e., a compound of low capacity, low control and low stability in perceived memory functions) - is related to a more frequent use of memory compensation strategies. Furthermore, Garrett and colleagues (2010) also revealed significant positive associations between measures of perceived stress and compensatory behavior. However, they used a general stress measure, whereas we used a memory-specific measure for perceived anxiety and stress (Ponds \& Jolles, 1996b).

In conclusion, we found evidence that demographic variables, memory related anxiety and memory related sense of control have predictive value for the spontaneous use of memory compensation strategies in healthy community-dwelling older adults. More remarkable is our evidence that depressive symptoms in older adults with perceived cognitive deficits restrain everyday memory compensation. Our findings have important implications for both theoretical and practical aspects of the management of cognitive losses due to normal aging and gains further insight in constructs of successful aging. It may lead to the development of more specific and successful intervention programs for older adults with perceived cognitive deficits. It seems especially important to screen older adults with cognitive problems for depressive symptomatology and spontaneous compensatory behavior, and offer them more tailor made interventions to treat their problems, as they seem to be a vulnerable group in the context of cognitive aging. 


\section{References}

Aiken, L. S., \& West, S. G. (1991). Multiple regression: Testing and interpreting interactions. Newbury Park, California: Sage.

Albert, M. S., Jones, K., Savage, C. R., Berkman, L., Seeman, T., Blazer, D., \& Rowe, J. W. (1995). Predictors of cognitive change in older persons: MacArthur studies of successful aging. Psychology and Aging, 10, 578-589.

Bäckman, L., \& Dixon, R. A. (1992). Psychological compensation: a theoretical framework. Psychological Bulletin, 112, 259-283.

Baltes, P. B., \& Baltes, M. M. (1990). Psychological perspectives on successful aging: the model of selective optimization with compensation. In P. B. Baltes (Ed.), Successful aging: Perspectives from the behavioral sciences (pp. 1-34). Cambridge: Cambridge University Press.

Belsley, D. A., Kuh, E., \& Welsch, R. E. (1980). Regression diagnostics: Identifying influential data and sources of collinearity. New York: Wiley.

Bierman, E. J., Comijs, H. C., Jonker, C., \& Beekman, A. T. (2005). Effects of anxiety versus depression on cognition in later life. American Journal of Geriatric Psychiatry, 13, 686-693.

Blazer, D. G. (2006). Successful aging. American Journal of Geriatric Psychiatry, 14, 2-5.

Bouma, J., Ranchor, A. V., Sanderman, R., \& Van Sonderen, E. (1995). Measuring symptoms of depression using the CES-D: a manual [Het meten van symptomen van depressie met de CES-D: een handleiding]. Groningen: Noordelijk Centrum voor Gezondheidsvraagstukken, Rijksuniversiteit Groningen.

Broadbent, D. E., Cooper, P. F., FitzGerald, P., \& Parkes, K. R. (1982). The Cognitive Failures Questionnaire (CFQ) and its correlates. British Journal of Clinical Psychology, 21 (Pt 1), 1-16.

Collins, M. W., \& Abeles, N. (1996). Subjective memory complaints and depression in the able elderly. Clinical Gerontologist, 16, 29-54.

Comijs, H. C., van Tilburg, T., Geerlings, S. W., Jonker, C., Deeg, D. J., van Tilburg, W., \& Beekman, A. T. (2004). Do severity and duration of depressive symptoms predict cognitive decline in older persons? Results of the Longitudinal Aging Study Amsterdam. Aging Clinical and Experimental Research, 16, 226-232.

Commissaris, C. J., Jolles, J., Verhey, F. R., Ponds, R. W. H. M., Damoiseaux, V., \& Kok, G. J. (1993). Forgetful or demented? Who worries and why? [Vergeetachtig of dement? Wie maakt zich zorgen en waarom?]. Tijdschrift voor Gerontologie en Geriatrie, 24, 144-149.

Craik, F. I., \& Bialystok, E. (2006). Cognition through the lifespan: mechanisms of change. Trends in Cognitive Sciences, 10, 131-138.

Crowther, M. R., Parker, M. W., Achenbaum, W. A., Larimore, W. L., \& Koenig, H. G. (2002). Rowe and Kahn's model of successful aging revisited: positive spirituality--the forgotten factor. Gerontologist, 42, 613-620.

De Bie, S. E. (1987). Toward a standardization of questions concerning demographic variables in population studies [Standaardvragen 1987 - Voorstellen voor uniformering van vraagstellingen naar achtergrondkenmkernen en interviews]. Leiden, The Netherlands: Leiden University Press.

De Frias, C. M., \& Dixon, R. A. (2005). Confirmatory factor structure and measurement invariance of the Memory Compensation Questionnaire. Psychological Assessment, 17, 168-178.

De Frias, C. M., Dixon, R. A., \& Bäckman, L. (2003). Use of memory compensation strategies is related to psychosocial and health indicators. Journals of Gerontology Series B: Psychological Sciences and Social Sciences, 58, P12-22.

Depp, C. A., \& Jeste, D. V. (2006). Definitions and predictors of successful aging: a comprehensive review of larger quantitative studies. American Journal of Geriatric Psychiatry, 14, 6-20.

Dixon, R. A. (1995). Promoting competence through compensation. In L. A. Bond (Ed.), Promoting successful and productive aging (Vol. 1, pp. 220-238). Thousand Oaks, Calif: Sage Publications.

Dixon, R. A., \& Backman, L. (2005). Principles of compensation in cognitive neurorehabilitation. In D. T. Stuss \& G. Winocur (Eds.), Cognitive neurorehabilitation (Vol. 2, pp. 59-72). Cambridge: Cambridge University Press. 
Dixon, R. A., \& Bäckman, L. (1992). The concept of compensation in cognitive aging: the case of prose processing in adulthood. International Journal of Aging and Human Development, 36, 199-217.

Dixon, R. A., \& de Frias, C. M. (2004). The Victoria Longitudinal Aging Study: From characterizing cognitive aging to illustrating patterns and predictors of changes in memory compensation. Aging, Neuropsychology, and Cognition, 11, 346-376.

Dixon, R. A., \& de Frias, C. M. (2007). Mild memory deficits differentially affect 6-year changes in compensatory strategy use. Psychology and Aging, 22, 632-638.

Dixon, R. A., de Frias, C. M., \& Bäckman, L. (2001). Characteristics of self-reported memory compensation in older adults. Journal of Clinical and Experimental Neuropsychology, 23, 650-661.

Dux, M. C., Woodard, J. L., Calamari, J. E., Messina, M., Arora, S., Chik, H., \& Pontarelli, N. (2008). The moderating role of negative affect on objective verbal memory performance and subjective memory complaints in healthy older adults. Journal of the International Neuropsychological Society, 14, $327-$ 336.

Evans, J. J., Wilson, B. A., Needham, P., \& Brentnall, S. (2003). Who makes good use of memory aids? Results of a survey of people with acquired brain injury. Journal of the International Neuropsychological Society, 9, 925-935.

Gallo, J. J., Rebok, G. W., Tennsted, S., Wadley, V. G., \& Horgas, A. (2003). Linking depressive symptoms and functional disability in late life. Aging and Mental Health, 7, 469-480.

Garrett, D. D., Grady, C. L., \& Hasher, L. (2010). Everyday memory compensation: the impact of cognitive reserve, subjective memory, and stress. Psychology and Aging, 25, 74-83.

Glisky, E. L., \& Glisky, M. L. (2005). Memory rehabilition in the elderly. In D. T. Stuss, G. Winocur \& I. H. Robertson (Eds.), Cognitive neurorehabilitation (pp. 347-361). Cambridge: Cambridge University Press.

Hertzog, C., Dixon, R. A., Hultsch, D. F., \& MacDonald, S. W. (2003). Latent change models of adult cognition: are changes in processing speed and working memory associated with changes in episodic memory? Psychology and Aging, 18, 755-769.

Hohaus, L. (2007). Remembering to age successfully: evaluation of a successful aging approach to memory enhancement. International Psychogeriatrics, 19, 137-150.

Jorm, A. F. (2000). Is depression a risk factor for dementia or cognitive decline? A review. Gerontology, 46, 219-227.

Kliegel, M., \& Zimprich, D. (2005). Predictors of cognitive complaints in older adults: a mixture regression approach. European Journal of Ageing, 2, 13-23.

Köhler, S., Van Boxtel, M. P., van Os, J., Thomas, A. J., O’Brien, J. T., Jolles, J., Verhey, F. R., \& Allardyce, J. (2010). Depressive Symptoms and Cognitive Decline in Community-Dwelling Older Adults. Journal of the American Geriatrics Society, 58, 873-879.

McDonald-Miszczak, L., Hertzog, C., \& Hultsch, D. F. (1995). Stability and accuracy of metamemory in adulthood and aging: a longitudinal analysis. Psychology and Aging, 10, 553-564.

McDougall, G. J. (1995). Memory Self-Efficacy and Strategy use in succesful elders. Educational Gerontology, 21, 357-373.

McDougall, G. J. (1996). Predictors of the use of memory improvement strategies by older adults. Rehabilitation Nursing, 21, 202-209.

Merckelbach, H., Muris, P., Nijman, H., \& De Jong, P. (1996). Self-reported cognitive failures and neurotic symptomatology. Personality and Individual Differences, 20, 715-724.

Minett, T. S., Da Silva, R. V., Ortiz, K. Z., \& Bertolucci, P. H. (2008). Subjective memory complaints in an elderly sample: a cross-sectional study. International Journal of Geriatric Psychiatry, 23, 49-54.

Mol, M. E., Ruiter, R. A., Verhey, F. R., Dijkstra, J., \& Jolles, J. (2008). A study into the psychosocial determinants of perceived forgetfulness: implications for future interventions. Aging and Mental Health, 12, 167-176.

Mol, M. E., Van Boxtel, M. P., Willems, D., Verhey, F. R., \& Jolles, J. (2009). Subjective forgetfulness is associated with lower quality of life in middle-aged and young-old individuals: a 9-year follow-up in older participants from the Maastricht Aging Study. Aging and Mental Health, 13, 699-705. 
Oxman, T. E., Barrett, J. E., Sengupta, A., \& Williams, J. W., Jr. (2000). The relationship of aging and dysthymia in primary care. American Journal of Geriatric Psychiatry, 8, 318-326.

Paganini-Hill, A., \& Clark, L. J. (2007). Preliminary assessment of cognitive function in older adults by clock drawing, box copying and narrative writing. Dementia and Geriatric Cognitive Disorders, 23, 74-81.

Paganini-Hill, A., Clark, L. J., Henderson, V. W., \& Birge, S. J. (2001). Clock drawing: analysis in a retirement community. Journal of the American Geriatrics Society, 49, 941-947.

Paterniti, S., Verdier-Taillefer, M. H., Dufouil, C., \& Alperovitch, A. (2002). Depressive symptoms and cognitive decline in elderly people. Longitudinal study. British Journal of Psychiatry, 181, 406-410.

Ponds, R. W., \& Jolles, J. (1996a). Memory complaints in elderly people: the role of memory abilities, metamemory, depression, and personality. Educational Gerontology, 22, 341-357.

Ponds, R. W., \& Jolles, J. (1996b). The Abridged Dutch Metamemory in Adulthood (MIA) Questionnaire: structure and effects of age, sex, and education. Psychology and Aging, 11, 324-332.

Riley, M. W. (1998). Successful aging. Gerontologist, 38, 151.

Rowe, J. W., \& Kahn, R. L. (1987). Human aging: usual and successful. Science, 237, 143-149.

Rowe, J. W., \& Kahn, R. L. (1997). Successful aging. Gerontologist, 37, 433-440.

Sachs-Ericsson, N., Joiner, T., \& Blazer, D. G. (2008). The influence of lifetime depression on self-reported memory and cognitive problems: Results from the National Comorbidity Survey-Replication. Aging and Mental Health, 12, 183-192.

Salthouse, T. A. (1996). The processing-speed theory of adult age differences in cognition. Psychological Review, 103, 403-428.

Schulz, R., \& Heckhausen, J. (1996). A life span model of successful aging. The American Psychologist, 51, 702-714.

Stern, Y. (2002). What is cognitive reserve? Theory and research application of the reserve concept. Journal of the International Neuropsychological Society, 8, 448-460.

Stern, Y. (2003). The concept of cognitive reserve: a catalyst for research. Journal of Clinical and Experimental Neuropsychology, 25, 589-593.

UNESCO (1976). International Standard Classification of Education (ISCED). Paris: United Nations Educational, Scientific and Cultural Organisation.

Van der Elst, W., Hoogenhout, E. M., Dixon, R. A., De Groot, R. H. M., \& Jolles, J. (in press). The Dutch Memory Compensation Questionnaire: psychometric properties and regression-based norms. Assessment.

Wilson, B. A. (2000). Compensating for cognitive deficits following brain injury. Neuropsychology Review, 10, 233-243.

Wilson, B. A., \& Watson, P. C. (1996). A practical framework for understanding compensatory behaviour in people with organic memory impairment. Memory, 4, 465-486.

Zimprich, D., Martin, M., \& Kliegel, M. (2003). Subjective cognitive complaints, memory performance, and depressive affect in old age: a change-oriented approach. International Journal of Aging and Human Development, 57, 339-366. 
Everyday memory compensation, cognitive reserve, and change in subjective and objective memory:

a 12-year longitudinal investigation based on the Maastricht Aging Study 


\begin{abstract}
This study presents a longitudinal investigation of the effects of everyday memory compensation on trajectories of subjective and objective memory, and its relation to cognitive reserve (as indicated by educational level). A total of 231 healthy adults aged 50 years and older were included. The participants were tested four times within twelve years. Linear mixed models were used to analyze the data. The results indicate that individuals with high educational levels (i.e., high levels of cognitive reserve) are not protected against decline in subjective and objective memory over time as a function of compensatory behavior. Furthermore, independent of educational level, similar trajectories of change in subjective and objective memory as a function of strategy use were identified. These findings do not support the prevailing cognitive reserve theory. Moreover, they show that spontaneous compensation merely leads to similar trajectories of change, but not to improvement in subjective or objective memory. This is in marked contrast to the results obtained with formal training of compensatory behavior.
\end{abstract}




\section{Introduction}

Aging is characterized by changes in particular cognitive functions. Due to structural and functional changes in the brain (Raz, 2000), a decline occurs in declarative memory (Hess, 2005; Zacks, Hasher, \& Li, 2000), speed of information processing (Salthouse, 1996), and inhibitory or executive functions (Craik \& Bialystok, 2006; Craik \& Grady, 2002; Van Hooren et al., 2007). Furthermore, and in addition to a decreased performance on objective cognitive tasks, many aging individuals complain about diminishing cognitive capacities and forgetfulness (Gino et al., 2010; Minett, Da Silva, Ortiz, \& Bertolucci, 2008; Ponds, Commissaris, \& Jolles, 1997). An important question in this context is how to minimize the impact of age-related changes in brain functions and cognitive performance on daily life functioning. Many researchers have focused their attention on 'successful aging', which encompasses optimal physical functioning and health combined with high levels of psychosocial and cognitive functioning (Blazer, 2006; Depp \& Jeste, 2006; Rowe \& Kahn, 1987, 1997).

Compensation is considered an important aspect of successful aging (Baltes \& Baltes, 1990; Depp \& Jeste, 2006; Garrett, Grady, \& Hasher, 2010). The topic of compensation for cognitive losses has received considerable attention in aging research (De Frias, Dixon, \& Bäckman, 2003; Dixon, de Frias, \& Bäckman, 2001; Garrett et al., 2010; Van der Elst, Hoogenhout, Dixon, De Groot, \& Jolles, in press), and in neurorehabilitation (Dixon \& Backman, 2005; Wilson, 2000; Wilson \& Watson, 1996). Several studies investigated functional compensation by examining agerelated changes in brain activity in, for example, the prefrontal regions by means of imaging techniques (Cabeza, 2002; Reuter-Lorenz \& Cappell, 2008). On a behavioral level, four different forms or mechanisms of psychological compensation can be distinguished, namely: 1) remediation (i.e., investing more time or effort in overcoming a loss), 2) substitution (i.e., developing new or using latent skills instead of declining or ineffective ones), 3) accommodation (i.e., adjusting goals and criteria to be more concordant with current demands and skills), and 4) assimilation (i.e., modifying environmental demands or expectations of others) (Bäckman \& Dixon, 1992; Dixon et al., 2001). Compensation at the behavioral level (i.e., psychological compensation) is thought to become operative when specific behavioral capacities are lost or reduced below the standard that is required for adequate everyday functioning (Bäckman \& Dixon, 1992; Baltes \& Baltes, 1990; Dixon, 1995).

A commonly held assumption is that compensatory behaviors are mechanisms that account for an individual's adaptation to (age-related) cognitive losses. It is thus assumed that the implementation of everyday memory compensation strategies allow individuals to overcome or mitigate their perceived or actual age-related cognitive losses (Dixon \& de Frias, 2004), and thus increase their chances to age successfully (Bäckman \& Dixon, 1992; Baltes \& Baltes, 1990). This assumption un- 
derlies the development and evaluation of many cognitive interventions for older adults. Indeed, despite the widespread variations in types of interventions, most of these found evidence that subjective and objective cognitive functions can be improved or prevented from relapsing by learning, training, and implementing compensatory techniques. Such effects are mainly task and domain specific, but can be maintained for a considerable amount of time (Ball et al., 2002; Floyd \& Scogin, 1997; Glisky \& Glisky, 2005; Kramer \& Willis, 2002; Rebok, Carlson, \& Langbaum, 2007; Stigsdotter Neely, 2000; Verhaeghen, Marcoen, \& Goossens, 1992). There is thus evidence that training of everyday memory compensatory behavior does contribute to a better adaptation to the consequences of cognitive aging. Hence, it seems to be of high importance to pay attention to everyday memory compensation to gain further insight into mechanisms of successful cognitive aging.

Compensation has been linked to the concept of 'cognitive reserve.' It has been argued that individuals with high levels of cognitive reserve (as reflected by, for example, their educational level) may exhibit less cognitive impairment over time as compared to people with lower levels of cognitive reserve (Stern, 2002, 2003), although findings on this topic are inconsistent (Anstey \& Christensen, 2000; Van Dijk, Van Gerven, Van Boxtel, Van der Elst, \& Jolles, 2008). This might in part be explained by more efficient compensatory mechanisms in higher educated individuals (Garrett et al., 2010; Stern, 2002, 2003). This statement is supported by a growing amount of imaging research that links functional compensation to differences in age-related cognitive decline (Cabeza, 2002; Reuter-Lorenz \& Cappell, 2008). Recently, Garrett and colleagues (2010) linked psychological compensation as measured by selfreports of everyday memory compensation to the concept of cognitive reserve. These authors hypothesized that individuals with a higher level of cognitive reserve (i.e., a higher level of education) report the use of more everyday memory compensatory strategies to meet an age-related increase in cognitive demands. In their opinion, higher educated individuals will exhibit a less pronounced age-related cognitive decline as a result of their increased everyday memory compensatory behavior (Garrett et al., 2010). Several cross-sectional studies, that investigated the covariates of everyday memory compensation, point however to the opposite conclusion. Everyday memory compensation seems to occur more frequently in less welleducated individuals as compared to their higher educated counterparts (De Frias et al., 2003; Garrett et al., 2010; Hoogenhout, Van der Elst, De Groot, \& Jolles, under review). These findings suggest that less well-educated individuals engage more often in everyday memory compensatory behaviors in order to deal with a lack of cognitive reserve and to cope with deteriorating cognitive functions. Until now, most studies on everyday memory compensation were cross-sectional. It has been argued before that longitudinal studies (in which compensatory behavior is linked to the concept of cognitive reserve) are needed to conduct a more direct test of the 
claim that people who engage in compensatory behaviors indeed exhibit less agerelated cognitive decline (Hoogenhout et al., under review).

Thus, psychological compensation is considered a mechanism that may contribute to successful (cognitive) aging. It has been hypothesized that it is related to the concept of cognitive reserve (i.e., individuals with high levels of cognitive reserve may exhibit less cognitive change over time, in part because they implement compensatory strategies). The present study investigates the long-term consequences of everyday memory compensation behavior for changes in subjective and objective memory in older adults. Specific attention is paid to the moderating influence of educational level, which is considered a proxy of cognitive reserve in this context. For this purpose, data from 231 cognitively healthy participants aged 50 years and older were used. They participated in the Maastricht Aging Study (MAAS), a large longitudinal study into the determinants of cognitive aging (Jolles, Houx, Van Boxtel, \& Ponds, 1995). Everyday memory compensation was measured at baseline. Subjective memory and objective memory were measured at baseline and again on four repeated occasions within twelve years.

\section{Methods}

\section{Participants and procedure}

Baseline measurements of MAAS were conducted between 1993 and 1996 (Jolles et al., 1995). Participants were recruited from a regional registration network of general practitioners (Metsemakers, Hoppener, Knottnerus, Kocken, \& Limonard, 1992). Participants with a medical condition that could interfere with cognitive functioning were excluded (i.e., cerebrovascular disease, chronic neurological pathology, mental retardation, psychopathology, or chronic psychotropic drug use). A total sample of $N=1,823$ cognitively intact individuals were included. Participants were stratified for three demographic variables that are known to affect cognitive functioning, namely age (ranging from $25 \pm 1$ up to $80 \pm 1$ years), gender, and educational level (ranging from $1=$ primary education, to $8=$ university degree) (De Bie, 1987). Participants were tested in four different panels. All participants filled in several questionnaires and their cognitive abilities were tested. The Mini-Mental State Examination (MMSE; Folstein, Folstein, \& McHugh, 1975) was administered to participants aged 50 years and older. The medical ethics committee of the Maastricht University Medical Centre approved the study and all participants gave their informed consent. More details on the design and rationale of the MAAS have been described elsewhere (Jolles et al., 1995).

In the present study, we only included individuals who were aged 50 years and older at baseline. This was done for several reasons. First, everyday memory com- 
pensation behavior tends to occur at an older age (De Frias et al., 2003; McDougall, 1996; Ponds \& Jolles, 1996; Van der Elst et al., in press). Second, the nature and prevalence of subjective and objective memory problems differ for older and younger adults (Anstey \& Christensen, 2000; Gino et al., 2010; Ponds et al., 1997). Third, the interval between baseline and the first follow-up in the MAAS differed as a function of baseline age (i.e., six years for participants who were younger than 50 at baseline and three years for participants who were older than 50 at baseline) (Jolles et al., 1995). A total sample of $N=996$ participants was aged 50 years or older at baseline. The data of 12 people were excluded because they had MMSE scores of 24 or lower, which is indicative of dementia (Folstein et al., 1975). The Strategy subscale of the Metamemory in Adulthood Questionnaire (MIA; Dixon, Hultsch, \& Hertzog, 1988; Ponds \& Jolles, 1996) was only administered to participants who were included in the first of four panels in the MAAS. Consequently, data from $N=231$ participants who filled in the Strategy subscale were available, which was the final sample for the current study.

Table 1 shows the distribution of gender and educational level per measurement occasion as a function of age group and for the total sample. The ethnic background of all participants was Caucasian and all were native Dutch speakers. The mean $(S D)$ IQ score was estimated with a shortened version of the Groningen Intelligence Test (GIT; Luteijn \& van der Ploeg, 1983), was 114.7 (SD = 12.6). Level of education (LE) was measured by classifying it in one of eight groups ranging from 1) primary education, to 8) university degree (De Bie, 1987). This LE system is often used in The Netherlands (De Bie, 1987) and is comparable with the International Standard Classification of Education (UNESCO, 1976). By means of a median split procedure, LE was classified in two groups, i.e., those with at most secondary education (LE low), and those above that level (LE high).

The first and second follow-up measurements were conducted three and six years after baseline, respectively. The third follow-up measurement, in which only self-report questionnaires (i.e., the MIA, see below) but no cognitive tests (i.e., VVLT, see below) were included, was conducted nine years after baseline. The fourth follow-up measurement, with mainly cognitive tests (but without the MIA), was carried out twelve years after baseline. Attrition rates between baseline and the first, second, and third follow-up measurement occasions were 31.2, 39.0, and 33.3 percent, respectively, for the sample that was administered the MIA. For the sample that was administered the VVLT, attrition rates between baseline and the first, second, and fourth follow-up measurement occasions were 21.6, 36.8, and 47.6 percent, respectively. 

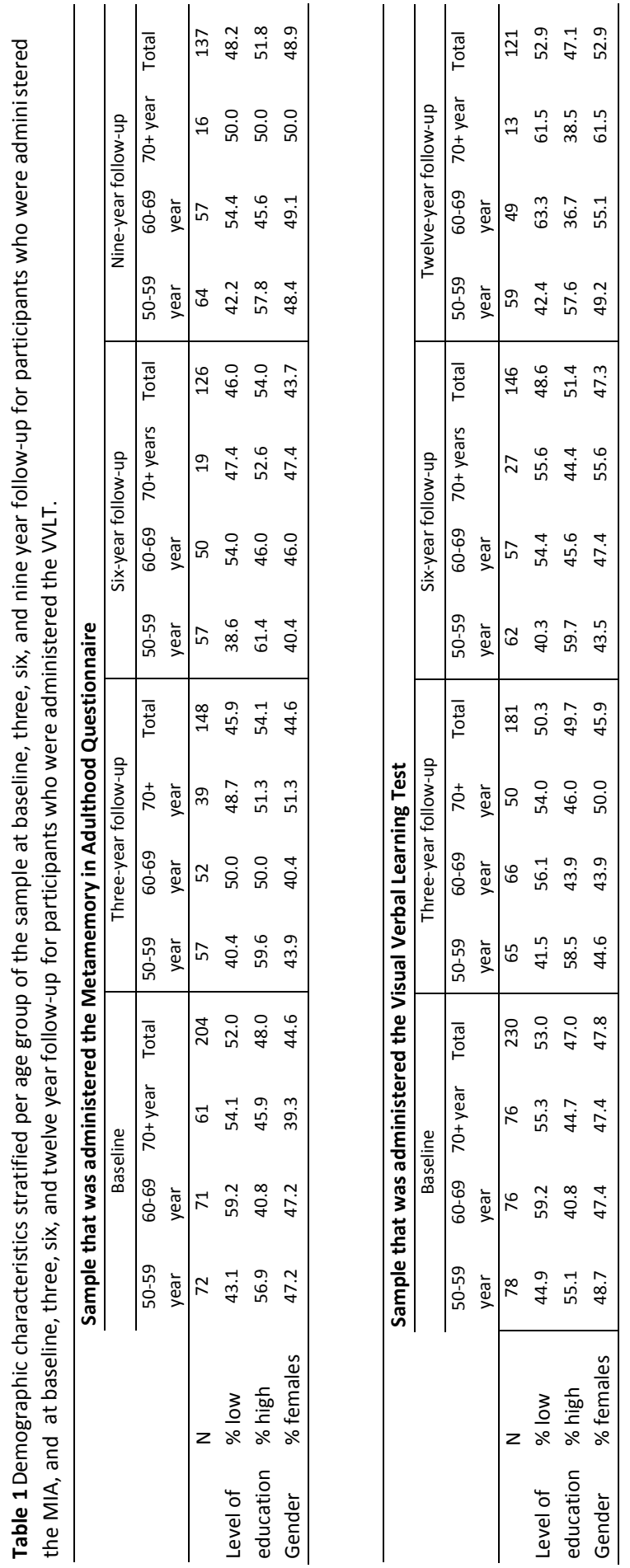


\section{Measures}

Everyday memory compensation behavior was measured with the Strategy subscale of the abridged Metamemory in Adulthood questionnaire (MIA; Ponds \& Jolles, 1996). The Strategy subscale can be further divided into an Internal and an External subscale, which are considered two different forms of substitution mechanisms that differ in the extent to which they are cognitively demanding (Dixon \& de Frias, 2004). Both scales consist of eight statements concerning the use of internal compensation strategies (e.g., making mental images or pictures in order to remember something) and external compensation strategies (e.g., writing shopping lists). All statements are answered on a 5-point Likert scale (ranging from $1=$ 'never' to $5=$ 'always'). Higher scores thus indicate the use of more internal or external strategies to compensate for everyday memory failures.

Subjective memory functioning was measured with the Capacity subscale of the abridged MIA (Ponds \& Jolles, 1996) This subscale contains twelve items concerning one's perceived memory capacity (e.g., I misplace things more frequently now than when I was younger). Again, all statements could be answered on a 5-point Likert scale (ranging from 1 = 'strongly agree' to 5 = 'strongly disagree'). Higher scores thus indicate higher perceived memory capacity.

Objective memory functioning was measured with the Visual Verbal Learning Test (VVLT; Van der Elst, Van Boxtel, van Breukelen, \& Jolles, 2005), which is a Dutch version of the Rey VVLT that measures verbal memory (Lezak, Howieson, \& Loring, 2004). In this test, fifteen low-associative words were presented one by one on a computer screen for one second in a fixed order and with a one-second time interval. Participants were asked to recall as many words as possible. There was no restriction on the output order. This procedure was repeated four more times. Twenty minutes after the last presentation, participants were asked again to recall as many words as possible (note that the participants were not informed beforehand that they would have to recall the words later). Parallel VVLT versions were used at each measurement occasion, because previous research revealed that there are pronounced practice effects in verbal memory tests, even after a test-retest interval of several years (Schmidt, 1996). The total score of all five trials (VVLT total recall 1-5) was used as a measure of the ability to learn new information. The delayed recall score (VVLT delayed recall) was used to measure the ability to consolidate information and to retrieve it from memory. Both VVLT scores were used as dependent measures in the present study.

\section{Statistical Analyses}

Linear mixed models (LMM) analyses were used to evaluate the influence of everyday memory compensation behavior on age-related changes in subjective and objective memory functioning over time. Predictors were age, age $^{2}$, gender, educa- 
tional level, time of measurement, MIA Strategy Internal and MIA Strategy External scores. We were specifically interested in the effect of the Educational level $x$ Strategy $x$ Time of measurement interaction to investigate whether changes in subjective and objective memory differed as a function of strategy use for people with a low and high educational level. In addition to this three-way interaction, all two-way interaction terms, which could be constructed with the terms that constituted the three-way interaction, were included in the full model to make the model hierarchical. Gender was also included in the full model because it is an important covariate of changes in cognitive functions (Anstey \& Christensen, 2000).

All models were estimated with restricted maximum likelihood (REML), rather than with maximum likelihood (ML). This was done because REML is better for estimating the covariance matrix and the standard errors of fixed effects. The mixed model assumed fixed effects of all predictors and an unstructured $4 \times 4$ covariance matrix for the repeated measures. This is equivalent to the multivariate method for ANOVA of repeated measures for complete data. Unlike repeated measures ANOVA, LMM analysis can handle missing data without requiring either imputation of missing values or list-wise deletion of persons with a missing value (Verbeke $\&$ Molenberghs, 2000). Age was centered (age = calendar age -65 ) before computing quadratic terms and interactions to avoid multicollinearity (Marquardt, 1980). Gender was dummy coded with male $=1$ and female $=0$. Time of measurement was dummy coded with three dummies (first follow-up, second follow-up, and third follow-up) with the baseline measurement as reference category. Level of education was coded in two levels (i.e., LE low $=0$ and LE high $=1$ ). The full models were then reduced in a stepwise hierarchical manner by eliminating the least significant predictor if its two-tailed $p$-value was above .01 . No predictor was removed from the model as long as it was also included in a higher-order term. Linearity, normality of the residuals (normal distribution of the residuals for the four measurement moments), and homoscedasticity (homogenous variance of the residuals over the range of the predicted scores, for the four measurement occasions) were examined graphically and analytically.

All analyses were conducted using PASW 18.0 for Windows. In order to avoid Type I errors that could be caused by multiple testing an alpha level of .01 was used in all analyses. All figures were made in R 2.11.1 (R-Development-Core-Team, 2010) for Linux.

\section{Results}

Compensation, educational level, and changes in subjective and objective memory Model assumptions of linearity, normality of the residuals, and homoscedasticity were met. None of the Strategy $x$ Educational level $x$ Time of measurement interac- 
tion terms were significant in the final model for any of the outcome measures (all $p$-values $>.01$ ). Thus there were no significant differences in the changes in subjective and objective memory over time as a function of strategy use for less welleducated and highly educated people. In addition, after removing the three-way interaction terms from the model, none of the two-way interactions were significant. Consequently, changes in subjective and objective memory over time did not differ as a function of the use of external or internal strategies, or as a function of educational level. After removing all two-way interactions from the model, we established a main effect of Strategy External as well as gender on MIA Capacity. Individuals who used fewer external memory compensation strategies and women reported a higher perceived memory capacity as compared to people who used more external memory compensation strategies and men. For the VVLT immediate recall 1-5 score and the VVLT delayed recall score, we only found significant effects of age, gender, and time of measurement (and of level of education for the VVLT immediate recall 1-5). Thus, no effects of Strategy Internal on any of the outcome variables were established. Strategy External only exhibited a significant main effect on MIA Capacity. The final models of the hierarchical linear mixed model analyses are presented in Table 2.

Table 2 Coefficients, standard errors, T-values, and their significance levels for the final linear mixed models with subjective and objective memory functioning as outcome variables.

\begin{tabular}{llcccc}
\hline Measure & Variable & Estimate & Std. Error & T & Sig. \\
\hline MIA Capacity & (constant) & 3.591 & .172 & 20.892 & $<.001$ \\
& Gender & -.187 & .071 & -2.647 & .009 \\
& Strategy External & -.019 & .006 & -3.308 & .001 \\
VVLT 1-5 & (constant) & 41.477 & .871 & 47.638 & $<.001$ \\
& Age & -.427 & .055 & -7.703 & $<.001$ \\
& Gender & -4.677 & .980 & -4.772 & $<.001$ \\
& LE & 3.031 & .982 & 3.087 & .002 \\
& Follow-up 3 years & 3.777 & .594 & 6.356 & $<.001$ \\
& Follow-up 6 years & 5.870 & .660 & 8.898 & $<.001$ \\
& Follow-up 12 years & 5.006 & .655 & 7.642 & $<.001$ \\
& (constant) & 8.880 & .241 & 36.841 & $<.001$ \\
& Age & -.123 & .018 & -6.955 & $<.001$ \\
& Gender & -1.262 & .316 & -3.993 & $<.001$ \\
& Follow-up 3 years & 1.086 & .193 & 5.629 & $<.001$ \\
& Follow-up 6 years & 1.451 & .189 & 7.661 & $<.001$ \\
& Follow-up 12 years & .945 & .208 & 4.536 & $<.001$ \\
\hline
\end{tabular}

Note. $\mathrm{MIA}=$ Metamemory in Adulthood questionnaire, VVLT = Visual Verbal Learning Test, LE $=$ Level of Education. A significance level of .01 was used in all analyses.

The full models included age, age ${ }^{2}$, gender, LE, first follow-up, second follow-up, third follow-up, Strategy Internal, Strategy External, Strategy Internal $x$ follow-up 1, Strategy Internal $x$ follow-up 2, Strategy Internal $x$ follow-up 3, Strategy External $x$ follow-up 1, Strategy External $x$ follow-up 2, Strategy External $x$ follow-up 3, Strategy Internal x Strategy External, Strategy Internal x LE, Strategy External x LE, Strategy Internal x LE x follow-up 1, Strategy Internal x LE x follow-up 2, Strategy Internal x LE x follow-up 3, Strategy External x LE x follow-up 1, Strategy External x LE x follow-up 2, Strategy External x LE x follow-up 3. 

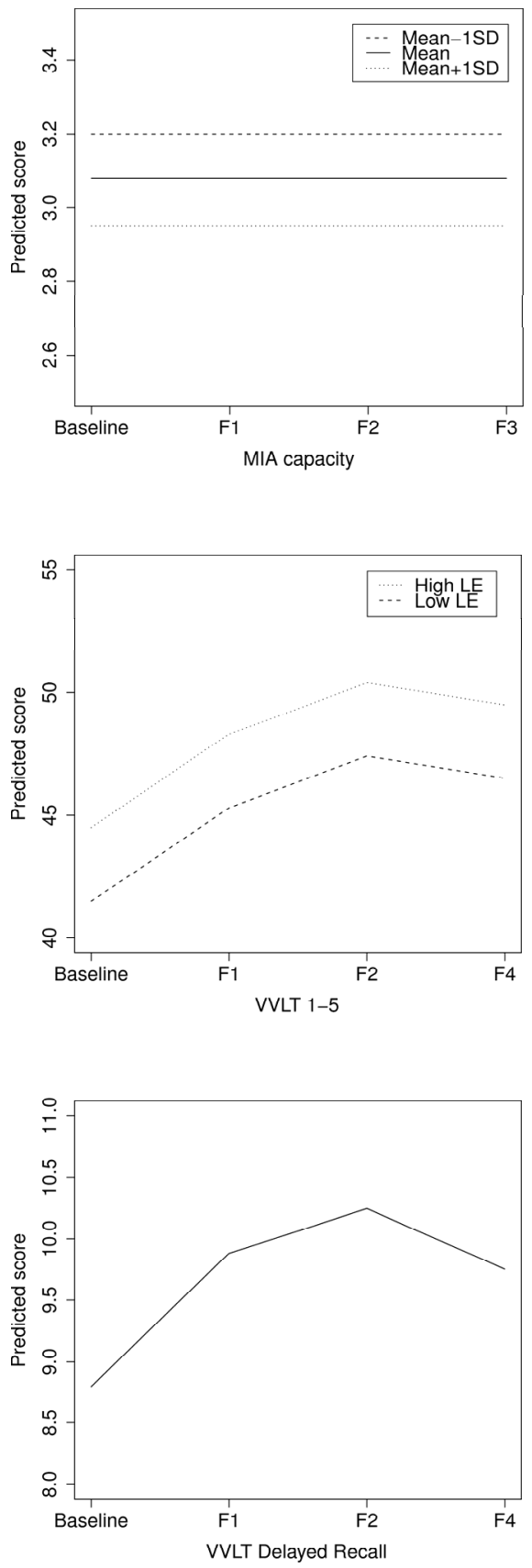

a. MIA Capacity score as a function of Strategy External (mean $+/-1 S D)$

b. VVLT 1-5 for low and high educated participants
c. VVLT delayed recall

Figure 1 Predicted scores for MIA Capacity (a), VVLT immediate recall trial 1-5 (b), and VVLT delayed recall (c) per measurement occasion for women aged 65 years. 
The results are graphically shown in Figure 1. Figure 1a presents the predicted MIA Capacity scores per measurement occasion for three Strategy External groups (i.e., Mean Strategy External score, Mean Strategy External score - $1 S D$ and Mean Strategy External score $+1 S D$ ). Figure $1 \mathrm{~b}$ presents the predicted VVLT immediate recall trial 1-5 scores per measurement occasion for participants with a low and high level of education. Figure 1c present the predicted VVLT delayed recall scores per measurement occasion. Note that the predicted scores for objective memory functioning (i.e., VVLT immediate recall 1-5 and VVLT delayed recall) increased as a function of measurement occasion. This suggests that practice effects have occurred (see the Discussion).

\section{Discussion}

In the present study a longitudinal investigation of the consequences of everyday memory compensation on trajectories of subjective and objective memory over time was carried out. Specific attention was paid to the moderating influence of educational level (a proxy of cognitive reserve) on compensatory behavior and cognitive functioning. Data from 231 cognitively healthy participants aged 50 years and older who participated in the Maastricht Aging Study (MAAS) were used (Jolles et al., 1995). Compensation is often considered an important mechanism that accounts for the adaptation to age-related cognitive losses. Thus, at least in theory, by implementating everyday memory compensatory behaviors, individuals might be able to overcome or mitigate perceived or actual cognitive losses (Bäckman \& Dixon, 1992; Baltes \& Baltes, 1990; Dixon, 1995; Dixon \& de Frias, 2004).

The extent to which compensation can be seen as a key mechanism of successful aging is the subject of an ongoing debate. It has been suggested previously that compensation is related to cognitive reserve (Garrett et al., 2010; Stern, 2002, 2003). With respect to functional compensation (i.e., maximizing performance by using alternative brain structures or networks) there is growing evidence for this theory (Cabeza, 2002; Reuter-Lorenz \& Cappell, 2008; Stern, 2002). Concerning psychological compensation (Bäckman \& Dixon, 1992) it has been hypothesized that individuals with high levels of cognitive reserve exhibit a less pronounced cognitive decline because they implement many compensatory strategies in everyday memory demanding situations (Garrett et al., 2010). Findings from cross-sectional studies (De Frias et al., 2003; Garrett et al., 2010; Hoogenhout et al., under review) point however to the opposite conclusion. Individuals with low educational levels engage more often in everyday memory compensatory behaviors than their higher educated counterparts, perhaps as a consequence of their lack of cognitive reserve (Hoogenhout et al., under review). 
The results of this longitudinal study showed no significant Time of measurement $x$ Strategy $x$ Educational level interaction terms. Thus, our results do not provide evidence for the hypothesis that individuals with high levels of cognitive reserve (as estimated by their educational level) exhibit less cognitive decline over time in subjective and objective memory functioning as a function of everyday memory compensatory behavior (Garrett et al., 2010). Furthermore, results showed no significant effects of any Time of measurement $x$ Strategy interaction terms on any of the outcome variables for subjective or objective memory functioning. Thus, our findings indicate that changes in subjective and objective memory over time are not affected by spontaneous everyday memory compensatory behavior. This is in marked contrast with findings of studies that investigate the effects of cognitive interventions in older adults. Many of these interventions focused on increasing compensatory behavior in older adults and enhancing their use of everyday mnemonic strategies. Positive (but mainly task and domain specific) effects on subjective and objective cognitive functioning, which can be maintained over a considerable period, are often the result (see for example Cavallini, Pagnin, \& Vecchi, 2003; Derwinger, Stigsdotter Neely, \& Backman, 2005; Rasmusson, Rebok, Bylsma, \& Brandt, 1999; Scogin, Prohaska, \& Weeks, 1998; Stigsdotter Neely, 2000; Troyer, 2001; Valentijn et al., 2005). This indicates therefore that there is evidence that formal training of everyday memory compensatory behavior results in positive effects on cognitive functioning of older adults. This finding is in line with the commonly held assumption that compensation leads to more successful (cognitive) aging (Bäckman \& Dixon, 1992; Baltes \& Baltes, 1990; Dixon \& de Frias, 2004; Dixon et al., 2001). The findings of our study indicate however that this is not the case for spontaneous compensatory behavior, i.e., when individuals are not actively stimulated to use strategies, such as was the case in our study. Apparently, spontaneous compensation does not lead to a less pronounced decline in subjective and objective memory. Perhaps this is a consequence of the fact that spontaneous compensation occurs only in individuals in whom some perceived or actual deficit is already present (Bäckman \& Dixon, 1992). In our study population, changes in subjective and objective memory were equally pronounced in individuals who used many compensatory strategies compared to those who used fewer compensatory strategies. At least, decline was not more pronounced in individuals who reported the use of many compensatory strategies. This might be an indication that everyday memory compensation slows down the cognitive aging process in individuals in whom perceived or actual deficits are already present. Further research is however needed.

The results of this study also point to a significant main effect of gender and Strategy External on perceived memory capacity (as measured with the MIA Capacity subscale). In line with previous research, women report higher memory capacity (Ponds \& Jolles, 1996). Furthermore, in our study individuals who use few external 
memory compensation strategies report higher perceived memory capacity. This offers further evidence that the presence of a perceived deficit is a necessary prerequisite of compensatory behavior. This is line with the theory of psychological compensation that states that compensation is only likely to occur in individuals with a certain degree of a perceived or actual deficit (Bäckman \& Dixon, 1992). For the VVLT scores only significant effects of commonly known demographical predictors (i.e., age, and gender, and only for VVLT immediate recall for level of education) were found, which is in line with previous studies (Anstey \& Christensen, 2000; Van der Elst et al., 2005).

There are several important aspects of this study that are worth noticing. First, we included a sample of older adults without clear objective cognitive problems. The theory of psychological compensation that was proposed by Bäckman and Dixon (1992) states that an actual or perceived deficit between individuals' skills and environmental demands is a prerequisite for compensatory behavior. The level of severity of this actual or perceived mismatch is also important. The relationship between the level of severity of a deficit and the probability of compensation can be expressed as an inverted U-shaped curve. According to this theory, individuals with small or pronounced deficits are less likely to compensate than individuals with a moderate (perceived or actual) deficit (Bäckman \& Dixon, 1992). Future research might focus on the consequences of everyday memory compensation in populations with more pronounced deficits to investigate whether comparable findings will be obtained.

Second, everyday memory compensation was measured by the Strategy subscale of the MIA (Dixon et al., 1988; Ponds \& Jolles, 1996). This subscale can be further divided into the use of External strategies and the use of Internal strategies (Ponds \& Jolles, 1996), which are both examples of substitution mechanisms of compensatory behavior (Bäckman \& Dixon, 1992). In order to obtain a more complete impression of compensatory behavior, several other mechanisms (e.g., remediation by the investment of more time or effort in overcoming a memory loss) are important too. At the time of the baseline measurement of MAAS (Jolles et al., 1995), instruments that incorporate a broader spectrum of everyday memory compensation strategies (e.g., the Memory Compensation Questionnaire; De Frias \& Dixon, 2005; Van der Elst et al., in press) were not yet available. Consequently, the effect of everyday memory compensation might have been underestimated because its assessment was restricted only to substitution mechanisms, while other important forms of compensation were ignored.

Third, information about the way in which compensatory behavior changes over time is not available in MAAS (Jolles et al., 1995). Previous studies revealed that the use of everyday memory compensation strategies is a process that evolves relatively slowly. Aging individuals seem to report an increased use of external strategies and a decrease in the use of more resource demanding strategies (e.g., internal mne- 
monic strategies). This within subject change of compensatory behavior highly differs between individuals (Dixon \& de Frias, 2004; Dixon et al., 2001). It is thus conceivable that our sample contained individuals for whom the use of everyday memory compensation strategies changed as a function of time, and whose subjective and objective memory functioning may have benefitted from everyday memory compensation attempts.

Fourth, as the results in Table 2 and Figure 1 show, there was a significantly positive effect of time of measurement on the VVLT immediate recall and VVLT delayed recall. This might incorrectly suggest an age-related increase in memory functioning. An alternative explanation is however more likely. Although MAAS made use of parallel test versions, the effect of procedural learning cannot be circumvented (Benedict \& Zgaljardic, 1998; Claus, Mohr, \& Chase, 1991; Hijman et al., 1992; Schmidt, 1996). In longitudinal studies a 'net-effect' is likely to occur, which reflects the positive effects of procedural learning and the negative effect of the true age-related decline in cognitive functioning. The positive change in VVLT immediate recall and VVLT delayed recall is probably a reflection of this net effect.

In conclusion, this paper presented a longitudinal investigation of the consequences of everyday memory compensation for trajectories of subjective and objective memory. Specific attention was paid to the association with cognitive reserve. This study included 231 healthy adults aged 50 years and older who were tested four times within twelve years. The results of this large-scale longitudinal study did not support a previous hypothesis (Garrett et al., 2010) that individuals with high levels of cognitive reserve exhibit a less pronounced cognitive decline as a consequence of everyday memory compensation. These findings are in contrast with those of studies into functional compensation, based on neurophysiological or imaging methods (Cabeza, 2002; Reuter-Lorenz \& Cappell, 2008). Furthermore, findings of this study indicate that the consequences of spontaneous and trained compensation differ. Training compensation might improve cognitive functioning in older adults (see for example Cavallini et al., 2003; Derwinger et al., 2005; Rasmusson et al., 1999; Scogin et al., 1998; Stigsdotter Neely, 2000; Troyer, 2001; Valentijn et al., 2005), while spontaneous compensatory behavior is only related to an equally pronounced change in subjective and objective memory.

These findings can be considered highly relevant. A longitudinal study on the impact of everyday memory compensation on trajectories of subjective and objective memory over time, and its relation to cognitive reserve has not been carried out before. Thus, this study makes an important contribution to the ongoing and very actual debate on the way in which we might optimize the (cognitive) functioning and wellbeing of older adults. 


\section{References}

Anstey, K., \& Christensen, H. (2000). Education, activity, health, blood pressure and apolipoprotein E as predictors of cognitive change in old age: a review. Gerontology, 46, 163-177.

Bäckman, L., \& Dixon, R. A. (1992). Psychological compensation: a theoretical framework. Psychological Bulletin, 112, 259-283.

Ball, K., Berch, D. B., Helmers, K. F., Jobe, J. B., Leveck, M. D., Marsiske, M., Morris, J. N., Rebok, G. W., Smith, D. M., Tennstedt, S. L., Unverzagt, F. W., \& Willis, S. L. (2002). Effects of cognitive training interventions with older adults: a randomized controlled trial. Journal of the American Medical Association, 288, 2271-2281.

Baltes, P. B., \& Baltes, M. M. (1990). Psychological perspectives on successful aging: the model of selective optimization with compensation. In P. B. Baltes (Ed.), Successful aging: Perspectives from the behavioral sciences (pp. 1-34). Cambridge: Cambridge University Press.

Benedict, R., \& Zgaljardic, D. (1998). Practice effects during repeated administrations of memory tests with and without alternate forms. Journal of Clinical and Experimental Neuropsychology, 20, 339352.

Blazer, D. G. (2006). Successful aging. American Journal of Geriatric Psychiatry, 14, 2-5.

Cabeza, R. (2002). Hemispheric asymmetry reduction in older adults: the HAROLD model. Psychology and Aging, 17, 85-100.

Cavallini, E., Pagnin, A., \& Vecchi, T. (2003). Aging and everyday memory: the beneficial effect of memory training. Archives of Gerontology and Geriatrics, 37, 241-257.

Claus, J., Mohr, E., \& Chase, T. (1991). Clinical trials in dementia: Learning effects with repeated testing. Journal of Psychiatry and Neuroscience, 16, 1-4.

Craik, F. I., \& Bialystok, E. (2006). Cognition through the lifespan: mechanisms of change. Trends in Cognitive Sciences, 10, 131-138.

Craik, F. I., \& Grady, J. G. (2002). Aging, memory, and frontal lobe functioning. In D. T. Stuss \& R. T. Knight (Eds.), Principles of frontal lobe function (pp. 528-540). New York: Oxford University Press.

De Bie, S. E. (1987). Toward a standardization of questions concerning demographic variables in population studies [Standaardvragen 1987 - Voorstellen voor uniformering van vraagstellingen naar achtergrondkenmkernen en interviews]. Leiden, The Netherlands: Leiden University Press.

De Frias, C. M., \& Dixon, R. A. (2005). Confirmatory factor structure and measurement invariance of the Memory Compensation Questionnaire. Psychological Assessment, 17, 168-178.

De Frias, C. M., Dixon, R. A., \& Bäckman, L. (2003). Use of memory compensation strategies is related to psychosocial and health indicators. Journals of Gerontology Series B: Psychological Sciences and Social Sciences, 58, P12-22.

Depp, C. A., \& Jeste, D. V. (2006). Definitions and predictors of successful aging: a comprehensive review of larger quantitative studies. American Journal of Geriatric Psychiatry, 14, 6-20.

Derwinger, A., Stigsdotter Neely, A., \& Backman, L. (2005). Design your own memory strategies! Selfgenerated strategy training versus mnemonic training in old age: an 8-month follow-up. Neuropsychological Rehabilitation, 15, 37-54.

Dixon, R. A. (1995). Promoting competence through compensation. In L. A. Bond (Ed.), Promoting successful and productive aging (Vol. 1, pp. 220-238). Thousand Oaks, Calif: Sage Publications.

Dixon, R. A., \& Backman, L. (2005). Principles of compensation in cognitive neurorehabilitation. In D. T. Stuss \& G. Winocur (Eds.), Cognitive neurorehabilitation (Vol. 2, pp. 59-72). Cambridge: Cambridge University Press.

Dixon, R. A., \& de Frias, C. M. (2004). The Victoria Longitudinal Aging Study: From characterizing cognitive aging to illustrating patterns and predictors of changes in memory compensation. Aging, Neuropsychology, and Cognition, 11, 346-376.

Dixon, R. A., de Frias, C. M., \& Bäckman, L. (2001). Characteristics of self-reported memory compensation in older adults. Journal of Clinical and Experimental Neuropsychology, 23, 650-661. 
Dixon, R. A., Hultsch, D. F., \& Hertzog, C. (1988). The Metamemory in Adulthood (MIA) questionnaire. Psychopharmacological Bulletin, 24, 671-688.

Floyd, M., \& Scogin, F. (1997). Effects of memory training on the subjective memory functioning and mental health of older adults: a meta-analysis. Psychology and Aging, 12, 150-161.

Folstein, M. F., Folstein, S. E., \& McHugh, P. R. (1975). “Mini-mental state.” A practical method for grading the cognitive state of patients for the clinician. Journal of Psychiatric Research, 12, 189-198.

Garrett, D. D., Grady, C. L., \& Hasher, L. (2010). Everyday memory compensation: the impact of cognitive reserve, subjective memory, and stress. Psychology and Aging, 25, 74-83.

Gino, S., Mendes, T., Maroco, J., Ribeiro, F., Schmand, B. A., de Mendonca, A., \& Guerreiro, M. (2010). Memory complaints are frequent but qualitatively different in young and elderly healthy people. Gerontology, 56, 272-277.

Glisky, E. L., \& Glisky, M. L. (2005). Memory rehabilition in the elderly. In D. T. Stuss, G. Winocur \& I. H. Robertson (Eds.), Cognitive neurorehabilitation (pp. 347-361). Cambridge: Cambridge University Press.

Hess, T. M. (2005). Memory and aging in context. Psychological Bulletin, 131, 383-406.

Hijman, R., Jolles, J., Verhoeven, W. M., Van Ree, J. M., Elderson, A., \& De Wied, D. (1992). Desglycinamide-(Arg8)-vasopressin in five trials with memory-disturbed patients. Human Psychopharmacology: clinical and experimental, 7, 7-23.

Hoogenhout, E. M., Van der Elst, W., De Groot, R. H., \& Jolles, J. (under review). Everyday memory compensation in older adults with cognitive complaints is moderated by depressive symptoms.

Jolles, J., Houx, P. J., Van Boxtel, M. P. J., \& Ponds, R. W. H. M. (1995). Maastricht Aging Study: determinants of cognitive aging. Maastricht: Neuropsych Publishers.

Kramer, A. F., \& Willis, S. L. (2002). Enhancing the cognitive vitality of older adults. Current Directions in Psychological Sciences, 11, 173-176.

Lezak, M. D., Howieson, D. B., \& Loring, D. W. (2004). Neuropsychological Assessment. Oxford: Oxford University Press.

Luteijn, F., \& van der Ploeg, F. A. E. (1983). Handleiding Groninger Intelligentietest (GIT) [Manual Groningen Intelligence Test]. Lisse: Swets \& Zeitlinger.

Marquardt, D. W. (1980). You should standardize the predictor variables in your regression models. Journal of the American Statistical Association, 75, 87-91.

McDougall, G. J. (1996). Predictors of the use of memory improvement strategies by older adults. Rehabilitation Nursing, 21, 202-209.

Metsemakers, J. F., Hoppener, P., Knottnerus, J. A., Kocken, R. J., \& Limonard, C. B. (1992). Computerized health information in The Netherlands: a registration network of family practices. British Journal of General Practice, 42, 102-106.

Minett, T. S., Da Silva, R. V., Ortiz, K. Z., \& Bertolucci, P. H. (2008). Subjective memory complaints in an elderly sample: a cross-sectional study. International Journal of Geriatric Psychiatry, 23, 49-54.

Ponds, R. W., Commissaris, C. J., \& Jolles, J. (1997). Prevalence and covariates of subjective forgetfulness in a normal population in The Netherlands. International Journal of Aging and Human Development, 45, 207-221.

Ponds, R. W., \& Jolles, J. (1996). The Abridged Dutch Metamemory in Adulthood (MIA) Questionnaire: structure and effects of age, sex, and education. Psychology and Aging, 11, 324-332.

R-Development-Core-Team (2010). R: A language and environment for statistical computing. Vienna, Austria: R Foundation for Statistical Computing.

Rasmusson, D. X., Rebok, G. W., Bylsma, F. W., \& Brandt, J. (1999). Effects of three types of memory training in normal elderly. Aging, Neuropsychology, and Cognition, 6, 56-66.

Raz, N. (2000). Aging of the brain and its impact on cognitive performance: integration of structural and functional findings. In F. I. M. Craik \& T. A. Salthouse (Eds.), The handbook of aging and cognition. Mahwah, NJ: Lawrence Erlbaum Associates. 
Rebok, G. W., Carlson, M. C., \& Langbaum, J. B. (2007). Training and maintaining memory abilities in healthy older adults: traditional and novel approaches. Journals of Gerontology Series B: Psychological Sciences and Social Sciences, 62 Spec No 1, 53-61.

Reuter-Lorenz, P., \& Cappell, K. A. (2008). Neurocognitive aging and the compensation hypothesis. Current Directions in Psychological Sciences, 17, 177-182.

Rowe, J. W., \& Kahn, R. L. (1987). Human aging: usual and successful. Science, 237, 143-149.

Rowe, J. W., \& Kahn, R. L. (1997). Successful aging. Gerontologist, 37, 433-440.

Salthouse, T. A. (1996). The processing-speed theory of adult age differences in cognition. Psychological Review, 103, 403-428.

Schmidt, M. (1996). Rey Auditory Verbal Learning Test: A handbook. Los Angeles, CA: Western Psychological Sciences.

Scogin, F., Prohaska, M., \& Weeks, E. (1998). The Comparative Efficacy of Self-Taught and Group Memory Training for Older Adults. Journal of Clinical Geropsychology, 4, 301-314.

Stern, Y. (2002). What is cognitive reserve? Theory and research application of the reserve concept. Journal of the International Neuropsychological Society, 8, 448-460.

Stern, Y. (2003). The concept of cognitive reserve: a catalyst for research. Journal of Clinical and Experimental Neuropsychology, 25, 589-593.

Stigsdotter Neely, A. S. (2000). Multifactorial memory training in normal aging: in search of memory improvement beyond the ordinary. In R. D. Hill, L. Backman \& A. Stigsdotter Neely (Eds.), Cognitive rehabilitation in old age. Oxford: Oxford University Press.

Troyer, A. K. (2001). Improving memory knowledge, satisfaction, and Functioning, via an education and intervention program for older adults. Aging, Neuropsychology, and Cognition, 8, 256-268.

UNESCO (1976). International Standard Classification of Education (ISCED). Paris: United Nations Educational, Scientific and Cultural Organisation.

Valentijn, S. A., Van Hooren, S. A., Bosma, H., Touw, D. M., Jolles, J., Van Boxtel, M. P., \& Ponds, R. W. H. M. (2005). The effect of two types of memory training on subjective and objective memory performance in healthy individuals aged 55 years and older: a randomized controlled trial. Patient Education and Counseling, 57, 106-114.

Van der Elst, W., Hoogenhout, E. M., Dixon, R. A., De Groot, R. H., \& Jolles, J. (in press). The Dutch Memory Compensation Questionnaire: Psychometric Properties and Regression-Based Norms. Assessment.

Van der Elst, W., Van Boxtel, M. P., van Breukelen, G. J., \& Jolles, J. (2005). Rey's verbal learning test: normative data for 1855 healthy participants aged 24-81 years and the influence of age, sex, education, and mode of presentation. Journal of the International Neuropsychological Society, 11, 290302.

Van Dijk, K. R., Van Gerven, P. W., Van Boxtel, M. P., Van der Elst, W., \& Jolles, J. (2008). No protective effects of education during normal cognitive aging: results from the 6-year follow-up of the Maastricht Aging Study. Psychology and Aging, 23, 119-130.

Van Hooren, S. A., Valentijn, A. M., Bosma, H., Ponds, R. W., Van Boxtel, M. P., \& Jolles, J. (2007). Cognitive functioning in healthy older adults aged 64-81: a cohort study into the effects of age, sex, and education. Aging, Neuropsychology, and Cognition, 14, 40-54.

Verbeke, G., \& Molenberghs, G. (2000). Linear Mixed Models for longitudinal data. New York: Springer.

Verhaeghen, P., Marcoen, A., \& Goossens, L. (1992). Improving memory performance in the aged through mnemonic training: a meta-analytic study. Psychology and Aging, 7, 242-251.

Wilson, B. A. (2000). Compensating for cognitive deficits following brain injury. Neuropsychology Review, 10, 233-243.

Wilson, B. A., \& Watson, P. C. (1996). A practical framework for understanding compensatory behaviour in people with organic memory impairment. Memory, 4, 465-486.

Zacks, R. T., Hasher, L., \& Li, K. Z. H. (2000). Human memory. In F. I. M. Craik \& T. A. Salthouse (Eds.), The handbook of aging and cognition (Vol. 2, pp. 293-357). Mahwah, NJ: Erbaum. 


\section{CHAPTER 7}

A comprehensive educational group intervention for older adults with cognitive complaints: background, content, and process evaluation 


\section{Abstract}

This paper presents a comprehensive intervention for older adults with cognitive complaints. It offers psycho-education about cognitive aging and contextual factors, focuses on skills and compensatory behavior, and incorporates group discussion. The intervention reduced negative emotional reactions towards cognitive functioning in healthy women aged 60 to 75 years. Its background and content are described in detail to enable application and replication. To investigate the possibility for large-scale implementation, a process evaluation was carried out. The results support participants' appreciation and point to better self-evaluations after intervention. This intervention may offer a valuable contribution to public health care for older adults. 


\section{Introduction}

Complaints about cognitive functions are highly prevalent, especially in older adults. Ponds and colleagues (1997), for example, showed that the prevalence of memory complaints is 41 percent in adults aged 54 to 66 years and 52 percent in adults aged 69 tot 86 years. Although prevalence rates varied significantly depending on the study sample and the way in which cognitive complaints were measured and defined (Jonker, Geerlings, \& Schmand, 2000; Mendes et al., 2008), results of other community-based studies were in line with these findings (Blazer, Hays, Fillenbaum, \& Gold, 1997; Jonker, Launer, Hooijer, \& Lindeboom, 1996; Mendes et al., 2008; Minett, Da Silva, Ortiz, \& Bertolucci, 2008). It is thus clear that a common complaint of normally aging individuals refers to cognitive changes. The presence of such perceived cognitive losses significantly contributes to a lowered quality of life (Mol et al., 2007; Mol, Van Boxtel, Willems, Verhey, \& Jolles, 2009). These cognitive problems are a source of worry and frustration for many aging individuals. Some of them are even afraid that this may be a sign of a degenerative disorder, like dementia (Commissaris et al., 1993; Commissaris, Ponds, \& Jolles, 1998; Mol, Ruiter, Verhey, Dijkstra, \& Jolles, 2008).

Approximately 11 percent of all community dwelling adults with memory complaints seems interested to participate in some sort of intervention. Education and memory training are the most preferred forms of intervention (Commissaris et al., 1998). Many individuals with perceived cognitive problems appeal on specialized healthcare services, like memory clinics (Comijs, Dik, Aartsen, Deeg, \& Jonker, 2005; Verhey et al., 2007). These facilities however offer highly specialized care (i.e., aimed at the identification and treatment of demented individuals) and are therefore costly (Verhey et al., 2007). There is thus a need for more appropriate and easily accessible interventions for relatively healthy older adults with cognitive complaints, especially in the face of our rapidly aging Western society.

In the past decades, many health care practitioners and researchers have devoted themselves to the development and evaluation of cognitive interventions for older adults. There is a widespread variation in types of interventions (Floyd \& Scogin, 1997; Glisky \& Glisky, 2005; Rebok, Carlson, \& Langbaum, 2007; Verhaeghen, Marcoen, \& Goossens, 1992). Many have their roots in the informationprocessing framework of cognitive aging, which states that normal age-related changes in memory are linked to changes in other cognitive domains or structures (Zacks, Hasher, \& Li, 2000), like cognitive slowing (Salthouse, 1996) or problems in inhibitory functions (Craik \& Bialystok, 2006; Van Hooren, Valentijn, Bosma, Ponds, Van Boxtel et al., 2007). The 'use it or lose it' hypothesis (Salthouse, 2006), for example, is a popular model for such interventions (McDougall, 2009). These interventions assume that older adults have the cognitive plasticity to benefit from cognitive training. Their primary aim is thus to improve cognitive function per se or prevent it 
from relapsing (Hess, 2005; McDougall, 2009). Such interventions usually involve some form of cognitive training (e.g., one or more mnemonic techniques like the method of loci, or visual imagery) (Floyd \& Scogin, 1997; Rebok et al., 2007; Verhaeghen et al., 1992). A very extensive study to the effects of cognitive training was ACTIVE (Advanced Cognitive Training for Independent and Vital Elderly), which compared three different cognitive training interventions (i.e., memory, reasoning, and speed of processing training) to a no-contact control group (Ball et al., 2002; Jobe et al., 2001). Such cognitive interventions typically brought about task and domain specific effects that were maintained for a considerable period of time (Ball et al., 2002; Rebok et al., 2007; Verhaeghen et al., 1992). Older adults thus benefitted from it. Effects however hardly generalized to other cognitive domains (Rebok et al., 2007; Verhaeghen et al., 1992), and did not lead to an increase in subjective cognitive functioning, wellbeing (Floyd \& Scogin, 1997), or everyday functioning (Willis et al., 2006). Consequently, it has been stated that future intervention studies should find a way to increase awareness, knowledge, and subjective cognitive functioning, and decrease negative beliefs and negative memory-related affect (Floyd \& Scogin, 1997; Hohaus, 2007; Rebok et al., 2007; Verhaeghen et al., 1992). This requires an alternative approach.

The current paper presents a new comprehensive educational group intervention for healthy older adults with perceived cognitive problems. A randomized controlled trial has revealed that this intervention was effective in reducing negative emotional reactions towards cognitive failures in healthy women, aged 60 to 75 years, with cognitive complaints (Hoogenhout, De Groot, Van der Elst, \& Jolles, under review). A common problem in the intervention literature is that a detailed description of evaluated intervention programs lacks (Floyd \& Scogin, 1997; Jobe et al., 2001; Schreurs, Colland, Kuijer, De Ridder, \& Van Elderen, 2003; Verhaeghen et al., 1992). This may hamper the accumulation of knowledge and improvement of care (Schreurs et al., 2003). The current study therefore describes the intervention's background and content in detail in order to enable application and replication by other researchers or practitioners in the field of healthcare or social gerontology. Finally, for large-scale implementation it is not only important to know whether an intervention is effective, but also whether participants accept it (Grol \& Wensing, 2006; Linnan \& Steckler, 2002; Parisi, Greene, Morrow, \& Stine-Morrow, 2007; Schreurs et al., 2003). For that reason a process evaluation was carried out in which participants' appreciation of the intervention and their self-evaluations after participation were investigated. The background of this new intervention program is given in the next paragraph. 


\section{Background}

It seems important to further consider the nature of cognitive complaints in healthy older adults first. Aging is often accompanied by actual changes in cognitive functions, like memory and learning (Craik \& Salthouse, 2000), speed of information processing (Salthouse, 1996), inhibitory functions and executive functions (Craik \& Bialystok, 2006; Craik \& Grady, 2002; Van Hooren, Valentijn, Bosma, Ponds, Van Boxtel et al., 2007). Subjective cognitive complaints may be indicative for actual age-related changes in cognitive functions (Jorm, Christensen, Korten, Jacomb, \& Henderson, 2001). Furthermore, they have some predictive value for Mild Cognitive Impairment (Petersen et al., 1999; Winblad et al., 2004), or even dementia (Geerlings, Jonker, Bouter, Ader, \& Schmand, 1999; Jonker et al., 2000). Yet, many studies showed that the association between subjective and objective cognitive functioning is weak (Kliegel, Zimprich, \& Eschen, 2005; Minett et al., 2008; Mol, Van Boxtel, Willems, \& Jolles, 2006). In fact, subjective cognitive complaints seem stronger related to non-cognitive factors. This has been found in studies involving, for example, metamemory (Comijs, Deeg, Dik, Twisk, \& Jonker, 2002; Mol et al., 2008; Ponds \& Jolles, 1996), depressive affect (Cargin, Collie, Masters, \& Maruff, 2008; Comijs et al., 2002; Kliegel \& Zimprich, 2005; Zimprich, Martin, \& Kliegel, 2003), personality traits (Comijs et al., 2002; Kliegel \& Zimprich, 2005; Ponds \& Jolles, 1996), and health (Comijs et al., 2002). The primary problem of the majority of older adults is thus a perceived cognitive loss that is often independent of actual cognitive changes.

It can thus be questioned whether much is to be gained by trying to enlarge cognitive capacity alone, while non-cognitive factors are ignored (Stuss et al., 2007). Accordingly, there is growing interest in interventions that adopt a more multidimensional approach to cognitive aging (McDougall, 2009). Such interventions combine, for example, strategy training with cognitive restructuring (Lachman, Weaver, Bandura, Elliott, \& Lewkowicz, 1992), psychosocial training (Stuss et al., 2007; Winocur, Palmer et al., 2007), and education about metacognitive processes (Valentijn et al., 2005; West, Bagwell, \& Dark-Freudeman, 2008) and about other contextual factors (Hohaus, 2007; Mohs et al., 1998; Troyer, 2001; Van Hooren, Valentijn, Bosma, Ponds, Van Boxtel et al., 2007). These interventions more or less fit a contextual framework of cognitive aging that was proposed by Hess (2005). He argued for the consideration of a broader constellation of factors as determinants of both intra-individual change and inter-individual variation in memory functioning, in addition to changes in the integrity and efficiency of the information-processing system. Examples of such contextual factors are: social context, health, lifestyle, negative age-stereotypes, personal goal setting, and beliefs about aging (Hess, 2005). Studies that investigated the effectiveness of such multidimensional cognitive interventions greatly differed in study design and outcome, with effects established on subjective cognitive functioning (Hohaus, 2007; Lachman et al., 1992; 
Mohs et al., 1998; Troyer, 2001; Valentijn et al., 2005; Van Hooren, Valentijn, Bosma, Ponds, Van Boxtel et al., 2007; West et al., 2008; Winocur, Craik et al., 2007), psychological wellbeing (Winocur, Craik et al., 2007; Winocur, Palmer et al., 2007), or objective cognitive performance (Craik et al., 2007; Hohaus, 2007; Levine et al., 2007; Mohs et al., 1998; Troyer, 2001; Valentijn et al., 2005; West et al., 2008).

These findings are very promising. Unlike cognitive training interventions that fit the information-processing framework of cognitive aging, such multidimensional interventions exhibit significant effects on aspects of subjective cognitive functioning and wellbeing. Thus, multidimensional interventions with a strong educational component that take both cognitive and non-cognitive factors into account, might meet the need for more effective interventions for older adults with cognitive complaints that was expressed by other researchers (Floyd \& Scogin, 1997; McDougall, 2009; Rebok et al., 2007; Verhaeghen et al., 1992).

\section{A new comprehensive educational group program}

In line with this growing enthusiasm for multidimensional cognitive interventions for older adults, we developed a new comprehensive educational group program that has evolved from previous successful intervention studies by our research group (Commissaris, Verhey, \& Jolles, 1996; Valentijn et al., 2005; Van Hooren, Valentijn, Bosma, Ponds, Van Boxtel et al., 2007). The intervention included eight 1.5hour sessions in four consecutive weeks and was offered in a small group format with six to nine participants per group. Its primary aim was to increase subjective cognitive functioning. In our opinion the fundamental problem of our target group was a perceived cognitive deficit that is related to, for example, negative feelings about cognitive functioning, but has limited predictive value for actual objective cognitive loss. We recently carried out a randomized controlled trial (Hoogenhout et al., under review) with an experimental and waiting list control condition. We included a carefully selected homogeneous sample of 60 healthy community dwelling older women aged 60 to 75 years with age-related perceived cognitive losses. A significant reduction in negative emotional reactions towards cognitive functioning was found in the experimental group compared to the waiting list control group one week after intervention. Theoretical perspectives and research findings provide a framework for the intervention's content.

The intervention had a strong educational focus. It offered psycho-education about normal age-related changes in memory, speed of information processing, attention capacity and executive functions (Craik \& Bialystok, 2006; Craik \& Grady, 2002; Salthouse, 1996; Van Hooren, Valentijn, Bosma, Ponds, Van Boxtel et al., 2007). Differences between normal age-related cognitive changes and cognitive decline in dementia were explained. It was emphasized that the presence of per- 
ceived cognitive problems has limited predictive value for Mild Cognitive Impairment or dementia (Winblad et al., 2004). Furthermore, the influence of several contextual factors (e.g., health, lifestyle, psychosocial functioning, beliefs, and negative aging stereotypes) on cognitive functioning was considered (Hess, 2005; Mol et al., 2008). A fundamental premise is that psycho-education enhances knowledge and increases individuals' insight into their own functioning. Knowledge is thought to enhance feelings of control (Lachman, 1991, 2000) and to modify negative beliefs (Troyer, 2001). It has a powerful compensatory and enriching effect, thus perceived cognitive losses could be overcome by the development of pragmatic knowledge (Bäckman \& Dixon, 1992; Baltes \& Baltes, 1990). The intervention emphasized the importance of finding a balance between gains and losses and fitted the ideas of Baltes and Baltes (1990) about successful aging through selection, optimization, and compensation. Selection refers to the process of adjusting expectations and changing personal goals to permit subjective experience of satisfaction and control. Optimization reflects the view that people engage in behaviors to enrich and augment their general reserves. Compensation results from a discrepancy between the level of performance, and situations and goal characteristics (Baltes \& Baltes, 1990). It enables individuals to adapt their behavior and implement appropriate strategies in everyday life to cope with this discrepancy (Bäckman \& Dixon, 1992; Dixon, 1995). More information was offered about skills and commonly applicable compensation strategies. Several principal mechanisms and forms of compensatory behavior were discussed (e.g., use of external aids and internal mnemonics, investing more time and effort) (Bäckman \& Dixon, 1992; Dixon, 1995; Dixon, de Frias, \& Bäckman, 2001). The importance of changing goals and expectations was emphasized (Bäckman \& Dixon, 1992), and the compensatory technique of Goal Management was introduced (Levine et al., 2000; Levine et al., 2007; Van Hooren, Valentijn, Bosma, Ponds, Van Boxtel et al., 2007). Another important aspect of the intervention was group discussion (Flynn \& Storandt, 1990; Valentijn et al., 2005) about societal and personal beliefs, negative aging stereotypes (Hess, 2005; Mol et al., 2008), and pessimistic and maladaptive attributions (Commissaris et al., 1993; Commissaris et al., 1998; Lachman \& McArthur, 1986). This may contribute to better adaptation to agerelated cognitive losses (Lachman, 1991).

\section{Methods}

\section{Intervention program}

The intervention program consisted of eight sessions with two sessions a week for four consecutive weeks. In line with findings from previous studies regarding optimal intervention design (Flynn \& Storandt, 1990; Verhaeghen et al., 1992), each 
session lasted for 1.5 hour and was offered in a small group format with six to nine participants per group. A healthcare psychologist and a research neuropsychologist facilitated all sessions. At the start of the intervention each participant received a workbook in which course information (i.e., session summaries, registration forms, and handouts) could be collected and notes could be taken.

The intervention was offered in a structured manner and within a standard time frame. Each session started with the evaluation and recapitulation of the content of the previous session. Homework assignments were discussed and questions were answered. In addition, themes and topics were introduced in short blocks supported by a PowerPoint slideshow with handouts. After each block, beliefs and attitudes with respect to a specific theme were shared and discussed within the group. Each session ended with a summary of the session's themes and topics, and a short preview of the homework assignments.

Session 1 served as an introductory session in which aims and themes of the intervention were introduced. Education about cognitive aging (e.g., normal versus pathological and successful aging) and subjective forgetfulness was offered. Furthermore, several contextual factors (e.g., physical and mental health, environmental demands, societal norms and personal beliefs) were considered. Finally, several negative aging stereotypes were discussed. Session 2 offered education about brain development and cerebral function, and information processing. Furthermore, several cognitive functions (i.e., memory, attention, and executive functions), and age-related changes in cognitive functions (e.g., memory decline and mental slowing) were considered. Session 3 further examined the interaction between memory and other cognitive functions (e.g., attention and executive functions). Education about planning, executive function and goal management was offered, and the concept of successful aging and relevant contextual factors was further discussed. Session 4 elaborated upon the differences between pathological aging versus normal and successful aging. Information about the prevalence and incidence as well as symptoms of dementia was offered. Finally, the influence of health and lifestyle on cognitive aging was discussed, and education about optimization and enhancing general reserve was offered. Session 5 offered education about the influence of psychological factors and mental wellbeing (e.g., depressive affect) on cognitive aging. The vicious circle of forgetting was discussed (i.e., perception of memory decline may lead to a lack of confidence and loss of control, which in turn may lead to more perceived memory problems). Furthermore, other contextual factors like environmental demands, and societal and personal beliefs and norms were discussed. Finally, education about the necessity to adjust expectations and personal goals was offered. Session 6 introduced the concept of compensation and explained the difference with restoration of function. Several forms of compensatory behavior were discussed (i.e., use of external aids, internal mnemonics, anticipating on environmental demand and reliance on others, investment of more time 
and effort). Examples of external and internal strategies were offered. Finally, the technique of goal management was considered. Session 7 further elaborated on the importance of investing more time and effort in everyday memory demanding tasks, and offered more extensive information about goal management. Session 8 served as a summary in which all themes were recapitulated on. Furthermore, the importance of generalization to everyday life was discussed. The intervention's content is listed in Table 1.

Table 1 Summary of the intervention program

\begin{tabular}{|c|c|c|}
\hline Session & Content & Homework \\
\hline 1 & $\begin{array}{l}\text { - First acquaintance } \\
\text { - Introduction to the intervention program } \\
\text { - Overview of themes } \\
\text { - Cognitive aging and subjective forgetfulness } \\
\text { - Contextual factors } \\
\text { - Aging stereotypes }\end{array}$ & $\begin{array}{l}\text { - Reading the summary } \\
\text { - Personal goals and expectations } \\
\text { - Cognitive diary } \\
\text { - Personal names for mental slips }\end{array}$ \\
\hline 2 & $\begin{array}{l}\text { - Successful aging } \\
\text { - Brain and cognition } \\
\text { - Information processing and memory } \\
\text { - Attention and mental slowness }\end{array}$ & $\begin{array}{l}\text { - Reading the summary } \\
\text { - Cognitive diary } \\
\text { - Speed and attention in daily life }\end{array}$ \\
\hline 3 & $\begin{array}{l}\text { - Planning and executive functioning } \\
\text { - Absent-minded slips } \\
\text { - Successful cognitive aging and contextual factors }\end{array}$ & $\begin{array}{l}\text { - Reading the summary } \\
\text { - Planning everyday tasks } \\
\text { - Absent-minded slips }\end{array}$ \\
\hline 4 & $\begin{array}{l}\text { - Health } \\
\text { - Lifestyle } \\
\text { - Normal aging versus dementia } \\
\text { - Optimization and enriching general reserve }\end{array}$ & $\begin{array}{l}\text { - Reading the summary } \\
\text { - Contextual factors in own situation }\end{array}$ \\
\hline 5 & $\begin{array}{l}\text { - Psychological factors } \\
\text { - Vicious circle of forgetting } \\
\text { - Societal and personal beliefs and expectations } \\
\text { - Adjusting expectations and personal goals }\end{array}$ & $\begin{array}{l}\text { - Reading the summary } \\
\text { - Getting older, what goes right? } \\
\text { - Spontaneous strategy use }\end{array}$ \\
\hline 6 & $\begin{array}{l}\text { - Compensation versus restoration } \\
\text { - External strategies } \\
\text { - Internal strategies } \\
\text { - Environmental demands } \\
\text { - Investing more time and effort } \\
\text { - Planning and goal management }\end{array}$ & $\begin{array}{l}\text { - Reading the summary } \\
\text { - Compensation in daily life } \\
\text { - Preventing absent minded slips }\end{array}$ \\
\hline 7 & $\begin{array}{l}\text { - Investing more time and effort } \\
\text { - Planning and goal management } \\
\text { - Preventing and handling time pressure }\end{array}$ & $\begin{array}{l}\text { - Reading the summary } \\
\text { - Goal management in daily life } \\
\text { - Time pressure in everyday tasks }\end{array}$ \\
\hline 8 & $\begin{array}{l}\text { - Recapitulation of themes } \\
\text { - Generalization }\end{array}$ & $\begin{array}{l}\text { - Reading the summary } \\
\text { - Generalization }\end{array}$ \\
\hline
\end{tabular}




\section{Participants and procedure}

Participants were recruited through advertisements in local and regional weeklies and through announcements on a regional radio station. Interested individuals could contact the researchers by telephone to receive more information about the intervention program and the study. A telephonic semi-structured interview was conducted in which participants were screened for the most important inclusion criteria (i.e., being a woman, aged between 60 and 75 years, reporting age-related cognitive complaints and/or concerns about becoming demented, good comprehension of the Dutch language). Participants were excluded if they reported any previous neurological disease (e.g., stroke or dementia) or psychiatric disorder (e.g., major depressive disorder or schizophrenia). An additional exclusion criterion was a score of 24 or lower on the Mini-Mental State Examination (Folstein, Folstein, \& McHugh, 1975).

Eligible individuals were sent an information letter about the intervention program and effect evaluation. In favor of the randomized controlled effect evaluation (Hoogenhout et al., under review), people who were willing to participate were randomly assigned to either an experimental or a waiting-list control group. All participants received an individual intake interview. Afterwards a double baseline cognitive assessment was carried out with approximately one week in between. Additionally, all participants filled in several self-report questionnaires. Within one or two weeks after baseline assessment, participants in the experimental condition were offered the intervention program. Participants in the control condition were placed on a waiting list. Approximately seven weeks after the start of the study, a follow-up assessment was carried out in all participants. Afterwards, participants in the waiting list control condition were offered the intervention program at the end of which they filled in the questionnaires again. The medical ethics committee of the Maastricht University Medical Centre approved the study and all participants gave their informed consent. A summary of the procedure and flowchart of participants is offered in Figure 1.

In addition to age and MMSE-score (Folstein et al., 1975), several other background variables were assessed. Educational level was measured on an 8-point ordinal scale, ranging from primary education to university education (De Bie, 1987). Information about marital status was collected (married or unmarried). Two subscales of the Eysenck Personality Inventory (EPQ; Sanderman, Arrindell, Ranchor, Eysenck, \& Eysenck, 1995) were administered to measure neuroticism (e.g., being emotional unstable), and extraversion (e.g., being talkative). These subscales consisted of 22 and 19 dichotomous items (i.e., 1 = yes, 0 =no). Higher scores indicated more neuroticism or extraversion. The Centre of Epidemiologic Studies Depression Scale (CES-D; Bouma, Ranchor, Sanderman, \& Van Sonderen, 1995) was administered to measure depressive symptomatology. It contained 20 statements concerning depressive symptoms (e.g., feeling lonely) in the week prior to test administra- 
tion. Participants had to indicate symptom frequency on a 4-point scale, ranging form 'seldom or never' $(=0)$ to 'usually or all the time' $(=4)$. Higher scores indicated more depressive symptoms (Bouma et al., 1995).

A total of $N=108$ participants were recruited of whom 60 were randomly assigned to the experimental and the waiting list control condition, which was necessary for effect evaluation (Hoogenhout et al., under review). All others did not meet inclusion criteria or refused to participate after they received more information about the intervention program and the experiment (see Figure 1).

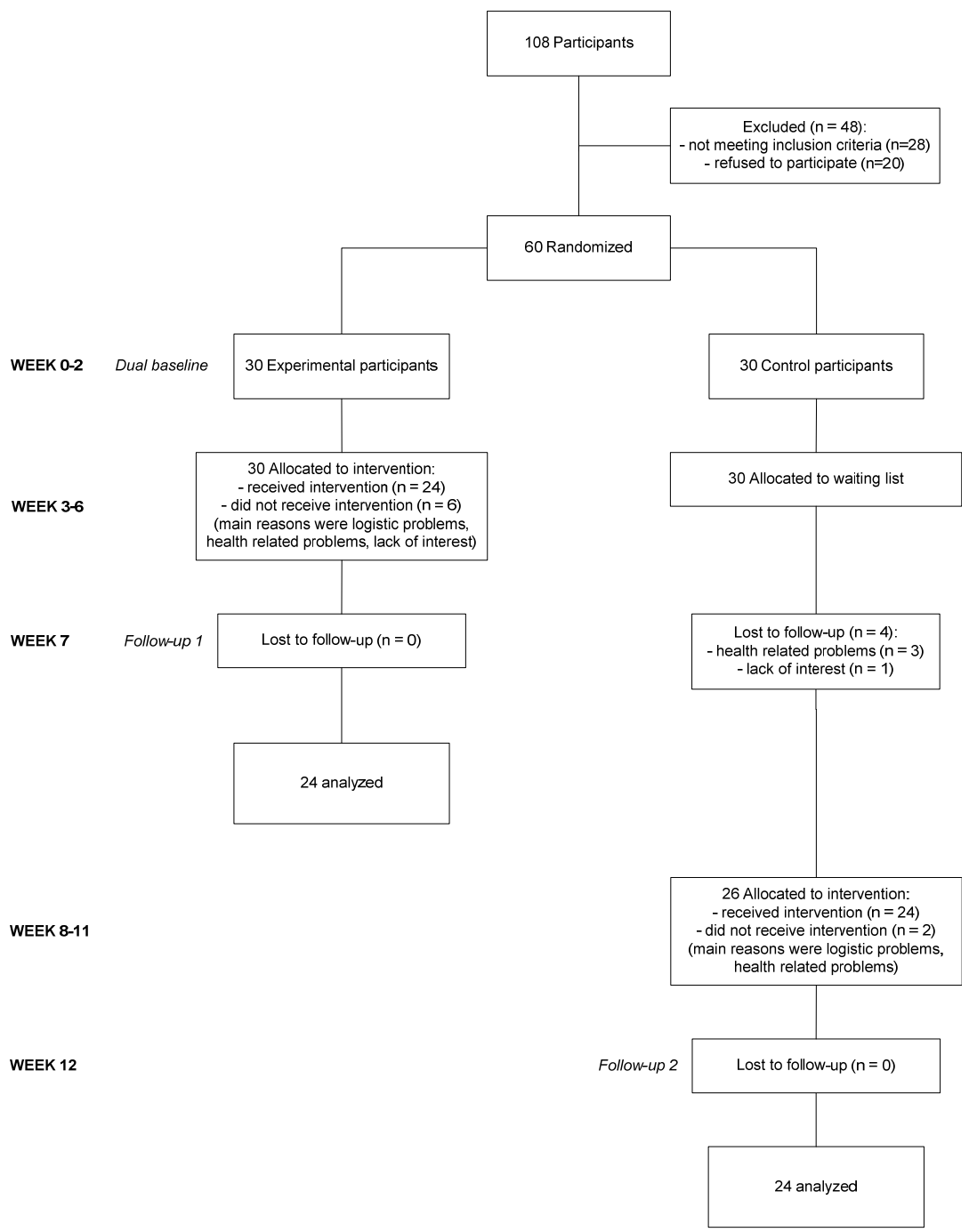

Figure 1 Flowchart of participants 
Participants' characteristics are listed in Table 2. Mean age of the total sample (i.e., experimental and waiting list control participants together) was 66.05 years ( \pm 4.32). Mean level of education was $4.07( \pm 1.95)$.

Table 2 Participants' characteristics: means and standard deviations

\begin{tabular}{llll}
\hline & $\begin{array}{l}\text { Total group } \\
(\boldsymbol{N}=\mathbf{6 0})\end{array}$ & $\begin{array}{l}\text { Experimental group } \\
(\boldsymbol{n}=\mathbf{3 0})\end{array}$ & $\begin{array}{l}\text { Control group } \\
(\boldsymbol{n}=\mathbf{3 0})\end{array}$ \\
\hline Age (years) & $66.05( \pm 4.32)$ & $66.00( \pm 4.23)$ & $66.10( \pm 4.48)$ \\
Educational level (8-point scale) & $4.07( \pm 1.95)$ & $4.14( \pm 2.03)$ & $4.00( \pm 1.90)$ \\
Marital status (\% married) & $57.9 \%$ & $51.7 \%$ & $64.3 \%$ \\
EPQ-Extraversion (range 0-19) & $9.93( \pm 3.36)$ & $9.88( \pm 3.19)$ & $9.96( \pm 3.56)$ \\
EPQ-Neuroticism (range 0-22) & $8.26( \pm 5.16)$ & $8.31( \pm 5.55)$ & $8.21( \pm 4.86)$ \\
CES-D (range 0-60) & $13.03( \pm 10.46)$ & $12.48( \pm 10.06)$ & $13.59( \pm 11.00)$ \\
MMSE & $29.18( \pm .99)$ & $29.24( \pm .99)$ & $29.11( \pm .99)$ \\
\hline
\end{tabular}

Note. $\mathrm{EPQ}=$ Eysenck Personality Questionnaire; CES-D = Centre of Epidemiologic Studies Depression Scale; MMSE = Mini Mental State Examination

\section{Measures}

\section{Participants' appreciation}

Within one week after the end of the intervention, participants were asked to indicate how they felt about the number, duration, and frequency of the sessions. They were also asked how they felt about the group size. Perceptions of the total quantity of information per session, and the extent to which the information was repeated were rated. Participants were asked to give their opinion about the way information was offered (i.e., PowerPoint presentation, handouts, and session summaries), the opportunity to ask questions, and the possibility to discuss topics. Questions could be answered on a 5-point scale. For example: 'In my opinion, the frequency of the sessions (i.e., twice a week for four consecutive weeks) was...: 1) far too little, 2) too little, 3) good, 4) too much, 5) far too much.' Afterwards, answers were categorized into three categories (e.g., too little, good, too much).

Participants were asked to evaluate the content of the sessions, peer support, and homework assignments. 'Evaluation of sessions' was measured by asking participants to rate whether the sessions were informative, useful, interesting, and enjoyable on a 5-point scale ranging from 1 ) not at all, to 5) very much. Afterwards a mean score was calculated. Likewise, 'evaluation of peer support' was measured using the mean rating of two statements about the extent to which it was informative and enjoyable. To evaluate 'homework assignments' participants were asked to indicate whether the homework assignments were informative, useful, interesting, and enjoyable, and whether they fitted sufficiently to the session's theme. Additionally, participants were asked how much time was spent on the homework assignments. Finally, participants were asked to give a global rating of the intervention program (i.e., 1 = lowest and 10 = highest). 


\section{Self-evaluations after participation}

Participants' were also asked to compare several aspects of their functioning after intervention to their functioning prior to intervention. Selected domains were: a) making cognitive mistakes, b) being hindered by cognitive mistakes, c) being worried about cognitive abilities, d) being afraid about becoming demented, and e) feeling able to cope with cognitive problems. All statements had to be rated on a 5point scale.

For example: 'Compared to my situation before the intervention, I am 1) much more worried about becoming demented, 2) more worried about becoming demented, 3) just as worried about becoming demented, 4) less worried about becoming demented, 5) much less worried about becoming demented.' A final option was: 9) I was not worried about becoming demented.

\section{Statistical analyses}

Non-parametric Mann-Whitney U tests (on age, CES-D score, EPQ scores, MMSE and educational level) and a Chi-square test for marital status were used to investigate differences between drop-outs and participants who completed the intervention and final assessment. To explore potential associations between background characteristics (i.e., age, educational level, personality traits, and depressive symptoms), and process evaluations and self-evaluations, Pearson's correlation coefficients were calculated. Afterwards, process and self-evaluation scores were regressed on background variables that showed significant correlations to one or more evaluation scores (i.e., age and educational level, and their interaction term). For this purpose, educational level was dichotomized by a median split procedure (i.e., LE low = those with at most intermediate vocational education $=0$; LE high $=$ those with more than intermediate vocational education $=1)$. Non-significant predictors $(p>.05)$ were excluded from the full models, but no predictor was removed as long as it was also included in a higher order term (Aiken \& West, 1991). All analyses were carried out with PASW 18.0 for Macintosh.

\section{Results}

\section{Attrition rate}

Of the $N=60$ participants who were included in the study, $n=48$ (i.e., $n=24$ experimental and $n=24$ waiting list control participants) completed the program and the final assessment. The majority of them (56.3\%) attended all eight sessions, $n=$ 17 (35.4\%) missed one session, and $n=4$ (8.3\%) missed two sessions. Participants who dropped out reported higher EPQ extraversion scores $(U=34.000, p=.028)$ 
than participants who finished the intervention. Drop out was not related to age, educational level, marital status, MMSE scores, EPQ neuroticism scores, or CES-D scores.

\section{Participants' appreciation}

The majority of the participants were satisfied with the total number of sessions (85.4\%), the duration of each session $(87.5 \%)$, the frequency of the sessions (i.e., twice a week in four consecutive weeks) $(79.2 \%)$, and the total quantity of information per session (85.4\%). A moderate number of participants were satisfied with the extent to which the information was repeated (60.4\%). Almost 40 percent of the participants preferred less repetition of the information. Furthermore, the majority of the participants were satisfied with the way in which the information was offered (97.9\%), the opportunity to ask questions $(87.5 \%)$, and the opportunity to discuss personal topics (75.0\%). All participants were satisfied with the group size. Participants' mean evaluation of the sessions content was $4.36( \pm .50)$ on a 5-point scale. Peer support was evaluated as $4.22( \pm .59)$ on a 5-point scale. Mean evaluation of the homework assignments was $4.03( \pm .59)$ on a 5-point scale. Participants spent 30 minutes on average to the homework assignments. The intervention received a mean global rating of $7.81( \pm .82)$ on a 10 -point scale.

\section{Self-evaluations after participation}

Of all $n=46$ participants who considered themselves forgetful, $n=32(65.2 \%)$ indicated they made (many) fewer cognitive mistakes after intervention. One person indicated to make more mistakes. Of all $n=39$ participants who felt hindered by their cognitive mistakes, $n=29$ (74.6\%) reported (much) less hindrance. Two participants (4.2\%) reported more hindrance. Of all $n=41$ participants who were worried about their cognitive abilities, $n=38$ (92.7\%) reported being (much) less worried. One participant indicated being much more worried. Of all $n=38$ participants who were afraid about becoming demented, $n=37$ (97.4.\%) reported being (much) less afraid. Of all $n=48$ participants, $n=41$ (85.4\%) considered themselves to be (much) more capable of handling their cognitive problems.

\section{Participants' characteristics in relation to evaluations}

Older participants preferred more sessions. Higher educated participants preferred more information per session, less repetition of the information, and less frequent sessions. No significant associations were found between other background characteristics (i.e., age, educational level, marital status, depressive symptoms, and per- 
sonality traits) and participants' process evaluations and self-evaluations. Relevant regression models are shown in Table 3.

Table 3 Linear regression models of evaluation scores following a step-down hierarchical procedure; the full models included age, educational level, age $\times$ educational level

\begin{tabular}{llccccc}
\hline & Variable & B & Std. Error B & T & Sig & Adj. $\mathbf{R}^{2}$ \\
\hline Number of sessions & (constant) & 5.027 & .870 & 5.776 & & \\
& Age & -.030 & .013 & -2.261 & $.029 *$ & .080 \\
Quantity of information & (constant) & 3.000 & .065 & 45.958 & & \\
& Educational level & -.263 & .104 & -2.536 & $.015^{*}$ & .123 \\
& & & & & & \\
Repetition of information & (constant) & 3.276 & .088 & 37.057 & & \\
& Educational level & .303 & .141 & 2.157 & $.036^{*}$ & .092 \\
& & & & & & \\
Frequency of sessions & (constant) & 3.310 & .073 & 45.203 & & \\
& Educational level & -.258 & .116 & -2.214 & $.032^{*}$ & .096 \\
\hline
\end{tabular}

$* p<.05$

\section{Discussion}

The present paper presented a new comprehensive educational group intervention for healthy older adults with perceived cognitive problems. This intervention is in line with a growing enthusiasm for multidimensional cognitive interventions for older adults (McDougall, 2009). Contrary to interventions that have been developed from an information-processing framework of cognitive aging (Ball et al., 2002; Floyd \& Scogin, 1997; McDougall, 2009; Rebok et al., 2007; Verhaeghen et al., 1992), such multidimensional cognitive interventions exhibited significant effects on, for example, subjective cognitive functioning (Hohaus, 2007; Lachman et al., 1992; Mohs et al., 1998; Troyer, 2001; Valentijn et al., 2005; Van Hooren, Valentijn, Bosma, Ponds, Van Boxtel et al., 2007; West et al., 2008; Winocur, Craik et al., 2007).

The comprehensive group intervention that was described in the current paper had a strong educational focus. It offered information about cognitive aging (Craik \& Bialystok, 2006; Salthouse, 1996; Van Hooren, Valentijn, Bosma, Ponds, Van Boxtel et al., 2007) and the influence of several contextual factors (e.g., psychosocial functioning, health, lifestyle, beliefs, and negative aging stereotypes) (Hess, 2005; Mol et al., 2008). Furthermore, several skills and strategies, which enable individuals to cope with and compensate for perceived cognitive deficits in their everyday lives, were discussed (Bäckman \& Dixon, 1992; Dixon, 1995; Dixon et al., 2001; Levine et al., 2007; Van Hooren, Valentijn, Bosma, Ponds, Van Boxtel et al., 2007). The intervention was offered in a group format, which was thought to optimize its effective- 
ness (Flynn \& Storandt, 1990; Valentijn et al., 2005) and to stimulate discussion about beliefs, negative aging stereotypes, and pessimistic and maladaptive attributions (Commissaris et al., 1993; Commissaris et al., 1998; Hess, 2005; Lachman \& McArthur, 1986; Mol et al., 2008). It incorporated principles of selective optimization through compensation (Baltes \& Baltes, 1990) and applied to a contextual perspective of cognitive aging (Hess, 2005). Fundamental to this intervention was the assumption that aging is often accompanied by perceived cognitive losses that are more related to non-cognitive factors (e.g., affect, metacognition, health) than to actual objective cognitive decline (Kliegel \& Zimprich, 2005; Minett et al., 2008; Mol et al., 2006; Zimprich et al., 2003). In our opinion, the only intervention that significantly shared content and characteristics with our program was described by Hohaus (2007). Unlike Hohaus we were able to carry out a fully randomized controlled trial to evaluate its effectiveness (Hoogenhout et al., under review).

The primary aim of the intervention was to improve subjective cognitive functioning. Recently, a randomized controlled trial was carried out in a homogeneous sample of 60 healthy community-dwelling women (aged 60 to 75 years) with perceived age-related cognitive problems. Results indicated that, compared to participants in the waiting list control condition, participants in the experimental condition reported less negative emotional reactions towards cognitive functioning one week after the intervention (Hoogenhout et al., under review). The intervention thus improved an important aspect of subjective cognitive functioning.

The present paper presented the results of a process evaluation that was carried out in order to investigate participants' acceptance and appreciation as well as their self-evaluations after intervention. Results showed that a large majority of participants were satisfied with the total number and frequency of the sessions, the amount of information per session, and the group size. Yet, almost 40 percent preferred less repetition of the information. The majority of participants also appreciated the way in which information was offered, the opportunity to ask questions, and the opportunity to discuss personal topics. Appreciation of the session's content, peer support, and homework assignments were also high. The mean global rating of the intervention was 7.81 on a 10-point scale. The majority of participants indicated that they made fewer cognitive mistakes, felt less hindered by their cognitive mistakes, were less worried, were less afraid about becoming demented, and considered themselves more capable of handling their cognitive problems after intervention. Thus the intervention program was not only effective in enhancing subjective cognitive functioning, it was also highly appreciated and accepted by participants and improved their self-evaluations on several important aspects of functioning. This is highly relevant for large-scale implementation (Grol \& Wensing, 2006; Linnan \& Steckler, 2002; Parisi et al., 2007; Schreurs et al., 2003).

Results also indicated that older participants more often wished for more sessions. Furthermore, higher educated participants required more information per 
session, less repetition of the information, and less frequent sessions. It can be concluded that such demographical background factors should be taken into account when intervention programs are designed. In future times, it is thus important to fine-tune the content and set-up of intervention programs for specific target groups. This statement is further supported by findings of recent studies that indicated that compliance and response to memory intervention programs were related to background variables, including age and educational level (Bagwell \& West, 2008; Langbaum, Rebok, Bandeen-Roche, \& Carlson, 2009).

It can be concluded that the intervention program that was described in the current paper may offer a valuable contribution to the field of public health care, especially in the face of our rapidly aging Western society. It effectively reduces negative emotional reactions towards cognitive functioning and is highly appreciated by participants. Furthermore, participants evaluate their functioning more positive after taking part in the intervention program. The current study described the background and content of the intervention program in detail in order to enable application and replication by other clinicians and researchers. This may enhance the accumulation of knowledge and the improvement of care. 


\section{References}

Aiken, L. S., \& West, S. G. (1991). Multiple regression: Testing and interpreting interactions. Newbury Park, CA: Sage.

Bäckman, L., \& Dixon, R. A. (1992). Psychological compensation: a theoretical framework. Psychological Bulletin, 112, 259-283.

Bagwell, D. K., \& West, R. L. (2008). Assessing compliance: active versus inactive trainees in a memory intervention. Clinical Interventions in Aging, 3, 371-382.

Ball, K., Berch, D. B., Helmers, K. F., Jobe, J. B., Leveck, M. D., Marsiske, M., Morris, J. N., Rebok, G. W., Smith, D. M., Tennstedt, S. L., Unverzagt, F. W., \& Willis, S. L. (2002). Effects of cognitive training interventions with older adults: a randomized controlled trial. Journal of the American Medical Association, 288, 2271-2281.

Baltes, P. B., \& Baltes, M. M. (1990). Psychological perspectives on successful aging: the model of selective optimization with compensation. In P. B. Baltes (Ed.), Successful aging: Perspectives from the behavioral sciences (pp. 1-34). Cambridge: Cambridge University Press.

Blazer, D. G., Hays, J. C., Fillenbaum, G. G., \& Gold, D. T. (1997). Memory complaint as a predictor of cognitive decline: a comparison of African American and White elders. Journal of Aging and Health, 9, 171-184.

Bouma, J., Ranchor, A. V., Sanderman, R., \& Van Sonderen, E. (1995). Measuring symptoms of depression using the CES-D: a manual [Het meten van symptomen van depressie met de CES-D: een handleiding]. Groningen: Noordelijk Centrum voor Gezondheidsvraagstukken, Rijksuniversiteit Groningen.

Cargin, J. W., Collie, A., Masters, C., \& Maruff, P. (2008). The nature of cognitive complaints in healthy older adults with and without objective memory decline. Journal of Clinical and Experimental Neuropsychology, 30, 245-257.

Comijs, H. C., Deeg, D. J., Dik, M. G., Twisk, J. W., \& Jonker, C. (2002). Memory complaints; the association with psycho-affective and health problems and the role of personality characteristics. A 6-year follow-up study. Journal of Affective Disorders, 72, 157-165.

Comijs, H. C., Dik, M. G., Aartsen, M. J., Deeg, D. J., \& Jonker, C. (2005). The impact of change in cognitive functioning and cognitive decline on disability, well-being, and the use of healthcare services in older persons. Results of Longitudinal Aging Study Amsterdam. Dementia and Geriatric Cognitive Disorders, 19, 316-323.

Commissaris, C. J., Jolles, J., Verhey, F. R., Ponds, R. W., Damoiseaux, V., \& Kok, G. J. (1993). Forgetful or demented? Who worries and why? [Vergeetachtig of dement? Wie maakt zich zorgen en waarom?]. Tijdschrift voor Gerontologie en Geriatrie, 24, 144-149.

Commissaris, C. J., Ponds, R. W., \& Jolles, J. (1998). Subjective forgetfulness in a normal Dutch population: possibilities for health education and other interventions. Patient Education and Counseling, 34, 25-32.

Commissaris, C. J., Verhey, F. R., \& Jolles, J. (1996). A controlled study into the effects of psychoeducation for patients with cognitive disturbances. Journal of Neuropsychiatry and Clinical Neuroscience, 8 , 429-435.

Craik, F. I., \& Bialystok, E. (2006). Cognition through the lifespan: mechanisms of change. Trends in Cognitive Science, 10, 131-138.

Craik, F. I., \& Grady, J. G. (2002). Aging, memory, and frontal lobe functioning. In D. T. Stuss \& R. T. Knight (Eds.), Principles of frontal lobe function (pp. 528-540). New York: Oxford University Press.

Craik, F. I., \& Salthouse, T. A. (2000). Handbook of aging and cognition. Mahwah, NJ: Lawrence Erlbaum Associates.

Craik, F. I., Winocur, G., Palmer, H., Binns, M. A., Edwards, M., Bridges, K., Glazer, P., Chavannes, R., \& Stuss, D. T. (2007). Cognitive rehabilitation in the elderly: effects on memory. Journal of the International Neuropsychological Society, 13, 132-142. 
De Bie, S. E. (1987). Toward a standardization of questions concerning demographic variables in population studies [Standaardvragen 1987 - Voorstellen voor uniformering van vraagstellingen naar achtergrondkenmkernen en interviews]. Leiden, The Netherlands: Leiden University Press.

Dixon, R. A. (1995). Promoting competence through compensation. In L. A. Bond (Ed.), Promoting successful and productive aging (Vol. 1, pp. 220-238). Thousand Oaks, Calif: Sage Publications.

Dixon, R. A., de Frias, C. M., \& Bäckman, L. (2001). Characteristics of self-reported memory compensation in older adults. Journal of Clinical and Experimental Neuropsychology, 23, 650-661.

Floyd, M., \& Scogin, F. (1997). Effects of memory training on the subjective memory functioning and mental health of older adults: a meta-analysis. Psychology and Aging, 12, 150-161.

Flynn, T. M., \& Storandt, M. (1990). Supplemental group discussions in memory training for older adults. Psychology and Aging, 5, 178-181.

Folstein, M. F., Folstein, S. E., \& McHugh, P. R. (1975). “Mini-mental state.” A practical method for grading the cognitive state of patients for the clinician. Journal of Psychiatry Research, 12, 189-198.

Geerlings, M. I., Jonker, C., Bouter, L. M., Ader, H. J., \& Schmand, B. (1999). Association between memory complaints and incident Alzheimer's disease in elderly people with normal baseline cognition. The American Journal of Psychiatry, 156, 531-537.

Glisky, E. L., \& Glisky, M. L. (2005). Memory rehabilition in the elderly. In D. T. Stuss, G. Winocur \& I. H. Robertson (Eds.), Cognitive neurorehabilitation (pp. 347-361). Cambridge: Cambridge University Press.

Grol, R. P., \& Wensing, M. (2006). Implementation: effective improvement of health care [Implementatie: effectieve verbetering van de gezondheidszorg]. Maarssen: Elsevier Gezondheidszorg.

Hess, T. M. (2005). Memory and aging in context. Psychological Bulletin, 131, 383-406.

Hohaus, L. (2007). Remembering to age successfully: evaluation of a successful aging approach to memory enhancement. International Psychogeriatrics, 19, 137-150.

Hoogenhout, E. M., De Groot, R. H. M., Van der Elst, W., \& Jolles, J. (under review). Effects of a comprehensive educational group intervention in older women with cognitive complaints: a randomized controlled trial.

Jobe, J. B., Smith, D. M., Ball, K., Tennstedt, S. L., Marsiske, M., Willis, S. L., Rebok, G. W., Morris, J. N., Helmers, K. F., Leveck, M. D., \& Kleinman, K. (2001). ACTIVE: a cognitive intervention trial to promote independence in older adults. Controlled Clinical Trials, 22, 453-479.

Jonker, C., Geerlings, M. I., \& Schmand, B. (2000). Are memory complaints predictive for dementia? A review of clinical and population-based studies. International Journal of Geriatric Psychiatry, 15, 983991.

Jonker, C., Launer, L. J., Hooijer, C., \& Lindeboom, J. (1996). Memory complaints and memory impairment in older individuals. Journal of the American Geriatrics Society, 44, 44-49.

Jorm, A. F., Christensen, H., Korten, A. E., Jacomb, P. A., \& Henderson, A. S. (2001). Memory complaints as a precursor of memory impairment in older people: a longitudinal analysis over 7-8 years. Psychological Medicine, 31, 441-449.

Kliegel, M., \& Zimprich, D. (2005). Predictors of cognitive complaints in older adults: a mixture regression approach. European Journal of Ageing, 2, 13-23.

Kliegel, M., Zimprich, D., \& Eschen, A. (2005). What do subjective cognitive complaints in persons with aging-associated cognitive decline reflect? International Psychogeriatrics, 17, 499-512.

Lachman, M. E. (1991). Perceived control over memory aging: developmental and intervention perspectives. Journal of Social Issues, 47, 159-175.

Lachman, M. E. (2000). Promoting a sense of control over memory aging. In R. D. Hill, L. Backman \& A. Stigsdotter Neely (Eds.), Cognitive rehabilitation in old age. Oxford: Oxford University Press.

Lachman, M. E., \& McArthur, L. Z. (1986). Adulthood age differences in causal attributions for cognitive, physical, and social performance. Psychology and Aging, 1, 127-132.

Lachman, M. E., Weaver, S. L., Bandura, M., Elliott, E., \& Lewkowicz, C. J. (1992). Improving memory and control beliefs through cognitive restructuring and self-generated strategies. Journals of Gerontology, 47, P293-299. 
Langbaum, J. B., Rebok, G. W., Bandeen-Roche, K., \& Carlson, M. C. (2009). Predicting memory training response patterns: results from ACTIVE. Journals of Gerontology B Series: Psychological Sciences and Social Sciences, 64, 14-23.

Levine, B., Robertson, I. H., Clare, L., Carter, G., Hong, J., Wilson, B. A., Duncan, J., \& Stuss, D. T. (2000). Rehabilitation of executive functioning: an experimental-clinical validation of goal management training. Journal of the International Neuropsychological Society, 6, 299-312.

Levine, B., Stuss, D. T., Winocur, G., Binns, M. A., Fahy, L., Mandic, M., Bridges, K., \& Robertson, I. H. (2007). Cognitive rehabilitation in the elderly: effects on strategic behavior in relation to goal management. Journal of the International Neuropsychological Society, 13, 143-152.

Linnan, L., \& Steckler, A. (2002). Process evaluation for public health interventions and research: an overview. In A. Steckler \& L. Linnan (Eds.), Process evaluation for public health interventions and research (pp. 1-23). San Francisco: John Wiley \& Sons, Inc.

McDougall, G. J., Jr. (2009). A framework for cognitive interventions targeting everyday memory performance and memory self-efficacy. Family and Community Health, 32, S15-26.

Mendes, T., Gino, S., Ribeiro, F., Guerreiro, M., de Sousa, G., Ritchie, K., \& de Mendonca, A. (2008). Memory complaints in healthy young and elderly adults: Reliability of memory reporting. Aging and Mental Health, 12, 177-182.

Minett, T. S., Da Silva, R. V., Ortiz, K. Z., \& Bertolucci, P. H. (2008). Subjective memory complaints in an elderly sample: a cross-sectional study. International Journal of Geriatric Psychiatry, 23, 49-54.

Mohs, R. C., Ashman, T. A., Jantzen, K., Albert, M., Brandt, J., Gordon, B., Rasmusson, X., Grossman, M., Jacobs, D., \& Stern, Y. (1998). A study of the efficacy of a comprehensive memory enhancement program in healthy elderly persons. Psychiatry Research, 77, 183-195.

Mol, M. E., Carpay, M., Ramakers, I., Rozendaal, N., Verhey, F. R., \& Jolles, J. (2007). The effect of perceived forgetfulness on quality of life in older adults; a qualitative review. International Journal of Geriatric Psychiatry, 22, 393-400.

Mol, M. E., Ruiter, R. A., Verhey, F. R., Dijkstra, J., \& Jolles, J. (2008). A study into the psychosocial determinants of perceived forgetfulness: implications for future interventions. Aging and Mental Health, 12, 167-176.

Mol, M. E., Van Boxtel, M. P., Willems, D., \& Jolles, J. (2006). Do subjective memory complaints predict cognitive dysfunction over time? A six-year follow-up of the Maastricht Aging Study. International Journal of Geriatric Psychiatry, 21, 432-441.

Mol, M. E., Van Boxtel, M. P., Willems, D., Verhey, F. R., \& Jolles, J. (2009). Subjective forgetfulness is associated with lower quality of life in middle-aged and young-old individuals: a 9-year follow-up in older participants from the Maastricht Aging Study. Aging and Mental Health, 13, 699-705.

Parisi, J. M., Greene, J. C., Morrow, D. G., \& Stine-Morrow, E. A. (2007). The Senior Odyssey: Participant experiences of a program of social and intellectual engagement. Activities, Adaptation and Aging, 31, 31-49.

Petersen, R. C., Smith, G. E., Waring, S. C., Ivnik, R. J., Tangalos, E. G., \& Kokmen, E. (1999). Mild cognitive impairment: clinical characterization and outcome. Archives of Neurology, 56, 303-308.

Ponds, R. W., Commissaris, C. J., \& Jolles, J. (1997). Prevalence and covariates of subjective forgetfulness in a normal population in The Netherlands. International Journal of Aging and Human Development, 45, 207-221.

Ponds, R. W., \& Jolles, J. (1996). Memory complaints in elderly people: the role of memory abilities, metamemory, depression, and personality. Educational Gerontology, 22, 341-357.

Rebok, G. W., Carlson, M. C., \& Langbaum, J. B. (2007). Training and maintaining memory abilities in healthy older adults: traditional and novel approaches. Journals of Gerontology B Series: Psychological Sciences and Social Sciences, 62 Spec No 1, 53-61.

Salthouse, T. A. (1996). The processing-speed theory of adult age differences in cognition. Psychological Review, 103, 403-428.

Salthouse, T. A. (2006). Mental exercise and Mental aging: evaluating the validity of the "Use it or Lose it" Hypothesis. Perspectives on Psychological Sciences, 1, 68-87. 
Sanderman, R., Arrindell, W. A., Ranchor, A. V., Eysenck, H. J., \& Eysenck, S. B. G. (1995). Measuring personality traits with the Eysenck Personality Questionnaire (EPQ) [Het meten van persoonlijkheidskenmerken met de Eysenck Personality Questionnaire (EPQ]. Groningen, The Netherlands: Noordelijk Centrum voor Gezondheidsvraagstukken, Rijksuniversiteit Groningen.

Schreurs, K. M., Colland, V. T., Kuijer, R. G., De Ridder, D. T., \& Van Elderen, T. (2003). Development, content, and process evaluation of a short self-management intervention in patients with chronic diseases requiring self-care behaviours. Patient Education and Counseling, 51, 133-141.

Stuss, D. T., Robertson, I. H., Craik, F. I., Levine, B., Alexander, M. P., Black, S., Dawson, D., Binns, M. A., Palmer, H., Downey-Lamb, M., \& Winocur, G. (2007). Cognitive rehabilitation in the elderly: a randomized trial to evaluate a new protocol. Journal of the International Neuropsychological Society, 13, 120-131.

Troyer, A. K. (2001). Improving memory knowledge, satisfaction, and Functioning, via an education and intervention program for older adults. Aging, Neuropsychology, and Cognition, 8, 256-268.

Valentijn, S. A., Van Hooren, S. A., Bosma, H., Touw, D. M., Jolles, J., Van Boxtel, M. P., \& Ponds, R. W. (2005). The effect of two types of memory training on subjective and objective memory performance in healthy individuals aged 55 years and older: a randomized controlled trial. Patient Education and Counseling, 57, 106-114.

Van Hooren, S. A., Valentijn, S. A., Bosma, H., Ponds, R. W., Van Boxtel, M. P., \& Jolles, J. (2007). Cognitive functioning in healthy older adults aged 64-81: a cohort study into the effects of age, sex, and education. Aging, Neuropsychology, and Cognition, 14, 40-54.

Van Hooren, S. A., Valentijn, S. A., Bosma, H., Ponds, R. W., Van Boxtel, M. P., Levine, B., Robertson, I., \& Jolles, J. (2007). Effect of a structured course involving goal management training in older adults: A randomised controlled trial. Patient Education and Counseling, 65, 205-213.

Verhaeghen, P., Marcoen, A., \& Goossens, L. (1992). Improving memory performance in the aged through mnemonic training: a meta-analytic study. Psychology and Aging, 7, 242-251.

Verhey, F. R., Ramakers, I., Jolles, J., Scheltens, P., Vernooij-Dassen, M. J., \& Olde Rikkert, M. (2007). Memory clinics in the Netherlands: development since 1998 [Geheugenpoli's in Nederland: ontwikkelingen sinds 1998]. Tijdschrift voor Gerontologie en Geriatrie, 38, 237-245.

West, R. L., Bagwell, D. K., \& Dark-Freudeman, A. (2008). Self-Efficacy and Memory Aging: The Impact of a Memory Intervention Based on Self-Efficacy. Aging, Neuropsychology, and Cognition, 15, 302-329.

Willis, S. L., Tennstedt, S. L., Marsiske, M., Ball, K., Elias, J., Koepke, K. M., Morris, J. N., Rebok, G. W., Unverzagt, F. W., Stoddard, A. M., \& Wright, E. (2006). Long-term effects of cognitive training on everyday functional outcomes in older adults. Journal of the American Medical Association, 296, 2805-2814.

Winblad, B., Palmer, K., Kivipelto, M., Jelic, V., Fratiglioni, L., Wahlund, L. O., Nordberg, A., Backman, L., Albert, M., Almkvist, O., Arai, H., Basun, H., Blennow, K., de Leon, M., DeCarli, C., Erkinjuntti, T., Giacobini, E., Graff, C., Hardy, J., Jack, C., Jorm, A., Ritchie, K., van Duijn, C., Visser, P., \& Petersen, R. C. (2004). Mild cognitive impairment--beyond controversies, towards a consensus: report of the International Working Group on Mild Cognitive Impairment. Journal of Internal Medicine, 256, 240-246.

Winocur, G., Craik, F. I., Levine, B., Robertson, I. H., Binns, M. A., Alexander, M., Black, S., Dawson, D., Palmer, H., McHugh, T., \& Stuss, D. T. (2007). Cognitive rehabilitation in the elderly: overview and future directions. Journal of the International Neuropsychological Society, 13, 166-171.

Winocur, G., Palmer, H., Dawson, D., Binns, M. A., Bridges, K., \& Stuss, D. T. (2007). Cognitive rehabilitation in the elderly: an evaluation of psychosocial factors. Journal of the International Neuropsychological Society, 13, 153-165.

Zacks, R. T., Hasher, L., \& Li, K. Z. H. (2000). Human memory. In F. I. M. Craik \& T. A. Salthouse (Eds.), The handbook of aging and cognition (Vol. 2, pp. 293-357). Mahwah, NJ: Erbaum.

Zimprich, D., Martin, M., \& Kliegel, M. (2003). Subjective cognitive complaints, memory performance, and depressive affect in old age: a change-oriented approach. International Journal of Aging and Human Development, 57, 339-366. 

Effects of a comprehensive educational group intervention in older women with cognitive complaints: a randomized controlled trial 


\section{Abstract}

The current study presents a new comprehensive educational group intervention that offers psycho-education about cognitive aging and contextual factors (i.e., negative age stereotypes, beliefs, health, and lifestyle), focuses on skills and compensatory behavior, and incorporates group discussion. Its effects were investigated in community-dwelling older women, who report normal age-related cognitive complaints. A randomized controlled trial with an experimental and waiting list control condition was carried out in a sample of 50 women aged 60-75 years. As the main problem of these individuals were perceived cognitive deficits without actual cognitive decrements, metacognition served as the primary outcome measure. Objective cognitive functioning and psychological wellbeing were secondary outcome measures. A double baseline and a follow-up assessment were carried out. Participants in the experimental condition reported significantly fewer negative emotional reactions towards cognitive functioning $(U=164.500, p=.004)$. The reported effect size ( $\delta=-.473$ ) was large. This new comprehensive educational group intervention reduces negative emotional reactions towards cognitive functioning, which seems a prerequisite for improved subjective cognitive functioning and wellbeing. It may contribute to the field of public health care for the growing number of normally aging adults, in whom the prevalence of cognitive complaints is about 40 to 50 percent. 


\section{Introduction}

One of the most common complaints of normal aging refers to cognitive changes. The prevalence of such perceived cognitive problems increases up to 41 percent in adults aged 54 to 66 years and 52 percent in adults aged 69 to 86 years (Ponds, Commissaris, \& Jolles, 1997). This is a source of worry and frustration in many older adults (Commissaris et al., 1993) and significantly contributes to a lowered quality of life (Mol, Van Boxtel, Willems, Verhey, \& Jolles, 2009). Although aging-related decrements in cognitive functions are largely inevitable, the association between cognitive complaints and actual cognitive decline is weak (Kliegel, Zimprich, \& Eschen, 2005; Minett, Dean, Firbank, English, \& O’Brien, 2005; Mol, Van Boxtel, Willems, \& Jolles, 2006). Nevertheless, many people who consider themselves to be forgetful are worried that this may be a sign of a pathological condition such as a degenerative brain disease (e.g., Alzheimer dementia) (Commissaris et al., 1993). They consequently appeal on specialized and costly healthcare services (e.g., memory clinics) (Comijs, Dik, Aartsen, Deeg, \& Jonker, 2005; Verhey et al., 2007). There is thus a major challenge to develop effective interventions for this target group, all the more because Western societies will face the consequences of a rapidly aging population in the next years.

A dominant view in cognitive aging research is that changes in memory reflect changes in the information-processing system, for example cognitive slowing (Salthouse, 1996) or problems in inhibitory functions (Craik \& Bialystok, 2006; Van Hooren, Valentijn, Bosma, Ponds, Van Boxtel et al., 2007). Although this information-processing framework is very useful, it might lead to an incomplete understanding and characterization of cognitive aging (Hess, 2005). For that reason, Hess (2005) argues for a broader consideration of cognitive aging from a life span perspective in which the adaptive nature of cognition as well as contextual factors (e.g., social context, negative stereotyping, personal goal setting, beliefs about aging, health and lifestyle) are taken into account. This alternative perspective to cognitive aging is multidimensional and has several implications for the development of interventions for older adults with cognitive complaints or objective decrements in cognitive functions.

Interventions in the context of cognitive aging traditionally involved cognitive training. A recent example is the extensive ACTIVE-study (Jobe et al., 2001) that compared three different cognitive training interventions (memory, reasoning, and speed of processing) to a no-contact control group. Such cognitive interventions typically bring about task and domain specific effects (Ball et al., 2002; Rebok, Carlson, \& Langbaum, 2007; Verhaeghen, Marcoen, \& Goossens, 1992) that hardly generalize to subjective cognitive functioning, wellbeing or everyday outcome (Ball et al., 2002; Floyd \& Scogin, 1997; Willis et al., 2006). It is stated that future intervention studies should find a way to increase awareness and knowledge, decrease 
negative beliefs, and decrease negative memory-related affect (Floyd \& Scogin, 1997; Hohaus, 2007; Rebok et al., 2007; Verhaeghen et al., 1992). This may be achieved by developing interventions with a strong educational focus that promote a more realistic understanding of cognitive aging and relevant contextual factors (e.g., health, lifestyle, beliefs, metacognition), counteract stereotypes and provide compensatory techniques (Floyd \& Scogin, 1997; Hess, 2005; Hohaus, 2007; Lachman, 1991; McDougall, 2009).

There are several intervention studies that combine strategy training with other approaches, like cognitive restructuring (Lachman, Weaver, Bandura, Elliott, \& Lewkowicz, 1992), psychosocial training (Stuss et al., 2007; Winocur et al., 2007), and education about metacognitive processes (Valentijn et al., 2005; West, Bagwell, \& Dark-Freudeman, 2008) or contextual factors (Hohaus, 2007; Mohs et al., 1998; Troyer, 2001; Van Hooren, Valentijn, Bosma, Ponds, Van Boxtel et al., 2007). Some of these studies used fully randomized controlled trials with an active control condition (Lachman et al., 1992; Mohs et al., 1998; Valentijn et al., 2005) and/or a nocontact control condition (Lachman et al., 1992; Stuss et al., 2007; Valentijn et al., 2005; Van Hooren, Valentijn, Bosma, Ponds, Van Boxtel et al., 2007; West et al., 2008; Winocur et al., 2007). Outcomes vary greatly with intervention effects established on subjective cognitive functioning (Hohaus, 2007; Lachman et al., 1992; Mohs et al., 1998; Troyer, 2001; Valentijn et al., 2005; Van Hooren, Valentijn, Bosma, Ponds, Van Boxtel et al., 2007; West et al., 2008; Winocur et al., 2007), psychological wellbeing (Winocur et al., 2007) or objective cognitive performance (Hohaus, 2007; Mohs et al., 1998; Troyer, 2001; Valentijn et al., 2005; West et al., 2008; Winocur et al., 2007).

The current study presents a new intervention program that has evolved from previous successful intervention studies by our research group (Commissaris, Verhey, \& Jolles, 1996; Valentijn et al., 2005; Van Hooren, Valentijn, Bosma, Ponds, Van Boxtel et al., 2007). This intervention offered psycho-education about normal agerelated cognitive changes, normal versus pathological cognitive aging, and the influence of contextual factors (e.g., health, lifestyle, psychosocial functioning, beliefs, and negative aging stereotypes) (Hess, 2005; Mol, Ruiter, Verhey, Dijkstra, \& Jolles, 2008). The intervention fitted the ideas of successful aging as defined by Baltes and Baltes (1990) in the model of selective optimization with compensation. In short, this model states that perceived age-related losses could be adapted for by three interacting processes: selection, optimization, and compensation. Selection refers to the process of adjusting expectations and changing personal goals to permit subjective experience of satisfaction and control. Optimization reflects the view that people engage in behaviors to enrich and augment their general reserves. Compensation results from a discrepancy between the level of performance, and situations and goal characteristics (Baltes \& Baltes, 1990). A considerable amount of time was spent on education about strategies that can reduce the impact of perceived cogni- 
tive losses in everyday life (e.g., investment of more time and effort, the use of external aids and internal strategies, changing expectations and relaxation of criteria, and modifying environmental demands and expectations of others) (Bäckman \& Dixon, 1992). A specific strategy that was discussed was Goal Management, which aims to reduce negative real-life effects of age-related losses in executive functions and strategic processing (Van Hooren, Valentijn, Bosma, Ponds, Van Boxtel et al., 2007). Another important aspect of the intervention was group discussion (Flynn \& Storandt, 1990; Valentijn et al., 2005) about societal and personal beliefs, negative aging stereotypes (Hess, 2005), and pessimistic and maladaptive attributions (Commissaris et al., 1993; Lachman \& McArthur, 1986), which may contribute to better adaptation to age-related cognitive losses (Lachman, 1991). The intervention was described in more detail in Hoogenhout, De Groot, and Jolles (in press).

To study the effectiveness of our intervention program, a randomized controlled trial was carried out in a homogenous sample of older community-dwelling women with cognitive complaints that can be attributed to normal aging. A fundamental premise was that the main problem of this target group was an agingrelated perceived cognitive decline that is related to, for example, negative feelings about cognitive functioning and a low sense of control, but has limited predictive value for actual cognitive losses (Kliegel et al., 2005; Mol et al., 2006). As is stated by other researchers, it is important to decrease, for example, negative feelings about cognitive functioning (Floyd \& Scogin, 1997; Hohaus, 2007; Rebok et al., 2007; Verhaeghen et al., 1992). For that reason, metacognitive functioning served as a primary outcome measure. Secondly, in order to investigate whether these effects generalized to other domains, the effects on objective cognitive performance and psychological wellbeing were examined.

\section{Methods}

\section{Participants}

Participants were recruited through announcements on a regional radio station, and through advertisements in local and regional weeklies. In order to create a homogenous study sample there were age (i.e., between 60 and 75 years) and gender (i.e., being woman) restrictions to inclusion. Previous research revealed that people in this age range generally report many cognitive complaints that can be ascribed to normal cognitive aging (Ponds et al., 1997). The creation of single gender intervention groups has a clinical advantage, because relevant topics and reported everyday cognitive problems differ for men and women (Van Hooren, Valentijn, Bosma, Ponds, Van Boxtel et al., 2007). 
Other inclusion criteria were: reporting age-related cognitive complaints and/or concerns about becoming demented (as measured with a semi-structured interview), and good comprehension of the Dutch language. Exclusion criteria were a score of 24 or lower on the Mini-Mental State Examination (Folstein, Folstein, \& McHugh, 1975), the occurrence of any neurological disorder (e.g., stroke or dementia), or any (previous) psychiatric disorder (e.g., major depressive disorder or schizophrenia).

\section{Procedure}

The study was designed as a randomized controlled trial. After screening by telephone, eligible persons were sent an information letter about the intervention study. People who were willing to participate were randomly assigned to an experimental or waiting list control condition. All participants then received an individual intake interview. A double baseline cognitive assessment was carried out with about one week in between. Additionally, all participants filled in several questionnaires at baseline. Within one or two weeks after the baseline assessment, participants in the experimental condition started the four-week intervention. Participants in the control condition were placed on a waiting list for four weeks. Both the cognitive tests and questionnaires were administered to all participants approximately seven weeks after the start of the study (see Figure 1). Afterwards, participants in the waiting list control condition were offered the intervention program. The medical ethics committee of the Maastricht University Medical Centre approved the study and all participants gave their informed consent.

\section{The intervention program}

The content of the intervention program is listed in Table 1. The 4-week intervention consisted of eight 1.5-hour group sessions, with six to nine participants per group. All sessions were facilitated a healthcare psychologist and a research neuropsychologist, who were not involved in the assessments. The same research neuropsychologist was involved in all intervention groups (i.e., three experimental and three waiting-list groups).

The intervention was offered in a structured manner and within a standard time frame. Each session started with the evaluation and recapitulation of the content of the previous session ( \pm 10 minutes). In addition, homework assignments were discussed and questions were answered ( \pm 10 minutes). Afterwards, several themes and topics were introduced one by one in short blocks, which was supported by a PowerPoint slideshow with handouts ( \pm 40 minutes in total). After each block, beliefs and attitudes with respect to the theme were shared and discussed in the group ( \pm 20 minutes in total). Each session ended with a summary of the session's 
themes, answering questions and a short preview of the homework assignments $( \pm$ 10 minutes). At the start of the intervention program, each participant received a workbook in which prints of each session's slideshow could be collected and notes could be taken. Homework assignments, registration forms and summaries of each session were supplied at the start of each session.

Table 1 Summary of the intervention program

\begin{tabular}{|c|c|c|}
\hline Session & Content & Homework \\
\hline 1 & $\begin{array}{l}\text { - First acquaintance } \\
\text { - Introduction to the intervention program } \\
\text { - Overview of themes } \\
\text { - Cognitive aging and subjective forgetfulness } \\
\text { - Contextual factors } \\
\text { - Aging stereotypes }\end{array}$ & $\begin{array}{l}\text { - Reading the summary } \\
\text { - Personal goals and expectations } \\
\text { - Cognitive diary } \\
\text { - Personal names for mental slips }\end{array}$ \\
\hline 2 & $\begin{array}{l}\text { - Successful aging } \\
\text { - Brain and cognition } \\
\text { - Information processing and memory } \\
\text { - Attention and mental slowness }\end{array}$ & $\begin{array}{l}\text { - Reading the summary } \\
\text { - Cognitive diary } \\
\text { - Speed and attention in daily life }\end{array}$ \\
\hline 3 & $\begin{array}{l}\text { - Planning and executive functioning } \\
\text { - Absent-minded slips } \\
\text { - Successful cognitive aging and contextual factors }\end{array}$ & $\begin{array}{l}\text { - Reading the summary } \\
\text { - Planning everyday tasks } \\
\text { - Absent-minded slips }\end{array}$ \\
\hline 4 & $\begin{array}{l}\text { - Health } \\
\text { - Lifestyle } \\
\text { - Normal aging versus dementia } \\
\text { - Optimization and enriching general reserve }\end{array}$ & $\begin{array}{l}\text { - Reading the summary } \\
\text { - Contextual factors in own situation }\end{array}$ \\
\hline 5 & $\begin{array}{l}\text { - Psychological factors } \\
\text { - Vicious circle of forgetting } \\
\text { - Societal and personal beliefs and expectations } \\
\text { - Adjusting expectations and personal goals }\end{array}$ & $\begin{array}{l}\text { - Reading the summary } \\
\text { - Getting older, what goes right? } \\
\text { - Spontaneous strategy use }\end{array}$ \\
\hline 6 & $\begin{array}{l}\text { - Compensation versus restoration } \\
\text { - External strategies } \\
\text { - Internal strategies } \\
\text { - Environmental demands } \\
\text { - Investing more time and effort } \\
\text { - Planning and goal management }\end{array}$ & $\begin{array}{l}\text { - Reading the summary } \\
\text { - Compensation in daily life } \\
\text { - Preventing absent minded slips }\end{array}$ \\
\hline 7 & $\begin{array}{l}\text { - Investing more time and effort } \\
\text { - Planning and goal management } \\
\text { - Preventing and handling time pressure }\end{array}$ & $\begin{array}{l}\text { - Reading the summary } \\
\text { - Goal management in daily life } \\
\text { - Time pressure in everyday tasks }\end{array}$ \\
\hline 8 & $\begin{array}{l}\text { - Recapitulation of themes } \\
\text { - Generalization }\end{array}$ & $\begin{array}{l}\text { - Reading the summary } \\
\text { - Generalization }\end{array}$ \\
\hline
\end{tabular}




\section{Measures}

\section{Metacognitive functioning}

The primary outcome measure was metacognitive functioning as assessed with the Maastricht Metacognition Inventory (MMI). The $\mathrm{MMI}$ is a new and psychometrically sound questionnaire that has several advantages over existing questionnaires (e.g., its focus on metacognition instead of metamemory) (Hoogenhout, Van der Elst, De Groot, \& Jolles, under review). It contains four subscales. The Ability scale consists of 16 items that measured everyday cognitive failures (e.g., difficulty to carry out two simultaneous tasks). The Affect scale contains 11 items that measured emotional reactions towards everyday cognitive failures (e.g., get annoyed when forgetting something). The Control scale contains 5 items that measured complaints about the sense of control over cognitive functioning (e.g., be unable to preserve oneself from cognitive decline). The Strategy scale contains 11 items that measured the use of compensation strategies (e.g., relate information to something that is known well). All items were rated on a 5-point Likert scale, ranging from 1 (= strongly disagree), to 5 (= strongly agree). Higher scores indicated more everyday cognitive failures, more emotional reactions towards cognitive failures, more complaints about the sense of control over cognitive functioning, or the use of more compensation strategies, respectively.

\section{Objective cognitive functioning and psychological wellbeing}

Objective cognitive functioning and psychological wellbeing were measured with composite scores in order to reduce the number of data, increase power, and improve ecological validity. For a detailed description of the calculation method see Van der Elst, Van Boxtel, Van Breukelen, and Jolles (2008). In order to control for procedural learning effects in cognitive assessment, only data from the second baseline assessment were used.

The Memory Quotient (MQ) was constructed by the Visual Verbal Learning Test (VVLT) (Van der Elst, Van Boxtel, Van Breukelen, \& Jolles, 2005), an adaptation to the Rey VVLT, that measured the ability to learn new information and the ability to retrieve information from memory. Fifteen low-associative words were presented on a computer screen one by one at a one-second-time interval. Participants were asked to recall as many words as possible. There was no restriction on the output order. This procedure was repeated five times. Twenty minutes after the last presentation, participants were asked again to recall as many words as possible. The total score of the first three trials (VVLT 1-3) and the delayed recall score (VVLT delayed) were used to construct the $\mathrm{MQ}$. Parallel versions were used for each assessment. Higher MQ scores indicate better memory functioning.

The Executive functioning and Speed Quotient (ESQ) is a composite measure that consists of the weighted scores on the Stroop Colour Word Test (SCWT), the 
Concept Shifting Test (CST), and the Letter Digit Substitution Test (LDST). The SCWT was a measure of interference control and speed of information processing. It consisted of three trials with 100 stimuli each. Participants were asked to read the names of colours (i.e., red, blue, green, and yellow), name the colours, and name the incongruous ink colour in which the colour name was printed (e.g., the word 'blue' was printed in yellow), as quickly as possible (Van der Elst, Van Boxtel, Van Breukelen, \& Jolles, 2006c). SCWT time (i.e., time needed to complete the third card) and SCWT errors (i.e., number of errors on the third trial) were used to construct the ESQ (Van der Elst et al., 2008). The CST is an adaptation of the Trail Making Test and consisted of several subtasks. In each subtask, 16 small circles were grouped in a larger circle. These small circles contained numbers (part A), letters (part B), and both numbers and letters (part C). Participants were asked to cross out the items as fast as possible in numerical order (part A), alphabetical order (part B), or alternating (part C). The time to complete each subtest was recorded (Van der Elst, Van Boxtel, Van Breukelen, \& Jolles, 2006a). Shifting score (CST shifting = CSTc $-[\mathrm{CSTa}+\mathrm{CSTb}] / 2$ ) and the number of errors made in part C (CST errors) were used to construct the ESQ (Van der Elst et al., 2008). The LDST measured general speed of information processing. A key gave the numbers 1 to 9 , each paired with a different letter. Participants were asked to replace randomized letters with appropriate numbers indicated by the key, as quickly and accurately as possible (Van der Elst, Van Boxtel, Van Breukelen, \& Jolles, 2006b). The number of correct substitutions made in 60 seconds (LDST60) was used to construct the ESQ (Van der Elst et al., 2008). Higher ESQ scores indicate better executive functioning and higher speed.

The Psychological Wellbeing Quotient (PWQ) was calculated using the Centre of Epidemiologic Studies Depression scale (CES-D, total score inverted; Bouma, Ranchor, Sanderman, \& Van Sonderen, 1995), the Neurovegetative Complaints Questionnaire (NCQ, two scale scores inverted; Hoogenhout, Van der Elst, De Groot, Van Boxtel, \& Jolles, 2010), and the mental composite score of the Medical Outcome Study 36-item Short-Form Health Survey (SF-36; Ware, Kosinski, \& Keller, 1994). The CES-D contained 20 statements concerning depressive symptoms (e.g., feeling lonely) in the week prior to test administration. Participants had to indicate symptom frequency on a 4-point scale, ranging from 'seldom or never' $(=0)$ to 'usually or all the time' (=3). Higher scores indicated more depressive symptoms (Bouma et al., 1995). The NCQ consisted of two subscales (with 11 and 9 items, respectively) that measured neurovegetative/somatic complaints (e.g., heart palpitations) or reactive/emotional complaints (e.g., irritability). Participants had to indicate the frequency of occurrence on a 4-point scale ranging from 1 (= no, never) to 4 (= yes, often). Higher scores indicated more complaints (Hoogenhout et al., 2010). The SF36 contained 36 items that can be divided in nine subscales. From a selection of these subscales, a composite for mental wellbeing can be calculated (Ware et al., 
1994). Higher SF-36 subscale scores indicated better mental wellbeing. Higher PWQ scores indicate better psychological wellbeing.

\section{Other measures}

In order to investigate participants' characteristics several background variables were assessed. Educational level was measured on an 8-point ordinal scale, ranging from primary education to university education. Furthermore, information about marital status was collected (married or unmarried). Two subscales of the selfreported Eysenck Personality Inventory (EPQ; Sanderman, Arrindell, Ranchor, Eysenck, \& Eysenck, 1995) were administered to measure neuroticism (e.g., being emotional unstable), and extraversion (e.g., being talkative). These subscales consisted of 22 and 19 dichotomous items (i.e., 1 = yes, $0=$ no), respectively. Higher scores indicated more neuroticism or extraversion.

\section{Statistical Analyses}

Differences in baseline characteristics between the groups (i.e., experimental and control) were investigated in order to verify whether randomization was successful. A One-way Analysis of Variance (ANOVA) was performed for age, and Mann Whitney $U$ tests for educational level, EPQ neuroticism and extraversion and MMSE scores. A Chi-square test was used to analyze differences in marital status.

In order to control for potential baseline differences in the outcome measures between the groups, change scores were calculated for all outcome measures. Normality assumptions were checked with Shapiro Wilks tests. In case of violation of the normality assumption, non-parametric Mann Whitney $U$ tests were carried out on relevant change scores. Otherwise, parametric ANOVAs were used to investigate differences between the groups. In addition, Cliff's $\delta$ scores were calculated, which are effect size estimates that are less sensitive to violations of the normality assumption. Like Cohen's d effect estimates (Cohen, 1988), Cliff's $\delta$ scores could be interpreted as small $(\delta=.147)$, medium $(\delta=.330)$, or large $(\delta=.474)$ effects (Kromrey \& Hogarty, 1998; Leech \& Onwuegbuzie, 2002; Romano, Kromrey, Coraggio, \& Skowronek, 2006).

Consistent with the rules for clinical trials (Altman et al., 2001), analyses were based on the principle of intention-to-treat. Full application of the intention-to-treat principle was, however, impossible because complete outcome data for participants who dropped-out before the end of the study were not available and could consequently not be analyzed. A significance level of .01 was used to adjust for multiple comparisons. All analyses were carried out using PASW 18.0 for Macintosh. 


\section{Results}

\section{Recruitment of participants}

Results of recruitment and randomization are given in Figure 1. A total of $N=108$ people were screened for participation. Forty-eight of them were excluded: $n=28$ did not meet inclusion criteria and $n=20$ declined to participate after receiving more information about the intervention and the experiment. The remaining $N=60$ participants were randomly assigned to either the experimental or the waiting-list control group. The experimental group started with $n=30$ participants. Six of them decided to end their participation prematurely, due to logistic problems $(n=3)$, health-related problems $(n=2)$ or lack of interest $(n=1)$. The waiting list control group started with $n=30$ participants, four of whom terminated their participation before the end of the study. The main reasons were health-related problems $(n=3)$ and lack of interest $(n=1)$. This resulted in a total sample of $N=50$ people, $n=24$ of them were experimental and $n=26$ were waiting list control participants.

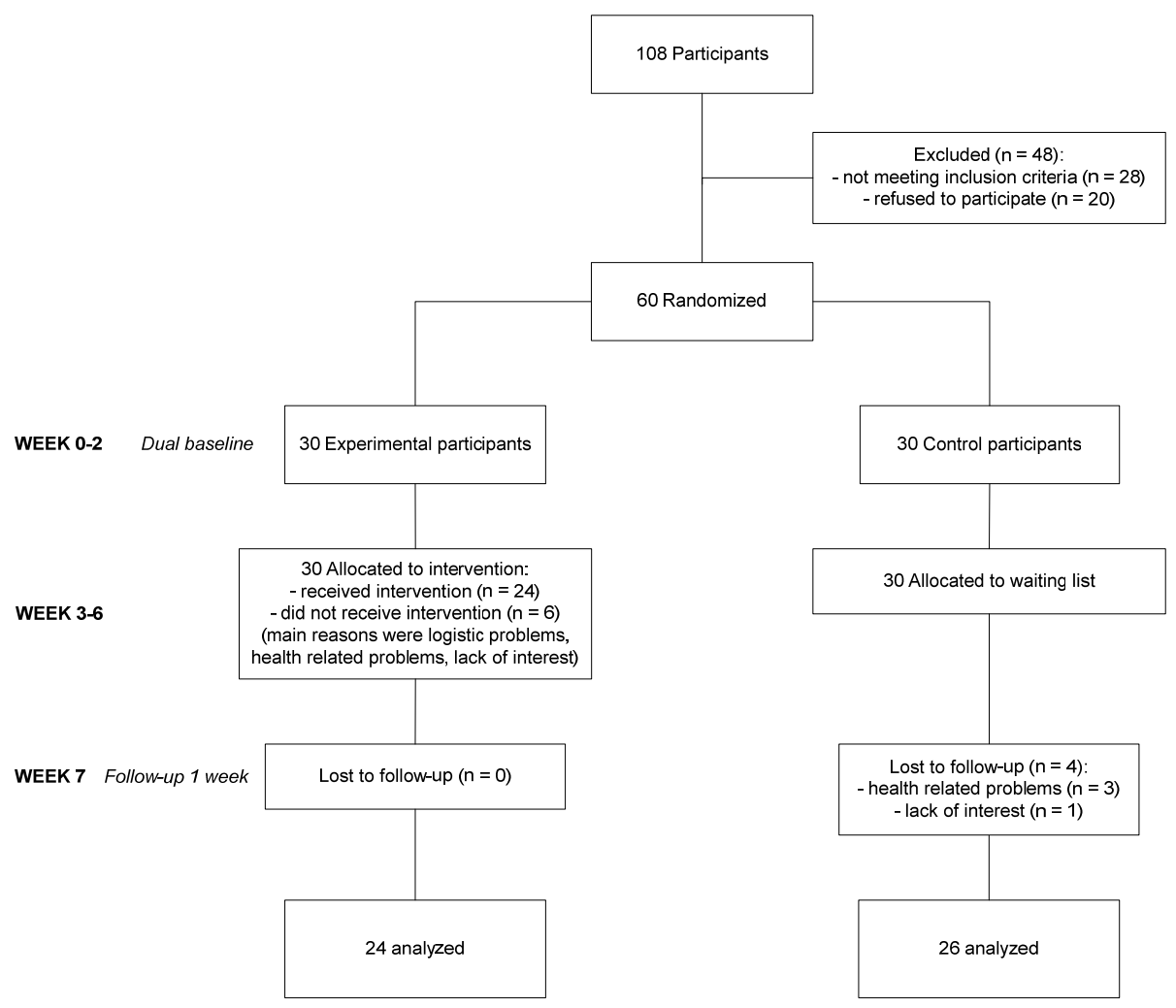

Figure 1 Flowchart of participants 


\section{Baseline characteristics}

There were no group differences in demographic characteristics, EPQ-scores, and MMSE scores at baseline (see Table 2). Participants who dropped out and participants who accomplished the study only differed in EPQ extraversion scores $(U=$ 34.000, $p=.028$ ), with those who dropped out reporting higher Extraversion levels.

Table 2 Participants' characteristics: means, standard deviations, and $p$-values

\begin{tabular}{llll}
\hline & Experimental group $(N=30)$ & Control group $(\mathbf{N}=\mathbf{3 0})$ & $\boldsymbol{p}$-value \\
\hline Age (years) & $66.00( \pm 4.23)$ & $66.10( \pm 4.48)$ & .928 \\
Educational level (8-point scale) & $4.14( \pm 2.03)$ & $4.00( \pm 1.90)$ & .867 \\
Marital status (\% married) & $51.7 \%$ & $64.3 \%$ & .337 \\
EPQ-Extraversion (range 0-19) & $9.88( \pm 3.19)$ & $9.96( \pm 3.56)$ & .761 \\
EPQ-Neuroticism (range 0-22) & $8.31( \pm 5.55)$ & $8.21( \pm 4.86)$ & .952 \\
MMSE & $29.24( \pm .99)$ & $29.11( \pm .99)$ & .563 \\
\hline
\end{tabular}

Note. $\mathrm{EPQ}=$ Eysenck Personality Questionnaire; MMSE = Mini Mental State Examination. ANOVA was used for age. A Chi-square test was used to analyze marital status. Mann Whitney $U$ tests were used to analyze educational level, EPQ-neuroticism and -extraversion, and MMSE scores.

\section{Intervention effects}

Results are presented in Table 3. Shapiro Wilks tests for normality indicated that the normality assumption was violated for the MMI-Affect, MMI-Control, MQ, and ESQ scores. Consequently, non-parametric Mann Whitney $U$ tests instead of parametric ANOVAs were carried out on these variables.

Analyses on the primary outcome measure (i.e., the $\mathrm{MMI}$ ) revealed a significant difference in Affect scores $(U=164.500, p=.004)$. Relative to their baseline functioning, participants in the experimental group reported less emotional reactions towards cognitive functioning than participants in the control condition immediately after intervention. The reported effect size $(\delta=-.473)$ could be interpreted as large (Leech \& Onwuegbuzie, 2002; Romano et al., 2006). There were no significant differences between the groups in Ability $(F(1,49)=.577, p=.451)$, Control $(U=$ $302.500, p=.852)$, and Strategy $(F(1,49)=1.713, p=.197)$ scores. Moreover, no significant differences were established in objective cognitive functioning as measured with the Memory Quotient $(U=229.000, p=.161)$ and the Executive functioning and Speed Quotient $(U=274.000, p=.616)$, or psychological wellbeing as measured with the Psychological Wellbeing Quotient $(F(1,49)=.069, p=.794)$. 
Table 3 Scores on all outcome measures (mean \pm SD) for the experimental and control group at baseline and follow-up assessments, and $p$-values and effect sizes from ANOVA's or Mann Whitney $U$ tests on change scores

\begin{tabular}{|c|c|c|c|c|}
\hline & Experimental group & Control group & $p$-value & Cliff's $\delta$ \\
\hline \multicolumn{5}{|l|}{ Metacognitive functioning } \\
\hline MMI-Ability scale & 24 & 26 & & \\
\hline Baseline & $46.83( \pm 9.44)$ & $50.12( \pm 10.61)$ & & \\
\hline Follow-up & $45.50( \pm 10.07)$ & $49.92( \pm 11.37)$ & .451 & -.163 \\
\hline MMI - Affect scale* & 24 & 26 & & \\
\hline Baseline & $30.50( \pm 6.65)$ & $32.81( \pm 8.51)$ & & \\
\hline Follow-up & $28.04( \pm 7.93)$ & $33.04( \pm 9.08)$ & $.004^{* *}$ & -.473 \\
\hline MMI - Control scale* & 24 & 26 & & \\
\hline Baseline & $12.13( \pm 2.91)$ & $13.77( \pm 4.11)$ & & \\
\hline Follow-up & $11.58( \pm 3.73)$ & $13.12( \pm 3.89)$ & .852 & -.107 \\
\hline MMI - Strategy scale & 24 & 26 & & \\
\hline Baseline & $42.58( \pm 4.13)$ & $43.65( \pm 4.84)$ & & \\
\hline Follow-up & $43.71( \pm 4.23)$ & $43.50( \pm 3.81)$ & .197 & .176 \\
\hline \multicolumn{5}{|l|}{ Cognitive functioning } \\
\hline Memory Quotient* & 24 & 25 & & \\
\hline Baseline & $109.20( \pm 14.62)$ & $102.86( \pm 16.23)$ & & \\
\hline Follow-up & $117.30( \pm 15.32)$ & $105.63( \pm 17.80)$ & .161 & .237 \\
\hline Executive functioning/Speed Quotient* & 23 & 26 & & \\
\hline Baseline & $108.04( \pm 6.80)$ & $105.37( \pm 12.91)$ & & \\
\hline Follow-up & $106.97( \pm 7.34)$ & $107.05( \pm 9.83)$ & .616 & -.084 \\
\hline \multicolumn{5}{|l|}{ Psychological wellbeing } \\
\hline Psychological Wellbeing Quotient & 24 & 26 & & \\
\hline Baseline & $103.72( \pm 14.93)$ & $96.57( \pm 16.31)$ & & \\
\hline Follow-up & $104.43( \pm 13.15)$ & $97.93( \pm 15.46)$ & .794 & -.016 \\
\hline
\end{tabular}

* In case of violation of the normality assumption non-parametric Mann Whitney $U$ tests were carried out instead of ANOVA's

$* * p<.01$

\section{Discussion}

The current study evaluated a new comprehensive educational group intervention in healthy older women with age-related cognitive complaints. This intervention evolved from previous successful intervention studies by our research group (Commissaris et al., 1996; Valentijn et al., 2005; Van Hooren, Valentijn, Bosma, Ponds, Van Boxtel et al., 2007). It applied to the contextual perspective of aging as proposed by Hess (Hess, 2005) and incorporated principles of selective optimization with compensation (Baltes \& Baltes, 1990). The program had a strong educational component, focused on the implementation of compensation strategies that can reduce the impact of perceived cognitive losses in everyday life, and incorporated group discussion about beliefs, aging stereotypes, attitudes and attributions. We considered an aging-related perceived cognitive decline and negative feelings about 
cognitive functioning the main problem of our target group, and consequently chose metacognition as the primary outcome measure. Objective cognitive performance and psychological wellbeing were secondary outcome measures.

Results indicated that participants in the experimental condition reported fewer negative emotional reactions towards cognitive functioning compared to participants in the waiting list control group immediately after intervention. Effect size estimates (Cliff's $\delta=-.473$ ) suggested that this effect could be interpreted as large (Leech \& Onwuegbuzie, 2002; Romano et al., 2006). The intervention thus improved an important aspect of metacognition. No statistical significant differences were found for other aspects of metacognition (i.e., everyday cognitive failures, complaints about a low sense of control, and the use of compensation strategies), objective cognitive functioning or psychological wellbeing. It is worth noticing that we included participants who were high performing on cognitive measures (i.e., we included a relatively healthy sample) (Van der Elst et al., 2005, 2006a, 2006b, 2006c). Nevertheless, reported Cliff's $\delta$ effect size estimates (see Table 3 ) point to medium effects in the expected direction on, for example, objective memory performance $(\delta=.237)$. With better power obtained by a larger study population this effect would likely have been statistically significant (Cohen, 1988).

There are several strengths of our study. First, we carried out a fully randomized controlled trial with an experimental group and a waiting list control group, which allows us to obtain relatively robust results and draw reliable conclusions (Altman et al., 2001). Note, however, that this study has several limitations that are common in psychosocial intervention research (e.g., the lack of a third non-specific placebo condition, lack of blindness of participants and trainers). Second, we included a homogeneous and carefully selected study sample to minimize the influence of inter-individual variability in functioning on group comparisons. It is worth to investigate whether positive effects extend to other target groups, like men, adults aged above 75 years, or individuals with mild cognitive impairment. Third, a common problem in intervention research is a lack of instruments that are sensitive enough to detect relatively small changes in functioning due to intervention (Floyd \& Scogin, 1997; Hohaus, 2007; Mohs et al., 1998; Verhaeghen et al., 1992), especially if healthy older adults are included who generally report minor problems and show relatively small cognitive loss (Hess, 2005; Hohaus, 2007). We therefore tried to optimize outcome measurement by using sensitive and ecologically valid cognitive composite scores (Van der Elst et al., 2008), and by developing a new metacognition instrument (i.e., the MMI) (Hoogenhout et al., under review) that had several advantages over existing instruments (e.g., its focus on metacognition instead of metamemory alone). The psychometric qualities of the MMI have been confirmed previously in a large population-based sample of 552 healthy older adults. The MMI turned out highly sensitive in detecting changes in emotional reactions towards cognitive functioning in the current study despite the fact that we dealt with a mod- 
erate to high functioning sample (Hoogenhout et al., under review) in whom large intervention gains are unlikely.

The findings of this study may be of high relevance. The intervention reduced negative emotional reactions towards cognitive functioning in a high functioning group of healthy older women whose main problems were perceived cognitive deficits instead of actual cognitive decrements. These results were obtained immediately after intervention. It has been argued that in the course of time other aspects of subjective cognitive functioning, objective cognitive functioning and/or psychological wellbeing are likely to change secondary to changes in metacognition or subjective cognitive functioning (McDougall, 2009; Van Hooren, Valentijn, Bosma, Ponds, Van Boxtel et al., 2007). Previous studies suggested that future intervention studies in healthy older adults with cognitive complaints should focus on decreasing negative beliefs and reducing negative memory-related affect. This goal was only marginally achieved by traditional interventions that primarily focus on cognitive training (Floyd \& Scogin, 1997; Hess, 2005; Hohaus, 2007; Rebok et al., 2007). Our findings indicated that a comprehensive educational approach, that incorporated principles of selection optimization and compensation (Baltes \& Baltes, 1990) and applied to a contextual perspective of cognitive aging (Hess, 2005), was effective in doing so. In our opinion, the only program that significantly shared characteristics and content with our intervention was described by Hohaus (2007). She compared an educational intervention that incorporated principles of selection optimization and compensation to an active control condition in twenty versus twenty community-dwelling older adults (aged 56 to 84 years). Significant differences between the groups were reported on measures of objective and subjective memory performance. Contrary to Hohaus (2007), we were able to carry out a randomized controlled trial. Furthermore, we performed a double baseline assessment to be sure that potential significant differences in cognitive outcome were not caused by procedural learning effects.

We consider the intervention a valuable contribution to the field of public health care, especially in face of a rapidly aging society. The prevalence of cognitive complaints in older adults is high (Ponds et al., 1997). This is often accompanied by worry and frustration (Commissaris et al., 1993), decrements in quality of life (Mol et al., 2009) and consequently with use of specialized and costly healthcare facilities (Comijs et al., 2005; Verhey et al., 2007). Our comprehensive educational group intervention may offer an opportunity for relatively low-level, time and cost effective treatment. This needs however further investigation. Unlike traditional mnemonic training interventions (Floyd \& Scogin, 1997; Rebok et al., 2007; Verhaeghen et al., 1992) the intervention program negative feelings towards cognitive functioning, which is strongly related to perceived cognitive decline in healthy normally aging individuals (Kliegel et al., 2005; Mol et al., 2008; Ponds et al., 1997). 


\section{References}

Altman, D. G., Schulz, K. F., Moher, D., Egger, M., Davidoff, F., Elbourne, D., Gotzsche, P. C., \& Lang, T. (2001). The revised CONSORT statement for reporting randomized trials: explanation and elaboration. Annuals of Internal Medicine, 134, 663-694.

Bäckman, L., \& Dixon, R. A. (1992). Psychological compensation: a theoretical framework. Psychological Bulletin, 112, 259-283.

Ball, K., Berch, D. B., Helmers, K. F., Jobe, J. B., Leveck, M. D., Marsiske, M., Morris, J. N., Rebok, G. W., Smith, D. M., Tennstedt, S. L., Unverzagt, F. W., \& Willis, S. L. (2002). Effects of cognitive training interventions with older adults: a randomized controlled trial. Journal of the American Medical Association, 288, 2271-2281.

Baltes, P. B., \& Baltes, M. M. (1990). Psychological perspectives on successful aging: the model of selective optimization with compensation. In P. B. Baltes (Ed.), Successful aging: Perspectives from the behavioral sciences (pp. 1-34). Cambridge: Cambridge University Press.

Bouma, J., Ranchor, A. V., Sanderman, R., \& Van Sonderen, E. (1995). Measuring symptoms of depression using the CES-D: a manual [Het meten van symptomen van depressie met de CES-D: een handleiding]. Groningen: Noordelijk Centrum voor Gezondheidsvraagstukken, Rijksuniversiteit Groningen.

Cohen, J. (1988). Statistical power analysis for the behavioral sciences. Hillsdal, NJ: Lawrence Erlbaum Associates.

Comijs, H. C., Dik, M. G., Aartsen, M. J., Deeg, D. J., \& Jonker, C. (2005). The impact of change in cognitive functioning and cognitive decline on disability, well-being, and the use of healthcare services in older persons. Results of Longitudinal Aging Study Amsterdam. Dementia and Geriatric Cognitive Disorders, 19, 316-323.

Commissaris, C. J., Jolles, J., Verhey, F. R., Ponds, R. W., Damoiseaux, V., \& Kok, G. J. (1993). Forgetful or demented? Who worries and why? [Vergeetachtig of dement? Wie maakt zich zorgen en waarom?]. Tijdschrift voor Gerontologie en Geriatrie, 24, 144-149.

Commissaris, C. J., Verhey, F. R., \& Jolles, J. (1996). A controlled study into the effects of psychoeducation for patients with cognitive disturbances. Journal of Neuropsychiatry and Clinical Neuroscience, 8 , 429-435.

Craik, F. I., \& Bialystok, E. (2006). Cognition through the lifespan: mechanisms of change. Trends in Cognitive Science, 10, 131-138.

Floyd, M., \& Scogin, F. (1997). Effects of memory training on the subjective memory functioning and mental health of older adults: a meta-analysis. Psychology and Aging, 12, 150-161.

Flynn, T. M., \& Storandt, M. (1990). Supplemental group discussions in memory training for older adults. Psychology and Aging, 5, 178-181.

Folstein, M. F., Folstein, S. E., \& McHugh, P. R. (1975). “Mini-mental state." A practical method for grading the cognitive state of patients for the clinician. Journal of Psychiatry Research, 12, 189-198.

Hess, T. M. (2005). Memory and aging in context. Psychological Bulletin, 131, 383-406.

Hohaus, L. (2007). Remembering to age successfully: evaluation of a successful aging approach to memory enhancement. International Psychogeriatrics, 19, 137-150.

Hoogenhout, E. M., De Groot, R. H., \& Jolles, J. (in press). A comprehensive educational group intervention for older adults with cognitive complaints: background, content, and process evaluation. Educational Gerontology.

Hoogenhout, E. M., Van der Elst, W., De Groot, R. H., \& Jolles, J. (under review). The Maastricht Metacognition Inventory: Factor structure, reliability and validity, and effects of age, sex, and education.

Hoogenhout, E. M., Van der Elst, W., De Groot, R. H., Van Boxtel, M. P., \& Jolles, J. (2010). The Neurovegetative Complaints Questionnaire in the Maastricht Aging Study: psychometric properties and normative data. Aging and Mental Health, 14, 613-623.

Jobe, J. B., Smith, D. M., Ball, K., Tennstedt, S. L., Marsiske, M., Willis, S. L., Rebok, G. W., Morris, J. N., Helmers, K. F., Leveck, M. D., \& Kleinman, K. (2001). ACTIVE: a cognitive intervention trial to promote independence in older adults. Controlled Clinical Trials, 22, 453-479. 
Kliegel, M., Zimprich, D., \& Eschen, A. (2005). What do subjective cognitive complaints in persons with aging-associated cognitive decline reflect? International Psychogeriatrics, 17, 499-512.

Kromrey, J. D., \& Hogarty, K. Y. (1998). Analysis options for testing group differences on ordered categorical variables: an empirical investigation of type I error control and statistical power. Multiple Linear Regression Viewpoints, 25, 70-82.

Lachman, M. E. (1991). Perceived control over memory aging: developmental and intervention perspectives. Journal of Social Issues, 47, 159-175.

Lachman, M. E., \& McArthur, L. Z. (1986). Adulthood age differences in causal attributions for cognitive, physical, and social performance. Psychology and Aging, 1, 127-132.

Lachman, M. E., Weaver, S. L., Bandura, M., Elliott, E., \& Lewkowicz, C. J. (1992). Improving memory and control beliefs through cognitive restructuring and self-generated strategies. Journal of Gerontology, 47, P293-299.

Leech, N. L., \& Onwuegbuzie, A. J. (2002). A call for greater use of nonparametric statistics. Paper presented at the Annual meeting of the Mid-South Educational Research Association.

McDougall, G. J. (2009). A framework for cognitive interventions targeting everyday memory performance and memory self-efficacy. Family and Community Health, 32, S15-26.

Minett, T. S., Dean, J. L., Firbank, M., English, P., \& O’Brien, J. T. (2005). Subjective memory complaints, white-matter lesions, depressive symptoms, and cognition in elderly patients. American Journals of Geriatric Psychiatry, 13, 665-671.

Mohs, R. C., Ashman, T. A., Jantzen, K., Albert, M., Brandt, J., Gordon, B., Rasmusson, X., Grossman, M., Jacobs, D., \& Stern, Y. (1998). A study of the efficacy of a comprehensive memory enhancement program in healthy elderly persons. Psychiatry Research, 77, 183-195.

Mol, M. E., Ruiter, R. A., Verhey, F. R., Dijkstra, J., \& Jolles, J. (2008). A study into the psychosocial determinants of perceived forgetfulness: implications for future interventions. Aging and Mental Health, 12, 167-176.

Mol, M. E., Van Boxtel, M. P., Willems, D., \& Jolles, J. (2006). Do subjective memory complaints predict cognitive dysfunction over time? A six-year follow-up of the Maastricht Aging Study. International Journal of Geriatric Psychiatry, 21, 432-441.

Mol, M. E., Van Boxtel, M. P., Willems, D., Verhey, F. R., \& Jolles, J. (2009). Subjective forgetfulness is associated with lower quality of life in middle-aged and young-old individuals: a 9-year follow-up in older participants from the Maastricht Aging Study. Aging and Mental Health, 13, 699-705.

Ponds, R. W., Commissaris, C. J., \& Jolles, J. (1997). Prevalence and covariates of subjective forgetfulness in a normal population in The Netherlands. International Journal of Aging and Human Development, 45, 207-221.

Rebok, G. W., Carlson, M. C., \& Langbaum, J. B. (2007). Training and maintaining memory abilities in healthy older adults: traditional and novel approaches. Journals of Gerontology B Series: Psychological Science and Social Science, 62 Spec No 1, 53-61.

Romano, J., Kromrey, J. D., Coraggio, K., \& Skowronek, J. (2006). Appropriate statistics for ordinal level data: Should we really be using t-test and Cohen's $d$ for evaluating group differences on the NSSE and other surveys? Paper presented at the annual meeting of the Florida Association of Institutional Research.

Salthouse, T. A. (1996). The processing-speed theory of adult age differences in cognition. Psychological Review, 103, 403-428.

Sanderman, R., Arrindell, W. A., Ranchor, A. V., Eysenck, H. J., \& Eysenck, S. B. G. (1995). Measuring personality traits with the Eysenck Personality Questionnaire (EPQ) [Het meten van persoonlijkheidskenmerken met de Eysenck Personality Questionnaire (EPQ]. Groningen, The Netherlands: Noordelijk Centrum voor Gezondheidsvraagstukken, Rijksuniversiteit Groningen.

Stuss, D. T., Robertson, I. H., Craik, F. I., Levine, B., Alexander, M. P., Black, S., Dawson, D., Binns, M. A., Palmer, H., Downey-Lamb, M., \& Winocur, G. (2007). Cognitive rehabilitation in the elderly: a randomized trial to evaluate a new protocol. Journal of the International Neuropsychological Society, 13, 120-131. 
Troyer, A. K. (2001). Improving memory knowledge, satisfaction, and Functioning, via an education and intervention program for older adults. Aging, Neuropsychology, and Cognition, 8, 256-268.

Valentijn, S. A., Van Hooren, S. A., Bosma, H., Touw, D. M., Jolles, J., Van Boxtel, M. P., \& Ponds, R. W. (2005). The effect of two types of memory training on subjective and objective memory performance in healthy individuals aged 55 years and older: a randomized controlled trial. Patient Education and Counseling, 57, 106-114.

Van der Elst, W., Van Boxtel, M. P., Van Breukelen, G. J., \& Jolles, J. (2005). Rey's verbal learning test: normative data for 1855 healthy participants aged 24-81 years and the influence of age, sex, education, and mode of presentation. Journal of the International Neuropsychological Society, 11, 290302.

Van der Elst, W., Van Boxtel, M. P., Van Breukelen, G. J., \& Jolles, J. (2006a). The Concept Shifting Test: adult normative data. Psychological Assessment, 18, 424-432.

Van der Elst, W., Van Boxtel, M. P., Van Breukelen, G. J., \& Jolles, J. (2006b). The Letter Digit Substitution Test: normative data for 1,858 healthy participants aged 24-81 from the Maastricht Aging Study (MAAS): influence of age, education, and sex. Journal of Clinical and Experimental Neuropsychology, 28, 998-1009.

Van der Elst, W., Van Boxtel, M. P., Van Breukelen, G. J., \& Jolles, J. (2006c). The Stroop color-word test: influence of age, sex, and education; and normative data for a large sample across the adult age range. Assessment, 13, 62-79.

Van der Elst, W., Van Boxtel, M. P., Van Breukelen, G. J., \& Jolles, J. (2008). A large-scale cross-sectional and longitudinal study into the ecological validity of neuropsychological test measures in neurologically intact people. Archives of Clinical Neuropsychology, 23, 787-800.

Van Hooren, S. A., Valentijn, S. A., Bosma, H., Ponds, R. W., Van Boxtel, M. P., \& Jolles, J. (2007). Cognitive functioning in healthy older adults aged 64-81: a cohort study into the effects of age, sex, and education. Aging, Neuropsychology, and Cognition, 14, 40-54.

Van Hooren, S. A., Valentijn, S. A., Bosma, H., Ponds, R. W., Van Boxtel, M. P., Levine, B., Robertson, I., \& Jolles, J. (2007). Effect of a structured course involving goal management training in older adults: A randomised controlled trial. Patient Education and Counseling, 65, 205-213.

Verhaeghen, P., Marcoen, A., \& Goossens, L. (1992). Improving memory performance in the aged through mnemonic training: a meta-analytic study. Psychology and Aging, 7, 242-251.

Verhey, F. R., Ramakers, I., Jolles, J., Scheltens, P., Vernooij-Dassen, M. J., \& Olde Rikkert, M. (2007). Memory clinics in the Netherlands: development since 1998 [Geheugenpoli's in Nederland: ontwikkelingen sinds 1998]. Tijdschrift voor Gerontologie en Geriatrie, 38, 237-245.

Ware, J. E., Kosinski, M., \& Keller, S. D. (1994). SF-36 Physical and Mental summary scales: a user's manual. Boston, MA: The Health Institute.

West, R. L., Bagwell, D. K., \& Dark-Freudeman, A. (2008). Self-Efficacy and Memory Aging: The Impact of a Memory Intervention Based on Self-Efficacy. Aging, Neuropsychology, and Cognition, 15, 302-329.

Willis, S. L., Tennstedt, S. L., Marsiske, M., Ball, K., Elias, J., Koepke, K. M., Morris, J. N., Rebok, G. W., Unverzagt, F. W., Stoddard, A. M., \& Wright, E. (2006). Long-term effects of cognitive training on everyday functional outcomes in older adults. Journal of the American Medical Association, 296, 2805-2814.

Winocur, G., Craik, F. I., Levine, B., Robertson, I. H., Binns, M. A., Alexander, M., Black, S., Dawson, D., Palmer, H., McHugh, T., \& Stuss, D. T. (2007). Cognitive rehabilitation in the elderly: overview and future directions. Journal of the International Neuropsychological Society, 13, 166-171. 
CHAPTER 9

Concluding remarks 
The prevalence of perceived cognitive problems in aging individuals is high. Not only old-old adults report many cognitive complaints, also many middle-aged and youngold individuals consider themselves to be forgetful (Ponds, Commissaris, \& Jolles, 1997). The presence of such perceived cognitive problems in relatively healthy young-old adults is related to increased worry and stress (Commissaris, Ponds, \& Jolles, 1998), a decreased quality of life (Mol, Van Boxtel, Willems, Verhey, \& Jolles, 2009), and an increased healthcare consumption (Comijs, Dik, Aartsen, Deeg, \& Jonker, 2005; Verhey et al., 2007). It can thus be considered a highly relevant health issue that needs appropriate intervention, particularly because the proportion of older adults will increase in the upcoming decades as a consequence of our aging society (CBS, 2010).

Aging is often accompanied by objective changes in several cognitive domains (Craik \& Bialystok, 2006; Salthouse, 1996; Zacks, Hasher, \& Li, 2000). Perceived cognitive problems in older adults are, however, much stronger related to noncognitive or contextual factors (e.g., mental health, personal and societal beliefs) rather than to actual cognitive decline (Cargin, Collie, Masters, \& Maruff, 2008; Kliegel \& Zimprich, 2005; Mol, Ruiter, Verhey, Dijkstra, \& Jolles, 2008; Pearman \& Storandt, 2004; Zimprich, Martin, \& Kliegel, 2003). It has been argued that the incorporation of such contextual factors in models of cognitive aging is necessary (Hess, 2005). They should also be considered in cognitive interventions for older adults (Floyd \& Scogin, 1997; Hess, 2005; Hohaus, 2007). It seems necessary to further improve the assessment of such contextual factors and to gain more insight in the way in which perceived cognitive problems in older adults could be treated.

The main aim of the present thesis was to further develop and evaluate an intervention program for young-old adults with perceived cognitive problems. Furthermore, the present thesis paid attention to the assessment of several noncognitive factors that are relevant in this context (i.e., metacognitive functioning, neurovegetative and somatic complaints, and everyday memory compensation). Moreover, the present thesis aimed to gain further insight in the way in which older adults deal with their perceived cognitive problems. More specifically, mechanisms and consequences of everyday memory compensation were investigated. In this final chapter, results and implications of the findings of the studies presented in this thesis are further elaborated upon.

\section{Assessment of contextual factors}

Three non-cognitive factors that are relevant in the context of cognitive aging were investigated in more depth in the present thesis. The Chapters 2, 3 and 4 paid specific attention to the assessment of metacognition, neurovegetative and somatic 
complaints (which are common indicators of depressive affect in older adults), and everyday memory compensation, respectively.

First, a new self-report questionnaire for metacognitive functioning in older adults, the Maastricht Metacognition Inventory (MMI), was presented in Chapter 2. Metacognition is considered a key construct in cognitive aging research. It refers to individuals' beliefs about cognitive functioning and incorporates several dimensions, like efficacy, control, and emotional reactions towards cognitive functioning (Hertzog, 2002; Hertzog \& Hultsch, 2000). A broad range of research papers in the past decades has linked aspects of metacognition to subjective and objective cognitive functions (see for example Ponds \& Jolles, 1996a; Soederberg Miller \& Lachman, 2000; Valentijn et al., 2006). Several cognitive interventions for older adults were also targeted at metacognitive functioning (McDougall, 2009; Valentijn et al., 2005; West, Bagwell, \& Dark-Freudeman, 2008). Its assessment is often restricted to metamemory (Gilewski, Zelinski, \& Schaie, 1990; Ponds \& Jolles, 1996b; Troyer \& Rich, 2002), though age-related cognitive changes and perceived cognitive problems are not limited to the domain of memory but extend to other cognitive domains as well (Craik \& Bialystok, 2006; Ponds, Van Boxtel, \& Jolles, 2000; Salthouse, 1996; Van Hooren, Valentijn, Bosma, Ponds, Van Boxtel, \& Jolles, 2007). It might thus be advantageous to have an assessment tool available that focuses on metacognition, instead of metamemory alone. The $\mathrm{MMI}$ aimed to assess four aspects of metacognition (i.e., everyday cognitive failures, emotional reactions towards cognitive failures, sense of control, and strategy use).

Second, Chapter 3 paid more attention to the assessment of neurovegetative and somatic complaints by means of the Neurovegetative Complaints Questionnaire (NCQ). The NCQ was originally developed by Bohnen and colleagues (1992), and has been proven useful in brain injured individuals (Bohnen, Jolles, Twijnstra, Mellink, \& Wijnen, 1995) and post-menopausal women (Hogervorst, Boshuisen, Riedel, Willeken, \& Jolles, 1999). Previous research revealed that the prevalence of depressive problems in older adults is often underestimated. This is, at least in part, caused by the atypical phenomenology of depressive problems in this age group (Alexopoulos et al., 2002; Gallo \& Rabins, 1999; Hybels \& Blazer, 2003). Older adults with depressive problems often present themselves with many somatic complaints rather than affective symptoms. This condition has previously been described as 'depression without sadness' (Gallo \& Rabins, 1999) or 'masked depression' (Collins \& Abeles, 1996). Depressive symptoms have been related to various age-related problems, like functional impairments in daily life (Gallo, Rebok, Tennsted, Wadley, \& Horgas, 2003), perceived cognitive problems (Kliegel \& Zimprich, 2005), worse performance on objective cognitive tasks (Dux et al., 2008), a more pronounced age-related cognitive decline (Köhler et al., 2010), and a higher risk to develop dementia (Jorm, 2000). It is thus important to diagnose depressive affect in older adults. The NCQ offers an opportunity to investigate neurovegetative and somatic complaints (in 
addition to reactive/emotional complaints) in more depth. A golden standard or DSM classification (APA, 1994) for 'depression without sadness' or 'masked depression' is currently lacking. Consequently, the NCQ can best be used in addition to more traditional DSM-IV-criteria based assessment tools, like the Beck Depression Inventory (BDI; Beck, Steer, \& Garbin, 1988), the Centre of Epidemiologic Studies Depression scale (CES-D; Bouma, Ranchor, Sanderman, \& Van Sonderen, 1995), or the Patient Health Questionnaire (PHQ; Spitzer, Kroenke, \& Williams, 1999).

Third, the psychometric properties of the Dutch version of the Memory Compensation Questionnaire (MCQ) were investigated in Chapter 4. Compensation is considered an important aspect of overall successful (cognitive) aging (Baltes \& Baltes, 1990; Depp \& Jeste, 2006; Dixon, 1995). An underlying assumption is that by implementing everyday memory compensation strategies (e.g., use of a calendar, investment of more time and effort, or use of internal mnemonics) individuals are able to mitigate or overcome their perceived or actual cognitive losses (Bäckman \& Dixon, 1992; Dixon \& de Frias, 2004). A previously presented theoretical framework of psychological compensation distinguished several forms or mechanisms (i.e., remediation, substitution, accommodation, and assimilation) (Bäckman \& Dixon, 1992). Compensation for age-related cognitive losses is usually assessed with selfreport questionnaires. The MCQ (De Frias \& Dixon, 2005; Dixon, de Frias, \& Bäckman, 2001) is the only instrument that extensively assesses different forms of compensatory behavior for age-related everyday memory losses. It incorporates seven subscales. Three of them assess memory substitution mechanisms (i.e., the use of external aids, internal mnemonics, and the investment of more time). Two of them assess memory remediation mechanisms (i.e., the recruitment of other people as memory aids, and the investment of more effort in memory demanding tasks). Two general subscales assess accommodation strategies, and the extent to which changes in compensatory behavior occurred in the past five to ten years.

The three instruments that were presented in this thesis had good psychometric properties (e.g., factorial validity, internal consistency, and convergent validity). For all instruments, demographically corrected regression-based normative data were presented. These three instruments can contribute to a more extended assessment and better understanding of several non-cognitive factors that are relevant in the context of cognitive aging. Other aspects of validity (e.g., discriminant validity and predictive validity) as well as test-retest reliability should be further investigated, especially for the MMI and NCQ. Furthermore, their sensitivity as outcome measures in intervention studies as well as their usefulness in other target groups needs further investigation. The $\mathrm{MMI}$ and $\mathrm{MCQ}$, for example, might be useful in more clinical populations, like patients with Mild Cognitive Impairment or patients in early stage of dementia (Dixon, Hopp, Cohen, de Frias, \& Backman, 2003). The NCQ has already been proven useful in brain-injured adults (Bohnen et al., 1992) and post-menopausal women (Hogervorst et al., 1999). Its usefulness 
could be further investigated in well-defined populations in which neurovegetative and somatic complaints are highly prevalent, like chronic pain patients (Wesley, Gatchel, Polatin, Kinney, \& Mayer, 1991) or depressed adults (Levitan, Lesage, Parikh, Goering, \& Kennedy, 1997). In clinical settings, the third instrument (i.e., the Dutch MCQ) appears most useful. After all, it is more and more common business in clinical settings to offer some sort of non-pharmacological intervention to patients with age-related cognitive problems or (amnestic) Mild Cognitive Impairment. These interventions usually include instruction and training in the use of mnemonic strategies (Joosten-Weyn Banningh, Kessels, Olde Rikkert, Geleijns-Lanting, \& Kraaimaat, 2008; Troyer, Murphy, Anderson, Moscovitch, \& Craik, 2008; Verhey et al., 2007). By means of the $\mathrm{MCQ}$, a more differentiated impression of spontaneous compensatory behavior might be obtained. It is thus worth to investigate which strategies are spontaneously used by an individual prior to intervention. In this way, interventions could be more fine-tuned to an individual's specific strengths, weaknesses, and needs.

\section{Everyday memory compensation}

Two studies in the present thesis focused in more depth on either the mechanisms or the consequences of everyday memory compensatory behavior. In Chapter 5 the predictive value of several variables on compensatory behavior (as measured with the MCQ) were investigated. Results confirmed significant associations with demographic variables (i.e., age, gender, and educational level) and aspects of metamemory. For example, and contrary to what one might expect based on studies to functional compensation (Cabeza, 2002; Garrett, Grady, \& Hasher, 2010; ReuterLorenz \& Cappell, 2008), lower educated individuals reported the use of more compensatory strategies as compared to their higher educated counterparts. This is in line with findings of previous studies (De Frias, Dixon, \& Bäckman, 2003; Garrett et al., 2010). Findings also indicated that compensatory behavior increased as a function of perceived cognitive problems, which is in line with the theoretical framework of psychological compensation (Bäckman \& Dixon, 1992). This increase was, however, less pronounced for individuals who reported many depressive symptoms compared to those who reported fewer depressive symptoms. Older adults with depressive problems are generally considered a highly vulnerable group in the context of (cognitive) aging. They exhibit more actual and perceived cognitive problems (Dux et al., 2008; Zimprich et al., 2003), show a more pronounced cognitive decline (Köhler et al., 2010), and are at a higher risk to develop dementia (Jorm, 2000). Based on the findings described in Chapter 5 , it can be concluded that older adults with depressive problems are even more vulnerable in the context of cognitive aging than was thought until now. They do not only exhibit more perceived cogni- 
tive problems and more age-related cognitive decline, but are also less likely to compensate for their everyday memory problems.

Many theories on successful (cognitive) aging implicitly claim that compensation offers a way to counterbalance, avoid, or overcome age-related (cognitive) deficits (Baltes \& Baltes, 1990; Depp \& Jeste, 2006; Dixon, 1995). This is also a basic assumption of many cognitive interventions for older adults, which often incorporate training in one or more mnemonic strategies. Results of such intervention studies demonstrate that subjective and objective cognitive functioning in older adults indeed can be improved by training them in the use of one or more mnemonic compensatory strategies (see for overviews Floyd \& Scogin, 1997; Glisky \& Glisky, 2005; Rebok, Carlson, \& Langbaum, 2007; Verhaeghen, Marcoen, \& Goossens, 1992). Longitudinal research on the effects of spontaneous compensatory behavior is not available. Furthermore, compensation has been linked to the concept of cognitive reserve (Stern, 2002). With respect to everyday memory compensation it has been suggested previously that individuals with high levels of cognitive reserve show a less pronounced cognitive decline, partly as a consequence of compensation (Garrett et al., 2010). In Chapter 6, a longitudinal study on the consequences of everyday memory compensation for trajectories of subjective and objective memory over time was presented. This study paid specific attention to the moderating influence of educational level, which is considered a proxy of cognitive reserve. Results did not provide evidence for the suggested association between cognitive reserve, compensation, and changes in subjective and objective memory. Furthermore, no significant differences were found in change in subjective and objective memory over time as a function of spontaneous compensatory behavior. This might in part be explained by the fact that spontaneous compensation is only likely to occur in individuals with some degree of perceived or actual cognitive deficits (Bäckman \& Dixon, 1992). Thus, although training of everyday memory compensation may lead to improved cognitive functions, spontaneous compensation is just associated with an equally pronounced decline in subjective and objective memory. There is an ongoing debate on how cognitive functioning in older adults could be optimized (Daffner, 2009; Depp, Vahia, \& Jeste, in press). Everyday memory compensation might be a key factor in successful cognitive aging. Therefore, the longterm consequences of everyday memory compensation need further investigation.

\section{Interventions}

There are widespread variations in types of interventions for older adults with perceived cognitive deficits. The primary aim of many cognitive interventions (especially the ones that have their roots in the information-processing framework of cognitive aging) is to improve cognitive functions per se or to prevent it from relaps- 
ing. Such interventions usually involve some sort of cognitive training and promote the use of mnemonic strategies. They have mainly task and domain specific effects that hardly generalize to everyday life, subjective cognitive functioning, or wellbeing (Floyd \& Scogin, 1997; Glisky \& Glisky, 2005; Hess, 2005; Rebok et al., 2007; Verhaeghen et al., 1992). The primary problem of many older adults is however a perceived cognitive loss that is often independent of actual cognitive decline. Is therefore questionable whether much can be gained by trying to enlarge cognitive capacity alone, while non-cognitive or contextual factors are ignored.

There is a growing enthusiasm for multidimensional cognitive interventions for this target group. These interventions combine strategy training with, for example, psycho-education about the importance of metacognitive processes or other contextual factors (Hohaus, 2007; Troyer, 2001; Valentijn et al., 2005; Van Hooren, Valentijn, Bosma, Ponds, Van Boxtel, Levine et al., 2007; West et al., 2008; Winocur et al., 2007). Such interventions more or less fit a contextual framework of cognitive aging (Hess, 2005). Studies on the effectiveness of such interventions differed in study design and outcome, with effects established on subjective cognitive functioning, objective cognitive performance and psychological wellbeing (Hohaus, 2007; Troyer, 2001; Valentijn et al., 2005; Van Hooren, Valentijn, Bosma, Ponds, Van Boxtel, Levine et al., 2007; West et al., 2008; Winocur et al., 2007). These findings are promising.

In this thesis a new comprehensive group intervention for relatively healthy young-old adults with perceived cognitive problems was evaluated. This intervention had a strong focus on psycho-education and emphasized the importance of finding a balance between gains and losses as is promoted in models of successful aging (Baltes \& Baltes, 1990; Depp \& Jeste, 2006). It offered information about skills and commonly applicable compensation strategies, and focused on (group) discussion about societal and personal beliefs, aging stereotypes, and pessimistic and maladaptive attributions. Its background and content were described in depth in Chapter 7. This chapter also presented the results of a process evaluation. Findings suggested that the intervention was highly accepted and appreciated by participants, which is important for large-scale implementation. For this purpose, it is necessary to additionally investigate the economic benefits and cost-effectiveness of such interventions in future research (Grol \& Wensing, 2006; Linnan \& Steckler, 2002). Appreciation was related to background variables. There were, for example, indications that higher educated individuals make other demands to interventions than their lower educated counterparts. Participants also rated several aspects of their functioning after the intervention as being higher as compared to their functioning prior to intervention. They claimed to make fewer cognitive mistakes, felt less hindered by their cognitive mistakes, were less worried about their cognitive skills, were less afraid about becoming demented, and considered themselves more capable of handling their cognitive problems as compared to their situation prior to 
the intervention. Based on these findings it was expected that the effectiveness on several aspects of functioning would be confirmed in a randomized controlled experiment.

Chapter 8 presented the results of such a randomized controlled trial that investigated the effects of this new intervention. Sixty healthy community-dwelling women aged 60 to 75 years with perceived cognitive problems were randomly assigned to an experimental or waiting-list control group. Findings indicated that participants in the experimental group reported significantly fewer negative emotional reactions towards cognitive functioning (e.g., get annoyed when forgetting something) as compared to participants in the waiting list group. No effects were established on other relevant outcome measures (e.g., everyday cognitive failures and sense of control). As is discussed in Chapter 8, there are several strengths, but also points of improvement of this randomized controlled trial. Nevertheless, this study supports the growing body of evidence that multidimensional cognitive interventions are effective in enhancing important aspects of cognitive functioning in older adults. There are indications that they might be even more effective than interventions that mainly aim to enhance cognitive functions per se by training them (Commissaris, Verhey, \& Jolles, 1996; Valentijn et al., 2005; Van Hooren, Valentijn, Bosma, Ponds, Van Boxtel, Levine et al., 2007; Winocur et al., 2007).

Although the randomized controlled trial that was presented in Chapter 8 identified a significant effect on negative emotional reactions towards cognitive functioning in the sample included, effects on other outcome measures were not established. Previous research revealed that this is a common finding in intervention studies that include relatively healthy and highly functioning older adults who exhibit subjective (cognitive) problems (Floyd \& Scogin, 1997; Rebok et al., 2007; Stuss et al., 2007; Verhaeghen et al., 1992). First, as was argued in the present thesis, it is unlikely that any effects on objective cognitive measures (e.g., laboratory based memory tests) will be established, because the main problem of most participants included in such studies concern perceived cognitive problems in the absence of actual cognitive deficits. Second, even if a large number of participants are included, the determination of significant effects is difficult, both on objective as well as on subjective outcome measures. This might in part be explained by a lack of assessment tools that are sensitive enough to detect subtle intervention effects (Shumaker, Legault, \& Coker, 2006). Despite extensive attempts to provide better instruments (some of which were described in the present thesis), there is an urgent need for suitable (and more ecologically valid) alternatives (Owsley, Sloane, McGwin, \& Ball, 2002; Spooner \& Pachana, 2006). 


\section{Conclusions}

The present thesis provided a broader range of psychometrically sound assessment tools (i.e., the $\mathrm{MMI}$, the $\mathrm{NCQ}$, and the $\mathrm{MCQ}$ ) to gain further insight in non-cognitive factors that are relevant in the context of cognitive aging. It is important to pay specific attention to such contextual factors to gain further insight in the nature of perceived cognitive problems in older adults. Such contextual factors should be considered in the development of interventions for this target group.

One contextual factor (i.e., everyday memory compensation) was investigated in more depth in this thesis. It can be concluded that older adults with depressive problems do not only exhibit more subjective and objective cognitive problems, but are less likely to compensate for their cognitive problems too. They are thus highly vulnerable in the context of cognitive aging. Moreover, it can be concluded that the spontaneous use of everyday memory compensation strategies is not related to differential trajectories of subjective and objective memory over time. Furthermore, there is no evidence for the hypothesis that individuals with high levels of cognitive reserve show a less pronounced decline of cognitive functions as a function of compensatory behavior. Further research on the long-term consequences of everyday memory compensatory behavior is however needed.

Results of this thesis supported findings of previous studies, which indicated that multidimensional cognitive interventions might be more suitable in enhancing functioning of older adults, rather than interventions that mainly focus on the training of cognitive functions per se. The present thesis also provided evidence that this type of intervention is highly accepted and appreciated by participants.

\section{Future research}

In the upcoming decades, Western societies will face the consequences of their rapidly aging populations. It is therefore important to continue research on the large and increasing group of older adults who exhibit perceived cognitive problems in the absence of any actual cognitive deficits (e.g., as a consequence of dementia). Further consideration of contextual factors in investigating the nature and treatment of these perceived cognitive problems is important. In future studies it will be worth investigating whether subgroups of older adults who are at high risk to develop perceived or actual age-related cognitive problems can be identified. The growing knowledge on the mediating influence of contextual factors is very useful for this purpose.

Furthermore, a growing number of studies indicate that background and contextual factors also play an important role in the extent to which individuals comply to and benefit from cognitive interventions. Compliance, for example, is related to 
health, self-efficacy, and educational level (Bagwell \& West, 2008). Age and educational level have been found predictive of responsiveness to cognitive training (Langbaum, Rebok, Bandeen-Roche, \& Carlson, 2009). Results presented in the current thesis indicate that background variables (i.e., age, gender, and educational level) are related to contextual factors (i.e., metacognitive functioning, neurovegetative and somatic complaints, and everyday memory compensation). Results particularly point to the importance of identifying depressive symptoms in older adults. Furthermore, research suggests that age and educational level are related to the degree of participants' acceptance and appreciation of an intervention. Future studies should therefore consider the development of more tailor-made interventions for subgroups of older adults with perceived age-related cognitive problems (e.g., high educated versus low educated individuals).

The present thesis provided for a broader range of assessment tools to investigate non-cognitive factors that are relevant in the context of cognitive aging. These instruments are useful in research as well as in clinical settings. The MCQ, for example, allows for a more differentiated assessment of the spontaneous use of compensatory strategies in patients with perceived or actual cognitive problems. This is, for example, of use in clinical settings as part of strategy training. Further research is however needed. Future studies should particularly aim to develop assessment instruments that are sensitive enough to identify intervention effects in the relatively healthy and high functioning group of older adults with perceived cognitive problems.

Findings of the present thesis further support the benefit of multidimensional interventions for older adults with perceived cognitive problems. Such interventions meet the need for suitable treatment of this target group. They might be useful in several settings, among which primary care and more specialized facilities, like Memory Clinics. Furthermore, it might be worth to investigate whether interventions with a comparable design are effective in other (clinical) target groups, like individuals with (amnestic) Mild Cognitive Impairment (Joosten-Weyn Banningh et al., 2008; Troyer et al., 2008). A particular challenge for future research concerns the development and evaluation of interventions that are appropriate for implementation in more easily accessible services. Multidimensional cognitive interventions - such as the one that was developed in the present thesis - might offer an opportunity for relatively easily approachable treatments for older adults with perceived cognitive problems without any objective cognitive deficits. An ultimate aim of such low-level interventions should be to keep the relatively large and still growing group of older adults away from specialized and costly healthcare services. All multidimensional interventions that were reviewed, discussed, described and evaluated in the present thesis followed a traditional approach, which was proved of worth. They all included multiple sessions at a certain (clinical) setting and were facilitated by trained professionals. They have been proven effective, are appreci- 
ated by participants, and may consequently contribute to 'evidence based practice.' Theories and evidence that underlie these multidimensional interventions may also be useful in other settings in which comparable results may be obtained against lower costs. Social gerontological services might be relevant in this respect. The use of telephone, video- and audiotapes, the internet, and social media for this purpose might also prove helpful (Hardt \& Hollis-Sawyer, 2007; Larner, 2003; Mol et al., 2007; Rebok et al., 2007). 


\section{References}

Alexopoulos, G. S., Borson, S., Cuthbert, B. N., Devanand, D. P., Mulsant, B. H., Olin, J. T., \& Oslin, D. W. (2002). Assessment of late life depression. Biological Psychiatry, 52, 164-174.

APA (1994). Diagnostic and Statistical Manual of Mental Disorders: DSM-IV. Washington: American Psychiatric Association.

Bäckman, L., \& Dixon, R. A. (1992). Psychological compensation: a theoretical framework. Psychological Bulletin, 112, 259-283.

Bagwell, D. K., \& West, R. L. (2008). Assessing compliance: active versus inactive trainees in a memory intervention. Clinical Interventions in Aging, 3, 371-382.

Baltes, P. B., \& Baltes, M. M. (1990). Psychological perspectives on successful aging: the model of selective optimization with compensation. In P. B. Baltes (Ed.), Successful aging: Perspectives from the behavioral sciences (pp. 1-34). Cambridge: Cambridge University Press.

Beck, A. T., Steer, R. A., \& Garbin, M. G. (1988). Psychometric properties of the Beck Depression Inventory: twenty-five years of evaluation. Clinical Psychology Review, 8, 77-100.

Bohnen, N. I., Jolles, J., Twijnstra, A., Mellink, R., \& Wijnen, G. (1995). Late neurobehavioural symptoms after mild head injury. Brain Injury, 9, 27-33.

Bohnen, N. I., Twijnstra, A., \& Jolles, J. (1992). Post-traumatic and emotional symptoms in different subgroups of patients with mild head injury. Brain Injury, 6, 481-487.

Bouma, J., Ranchor, A. V., Sanderman, R., \& Van Sonderen, E. (1995). Measuring symptoms of depression using the CES-D: a manual. [Het meten van symptomen van depressie met de CES-D: een handleiding]. Groningen: Noordelijk Centrum voor Gezondheidsvraagstukken, Rijksuniversiteit Groningen.

Cabeza, R. (2002). Hemispheric asymmetry reduction in older adults: the HAROLD model. Psychology and Aging, 17, 85-100.

Cargin, J. W., Collie, A., Masters, C., \& Maruff, P. (2008). The nature of cognitive complaints in healthy older adults with and without objective memory decline. Journal of Clinical and Experimental Neuropsychology, 30, 245-257.

CBS (2010). Statline database: population. Retrieved 20 May 2010: http://statline.cbs.nl

Collins, M. W., \& Abeles, N. (1996). Subjective memory complaints and depression in the able elderly. Clinical Gerontologist, 16, 29-54.

Comijs, H. C., Dik, M. G., Aartsen, M. J., Deeg, D. J., \& Jonker, C. (2005). The impact of change in cognitive functioning and cognitive decline on disability, well-being, and the use of healthcare services in older persons. Results of Longitudinal Aging Study Amsterdam. Dementia and Geriatric Cognitive Disorders, 19, 316-323.

Commissaris, C. J., Ponds, R. W. H. M., \& Jolles, J. (1998). Subjective forgetfulness in a normal Dutch population: possibilities for health education and other interventions. Patient Education and Counseling, 34, 25-32.

Commissaris, C. J., Verhey, F. R., \& Jolles, J. (1996). A controlled study into the effects of psychoeducation for patients with cognitive disturbances. The Journal of Neuropsychiatry and Clinical Neuroscience, 8 , 429-435.

Craik, F. I., \& Bialystok, E. (2006). Cognition through the lifespan: mechanisms of change. Trends in Cognitive Sciences, 10, 131-138.

Daffner, K. R. (2009). Promoting Successful Cognitive Aging: A Comprehensive Review. Journal of Alzheimer's Disease.

De Frias, C. M., \& Dixon, R. A. (2005). Confirmatory factor structure and measurement invariance of the Memory Compensation Questionnaire. Psychological Assessment, 17, 168-178.

De Frias, C. M., Dixon, R. A., \& Bäckman, L. (2003). Use of memory compensation strategies is related to psychosocial and health indicators. Journals of Gerontology Series B: Psychological Sciences and Social Sciences, 58, P12-22.

Depp, C. A., \& Jeste, D. V. (2006). Definitions and predictors of successful aging: a comprehensive review of larger quantitative studies. American Journal of Geriatric Psychiatry, 14, 6-20. 
Depp, C. A., Vahia, I. V., \& Jeste, D. (in press). Successful aging: focus on cognitive and emotional health. Annual Review of Clinical Psychology, 6, 527-550.

Dixon, R. A. (1995). Promoting competence through compensation. In L. A. Bond (Ed.), Promoting successful and productive aging (Vol. 1, pp. 220-238). Thousand Oaks, Calif: Sage Publications.

Dixon, R. A., \& de Frias, C. M. (2004). The Victoria Longitudinal Aging Study: From characterizing cognitive aging to illustrating patterns and predictors of changes in memory compensation. Aging, Neuropsychology, and Cognition, 11, 346-376.

Dixon, R. A., de Frias, C. M., \& Bäckman, L. (2001). Characteristics of self-reported memory compensation in older adults. Journal of Clinical and Experimental Neuropsychology, 23, 650-661.

Dixon, R. A., Hopp, G. A., Cohen, A. L., de Frias, C. M., \& Backman, L. (2003). Self-reported memory compensation: similar patterns in Alzheimer's disease and very old adult samples. Journal of Clinical and Experimental Neuropsychology, 25, 382-390.

Dux, M. C., Woodard, J. L., Calamari, J. E., Messina, M., Arora, S., Chik, H., \& Pontarelli, N. (2008). The moderating role of negative affect on objective verbal memory performance and subjective memory complaints in healthy older adults. Journal of the International Neuropsychological Society, 14, 327 336.

Floyd, M., \& Scogin, F. (1997). Effects of memory training on the subjective memory functioning and mental health of older adults: a meta-analysis. Psychology and Aging, 12, 150-161.

Gallo, J. J., \& Rabins, P. V. (1999). Depression without sadness: alternative presentations of depression in late life. American Family Physician, 60, 820-826.

Gallo, J. J., Rebok, G. W., Tennsted, S., Wadley, V. G., \& Horgas, A. (2003). Linking depressive symptoms and functional disability in late life. Aging and Mental Health, 7, 469-480.

Garrett, D. D., Grady, C. L., \& Hasher, L. (2010). Everyday memory compensation: the impact of cognitive reserve, subjective memory, and stress. Psychology and Aging, 25, 74-83.

Gilewski, M. J., Zelinski, E. M., \& Schaie, K. W. (1990). The Memory Functioning Questionnaire for assessment of memory complaints in adulthood and old age. Psychology and Aging, 5, 482-490.

Glisky, E. L., \& Glisky, M. L. (2005). Memory rehabilition in the elderly. In D. T. Stuss, G. Winocur \& I. H. Robertson (Eds.), Cognitive neurorehabilitation (pp. 347-361). Cambridge: Cambridge University Press.

Grol, R. P., \& Wensing, M. (2006). Implementation: effective improvement of health care [Implementatie: effectieve verbetering van de gezondheidszorg]. Maarssen: Elsevier Gezondheidszorg.

Hardt, J. H., \& Hollis-Sawyer, L. (2007). Older adults seeking healthcare information on the internet. Educational Gerontology, 33, 561-572.

Hertzog, C. (2002). Metacognition in older adults: implications for application. In T. J. Perfect \& B. L. Schwartz (Eds.), Applied metacognition (pp. 169-196). London: Cambridge University Press.

Hertzog, C., \& Hultsch, D. F. (2000). Metacognition in adulthood and old age. In F. I. Craik \& T. A. Salthouse (Eds.), Handbook of aging and cognition (pp. 417-466). Mahwah, NJ: Lawrence Erlbaum Associates.

Hess, T. M. (2005). Memory and aging in context. Psychological Bulletin, 131, 383-406.

Hogervorst, E., Boshuisen, M., Riedel, W., Willeken, C., \& Jolles, J. (1999). 1998 Curt P. Richter Award. The effect of hormone replacement therapy on cognitive function in elderly women. Psychoneuroendocrinology, 24, 43-68.

Hohaus, L. (2007). Remembering to age successfully: evaluation of a successful aging approach to memory enhancement. International Psychogeriatrics, 19, 137-150.

Hybels, C. F., \& Blazer, D. G. (2003). Epidemiology of late-life mental disorders. Clinics in Geriatric Medicine, 19, 663-696.

Joosten-Weyn Banningh, L. W., Kessels, R. P., Olde Rikkert, M. G., Geleijns-Lanting, C. E., \& Kraaimaat, F. W. (2008). A cognitive behavioural group therapy for patients diagnosed with mild cognitive impairment and their significant others: feasibility and preliminary results. Clinical Rehabilitation, 22, 731740. 
Jorm, A. F. (2000). Is depression a risk factor for dementia or cognitive decline? A review. Gerontology, 46, 219-227.

Kliegel, M., \& Zimprich, D. (2005). Predictors of cognitive complaints in older adults: a mixture regression approach. European Journal of Ageing, 2, 13-23.

Köhler, S., Van Boxtel, M. P., van Os, J., Thomas, A. J., O’Brien, J. T., Jolles, J., Verhey, F. R., \& Allardyce, J. (2010). Depressive Symptoms and Cognitive Decline in Community-Dwelling Older Adults. Journal of the American Geriatrics Society, 58, 873-879.

Langbaum, J. B., Rebok, G. W., Bandeen-Roche, K., \& Carlson, M. C. (2009). Predicting memory training response patterns: results from ACTIVE. Journals of Gerontology B Series: Psychological Sciences and Social Sciences, 64, 14-23.

Larner, A. J. (2003). Use of the internet and of the NHS direct telephone helpline for medical information by a cognitive function clinic population. International Journal of Geriatric Psychiatry, 18, 118-122.

Levitan, R. D., Lesage, A., Parikh, S. V., Goering, P., \& Kennedy, S. H. (1997). Reversed neurovegetative symptoms of depression: a community study of Ontario. American Journal of Psychiatry, 154, 934940.

Linnan, L., \& Steckler, A. (2002). Process evaluation for public health interventions and research: an overview. In A. Steckler \& L. Linnan (Eds.), Process evaluation for public health interventions and research (pp. 1-23). San Francisco: John Wiley \& Sons, Inc.

McDougall, G. J. (2009). A framework for cognitive interventions targeting everyday memory performance and memory self-efficacy. Family and Community Health, 32, S15-26.

Mol, M. E., De Groot, R. H., Hoogenhout, E. M., Aben, A., Verhey, F., \& Jolles, J. (2007). An evaluation of the use of a website and telephonic information service as public education about forgetfulness. $T e$ lemedicine Journal and E-Health, 13, 433-443.

Mol, M. E., Ruiter, R. A., Verhey, F. R., Dijkstra, J., \& Jolles, J. (2008). A study into the psychosocial determinants of perceived forgetfulness: implications for future interventions. Aging and Mental Health, 12, 167-176.

Mol, M. E., Van Boxtel, M. P., Willems, D., Verhey, F. R., \& Jolles, J. (2009). Subjective forgetfulness is associated with lower quality of life in middle-aged and young-old individuals: a 9-year follow-up in older participants from the Maastricht Aging Study. Aging and Mental Health, 13, 699-705.

Owsley, C., Sloane, M., McGwin, G., Jr., \& Ball, K. (2002). Timed instrumental activities of daily living tasks: relationship to cognitive function and everyday performance assessments in older adults. Gerontology, 48, 254-265.

Pearman, A., \& Storandt, M. (2004). Predictors of subjective memory in older adults. Journals of Gerontology B Series: Psychological Sciences and Social Sciences, 59, P4-6.

Ponds, R. W., Commissaris, C. J., \& Jolles, J. (1997). Prevalence and covariates of subjective forgetfulness in a normal population in The Netherlands. International Journal of Aging and Human Development, 45, 207-221.

Ponds, R. W., \& Jolles, J. (1996a). Memory complaints in elderly people: the role of memory abilities, metamemory, depression, and personality. Educational Gerontology, 22, 341-357.

Ponds, R. W., \& Jolles, J. (1996b). The Abridged Dutch Metamemory in Adulthood (MIA) Questionnaire: structure and effects of age, sex, and education. Psychology and Aging, 11, 324-332.

Ponds, R. W., Van Boxtel, M. P., \& Jolles, J. (2000). Age-related changes in subjective cognitive functioning. Educational Gerontology, 26, 67-81.

Rebok, G. W., Carlson, M. C., \& Langbaum, J. B. (2007). Training and maintaining memory abilities in healthy older adults: traditional and novel approaches. Journals of Gerontology Series B: Psychological Sciences and Social Sciences, 62 Spec No 1, 53-61.

Reuter-Lorenz, P., \& Cappell, K. A. (2008). Neurocognitive aging and the compensation hypothesis. Current Directions in Psychological Sciences, 17, 177-182.

Salthouse, T. A. (1996). The processing-speed theory of adult age differences in cognition. Psychological Review, 103, 403-428. 
Shumaker, S. A., Legault, C., \& Coker, L. H. (2006). Behavior-based interventions to enhance cognitive functioning and independence in older adults. Journal of the American Medical Association, 296, 2852-2854.

Soederberg Miller, L. M., \& Lachman, M. E. (2000). Cognitive performance and the role of control beliefs in midlife. Aging, Neuropsychology, and Cognition, 7, 69-85.

Spitzer, R. L., Kroenke, K., \& Williams, J. B. (1999). Validation and utility of a self-report version of PRIMEMD: the PHQ primary care study. Primary Care Evaluation of Mental Disorders. Patient Health Questionnaire. Journal of the American Medical Association, 282, 1737-1744.

Spooner, D. M., \& Pachana, N. A. (2006). Ecological validity in neuropsychological assessment: a case for greater consideration in research with neurologically intact populations. Archives of Clinical Neuropsychology, 21, 327-337.

Stern, Y. (2002). What is cognitive reserve? Theory and research application of the reserve concept. Journal of the International Neuropsychological Society, 8, 448-460.

Stuss, D. T., Robertson, I. H., Craik, F. I., Levine, B., Alexander, M. P., Black, S., Dawson, D., Binns, M. A., Palmer, H., Downey-Lamb, M., \& Winocur, G. (2007). Cognitive rehabilitation in the elderly: a randomized trial to evaluate a new protocol. Journal of the International Neuropsychological Society, 13, 120-131.

Troyer, A. K. (2001). Improving memory knowledge, satisfaction, and Functioning, via an education and intervention program for older adults. Aging, Neuropsychology, and Cognition, 8, 256-268.

Troyer, A. K., Murphy, K. J., Anderson, N. D., Moscovitch, M., \& Craik, F. I. (2008). Changing everyday memory behaviour in amnestic mild cognitive impairment: A randomised controlled trial. Neuropsychological Rehabilitation, 18, 65-88.

Troyer, A. K., \& Rich, J. B. (2002). Psychometric properties of a new metamemory questionnaire for older adults. Journals of Gerontology Series B: Psychological Sciences and Social Sciences, 57, P19-27.

Valentijn, S. A., Hill, R. D., Van Hooren, S. A., Bosma, H., Van Boxtel, M. P., Jolles, J., \& Ponds, R. W. (2006). Memory self-efficacy predicts memory performance: results from a 6-year follow-up study. Psychology and Aging, 21, 165-172.

Valentijn, S. A., Van Hooren, S. A., Bosma, H., Touw, D. M., Jolles, J., Van Boxtel, M. P., \& Ponds, R. W. H. M. (2005). The effect of two types of memory training on subjective and objective memory performance in healthy individuals aged 55 years and older: a randomized controlled trial. Patient Education and Counseling, 57, 106-114.

Van Hooren, S. A., Valentijn, A. M., Bosma, H., Ponds, R. W., Van Boxtel, M. P., \& Jolles, J. (2007). Cognitive functioning in healthy older adults aged 64-81: a cohort study into the effects of age, sex, and education. Aging, Neuropsychology, and Cognition, 14, 40-54.

Van Hooren, S. A., Valentijn, S. A., Bosma, H., Ponds, R. W., Van Boxtel, M. P., Levine, B., Robertson, I., \& Jolles, J. (2007). Effect of a structured course involving goal management training in older adults: A randomised controlled trial. Patient Education and Counseling, 65, 205-213.

Verhaeghen, P., Marcoen, A., \& Goossens, L. (1992). Improving memory performance in the aged through mnemonic training: a meta-analytic study. Psychology and Aging, 7, 242-251.

Verhey, F. R., Ramakers, I., Jolles, J., Scheltens, P., Vernooij-Dassen, M. J., \& Olde Rikkert, M. (2007). Memory clinics in the Netherlands: development since 1998 [Geheugenpoli's in Nederland: ontwikkelingen sinds 1998]. Tijdschrift voor Gerontologie en Geriatrie, 38, 237-245.

Wesley, A. L., Gatchel, R. J., Polatin, P. B., Kinney, R. K., \& Mayer, T. G. (1991). Differentiation between somatic and cognitive/affective components in commonly used measurements of depression in patients with chronic low-back pain. Let's not mix apples and oranges. Spine, 16, S213-215.

West, R. L., Bagwell, D. K., \& Dark-Freudeman, A. (2008). Self-Efficacy and Memory Aging: The Impact of a Memory Intervention Based on Self-Efficacy. Aging, Neuropsychology, and Cognition, 15, 302-329.

Winocur, G., Craik, F. I., Levine, B., Robertson, I. H., Binns, M. A., Alexander, M., Black, S., Dawson, D., Palmer, H., McHugh, T., \& Stuss, D. T. (2007). Cognitive rehabilitation in the elderly: overview and future directions. Journal of the International Neuropsychological Society, 13, 166-171. 
Zacks, R. T., Hasher, L., \& Li, K. Z. H. (2000). Human memory. In F. I. M. Craik \& T. A. Salthouse (Eds.), The handbook of aging and cognition (Vol. 2, pp. 293-357). Mahwah, NJ: Erbaum.

Zimprich, D., Martin, M., \& Kliegel, M. (2003). Subjective cognitive complaints, memory performance, and depressive affect in old age: a change-oriented approach. International Journal of Aging and Human Development, 57, 339-366. 


\section{Summary}

Perceived age-related cognitive problems are highly prevalent in older adults, not only in old-old individuals but also in the young-old (i.e., \pm 55 years and older). As a consequence of our rapidly aging Western society, the number of individuals with perceived age-related cognitive problems will increase in the upcoming decades. Such perceived cognitive problems in older adults are related to worries, stress, a lowered quality of life, and an increased healthcare consumption. It is thus a highly relevant health issue that needs appropriate intervention. The association between perceived cognitive problems and actual cognitive losses is weak. The majority of older individuals exhibit perceived cognitive problems in the absence of any pathological cognitive losses (due to, for example, dementia). The association between perceived cognitive problems and non-cognitive or contextual factors seems much stronger. It has been argued before that these contextual factors (e.g., depressive affect, metacognitive functioning) should be incorporated in models of cognitive aging. They should also be considered in the development of interventions for older adults with perceived cognitive problems. Until now, our knowledge about how older adults deal with their perceived cognitive problems and the way in which they should be treated is insufficient. Furthermore, the assessment of contextual factors in the context of cognitive aging needs further improvement. The main aim of this thesis was to develop and evaluate a new comprehensive educational group intervention program for relatively healthy young-old adults. Furthermore, this thesis aimed to provide a broader range of psychometrically sound instruments, which assess several relevant contextual factors (i.e., metacognitive functioning, depressive affect, and compensatory behavior). Finally, this thesis aimed to investigate the mechanisms and consequences of everyday memory compensation in older adults. In Chapter 1, a general introduction to this thesis was given.

Chapter 2 presented a newly developed self-report instrument for metacognitive functioning in older adults: the Maastricht Metacognition Inventory (MMI). The $\mathrm{MMI}$ consisted of four subscales that measured everyday cognitive failures, emotional reactions to cognitive failures, sense of control, and the use of compensation 
strategies. Its psychometric properties and the impact of demographic variables on the subscales of the MMI were investigated in 552 cognitively healthy individuals aged 50 to 95 years. Confirmatory factor analyses confirmed the four-factor structure underlying the $\mathrm{MMI}$ and reduced its number of items to 43 items. Its reliability and validity were established. Age and educational level, but not gender, were significant predictors of several aspects of metacognitive functioning. Regressionbased normative data were provided.

In Chapter 3, a questionnaire that assessed neurovegetative and somatic complaints as well as reactive emotional complaints was presented: the Neurovegetative Complaints Questionnaire (NCQ). These symptoms are often indicative of a 'masked depression' or a 'depression without sadness' in older adults. Exploratory factor analyses with data from $N=1,105$ healthy adults aged 24 to 81 years who participated in the Maastricht Aging Study revealed that two factors underlay the responses on the NCQ. Internal consistency was acceptable and convergent validity was sufficient. Women and older participants were characterized by more neurovegetative/somatic and reactive/emotional complaints as compared to males and younger people. Regression-based normative data were provided.

Chapter 4 presented the Dutch version of the Memory Compensation Questionnaire (MCQ). Until now only an English version of this instrument (that assesses the variety and extent to which an individual compensates for actual or perceived memory losses) was available. The psychometric properties of this translated MCQ were investigated in 556 cognitively healthy adults aged 50 to 95 years. Confirmatory factor analyses indicated that the seven-factor structure of the Dutch MCQ corresponded well with that of the original English version. The reliabilities of all subscales were high. Demographic variables affected most of the MCQ scale scores. Regression-based normative data were provided.

The main aim of Chapter 5 was to investigate the moderating effect of depressive symptoms on the association between subjective cognitive complaints and compensatory behavior in older adults. Demographic variables and aspects of metamemory were also included as potential predictors. Data of 556 community dwelling older adults aged 50 to 95 years were used. Results from multiple hierarchical linear regression analyses revealed that compensatory behavior increased as a function of self-reported cognitive complaints. This increase was however less pronounced for older adults who also reported many depressive symptoms. Age, gender, and educational level as well as aspects of metamemory were also predictive for the scores on several MCQ subscales.

Chapter 6 investigated the consequences of everyday memory compensation for trajectories of change in subjective and objective memory over time. Specific attention was paid to the moderating influence of cognitive reserve as estimated by educational level. Data from 231 healthy adults aged 50 years and older who participated in the Maastricht Aging Study were used. Their subjective and objective 
memory functions were repeatedly tested at four measurement occasions within twelve years. Linear mixed models analyses showed similar trajectories of change in subjective and objective memory over time as a function of strategy use. Furthermore, in contrast with the cognitive reserve theory, individuals with high educational levels (i.e., high levels of cognitive reserve) did not exhibit less pronounced changes in subjective and objective memory over time as a function of everyday memory compensation.

In Chapter 7 the background and content of a new comprehensive educational group intervention for healthy older adults with perceived cognitive problems was presented. A process evaluation was carried out in 48 female participants aged 60 to 75 years (of the original number of 60 included) who conducted the final assessment. Results supported their appreciation and acceptance of the intervention. Furthermore, participants evaluated several aspects of their functioning after participation in the intervention higher as compared to their functioning prior to participation. These findings are imperative to large-scale implementation of this intervention.

In Chapter 8 an effect evaluation of this new comprehensive educational group intervention was carried out following a randomized controlled design with an experimental and a waiting list control condition. A total of 60 relatively healthy women (aged 60 to 75 years) with perceived cognitive problems were included. A total of 50 participants finished the complete trial. Participants in the experimental condition reported significantly fewer negative emotional reactions towards cognitive functioning as compared to participants in the waiting list control condition one week after the intervention.

The last chapter of this thesis, Chapter 9, offered a general discussion of the previous chapters as well as concluding remarks. It was emphasized that it is important to pay specific attention to contextual factors to gain further insight in the nature of (perceived) cognitive problems in older adults. The usefulness in clinical and research settings of the assessment tools that were presented in this thesis as well as the applicability of the evaluated intervention were discussed. Specific recommendations for further research were made, especially with regard to future approaches to intervention in the growing group of older adults with perceived cognitive problems in the absence of any actual cognitive deficits. 



\section{Samenvatting}

Leeftijdsgerelateerde cognitieve klachten komen veelvuldig voor bij ouderen, niet alleen bij oudere-ouderen maar ook bij jongere-ouderen ( \pm 55 jaar en ouder). Als gevolg van onze snel vergrijzende Westerse samenleving, zal het aantal individuen dat leeftijdsgerelateerde cognitieve problemen ervaart in de komende decennia toenemen. Zulke cognitieve problemen bij ouderen geven aanleiding tot bezorgdheid, stress, een afname in de ervaren kwaliteit van leven en een toename van de gezondheidszorgconsumptie. Het is dan ook een erg relevant gezondheidsprobleem waarvoor adequate interventies nodig zijn. De relatie tussen ervaren cognitieve klachten en daadwerkelijke cognitieve tekorten is zwak. Het merendeel van de ouderen ervaart cognitieve klachten in afwezigheid van pathologische cognitieve tekorten (als gevolg van bijvoorbeeld dementie). Het verband tussen ervaren cognitieve klachten en niet-cognitieve of contextuele factoren lijkt veel sterker te zijn. Er werd al eerder voor gepleit om zulke contextuele factoren (bv. depressieve stemming en metacognitief functioneren) in te bedden in modellen van cognitieve veroudering. Ze zouden ook in ogenschouw genomen moeten worden bij de ontwikkeling van interventies voor ouderen met ervaren cognitieve problemen. Tot op heden is de kennis over de manier waarop ouderen omgaan met hun cognitieve klachten en de wijze waarop deze klachten behandeld zouden moeten worden echter onvoldoende. Bovendien is er ruimte voor verbetering in de wijze waarop deze contextuele factoren worden gemeten. Het hoofddoel van het onderzoek dat beschreven staat in dit proefschrift was om een nieuwe educatieve groepsinterventie voor cognitief relatief gezonde ouderen te ontwikkelen en te evalueren. Bovendien poogde dit onderzoek te voorzien in een breder scala aan psychometrisch adequate instrumenten die verschillende relevante contextuele factoren (metacognitief functioneren, depressieve stemming en compensatiegedrag) in kaart kunnen brengen. Tenslotte had het onderzoek beschreven in dit proefschrift tot doel om de mechanismen en consequenties van alledaagse geheugencompensatie van ouderen te meten. In hoofdstuk 1 werd een algemene introductie van dit proefschrift gegeven. 
Hoofdstuk 2 onderzocht een nieuw zelfrapportage instrument voor metacognitief functioneren bij ouderen: de Maastricht Metacognition Inventory (MMI). De MMI bestond uit vier subschalen die alledaagse cognitieve tekorten, emotionele reacties op deze cognitieve tekorten, gevoelens van controle, en het gebruik van compensatiestrategieën meten. De psychometrische kenmerken van $\mathrm{MMI}$ alsook de impact van demografische variabelen op de verschillende subschalen werden onderzocht in 552 cognitief gezonde individuen in de leeftijd van 50 tot 95 jaar. Confirmatieve factor analyses bevestigden de a priori verwachte factorstructuur die ten grondslag lag aan de $\mathrm{MMI}$ en reduceerden het aantal items tot 43 . De betrouwbaarheid en validiteit werden vastgesteld voor elke schaal van de MMI. Leeftijd en opleidingsniveau, maar niet geslacht, waren significante voorspellers van verschillende aspecten van metacognitief functioneren. Regressiegebaseerde normgegevens werden ontwikkeld.

In hoofdstuk 3 werd een vragenlijst onderzocht die neurovegetatieve en somatische klachten alsook emotionele klachten meet: de Neurovegetative Complaints Questionaire (NCQ). Neurovegetatieve/somatische symptomen zijn vaak indicatief voor een 'verborgen depressie' of een 'depressie zonder somberheid' bij ouderen. Exploratieve factor analyses met data van 1,105 gezonde ouderen tussen 24 en 81 jaar die deelnamen aan de Maastricht Aging Study lieten zien dat er twee factoren ten grondslag lagen aan het antwoordpatroon op de NCQ. De interne consistentie van de NCQ was acceptabel en de convergente validiteit was voldoende. Vrouwen en oudere participanten rapporteerden meer neurovegatieve/somatische klachten en meer emotionele klachten in vergelijking met mannen en jongere participanten. Regressiegebaseerde normgegevens werden ontwikkeld.

In hoofdstuk 4 werd de Nederlandse versie van de Memory Compensation Questionnaire (MCQ) onderzocht, een instrument dat de verscheidenheid en mate waarin een individu compenseert voor daadwerkelijke of ervaren geheugentekorten meet. De psychometrische kwaliteiten van de Nederlandse versie van de MCQ werden onderzocht in 556 cognitief gezonde ouderen in de leeftijd van 50 tot 95 jaar. Confirmatieve factor analyses lieten zien dat de zeven-factoren structuur van de Nederlandse MCQ goed overeenkwam met de factorstructuur van de originele Engelse versie. De betrouwbaarheid van alle subschalen was hoog. Demografische variabelen waren van invloed op de meeste MCQ schaalscores. Ook hier werden regressiegebaseerde normgegevens ontwikkeld.

Het hoofddoel van hoofdstuk 5 was om de mediërende invloed van depressieve symptomen op de relatie tussen subjectieve cognitieve klachten en compensatiegedrag bij ouderen te onderzoeken. Demografische variabelen en aspecten van metageheugen werden eveneens geïncludeerd als mogelijke voorspellers. De gegevens van 556 ouderen in de leeftijd van 50 tot 95 jaar werden gebruikt. De resultaten van multipele hiërarchische lineaire regressie analyses lieten zien dat compensatiegedrag toenam als functie van gerapporteerde cognitieve klachten. Deze toename was 
echter minder sterk voor ouderen die eveneens veel depressieve symptomen rapporteerden. Leeftijd, geslacht en opleidingsniveau alsook aspecten van metageheugen waren eveneens voorspellend voor de scores op de verschillende MCQ subschalen.

Hoofdstuk 6 onderzocht de gevolgen van alledaagse geheugencompensatie voor de verandering van subjectieve en objectieve geheugencapaciteit over tijd. Specifieke aandacht werd besteed aan de mediërende invloed van cognitieve reserve (zoals geschat door opleidingsniveau) op de relatie tussen geheugencompensatie en veranderingen in subjectieve en objectieve geheugencapaciteit over tijd. Daarvoor werden de gegevens gebruikt van 231 gezonde ouderen in de leeftijd van 50 jaar en ouder die deelnamen aan de Maastricht Aging Study. Hun subjectieve en objectieve geheugenfuncties werden herhaaldelijk onderzocht op vier verschillende meetmomenten (gespreid over twaalf jaar). Linear mixed models analyses lieten gelijke veranderingen van subjectief en objectief geheugen over tijd zien als een functie van compensatiegedrag. Een belangrijke bevinding was dat individuen met een hoger opleidingsniveau niet een minder nadrukkelijke afname in subjectief en objectief geheugen over tijd lieten zien als functie van compensatiegedrag, terwijl dit wel verwacht werd vanuit de cognitieve reserve theorie.

In hoofdstuk 7 werden de achtergrond en inhoud van een nieuwe educatieve groepsinterventie voor gezonde ouderen met ervaren cognitieve klachten gepresenteerd. Een procesevaluatie werd uitgevoerd onder 48 vrouwelijke participanten in de leeftijd van 60 tot 75 jaar. De resultaten toonden aan dat de deelnemers de interventie waardeerden. Bovendien oordeelde het overgrote deel van de participanten dat verschillende aspecten van hun functioneren verbeterd waren na de interventie. Deze resultaten zijn van belang voor grootschaliger implementatie van de interventie.

In hoofdstuk 8 werd een effectevaluatie van dit nieuwe educatieve interventieprogramma volgens een gerandomiseerde opzet met een experimentele en wachtlijstcontrole groep uitgevoerd. Er werden in totaal 60 relatief gezonde vrouwen (in de leeftijd van 60 tot 75 jaar) met ervaren cognitieve problemen geïncludeerd in de studie. Participanten in de experimentele conditie rapporteerden een week na deelname aan de interventie significant minder negatieve emotionele reacties ten aanzien van hun cognitief functioneren in vergelijking met participanten uit de wachtlijstcontrole groep.

Tot slot werden in het laatste hoofdstuk van dit proefschrift, hoofdstuk 9, de belangrijkste bevindingen uit de voorgaande hoofdstukken bediscussieerd. Er werd benadrukt dat het belangrijk is om specifieke aandacht aan contextuele factoren te besteden om zo meer inzicht te krijgen in de aard van ervaren cognitieve problemen bij ouderen. De bruikbaarheid in klinische en onderzoekssettings van de verschillende meetinstrumenten die in dit proefschrift werden gepresenteerd werd bediscussieerd. Specifieke aanbevelingen voor vervolgonderzoek werden gedaan, vooral met 
betrekking tot toekomstige benaderingen voor interventies in de groeiende groep ouderen met ervaren cognitieve problemen zonder daadwerkelijke cognitieve stoornissen. 


\section{Dankwoord}

Hoewel je het schrijven van een proefschrift uiteindelijk grotendeels alleen moet doen, zou ik het zeker geen eenzame ervaring willen noemen. Dat is te danken aan iedereen die in de afgelopen jaren met mij is mee gelopen, mij heeft geholpen of naast mij heeft gestaan. Het is fijn op deze plek tot hen een woord van dank te kunnen richten.

Allereerst dank aan alle deelnemers en medewerkers van zowel de interventiestudie, de KBO-postenquête, als de Maastricht Aging Study, zonder wiens inzet en medewerking er van dit proefschrift geen sprake kon zijn.

Prof. Dr. Jolles, beste Jelle, dank dat ik mocht plaatsnemen op 'jouw bagagedrager'. Je hebt de kiem gelegd voor mijn verdere toekomst als onderzoeker. Ik heb veel van je geleerd!

Dr. De Groot, beste Renate, jij bent degene die altijd een rotsvast vertrouwen in de goede afloop van deze exercitie heeft uitgestraald. Dank je!

Dr. Van der Elst, beste Wim, je zult waarschijnlijk nog niet eens half kunnen inschatten hoe waardevol jouw bijdragen aan mijn ontwikkeling als wetenschapper zijn geweest. Jouw enthousiasme voor het doen van onderzoek en je snelheid van denken en handelen zijn inspirerend. Dank daarvoor!

Alle collega's en oud-collega's bij NP. Het waren mede dankzij jullie fijne jaren. Martin van Boxtel, dank je voor je co-auteurschap en je kritische blik op een aantal van mijn stukken. Petra Hurks, dank je voor je relativerende peptalks in de trein in de eerste jaren van dit avontuur. Kamergenootjes, Aukje Aben en Olga Schiepers. Aukje, jij staat wat mij betreft symbool voor de Limburgse gezelligheid. Dank je! Olga, dank voor je rust, je humor en je kritische feedback. Oud-stagiaires Annelies Wouters, Annette Joosten en Sil Aarts, dank voor jullie hulp bij de interventiestudie. 
Oud-collega's van de afdeling Medische Psychologie in het VieCuri Medisch Centrum in Venlo, dank jullie voor de gezelligheid, collegialiteit, interesse en steun. Eric van Balen, dank je voor de mogelijkheid die je me bood om me naast mijn promotietraject te bekwamen als clinicus. Floris Kuipéri, jouw enthousiasme voor de neuropsychologische praktijk was bijzonder aanstekelijk. Ik denk met veel genoegen terug aan onze supervisiegesprekken.

Oud-collega's van de afdeling Medische Psychologie in het Elkerliek ziekenhuis in Helmond. Mijn maanden als waarnemer waren kort maar krachtig. Wat was het bij jullie leuk en leerzaam! Dank voor alle gezelligheid en interesse. Yindee van Os, het was druk voor je om alles te superviseren, maar wat deed je dat grondig en goed. Dank daarvoor!

Huidige collega's bij de Vitalis Behandelgroep in Eindhoven. Een ware cultuurshock was de eerste tijd bij jullie, maar het wende snel. Ik was op zoek naar een dynamische baan en dat is precies wat ik gevonden heb. Voorlopig ben ik bij jullie nog lang niet uitgeleerd.

Mijn dierbare vriendinnen, vrienden en familie: Helma, Robby, Zoran, Levi, Hester, Coen, Faas, Maartje, Alex, Lenny, Marjolijn, Paul, Noah, Tanja, Jeroen, Stan, Tom, Suzanne, Bart, Noor, Lia, Jeroen, Maike, Monique, Marcel, Koen, Vera, Sem, Lasse, Tomas, Clara Adèle, Jan, Aeltsje, Hanne, Rinda, Nynke, Peter, Elly. Jullie zorgden voor een leven naast het proefschrift. Dank voor alle gezelligheid en mooie momenten. Dat er nog maar veel mogen volgen!

Mijn lieve vriendinnen en paranimfen Marjolijn Bragt en Lia Baars, wat fijn dat juist jullie vandaag achter mij staan.

Lieve Marjolijn, het is ongelofelijk hoe onze levens de afgelopen jaren met elkaar verweven waren. Wat hebben we samen veel mee gemaakt. Vieze Annie, heel veel treinreizen, promotielief en -leed, paardrijden, samen zwanger zijn en moeder worden. Het is stil in Eindhoven sinds jullie vertrek naar Leeuwarden. Ik hoop dat er nog veel gezellige logeerpartijtjes zullen volgen.

Lieve Lia, samen starten, samen afsluiten, dat spreekt voor zich. De afgelopen jaren kenmerkten zich door zoeken naar van alles en nog wat, maar vooral naar onszelf. Ik ken niemand anders die zo getalenteerd is in: a. het doen van onderzoek, b. het coördineren van allerhande projecten tegelijkertijd, c. het onderhouden van vriendschappen, d. het op de hoogte zijn van werkelijk elke roddel. Zonder jou was mijn promotietraject simpelweg een stuk minder gezellig geweest.

Lieve Maike, een speciaal woord van dank voor jou. Als er drie paranimfen zouden mogen zijn dan had ook jij wat mij betreft achter mij gestaan vandaag. Wat was het 
relativerend te merken dat promotielief en -leed los staan van project, universiteit en promotieteam. Ik bewonder je moed en doorzettingsvermogen!

Lieve papa en mama, jullie hebben mij altijd gestimuleerd het beste in mijzelf naar boven te halen. Bedankt voor jullie steun op zoveel vlakken. Zonder jullie hulp in de laatste maanden van het schrijven van dit proefschrift zou ons leven al snel een grote puinhoop geworden zijn. Jullie zijn mij enorm dierbaar!

Lieve oma, wat delen we veel. Op alle hoogtepunten bent $u$ er bij geweest. Geen verjaardagsfeestje werd overgeslagen. $\mathrm{l}$ weet hoe moeilijk $\mathrm{u}$ het vindt verstek te moeten laten gaan nu mijn 'proefwerk' eindelijk af is en verdedigd moet worden.

Lieve heit en mem, dank voor jullie interesse in mijn reilen en zeilen, jullie hulp en jullie gezelligheid. Het is fijn dat jullie er zijn.

Lieve Popke Rein, je laatste plaatsje heb je moeten afstaan aan een minstens zo speciaal iemand. De afgelopen jaren zouden stukken minder succesvol geweest zijn zonder jou aan mijn zijde. Wat hou ik van jou en wat hou ik van ons leven samen! Dank je voor al je liefde, voor je relativeringsvermogen, voor je niet aflatende vertrouwen en bovenal voor je vingers die me wijzen op mezelf.

Marit, lieve schat, jij bent het levende bewijs dat er zoveel is wat we niet weten. Van de grondigheid waarmee jij de wereld bestudeert kan menig onderzoeker nog veel leren. Het is heerlijk dat jij er bent. 



\section{Publications}

Mol, M. E., De Groot, R. H., Hoogenhout, E. M., Aben, A., Verhey, F. R., \& Jolles, J. (2007). An evaluation of the use of a website and telephonic information service as public education about forgetfulness. Telemedicine Journal and E-Health, 13(4), 433-443.

Hoogenhout, E. M., Van der Elst, W., De Groot, R. H., Van Boxtel, M. P., \& Jolles, J. (2010). The Neurovegetative Complaints Questionnaire in the Maastricht Aging Study: psychometric properties and normative data. Aging and Mental Health, 14(5), 613-623.

Hoogenhout, E. M., De Groot, R. H., \& Jolles, J. (in press). A new comprehensive educational program for older adults with cognitive complaints: background, content, and process evaluation. Educational Gerontology.

Van der Elst, W., Hoogenhout, E. M., Dixon, R. A., De Groot, R. H., \& Jolles, J. (in press). The Dutch Memory Compensation Questionnaire: psychometric properties and regression-based norms. Assessment.

Hoogenhout, E. M., De Groot, R. H., Van der Elst, W., \& Jolles, J. (under review). Effects of a comprehensive educational group intervention in older women with cognitive complaints: a randomized controlled trial.

Hoogenhout, E. M., Van der Elst, W., De Groot, R. H., \& Jolles, J. (under review). Metacognition in aging: The Maastricht Metacognition Inventory, and effects of age, gender, and educational level.

Hoogenhout, E. M., Van der Elst, W., De Groot, R. H., \& Jolles, J. (under review). Everyday memory compensation in older adults with cognitive complaints is moderated by depressive symptoms.

Hoogenhout, E. M., Van der Elst, W., Van Boxtel, M. P., De Groot, R. H., \& Jolles, J. (under review). Everyday memory compensation, cognitive reserve, and change in subjective and objective memory: A 12-year longitudinal investigation based on the Maastricht Aging Study. 



\section{Curriculum Vitae}

Esther Hoogenhout werd geboren op 22 september 1980 in Dordrecht. Van 1992 tot 1998 doorliep zij het VWO aan de Christelijke Scholengemeenschap Walcheren in Middelburg. In 1998 startte zij met de studie Psychologie aan de Universiteit van Tilburg. Zij koos voor een vrije afstudeerrichting met het accent op klinische neuropsychologie, waarvoor zij extra cursussen aan de Katholieke Universiteit Nijmegen volgde. Een klinische stage werd verricht bij de afdelingen Neurologie/ Neurochirurgie en Revalidatie van het UMC Utrecht. Een afstudeeronderzoek werd in samenwerking met de Universiteit Utrecht uitgevoerd. Na het behalen van haar doctoraal diploma startte zij in 2005 bij de afdeling Psychiatrie en Neuropsychologie van de Universiteit Maastricht. Gedurende de daarop volgende jaren deed zij onderzoek naar cognitieve klachten bij gezonde ouderen, factoren die daarmee samenhangen, de wijze waarop deze factoren gemeten kunnen worden, en de mogelijkheden voor interventie. De resultaten hiervan zijn beschreven in dit proefschrift. Tijdens haar promotietraject is zij tevens werkzaam geweest bij de afdelingen Medische Psychologie van het VieCuri Medisch Centrum in Venlo en het Elkerliek Ziekenhuis in Helmond. Momenteel is zij als psycholoog werkzaam bij de Vitalis Behandelgroep in Eindhoven. Zij is getrouwd met Popke Rein Munniksma en sinds juni 2009 moeder van Marit. 